\title{
Report of the NIST Workshop on Digital Signature Certificate Management \\ December 10-11, 1992
}

Dennis K. Branstad Editor

U.S. DEPARTMENT OF COMMERCE Technology Administration National Institute of Standards and Technology

Computer Systems Laboratory Gaithersburg, MD 20899

\section{UE




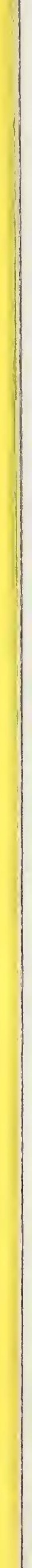




\section{Report of the NIST Workshop on Digital Signature Certificate Management December 10-11, 1992}

Dennis K. Branstad Editor

U.S. DEPARTMENT OF COMMERCE Technology Administration National Institute of Standards and Technology Computer Systems Laboratory Gaithersburg, MD 20899

October 1993

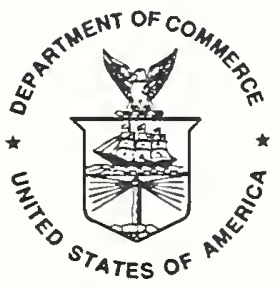

U.S. DEPARTMENT OF COMMERCE Ronald H. Brown, Secretary

TECHNOLOGY ADMINISTRATION Mary L. Good, Under Secretary for Technology

NATIONAL INSTITUTE OF STANDARDS AND TECHNOLOGY

Arati Prabhakar, Director 

PAGE

1. Executive Summary

1.1 Purpose of the Workshop

1.2 Structure of the Workshop

1.3 Summary of the Major Issues

1.4 Workshop Recommendations

2. Workshop Participants 3

3. Day 1 - Morning Presentations 4

3.1 MITRE Certificate Infrastructure study status 4

3.2 MITRE Certificate Technology Findings 4

3.3 CEC Certificate Workshop Report 6

3.4 International Interests 4

3.4.1 Communications Security Establishment (CSE), Canada 7

3.4.2 University College London (UCL) 7

4. Day 1 - Afternoon Presentations 8

4.1 Federal Interests 8

4.1.1 NASA Digital Signature and Security Services System 8

4.1 .2 GSA Perspective 1

4.2 Commercial Interests 9

4.2.1 RSA, Inc. 9

4.2.2 Fischer International 10

4.3 What's in a Public Key Certificate 10

4.4 Initial Recommendations 12

4.5 X.509 Certificate Format 12

4.6 General Discussion of Certificate Revocation
Lists and Naming

5. Day 2 - Morning Presentations 15

5.1 ANSI X9 Certificate Format 15

5.1.1 X9.F.1 Standards Activities: An Introduction 15

5.1.2 Credentials (ASN.1 Syntax) 15

5.2 Certificate Format Discussion/Recommendations 16

5.3 Demo of RSA Certificate Issuing system 18

5.4 U.S. Postal Service Security offerings 18

5.5 Report on the EC 19

5.6 Certificate Management Discussion 20

6. List of Acronyms 21

Appendix A. Public Key Infrastructure Study Certification Workshop A-1

Appendix B. Certificate Technology Findings B-1

Appendix C. Electronic Signature, The Key to Mobility C-1

Appendix D. NASA Digital Signature \& Security Services system D-1

Appendix E. What's in a Public-Key Certificate? E-1

Appendix F. Security Certificates F-1

Appendix G. X9.F.1 Standards Activities: An Introduction G-1 
Appendix H. ASN.1 Structures for Certificate Management

Appendix I. U.S. Postal Service Security offerings

Appendix J. American National Standard X9.30-199x (draft)

Appendix K. Contribution to the Workshop on Electronic

Signatures, Brussels, 1 December 1992

$\mathrm{J}-1$

Appendix L. Viewgraphs presented at NIST Symposium on

Applications of the Digital Signature

standard, February 1993

$\mathrm{L}-1$ 


\subsection{Purpose of the Workshop}

The purpose of the workshop was to review the existing and required technologies for digital signature certification authorities and to develop recommendations for certificate contents, formats, generation, distribution and storage. The results of the workshop will be provided to MITRE Corporation as input to its federally sponsored study of signature certification authorities.

Invited participants represented various constituencies including the federal government, commercial organizations, standards organizations, and international interests.

\section{2 structure of the Workshop}

The workshop was organized as a sequence of presentations on selected topics, including: certificate infrastructure and technology, planned security offerings, needs of government organizations, international and commercial interests in digital signature technology, international standards for security in the context of $x .509$, and specific certificate contents and formats. Discussion about particular topics such as the contents of a certificate or a proposed hierarchy of certificate management authorities was not confined to any particular presentation but rather occurred in a continuous fashion throughout the two days of the workshop.

This report provides a summary of the major discussion points. It is organized chronologically by presentation.

\subsection{Summary of the Major Issues}

The major topics of discussion were certificate format, certification revocation lists (CRL's), possible certificate management hierarchies, and the difference between authentication and authorization certificates. Also discussed were the possibility of multiple signatures on a single certificate, liability, trust, cross certification, and different levels of assurance.

What follows is a summary of the major issues identified by workshop participants that must be addressed by any proposed certificate management solution.

1. Certificate Revocation Lists

Certificate Revocation List management is of utmost importance to certificate users and must be done correctly. The following questions were discussed: Who is responsible for reporting a compromise or change of attribute?; Within what time frame should that reporting be done?; If it is a shared responsibility of the user and the CA (Certification Authority), how exactly will that responsibility be shared? How often will CRL's be issued? What will their format be, (e.g. PEM, X9F, X.509)? 
2. Certificate Management Hierarchies

An integrated Certificate Authority structure must be a hierarchy. What will that hierarchy be for the federal government? Will it be formed along organizational lines or communities of interest? A naming schema for the federal government needs to be worked out. Who will do this? Will the choices in naming need to be restricted?

\section{Costs}

What are the cost estimates for each choice of hierarchy? What metrics can be used?

\section{Certificates}

Should we standardize requests for certificates or is this a local matter? Should we have multiply signed certificates and are these another kind of certificate in addition to authentication and authorization. What will be the format of an authorization certificate? Will the new work in security information objects be of use for authorization certificates? How should the unique id field of the $1992 \times .509$ certificate be used?

\subsection{Workshop Recommendations} issues:

The following list represents consensus on several of the major

1. Use the X.509 certificate format for authentication (identification) certificates.

2. At least two kinds of certificates should be supported:

a) Authentication certificates; and

b) Authorization certificates (for access control)

3. An individual should have multiple certificates corresponding to different roles.

4. International standards should be utilized.

5. A certificate management hierarchy should include strict name subordination (in the $\mathrm{X} .500$ sense) below the level of a CA.

6. CA's should support different assurance levels and they should publicize their policies.

7. An authorization certificate should contain the minimum amount of information which serves the purpose and this information should be closely coupled with the owner of the certificate (i.e., authentication information). This reduces the need to reissue certificates when authorities change. 
2. Workshop Participants

Aiken, Dina

Ankney, Rich, Fischer International

Barker, Elaine, NIST

Baum, Michael

Branstad, Dennis, NIST

Chamberlain, Chuck, U.S. Postal Service

Chang, Shu-Jen, NIST

Crocker, Steve

Dusse, Steve, RSA Data Security, Inc.

Fischer, Addison

Galitzer, Shari, MITRE Corporation

Geiter, Jisoo

Gill, Dave, MITRE Corporation

Greenlee, Blake, M. Blake Greenlee Associates, Ltd.

Humphreys, Ted, Commission of the European Communities

Kent, Steve, BBN Communications

Moreau, Jean-Maurice, Communications Security Establishment, Canada

Shomo, Larry, NASA

Smid, Miles, NIST

Williams, Al, GSA

Williams, Peter, University College London 


\section{Day 1 - Morning Presentations}

\subsection{Digital Signature Certificate Infrastructure study}

Dave Gill, MITRE, Deputy Task Leader for the NIST sponsored digital signature certificate infrastructure study, presented an overview of that study, including the following topics: why an infrastructure is needed; one possible hierarchy; how the study is being conducted; a time table for deliverables; and who is funding and participating in the study.

An infrastructure is clearly needed to manage the public keys and provide some level of assurance as to their authenticity. The number of keys is potentially quite large (consider the IRS using this for electronic submission of 1040 forms). The potentially large number of keys implies the need for some sort of hierarchy of certificate authorities. Potential hierarchies that MITRE is considering include one used by the North American Directory Forum (NADF), one based on organizations, or one based on communities of interest, i.e. groups with the same security policies or requirements. The question of who will manage the US Government portion of the hierarchy is open for debate. MITRE's current thinking going into this workshop is that the responsibility may be divided among different agencies based primarily on different security requirements.

The methodology used in the study involves obtaining input from private organizations, federal agencies, standards organizations, and security experts and using that input to derive a set of user, legal and technical requirements.

Draft requirements in these three areas are due at the end of January, 1993. After that time, more interviews with federal agencies will take place regarding their intended application of digital signature technology. Infrastructure alternatives will be proposed by mid-March and the infrastructure analysis will be complete by June, 1993.

Eight federal agencies are funding the study; NIST is the coordinating agency. Dennis Branstad, the workshop coordinator, pointed out that the agencies funding the study are very interested in digital signature technology and the supporting infrastructure. He stated that the recommendation of the MITRE study will go to OMB who will be asked to act on it.

\subsection{MITRE Certificate Technology Findings}

Shari Galitzer presented MITRE's view of the current certificate technology. She discussed specific issues that need to be addressed in defining a certificate management infrastructure that can be extended easily and can support many different applications. She focussed on four separate areas: architecture, security policy, functional components and resource requirements.

The hypothesis that the infrastructure must be a hierarchy was reinforced. A question of organization is, "Should the infrastructure 
be formed along organizational lines or communities of interest?" Interviews with various federal agencies about their user and legal requirements will be used to guide the final recommendation. It was suggested by several participants that MITRE ask the STU-III support people about the choices that were made regarding the key management structure for the STU-III system. Why is it flat? Does the structure relate to the security policy? Would they do it differently next time? MITRE was reminded that it is important to put the STU-III work in the context of the environment in which it operates; while some of the STUIII experience may be relevant to the digital signature infrastructure, it would be unwise to duplicate the STU-III choices without analysis.

The discussion then centered on the scope of MITRE's study. Their charter is to recommend an infrastructure for government agencies. The scope of NIST's responsibilities does not include telling private industry what to do. However it is recognized that the recommended digital signature support infrastructure must work in an international environment and with the private sector. There is a strong interest in maintaining interoperability and compatibility with recognized standards. If the design is good, others may wish to duplicate it.

The issue of trust was then raised. One of the questions addressed was, "Which organizations could be trusted and what should be required of certifying authorities so that their certificates can be trusted?" The idea that there are different kinds of certificates and that a single certificate will not satisfy all needs was introduced.

Major issues under the topic of security policy included: who should generate the keys; how to manage CRL's; what are the security requirements for managing a CA (certification authority); and how to deal with multiple roles of individuals. The ultimate goal is an infrastructure that will support a variety of security rules (i.e. policies) that any organization might want to impose/adopt.

A lot of discussion centered around the question of how to provide for the multiple roles that an individual may hold at any one time. Should the same public key be in multiple authorization certificates? Should the same certificate be used for multiple roles? If the certificates or roles are associated with different organizations with different security policies and levels of assurance, it is unlikely that either of these alternatives will work. If one certificate has multiple authorizations with respect to the various roles bound into it, anytime one of the roles changes the whole certificate must be reissued. If those authorizations were all from different organizations, who would sign it? It was recognized by the participants that authentication and access control are two fundamentally different operations and that there is a need for different kinds of certificates. It was pointed out that X.509 is deficient in the aspect of handling multiple roles. New standards work is in progress on defining a more generic syntax for a "security certificate" that will be an extension to X.509 and allow different security services to be provided.

A discussion was held regarding who is responsible for making it known that a certificate has been revoked. A typical approach to answering a question like this is to look at how it is done now in paper 
and then to look at the technical and legal ramifications encountered when the manual procedure is automated. In the current revocation practice for credit cards, there is a split responsibility for financial liability between the credit card holder and the credit card issuer. The participants agreed that a split approach will probably be used electronically as well, with responsibility for notification and for liability shared between the user and the certification authority.

The costs of the certificate management alternatives will be considered in the study. MITRE is eager for input on metrics to be used for analyzing costs. Cost is clearly an important issue. At least two ways of looking at costs were articulated. One is the business viewpoint which says, "What cost is acceptable so that a digital signature will be used?". The lower the cost the better (twenty-nine cents per signing was suggested). If the cost of the infrastructure is amortized over the total usage, then the cost per transaction is lower. However, if low value transactions dominate and there is no need for a signature on them, then the cost per signature will go up. The other viewpoint on costs is the futuristic approach, also referred to as the "certification field of dreams." This view is that we cannot anticipate today all the possible applications that may use certificates in the future. Therefore we cannot do a pure cost analysis. Rather we build the system in anticipation that other uses will occur. An analogy was drawn here to the work that has been done in computer communications. There is a need to balance these two viewpoints.

\subsection{CEC Certificate Workshop Report}

Ted Humphreys of the Commission of the European Communities (CEC) presented the results of a workshop held in Brussels on December 1-2, 1992. The title of the workshop was "Electronic Signature: The Key to Mobility". Ted explained the process by which a "Call for Ideas" was issued in May, 1992, and then the responses summarized in a document published in October, 1992. There was an overwhelming response to the Call for Ideas from the international community. Many application areas for electronic signatures were identified, including medical informatics, transportation, aerospace and personal communications. The workshop in Brussels was held to further explore the issues raised by the respondents.

Ted reinforced the idea that $x .509$ is applicable for a number of different security services (primarily related to authentication) but needs to be expanded to handle the very important idea of access control. He stressed the importance of using international standards and not reinventing what already exists.

A question was asked about the requirement for a license to import cryptography in some European countries. This and other legal issues are being addressed. Not only are there legal differences internationally, but also internally within the European community. Ted gave an example of unique identifiers which are acceptable in some countries in Europe and not acceptable in others. Another question was asked about the differences between the legal systems in Europe with regard to cryptography. A study is being done that addresses the various European legal perspectives on intellectual property rights 
issues. Dennis Branstad announced that NIST is sponsoring a study on export laws and other legal topics related to cryptography in the United states and other countries.

Ted finished his presentation by pointing out that the British Post office is looking at digital signatures and how to link up with their counterparts in other countries.

\subsection{International Interests}

\subsubsection{Communications Security Establishment (CSE), Canada}

An informal report was given by Jean-Maurice Moreau of the CSE. CSE is the Canadian government agency that provides advice on communications security. Its scope of authority is both "low-grade" and "high-grade" applications, or what we would call unclassified and classified. CSE wants agencies to implement electronic authentication and authorization for electronic transfers. They are now in the definition state, looking at the user requirements. A requirements paper will be produced by the end of February, 1993. The architecture should be defined by the summer.

\subsubsection{University College London (UCL)}

Peter williams talked about the security related work being done at UCL that is funded by the CEC. It is a pilot project that by the end of 1993 will have 30 sites in three different countries exchanging X.400 (Message Handling Systems) and X.500 (Directory) services and have a certification infrastructure in place. They are using existing Open System Interconnection (OSI) protocols and are not involved in a discussion of what should be in certificates. In this project, UCL is taking a different approach. Instead of defining and analyzing the requirements for an infrastructure first, they are implementing a prototype infrastructure first and will perform the analysis afterwards.

The countries involved are using their own implementations of the OSI protocols and security toolkits to avoid import and export rules. It was commented that using multiple implementations is a good way to check out the protocol specifications. In response to a question about possible U.S. involvement in this project, Peter said that UCL welcomed U.S. participation; just bring your own software. 
4. Day 1 - Afternoon Presentations

4.1 Federal Interests

4.1.1 NASA Digital Signature and Security Services System

Larry Shomo described NASA's need to replace paper documents with electronic ones and to do so in a uniform way across the organization. While financial applications were the impetus to the original idea, there is an interest in developing a much broader infrastructure that will support many applications. Providing a complete electronic document environment for NASA would go beyond just security features and would include the ability to (1) read documents prepared with previous versions or types of software, (2) maintain electronic archives, and (3) perform search and retrieval of documents. NASA interacts with businesses and universities throughout the world and any solution must work in this context. Furthermore, it must be capable of operating on and with a diverse set of hardware and software.

With those requirements stated, Larry went on to describe an ambitious set of objectives that the system should meet and services it should provide. He stated that NASA's Information Research Management (IRM) council has adopted this system as a standard for NASA. He also hopes that if done right, other government agencies may adopt it as well. He expects an interagency agreement to be signed with NIST by early January; a prototype system developed within 11 months; and 6 months later, the technical specifications should be available for a Request for Proposal (RFP).

\subsubsection{GSA Perspective}

Al Williams stated GSA's objective: to replace a number of paper documents with electronic equivalents (the same as NASA). They would like to see a government-wide, classified and un-classified, integrated solution that provides many different types of security services. He recognized that trust is required in those providing the security services. His comment that this should be "integrated" provoked much discussion. This discussion paralleled a similar discussion in the morning session on how to figure cost. The question is, "Can you design a complete system that anticipates every future requirement and every application's need, or should you start with one area, e.g. the certificate infrastructure for supporting digital signatures, and design it without the applications already developed and in place?" There is considerable feeling that it is possible and a good idea to focus on a single area, do a good job and learn from the experience. There is a danger that too large a project will not succeed. Another comment concerned the feasibility of expecting vendors to incorporate specific security services into their products, such as secure logins in the operating system, and in so doing make those services available for off the shelf purchase. While it may be possible for the government to hire a contractor to build security services at the application level, it is difficult, if not impossible, to get vendors to change their operating system or network protocol in response to government requirements. 
4.2.1 RSA, Inc.

Steve Dusse described RSA Data Security, Inc.; its history, its customers, its concerns, and then stressed their interest in supporting not just the RSA algorithm but also other "cryptographic solutions" including DES, DSS, etc. He described their work on PKCS (Public Key Cryptography standards). The certificate used in this standard is compatible with PEM (Privacy Enhanced Mail) certificates and in tune with the 1992 X.509 standard. The PKCS will be used by several vendors, including Apple and Microsoft, to produce office workgroup software. He described a new product for $\mathrm{CA}^{\prime} \mathrm{s}$ to be used for issuing certificates. This product includes a database to be used by the CA's for certificate management, tracking and querying. It also includes a signing unit, built by BBN, that is tamper proof (the private key is destroyed if the box is tampered with), makes a public-private key pair for signing certificates where the private key remains inside the unit, and is controlled by "user-friendly" software.

Steve stated that while we know a lot about certificates and their format, their use is still new in the business world and we lack experience in certificate management. He further asserted that certificates provide assurance of identity but little is understood about liability. For these reasons, a continuance of pair wise agreements may be required among cooperating organizations in order to conduct business.

The discussion then moved to X.509 certificates and the need for authentication and authorization certificates. X.509 certificates were developed to satisfy a need for strong authentication in the context of the Directory. There are now applications that need wider services and $\mathrm{X} .509$ is being improved to offer more generic certificates.

It is useful when discussing possible authorization certificates to consider how access control is accomplished in operating systems. Access control can be done by using access control lists (which represent the columns of an access control matrix) or by using capabilities (which represent the rows of the same matrix). They both perform equivalent functions but have unique tradeoffs. Access control lists consist of all the entities that have a right to access a particular resource. Capabilities are tickets that an entity presents when accessing a resource that say the entity has the proper access rights. It is possible to build an identity based access control scheme using X.509 certificates as entries in an access control list. One potential drawback is the cost of managing those lists. Another one is that while one $C A$ may be trusted to vouch for someone's identity, another $C A$ or organization may need to authorize that identified individual. Certificates could have multiple signatures, but as soon as one item in the certificate changes, the entire certificate must be reissued. If the capability approach is chosen instead of an ACL approach, then a new certificate format is needed for an authorization certificate. This format should be sufficiently general so that it can be used by any application. 
Another topic which arose from the previous discussion was how to make an identity unique. Your name is guaranteed unique only if enough context is provided to differentiate you from others with the same name, e.g. your home address or your employer and position in that company. Much of that information may be of no interest for the purposes of certificate management. On the other hand, if using identity based access control, the application may wish to use the related information supplied with the name to make a decision about authorization.

\subsubsection{Fischer International}

Addison Fischer, president of Fischer International, introduced his company and his primary concerns as a software producer for an international market. His company produces four RSA based products, including a PEM implementation. They use the X.509 certificate format. His message was that since his company does software for many customers, not just the government, the government should stay with the standards that everyone else is using if they want to buy products off the shelf. He also expressed a concern over supporting multiple cryptographic algorithms. It was pointed out that many algorithms could coexist within a particular certificate infrastructure. In particular, the X.509 certificate format gives the ability to select different algorithms or key lengths.

\subsection{What's in a Public Key Certificate?}

Steve Kent explained his view of what should be in a public key certificate and why. He explained that it is difficult to get one certificate to fit all needs. There are different attributes that are of interest to different applications (e.g clearance levels in the military or financial authority in business), there are different entities to vouch for these attributes, and there are different validity time frames. All these reasons suggest that there will be more than one certificate for each individual, as well as more than one type of certificate (e.g. authentication and authorization). Concern was voiced that the certificates would proliferate rapidly and we would have the electronic equivalent of a thick billfold. It was agreed that while one certificate per individual will not work, in part because organizations want to control their authorizations and because differing levels of assurance of identity may be needed, it is important not to have too many certificates since the management would become unwieldy.

It was again mentioned that X.509 is being extended to handle a wider range of applications. Standards work is progressing on defining "security certificates" to support security information objects. It was asserted that certificates of a more general type could be used for rule-based authorization where identity was not important or desired.

The next discussion centered on the issue of trust and levels of trust. First, we must trust the issuer to vouch for the validity of the attributes that are bound in the certificate and that they have been accurately bound. Second, how will a CA identify any entity and to what level of assurance? Will there be different levels of assurance offered by a single $C A$, that is, will a single CA offer different levels of checking attributes; or will there be different levels of CA's, that is, 
will some CA's require higher validity assurance of the attributes presented to them? It was agreed that there would be different levels of CA's, that they would make their policies known, and anything signed by them would comply with that standard of checking. For instance, a CA signing certificates in a classified environment would do a higher level of checking than a CA in an unclassified environment.

Steve's last point about trust was that "A certificate vouching for an identity binding does not imply trust in the identified entity." It is important not to get confused about what we are trusting and what is being certified.

Another issue regarding certificates is that of revocation. If we use the capability analogy from operating systems to describe a certificate, then we know that revocation is difficult. You cannot, in general, find all the certificates and "pull" them back. It was suggested that when certificates are used as authorization, then a combination of a "push" and "pull" model must be used, especially as the number of users gets larger. In particular, revocation lists could be periodically published ("push") and also the most current version could be available online for checking if the transaction is valuable enough ("pull").

The discussion then went back to authorization certificates vs. identification certificates. Concerns were raised that having too many different formats for certificates would make implementation difficult. It was suggested that an appropriately general format for an authorization certificate could be developed that would represent a compromise between fixed fields required for all applications and some flexibility to define new attributes for particular applications. It was agreed that binding too much unrelated information about an individual into one authorization certificate would be a bad idea for several reasons. One, there may be privacy concerns associated with some of the identifying information. Two, if one piece of information changes then the entire certificate must be reissued. If identification is separated from authorization, then changing an authorization certificate would occur less often. By binding less information into a certificate, certificates could support the principle of least privilege or need to know.

The issue of individual names was raised. The X.509 subject field is a distinguished name. This format is well-defined, however, the naming hierarchy for the United States (C=US) is not yet worked out. The NADF (North American Directory Forum), a self-appointed group, is working on one schema for an $x .500$ directory project. This does not address certificates directly. Steve kent suggested that the names would separate an individual's role from his/her unique identity. If we assume that people change roles frequently within an organization, then this would minimize name changes and subsequent reissuing of identification certificates. On the other hand, if movement is rare in an organization this may not be needed. It seemed clear that some guidance should be provided on the schema for the U.S. Government, but it was not clear what that would be. 
Based on the discussions on certificate contents that had taken place throughout the day, two recommendations were endorsed by the participants. They were:

- There should be at least two types of certificates, an identification certificate and an authorization certificate. They may have different contents and formats because they have a different set of requirements.

- The format for the identification certificate should be X.509. The format for the authentication certificate is unknown at this time but will be different from the id certificate.

A participant pointed out that certificates may not always be the proper choice for authorization. In some situations, other mechanisms could be used. It was clarified that the "security certificate" is a general term not to be confused with authorization certificate.

\subsection{X.509 Certificate Format}

Ted Humphreys presented a summary of identified deficiencies in the 1988 version of the X.509 certificate format and in the revocation list format. Some, but not all of these defects, are addressed in the 1992 version of the standard. The particular deficiencies relating to the format of the certificates are listed in his paper "Security certificates". They include concerns over reuse of Distinguished Names, how to distinguish between a user certificate and a CA certificate, and how the certificate is stored.

The defects in the revocation list format and/or suggested repairs include: a change in the ASN.1 syntax from a SIGNED SEQUENCE OF SEQUENCE to a SEQUENCE OF SIGNED SEQUENCE; there is a difference in the date at which a user requests revocation and when it is actually done; there is no indication of when the next revocation list will be issued; and the management of a potentially very large revocation list. steve Kent explained the difference between the proposed way of doing revocation lists (SEQUENCE OF SIGNED SEQUENCE) and the way that PEM does it. In $X .509$, when a notice of a revoked certificate is signed by the issuer of that certificate and stored in a revocation list, it is acceptable for the issuer of the revocation list to be different from the issuer of the notices of revoked certificates within it. The PEM group did not adopt this, since a CA should not be able to revoke a certificate that someone else signed, and therefore they chose a different structure (SIGNED SEQUENCE OF SEQUENCE). The syntax of the revocation lists is significantly different in PEM and X.509. The question was asked, could one group accept the other's proposal. Steve Kent replied that for PEM, putting in the next date of issue for a CRL is a security issue and could not be negotiated. This feature is still lacking in the 1992 standard. Ted suggested that future work on security services not arising in the context of the Directory will be handled in other groups as a general security problem. Work on more general security information objects may overcome this difference between the two groups. 
A further incompatibility surfaced when the group was told that the ANSI X.9 revocation list format uses the basic PEM format but then adds a reason code that tells why the certificate was revoked. The reasoning behind this is that in the financial community, if it were a serious key compromise, they would want to move quickly to limit damage. On the other hand, less serious reasons, such as a change of affiliation might result is a more measured response.

\subsection{General Discussion of Certificate Revocation Lists and Naming}

Some of the issues regarding CRL management were discussed. One issue is how the CRL's can be used to provide a nonrepudiation service. In order to show that a signature was valid at a particular time, it is not sufficient to store just the CRL that is in use at that time. Rather, an updated CRL must also be stored when it is next issued, in case the key is compromised between the time of issue of the first and second CRL. How often CRL's will be published is not yet specified and will probably be a local management decision by a CA.

A question was asked about how many certificates would be on a CRL. It appears that the number of certificates will be a function of how much information is bound into a certificate. For instance, if attributes such as the position held in the company are in the DistinguishedName and that position is likely to change often, then the list could get very large.

Other issues include: who is responsible for reporting a compromise or change of attribute and within what time frame should that reporting be done. If we follow the credit card model, then the reporting should be done by the user in a timely fashion (e.g. within three days). Specifying what is a timely fashion may not be easy. And while limiting financial liability may work in the credit card case, the analogy may not hold with certificates. It was suggested that a company may need to buy employee bonds in order to limit their liability. Also, some steps may be taken manually to limit damage by checking recent orders or signed contracts and determining if it is possible to cancel them. These types of action are outside the nonrepudiation service.

Peter williams opened a discussion on naming by asserting that because of the deficiency in X.509 (88) it is possible for a user to pose as a CA, and in order to combat this threat a strict hierarchy must occur in the naming scheme. Steve kent responded that there is no requirement that the certification hierarchy follow the $\mathrm{X} .500$ naming hierarchy and offered the PEM approach as an example solution. The subject name must be in a strict subordinate relationship to the issuer, but the issuer (CA) may be anywhere in the naming tree. It is clear that a hierarchy is needed as a way of managing certificates, it's just not clear which one. One assertion is that if $C=U S$ is controlled by ANSI, then if the certification hierarchy must be identical to the $\mathrm{X} .500$ hierarchy, no one could issue certificates until ANSI set up a certification granting authority. There is a problem identifying the root of the certification hierarchy; no organization has indicated they are ready to assume that role and no organization has been approved for that role. There is also a social acceptability issue associated with naming. If the objects named contain great semantic content, people 
want more choice over the names assigned to those objects. Objects such as ethernet addresses or internet protocol (ip) addresses do not generate the same strong emotional response. One suggestion is to have a number of different domains, i.e., several public and multiple private domains. Another was that one certification hierarchy specified as a preferred model could convey benefits such as increased trust in the certification path. Further, having a single model will promote (but not guarantee) interoperability.

The day's sessions ended with a brief cost/benefit analysis of implementing security. Both business and government may find security unattractive if the estimated cost of the cure exceeds expected savings. Some participants said that losses could escalate in an electronic environment. Some would like a complete analysis of a threat model. MITRE stated that they needed more input on how to measure the costs of managing certificates. 


\section{Day 2 - Morning Presentations}

\subsection{ANSI X9 Certificate Format}

\subsubsection{X9F1 Standards Activities: An Introduction}

Blake Greenlee presented an overview of the security standards activities involving the financial services industry. The ANSI X9F1 group is working on two sets of public key standards, one using irreversible algorithms (X9.30) and one using reversible algorithms (x9.31). Both of these standards include four parts, the signature algorithm itself, the associated hash algorithm, certificate management and management of symmetric keys. He discussed briefly some of the requirements for managing hot lists (CRLs) and what the hot lists should contain.

He defined some requirements placed upon a CA regarding liability and responsibility. Items such as identifying the requestor and protecting the CA's private key are on the list. Also included is a stringent requirement that the $\mathrm{CA}^{\prime} \mathrm{s}$ private key be generated inside a crypto-module and NEVER appear outside that module in either plaintext or enciphered form. From these requirements and from the implementation of sound management practices, it follows that the CA will be trusted by its subscribers.

The final viewgraph contained a table of actions to be taken upon revocation of a certificate. How a reason code for revocation would be used in practice and the actions to be taken by the entity certified, the $C A$, and the users of the certificate were presented in detail.

The status of the proposed standards was discussed. The secure hash algorithm for the irreversible algorithm is in draft form and should be an ANSI standard by the end of the first quarter of 1993. The certificate management portion of the standard should be voted on by the summer. Other parts of $\mathrm{X} 9.31$ will be reviewed at the March meeting.

\subsubsection{Credentials}

Elaine Barker of NIST showed the ASN.1 specifications for what a certificate requesting party would present to the $C A$ to put into the certificate. These are called credentials. The required attributes have been brought into alignment with the X.509 certificate contents. The issue of whether there were additional restrictions placed on the values of these attributes, such as subject name, was raised. For the banking community this has been deliberately not specified, leaving maximum flexibility. It is anticipated that these will be private systems with a relatively flat hierarchy. It was noted that national systems may in fact wish to narrow down the choices of naming schema and so remove some of this flexibility.

The ASN.1 specification for a multiply signed certificate was presented. The ANSI X9F1 members perceive a possible requirement for multiply signed certificates in applications such as syndicated loan agreements. The multiple signatures are computed just on the 
certificate information; it is not a signature on a signature, although that may be a future operation. A lot of discussion occurred over the difference between signing a document and signing a certificate and the need to keep these two ideas differentiated.

Other issues that were identified and discussed, but not resolved, include: how to sequence multiple signatures in order of time; how to indicate how many signatures you need; how changes can be made after a signature is applied (this relates to documents not certificates); and how many primes are needed for multiple signatures.

Elaine finished by showing the ASN.1 specs for the Certificate Revocation List and for the Attribute certificate. There was considerable discussion over what would be revoked in the case of $C A$ compromise. If we stop using the compromised $C A$ key, do we also need to stop using a user's key in any certificate signed with that (now) compromised key? It was pointed out that we must differentiate between the idea that we are revoking certificates and not revoking keys. That is, it is not in general necessary to reissue a user's public/private key pair due to $\mathrm{CA}$ compromise. After an appropriate investigation, you may reissue certificates signed in error, or hot list certificates as necessary, but the keying material may still be valid.

The discussion then returned to the liability of the CA. The requirements presented by Mr. Greenlee were very detailed, very specific. A question was asked, who would step up to those requirements, given the concerns over liability? Blake asserted that he anticipates a CA at each Federal Reserve District and that having these rules and policies in place will help clarify their responsibilities. The CA is clearly liable for doing its job properly, that is, binding the attributes correctly. It was suggested that MITRE consider these liability discussions when it produces its report.

\subsection{Certificate Format Discussion}

Rich Ankney led the discussion on certificate format. He presented a list of discussion points and went over each of them. The first point established that the X.509 certificate is indeed used as a base for PEM and $\mathrm{X} 9 \mathrm{~F}$ activities and would be suitable for use by the government as an authentication certificate. The 1992 version of the $x .509$ certificate is preferable; it has a unique id field that will be useful for a variety of purposes. It was felt that while the exact semantics of the User Identifier (UID) field should be left somewhat open, additional guidance should be given to minimize the flexibility and potential confusion. That guidance is not yet determined. One possible use is to determine, in the case of multiple certificates for one subject, which private key of the CA signed a particular certificate. Another question was how to convey the necessary Digital Signature Algorithm (DSA) parameters for use with a certificate. It was felt that conveying them in each certificate in the subjectPublickey Info field was appropriate. Even though it requires a certain amount of bandwidth, that is a reasonable tradeoff when one goal of using certificates is to avoid prenegotiations and to have all the information necessary to use the certificate in the certificate itself. 
Point two on the list related to the attribute certificate defined by $\mathrm{X} 9 \mathrm{~F}$ and whether that kind of certificate would be useful for the government. It was suggested that it might be too early to decide on specific attributes, since we lack experience in this particular area. The security information object work that is going on in ISO SC 27 working Group 1 appears to be the right mechanism to use for future development. It was also pointed out that the CA that does the authentication, and the CA that issues the authorization, may not be the same; in fact, they should not be the same CA.

The next point was about multiple signatures on certificates, another feature provided in X9F. This provoked a great deal of discussion. Many of the concerns about multiple signatures may lie outside the scope of the certificate discussion, as they are application specific. For instance, is the order of signing relevant, can there be substitute signers, can you annotate documents or change them after signing, how will you indicate that multiple signers are needed. MITRE was directed to look at the possibility of using multiple signatures on certificates or if necessary, using multiple certificates to sign one public key. It was asserted that no one government CA may want to take complete responsibility. On the other hand, it was also pointed out that if there are doubly signed authentication certificates, the $C^{\prime} A^{\prime}$ may not be acting as a $C A$ should if they are unwilling individually to vouch for the validity of a certificate. Also, if we are talking about doubly signed X.509 certificates, then they are no longer X.509 certificates, but in fact, are an additional type of certificate. There was no consensus on this issue.

Point four regarded other security services that might make use of the infrastructure. Peer entity authentication was an easily agreed upon service. It was felt that other services might be outside the scope of MITRE's report, and while important and useful to specify these services more fully, given our time constraints at this workshop, discussion was postponed.

Point five addressed which format to use for the CRL's: X.509, PEM or $\mathrm{X9F}$ ? The use of the reason code by $\mathrm{X9F}$ was (again) explained. The use in PEM of a next update time was viewed favorably by the participants. In the interests of compatibility, Rich Ankney said he would see if the X9F group would accept an "optional" designation for the reason code. A request was made to consider including a version number. That was also considered a good idea, but would have to go back to the various standards groups. There was some concern about retaining the ability to revoke a user's certificate if the issuer's private key were lost. Since none of the proposed CRL formats contain any keying material, this was not felt to be a problem.

A question was asked about why we should standardize the certificate request. There are two ways of looking at this. The first position says that each CA operates independently based on the needs of the community it serves and so these decisions should made be locally. The second position says that in the interest of buying off the shelf software to do the request for a certificate, we should have one standard format. 


\subsection{Demo of RSA Certificate Issuing System}

Steve Dusse of RSA, inc. gave a demonstration of a system to do RSA key pair generation and issue certificates. This system is scheduled for release early in 1993. It consists of: a certificate signing unit manufactured by BBN in which the RSA key pair is generated, a data base component for certificate management, and some "user-friendly" software that allows the issuer to enter and view various attributes associated with a transaction. The system is set up to issue "subordinate" certificates, in that the user's Distinguished Name will be strictly subordinate to the issuer. He emphasized that while the strict subordination is required in the naming, other attribute/value pairs are not restricted. However, a particular organization may wish to enforce some restrictions based on their policies. This is acceptable as long as it does not conflict with the standards. Another feature that was mentioned was the ability to generate the user's public key inside or outside of the box. This ability might be useful in a smart card environment.

\subsection{U.S. Postal Service Security offerings}

Chuck Chamberlain described how the postal service is planning to transition from a hard copy world to an electronic world, and what value-added services they might provide. He began with a brief overview of what happens in the paper world today with registered and certified mail. He moved quickly to a description of three services that they could provide in support of electronic commerce for the federal government. These include identity authentication, an electronic postmark and an audit trail and integrity check of certificates.

To provide the first service, identity authentication, the postal service would act as a certification authority. In his example, a government employee dials in to a post office computer and requests a certificate. Once the employee has entered the appropriate data, a certificate is built. An application form is then printed on the employee's local printer. This form can be presented at any post office where the requestor's identity is verified and the form signed. The certificate is then activated and sent to the requestor via email.

The second service provides the equivalent of a trusted timestamp. Some anticipated uses include verifying the date of submission and integrity of bids, proving intellectual property and sealing files for subsequent IRS audit. A related discussion about the semantic difference between proof of delivery (it got to someone) and proof of receipt (it got to the designated recipient) occurred at this time.

This led to a discussion of naming and hierarchies and their relation to the international standards, e.g. X.400 and X.500. It was suggested that the standards require management domains and no organization has really addressed that need by establishing a national policy or by providing a national authority. The PEM model was proposed as a useful way to view things. The USPS could be a PCA (Policy Certification Authority) with established policies that may prove useful to a wide variety of applications. There could be other PCA's serving the banking industry or other agencies with different security 
requirements. The important thing to remember with the PEM model is that it does not require a strict adherence to the naming hierarchy except below the level of the CA. In that sense, the Post office would not be "higher" in the naming hierarchy than other agencies that might use it services; no name will start with "org=usps"!

Chuck stated that he thought other agencies would want to do their own authentication and that they (the postal service) might provide a cross certification service or a common root. The USPS could also assist with managing the CRL's between them. He looks to the work on X.500 implementations to help their efforts, particularly the NADF work on a central authority for synchronizing the directories.

A question about how well the PCA idea scales was raised. It was felt that scaling does not pose an assurance problem but rather a human interface problem with deciding if a particular CA should have signed a particular certificate. If a certain locality of reference holds, and you deal with only a few $\mathrm{CA}^{\prime}$ s on a normal basis, then this affect may be mitigated.

\subsection{Report on the EC}

Ted Humphreys reported on activities in support of the European Community and European policies in contrast to national policies in Europe. He presented the action plan associated with the only council decision issued in the area of security. This decision was ratified in March 1992. Another decision on data protection is expected to be ratified soon.

The action plan had five points: identify user requirements; look at solutions for intermediate and interim needs; develop long-term specifications and standards; look at operational deployment; and ultimately the provision of security. Under this action plan they have various activities going on, including some pilot projects. There is a firm commitment to international standardization with the associated procurement implications.

The topic of universal electronic addressing was discussed. It was pointed out that in Europe, the directories are maintained by the telecomm companies and are their property. Further, the telephone companies have not gotten together to offer a Pan European directory service due to competition, regulation, etc. This holds back development of certification authorities. They are looking at the postal codes and the postal systems as a way of setting up a certification system.

The legal issues remain difficult to sort out in Europe. Ted hopes new legislation at the European level will help this situation. MITRE was reminded that we may need legislation here as well to solve some of the issues regarding name changes in case of death, marriage, incapacity, bankruptcy, etc. 


\subsection{Certificate Management Discussion}

Steve Kent presented an example of a certification hierarchy, the one currently being set up for the PEM effort. The PEM hierarchy has three levels, a root, the PCA's and the CA's. The root is needed so that the international standards "work" and to register the Policy Certification Authorities. The root sets some minimum standards that all PCA's must follow, that is, what information a PCA must tell its customers so that they can compare the services offered by different PCA's. The root must also verify that applicants for a PCA are who they claim they are. After verification, the root will sign a certificate for the PCA.

The specific criteria for various levels of assurance will not be set by the root. Each PCA will have a policy statement that specifies, for instance, how it protects its keys, how often it issues CRL's, etc. It is anticipated that there will be a range of PCA's from high quality with rather stringent requirements to a low end, persona PCA which offers an anonymous service with no verification of identity, only a guarantee of uniquely named certificates. A draft policy statement for a high quality PCA will be circulated on the PEM-DEV list early in the first quarter of 1993. It will include many of the things listed about responsibilities of a CA with regard to CRL's as stated earlier in the X9.F standards activities presentation.

A question was asked about how an infrastructure for the federal agencies would fit into this particular hierarchy. The response was that they could be another PCA. It was again emphasized that there is no relationship between the name of the PCA and the rest of the certification tree below it. In principle, it would be possible to have a PCA for each domain and have the PCA's cross certify themselves. This leads to the problem of determining the exact assurance that one has in any given certificate chain. Having one root solves a number of problems, it provides a certain level of confidence by specifying the rules that a PCA must follow and you only need one public key, the key of the root, to build correct certificate paths. Steve asserted that having a level in the hierarchy that incorporates the idea of policy would be useful in supporting communities of interest and that the only remaining choice is how to implement it, either by using a root or by relying on cross certification. And if a root is seen as a useful feature, who will pick that root?

Some clarifications were made regarding how the PEM hierarchy worked. Anyone who is willing to abide by the rules that are common to all PCA's and pay the management fee to the root can become a PCA. The naming depth is arbitrary. Below the $C A$, all names are constrained to be subordinate to that $C A$. An individual may have multiple certificates representing different assurance levels and issued by the same CA (who is certified by two different PCA's). This can be accommodated with the 1992 format by using the UID field. It is also clear that a high assurance $C A$ will charge more for its services. The hierarchy will be extended to include process names; a draft RFC discussing this will be released soon.

At this point, the meeting was adjourned, time had run out! Dennis 
Branstad thanked all the attendees for coming and gave a special thanks to steve kent for being the workshop facilitator.

\section{List of Acronyms}

ACL

ANSI

ADMD

CA

CCITT

CEC

CRI

CSE

DES

DSA

DSS

IRM

IP

ISO

NADF

NIST

OSI

PCA

PEM

PKCS

RFP

RSA

stu-III

UID
Access Control List

American National standards Institute

Administrative Management Domain

Certificate Authority

International Telegraph and Telephone Consultative Committee Commission of the European Communities

Certificate Revocation Iist

Communications Security Establishment

Data Encryption standard

Digital Signature Algorithm

Digital Signature Standard

Information Resources Management

Internet Protocol

International Organization for standardization

North American Directory Forum

National Institute of Standards and Technology

Open Systems Interconnection

Policy Certification Authority

Privacy Enhanced Mail

Public Key Cryptography standard

Request for Proposal

Rivest, Shamir, and Adleman

Secure Telephone Unit

User Identifier 

APPENDIX A

\section{PUBLIC KEY INFRASTRUCTURE STUDY CERTIFICATION WORKSHOP}

David L. Gill

MITRE Corporation 


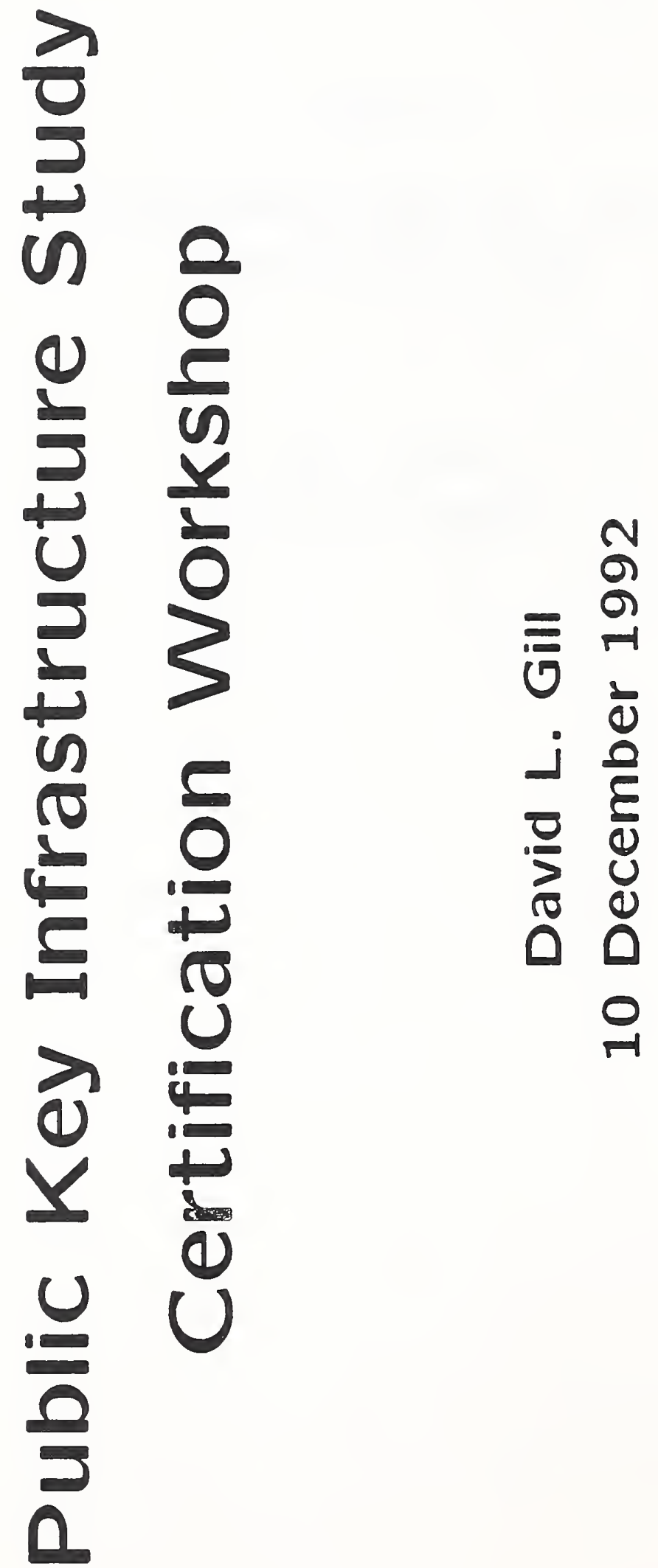




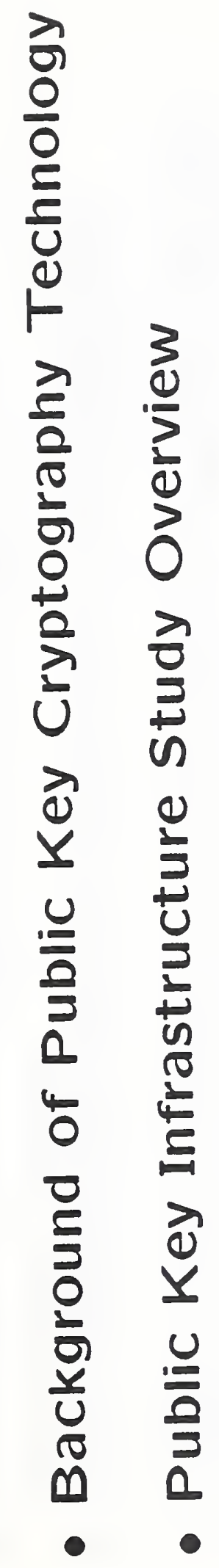



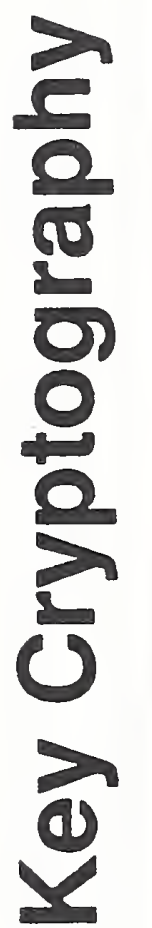

$\frac{0}{2}$

$4=$

0

C2

(3)

a)

0

4

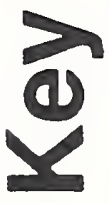

5

(1)

2

4

$2=$
025
$i=0$

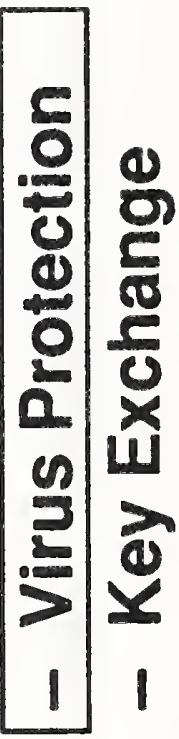

(2)

(1)

6

9

$\sum_{0}^{\infty}$ ह

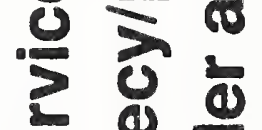

ฮ อ

c)

(1)

(1)

(1) 0

E 0

อ 130

(1) $\frac{0}{3}$

ह 2

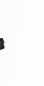

2

a)

020

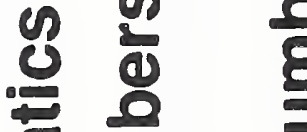

을

를

d) 5

$\infty 0$

$E$

ह 1

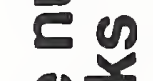

a)

ह5

항

8

(a)

11

a) 15

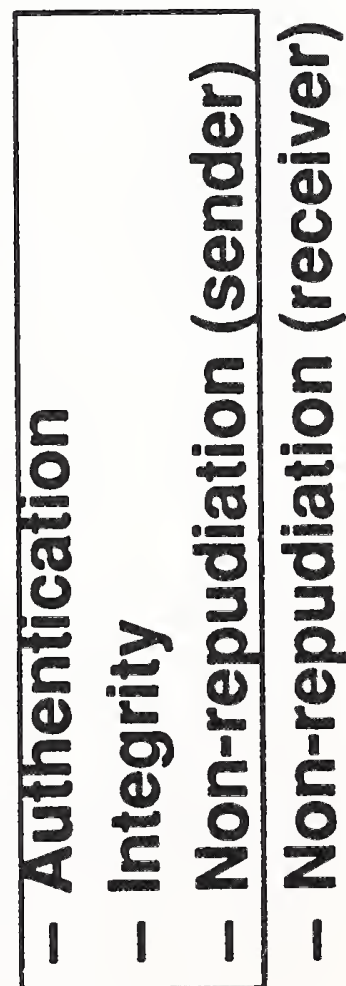

60 की

(8) 0

(1) 늘

(1) 2

8

$\infty$

00 (1)

क)

$\Rightarrow$ कर

อ

000 

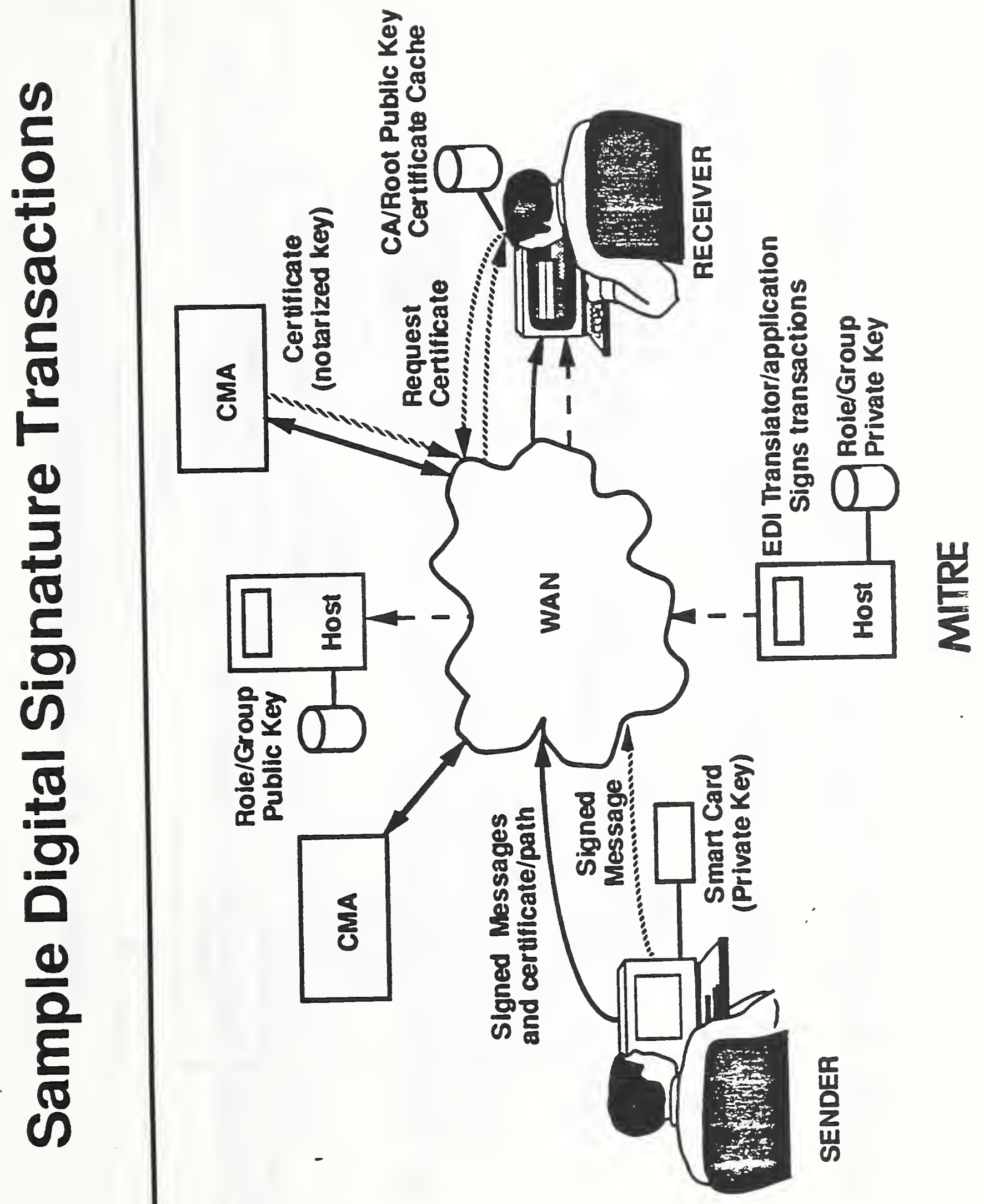


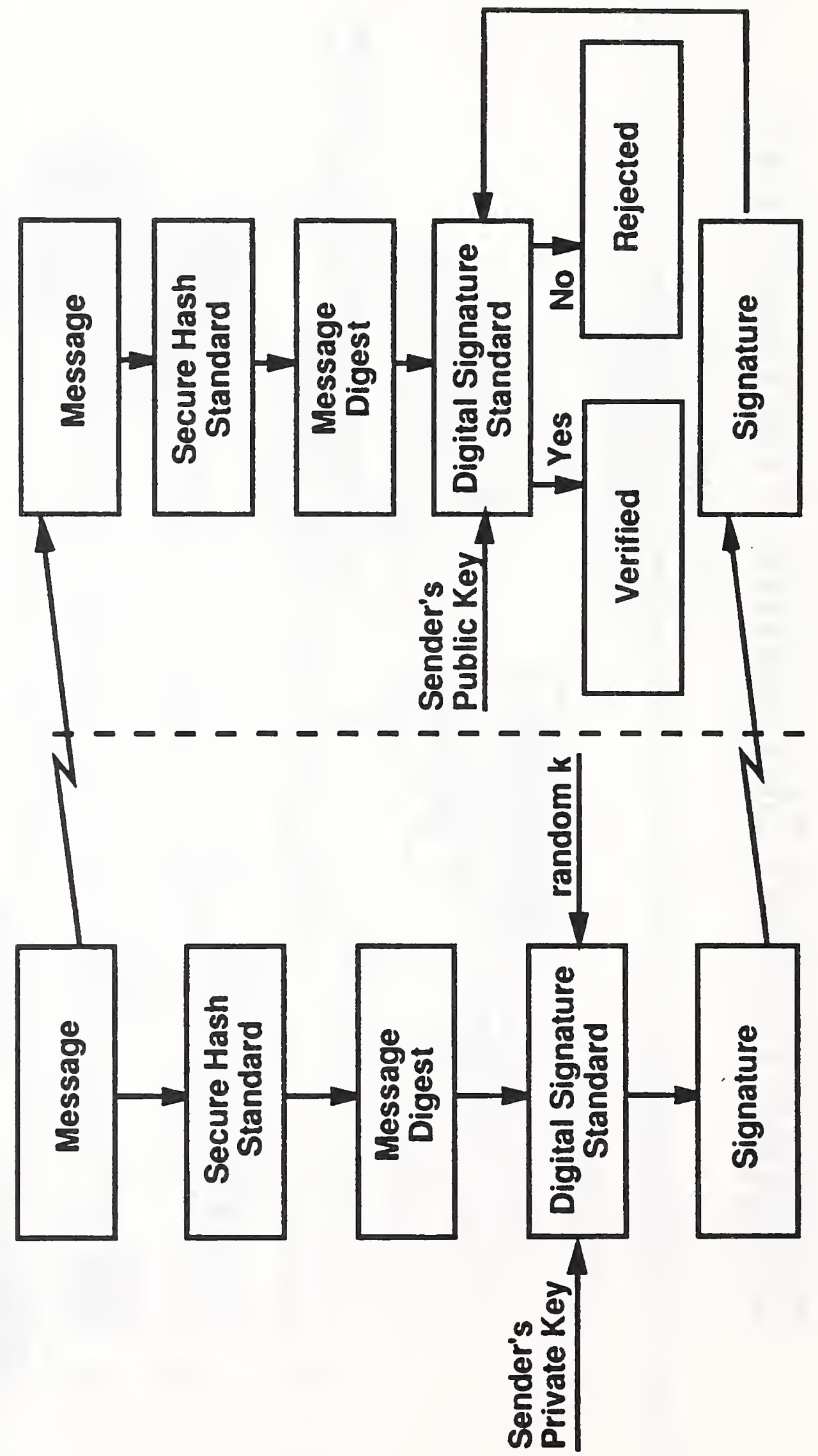

$\frac{4}{2}$ 


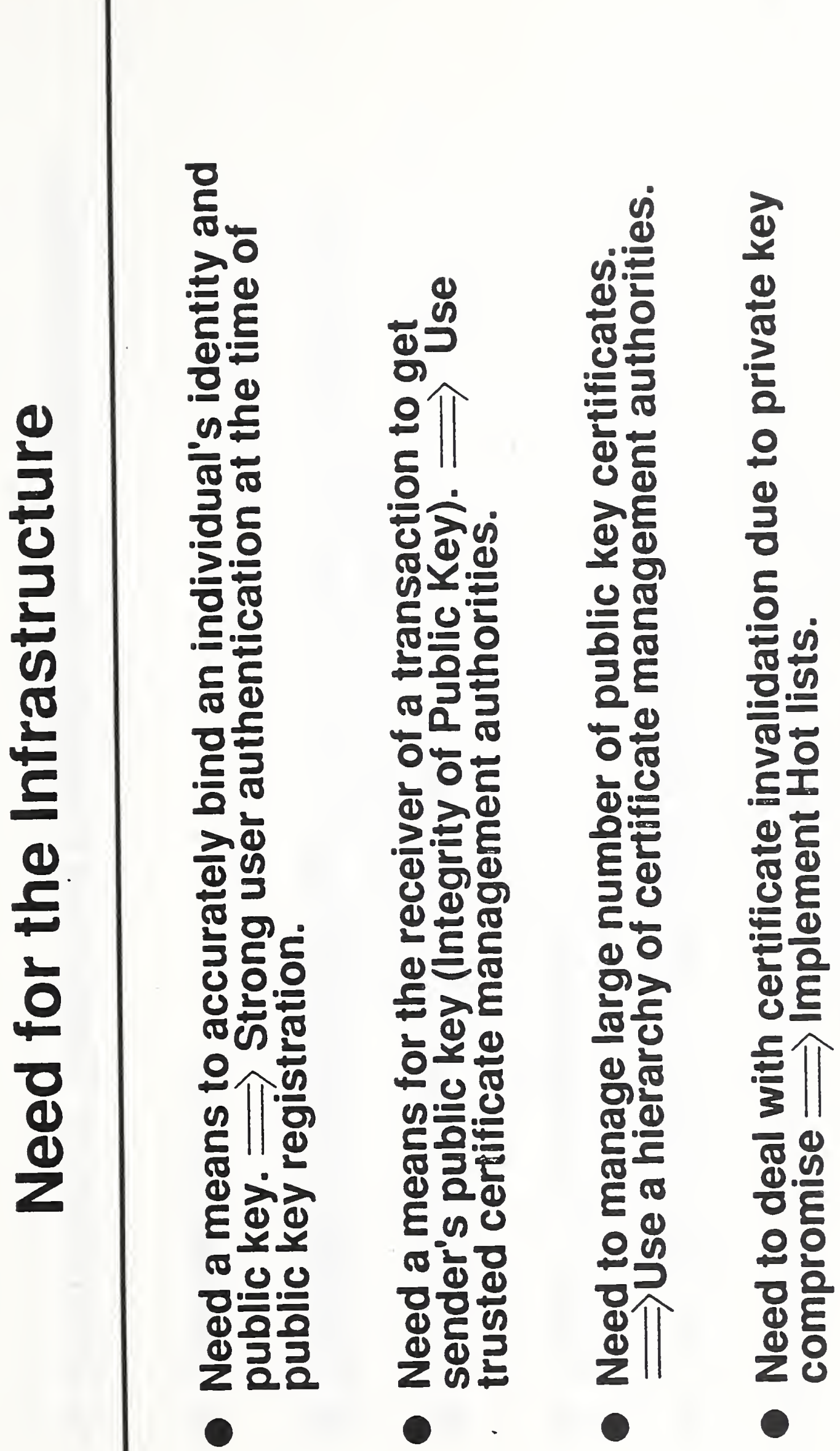




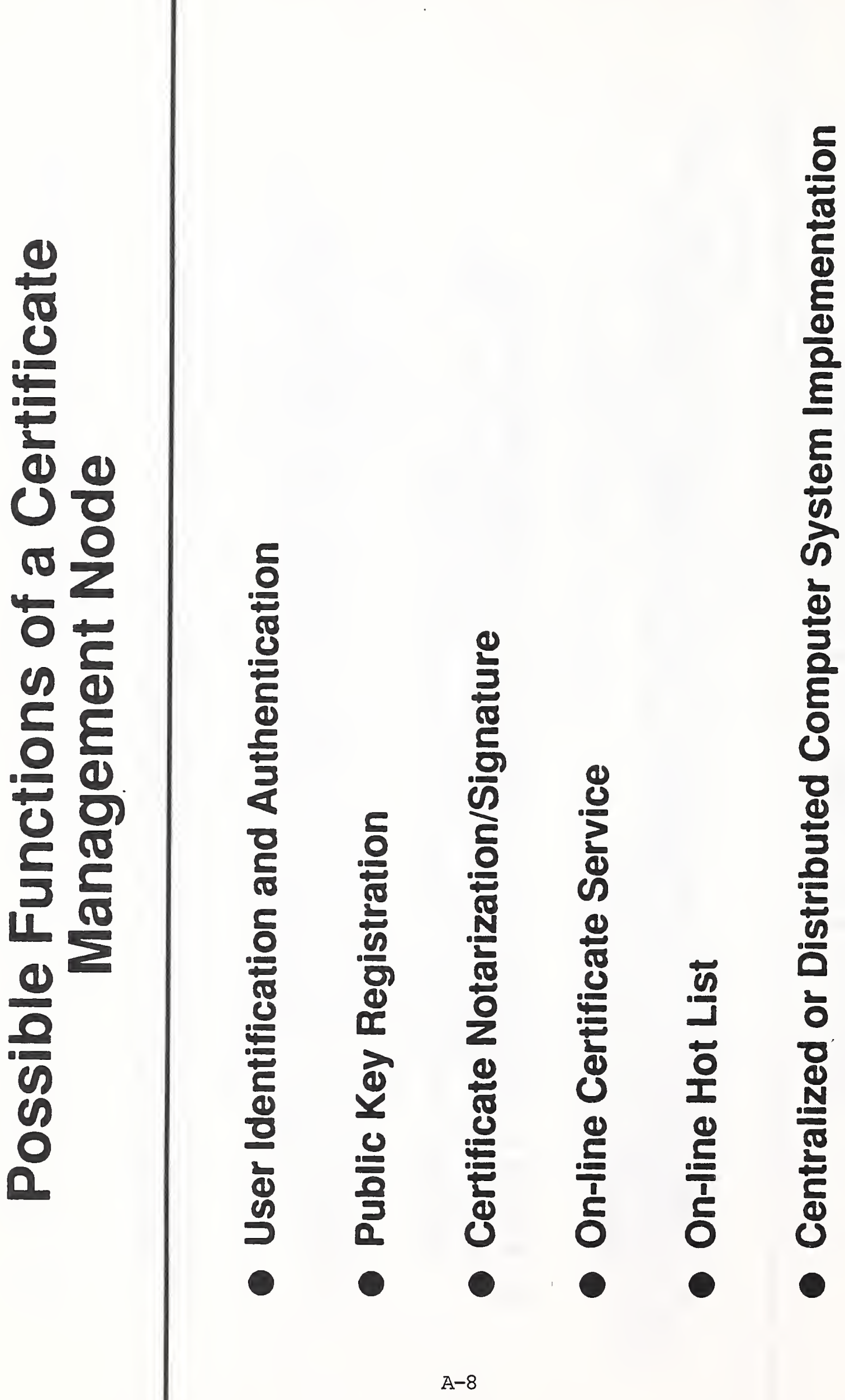




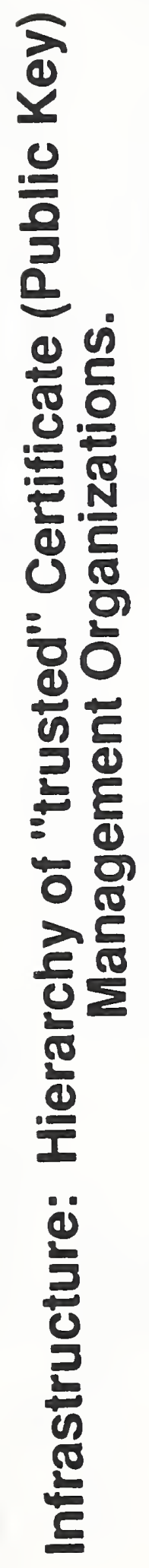

A-9 


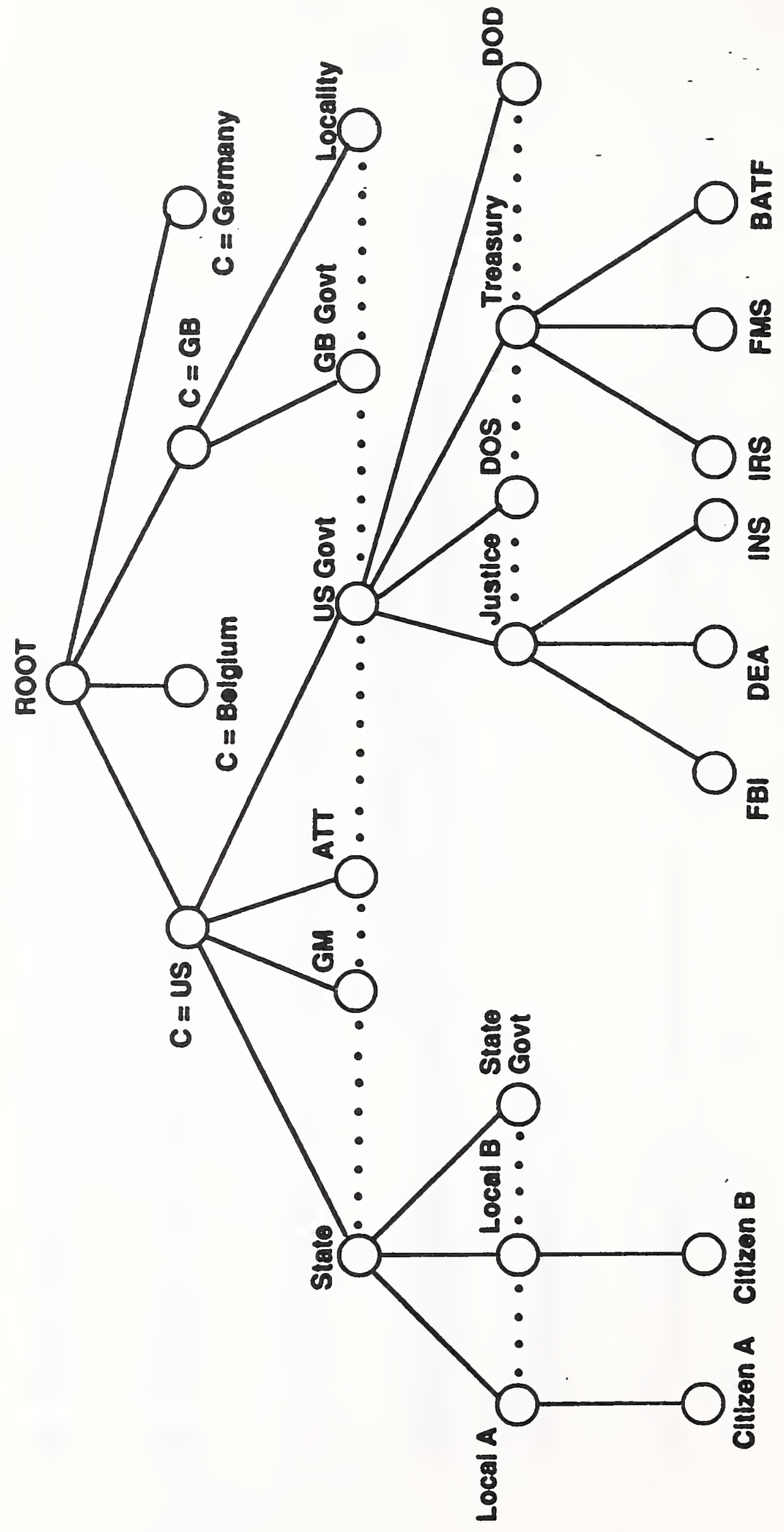




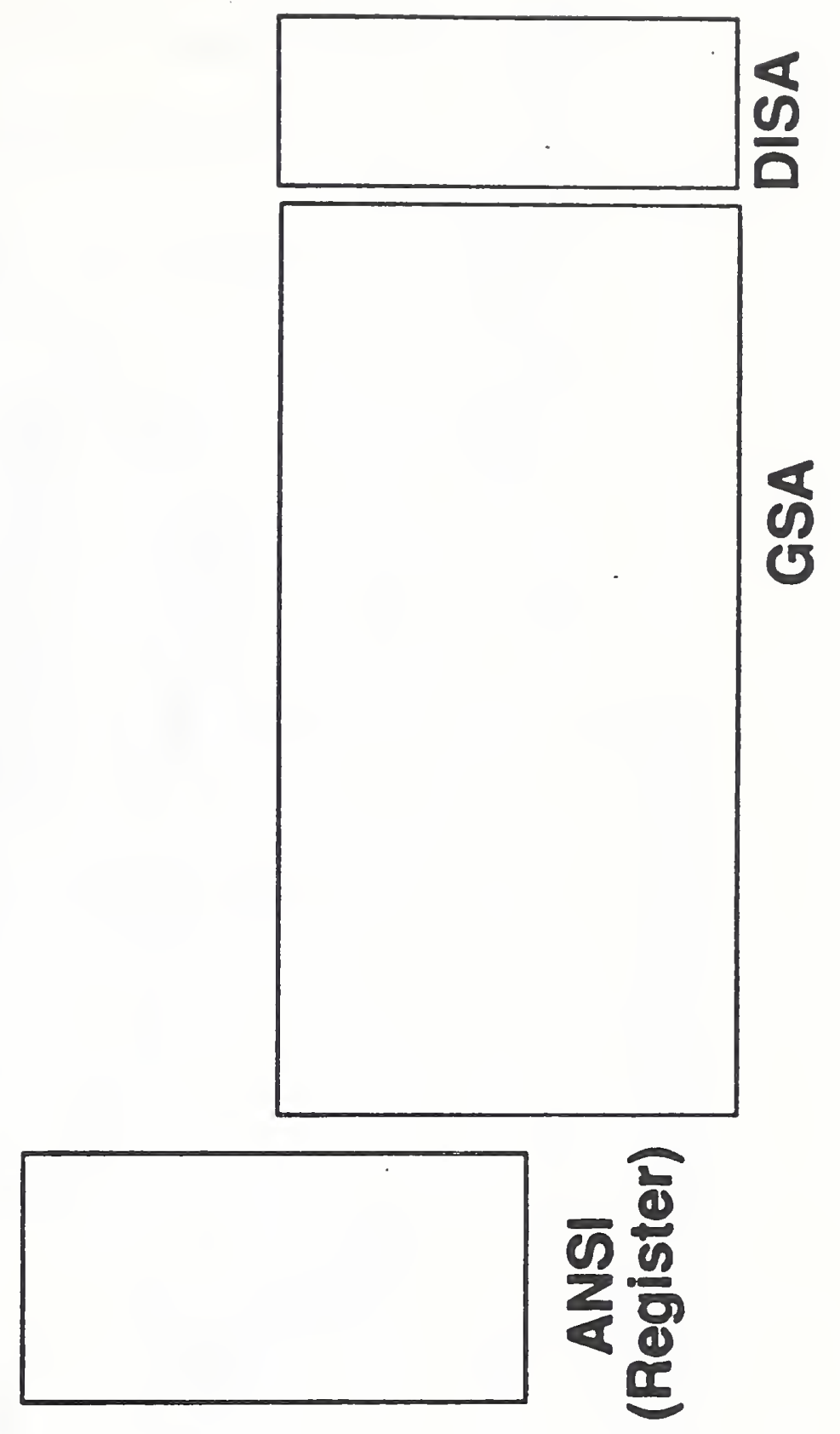

A-11

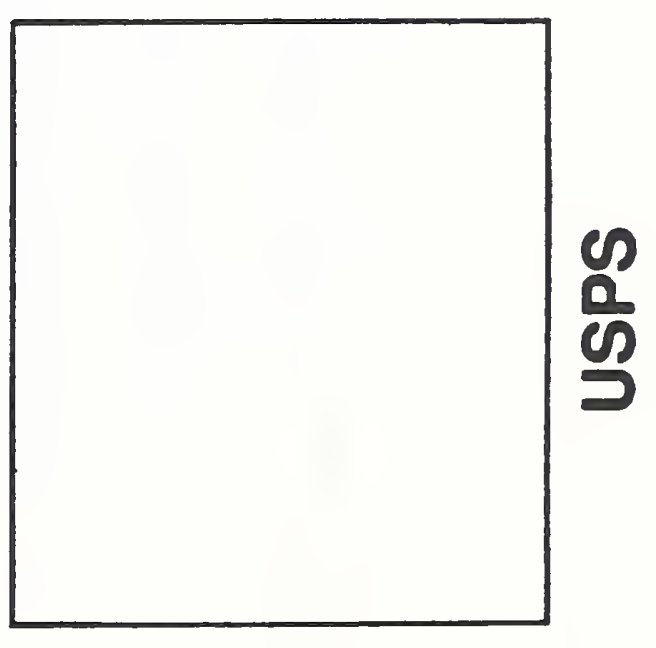



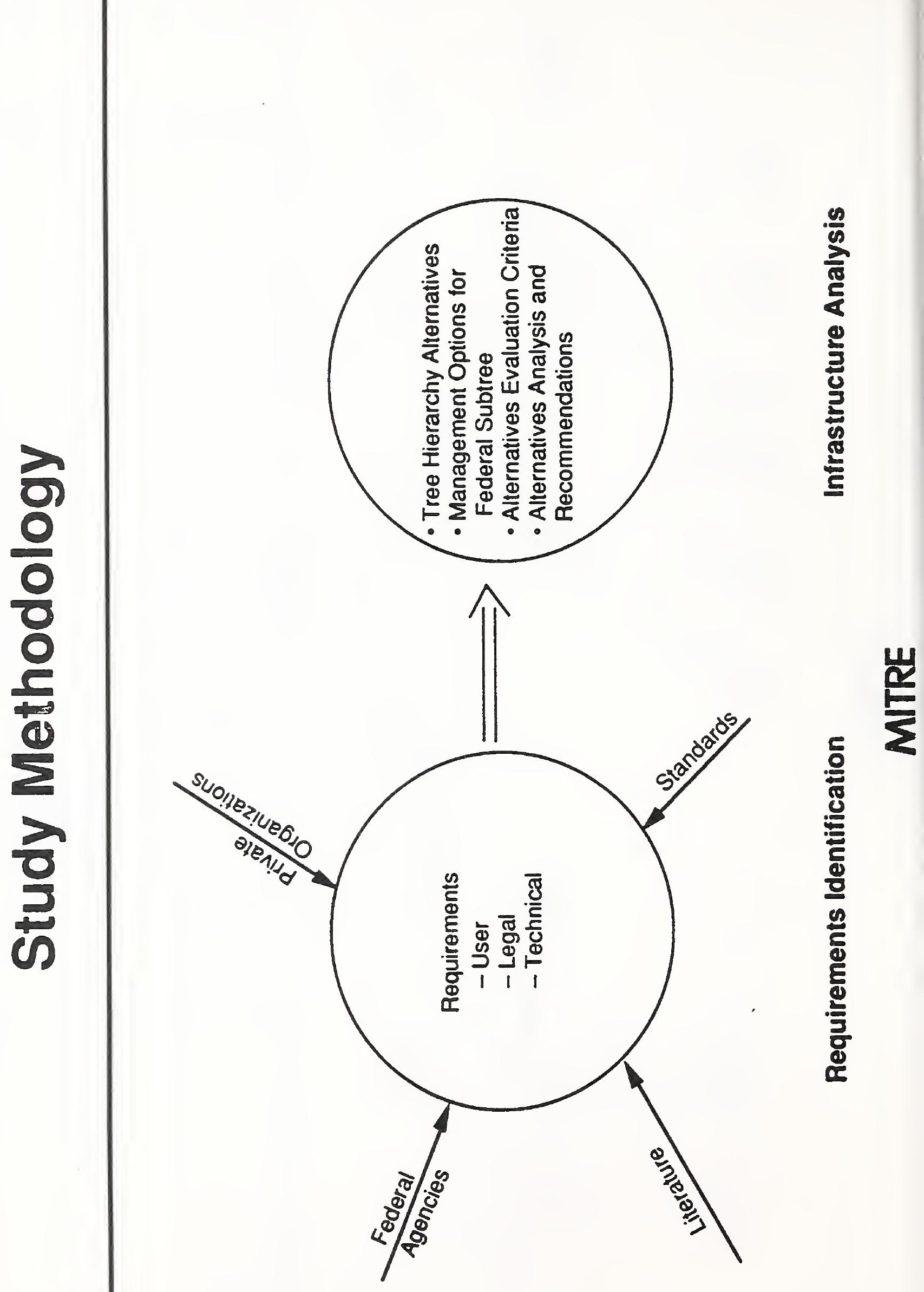


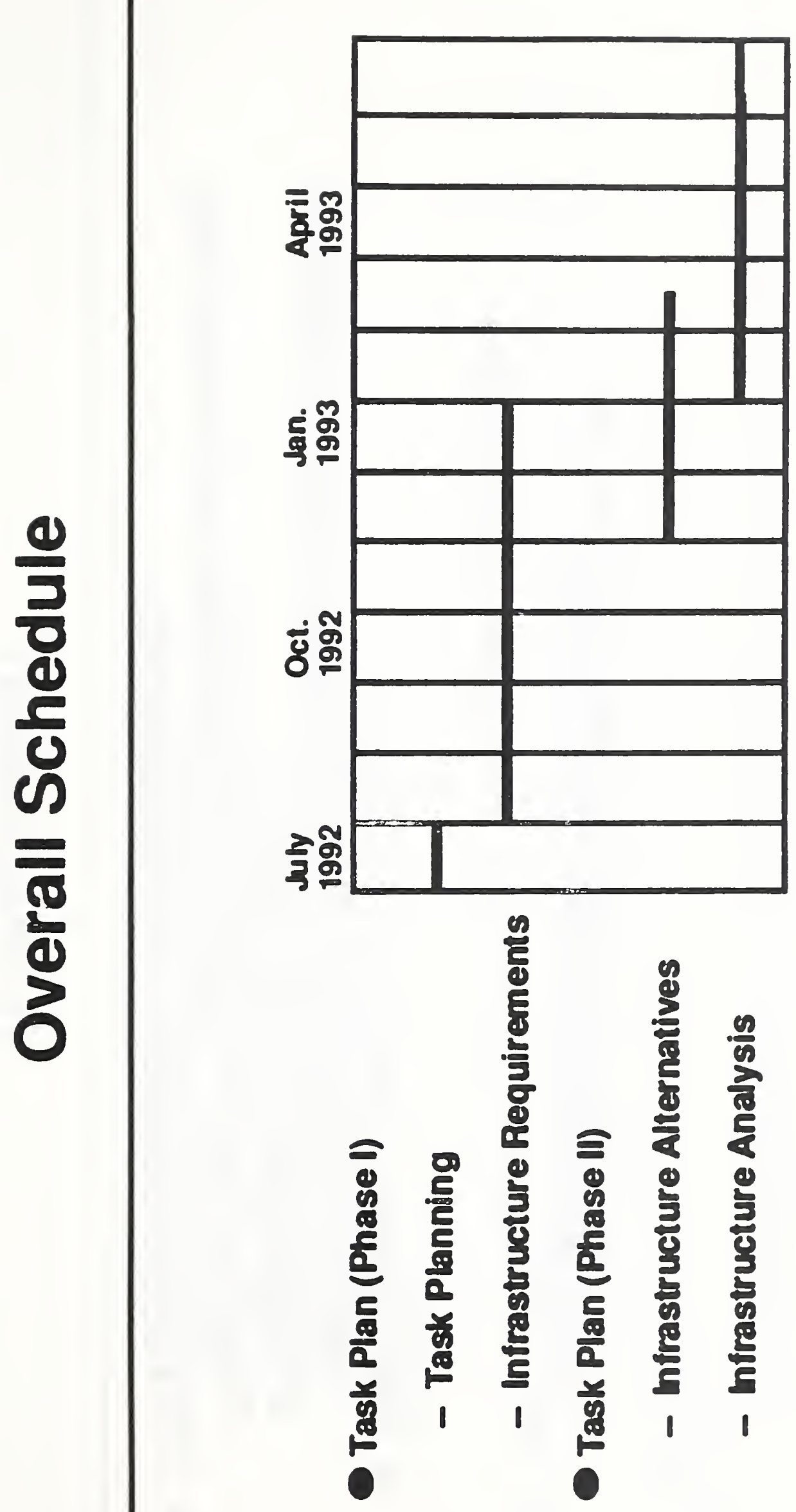

宸 


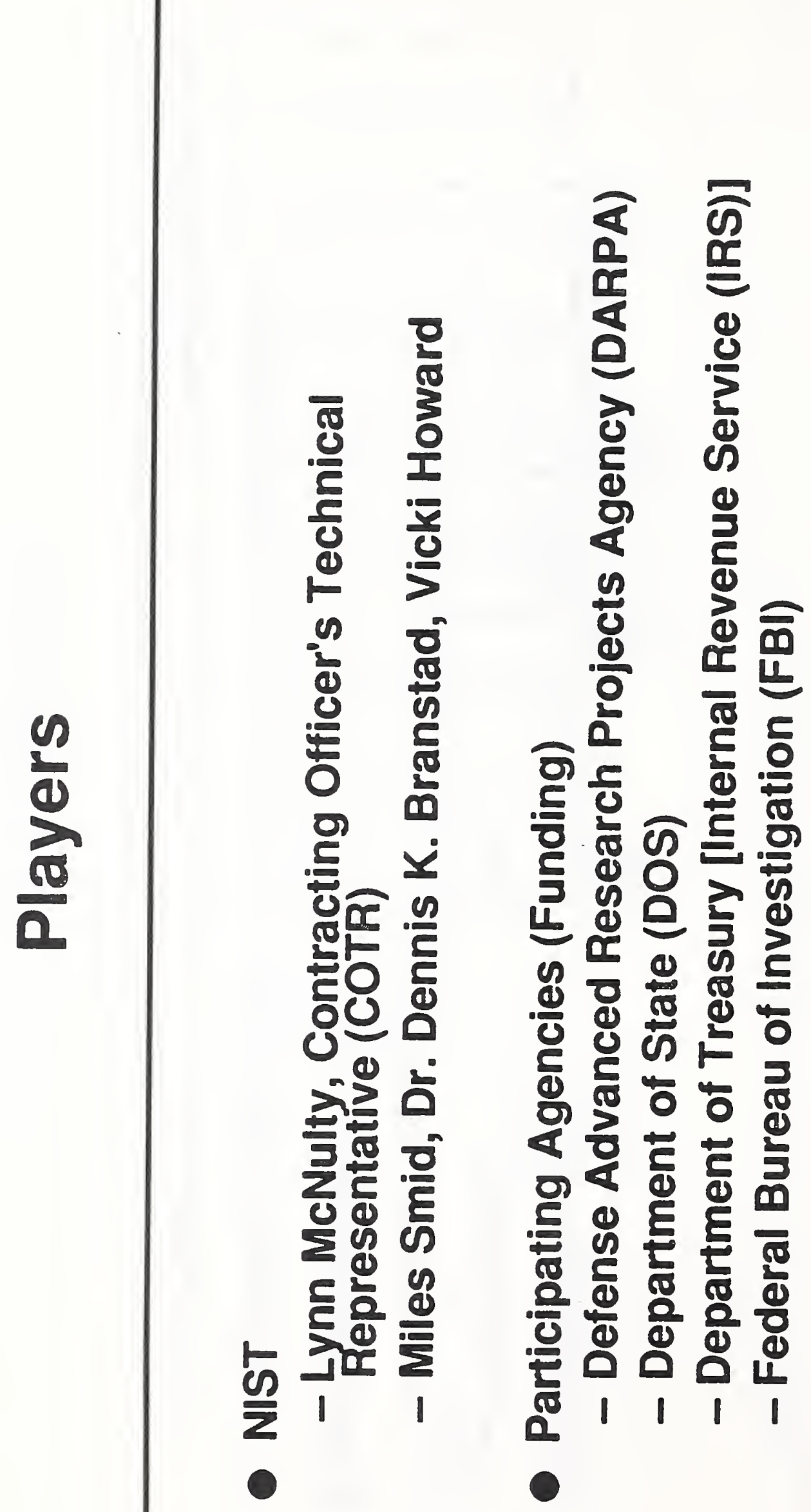




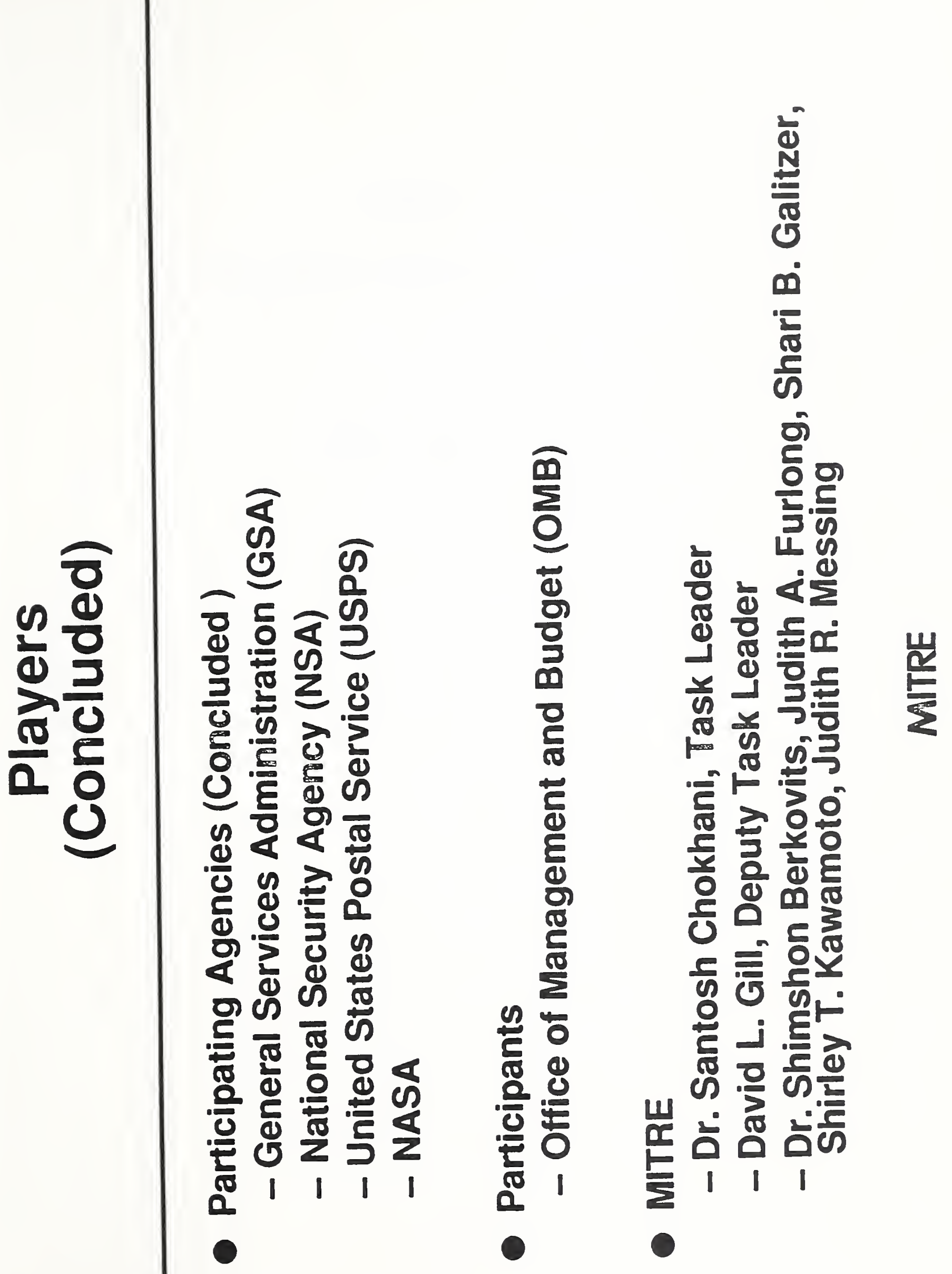




\title{
APPENDIX B
}

CERTIFICATE TECHNOLOGY FINDINGS

\author{
Shari Galitzer
}

MITRE Corporation 

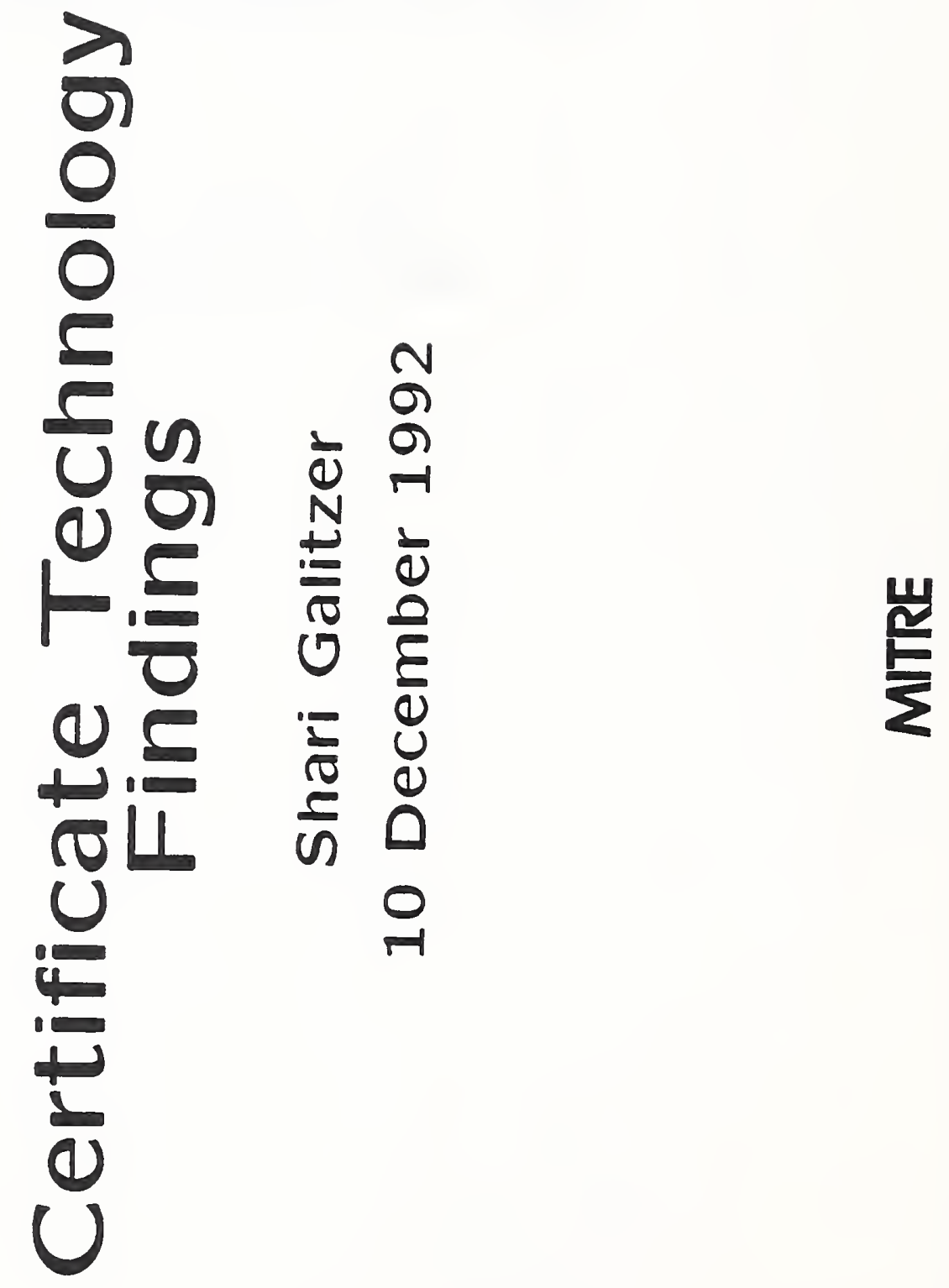
$\frac{0}{2} \frac{1}{2}$

$\frac{\lambda}{\vec{\theta}}$

긍

$\stackrel{0}{F}$

(1) N

4 흥

ن 4

$\div 0$

○ 은

n n

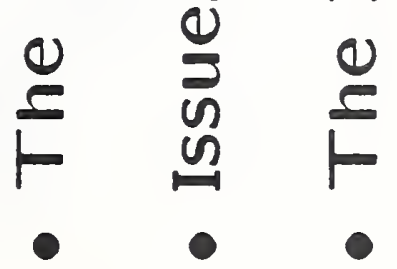

$\frac{W}{\Sigma}$ 

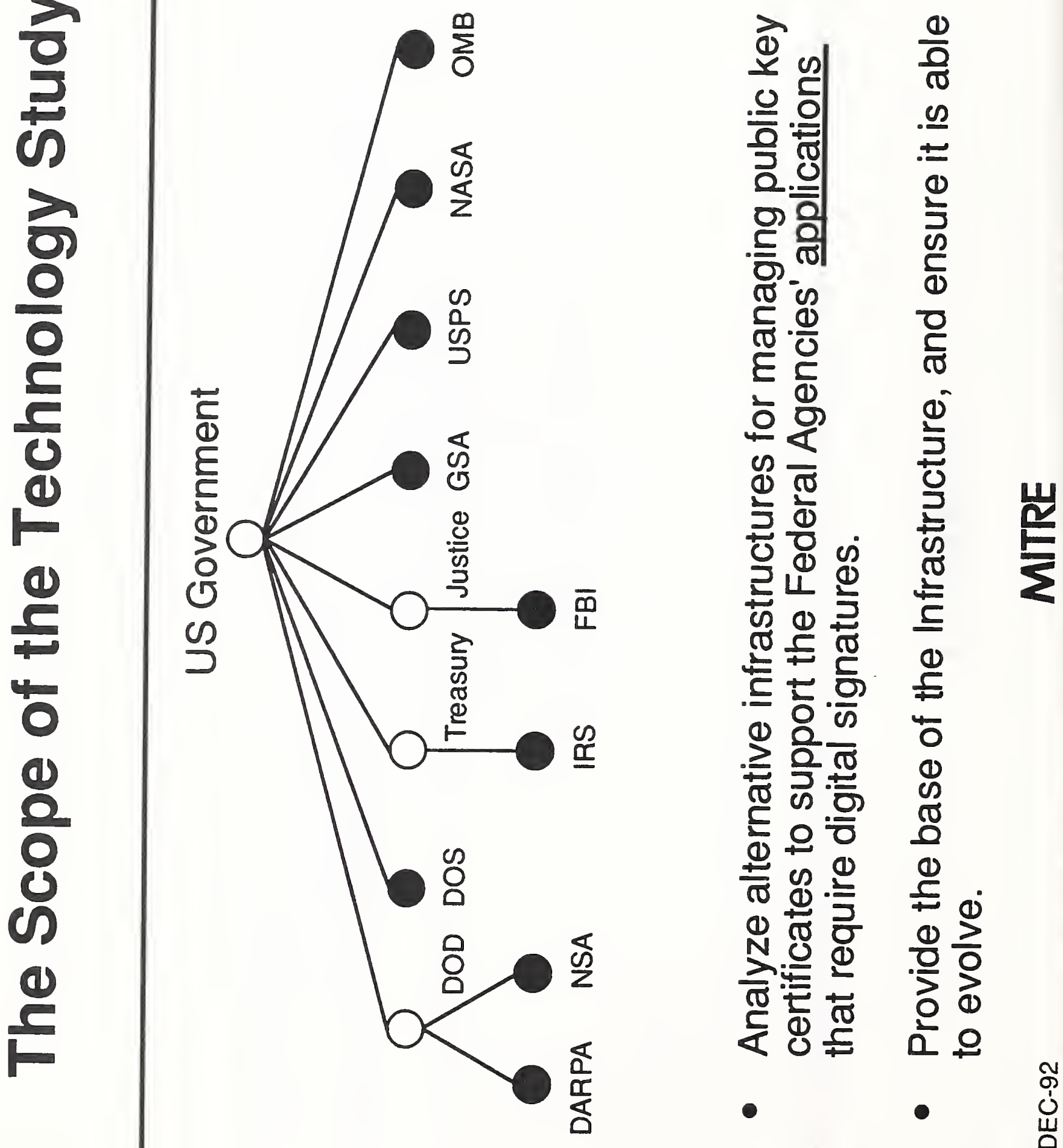


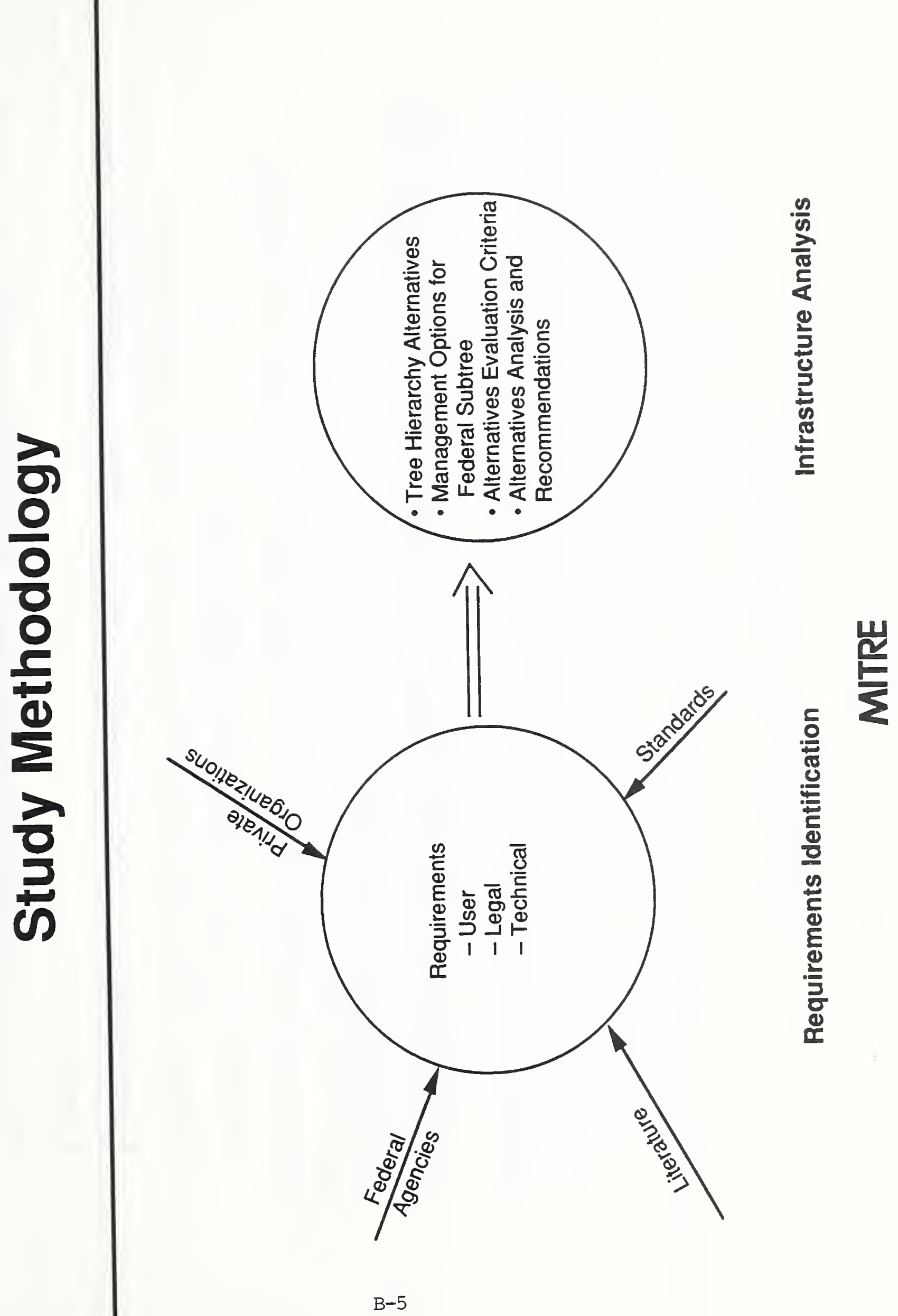



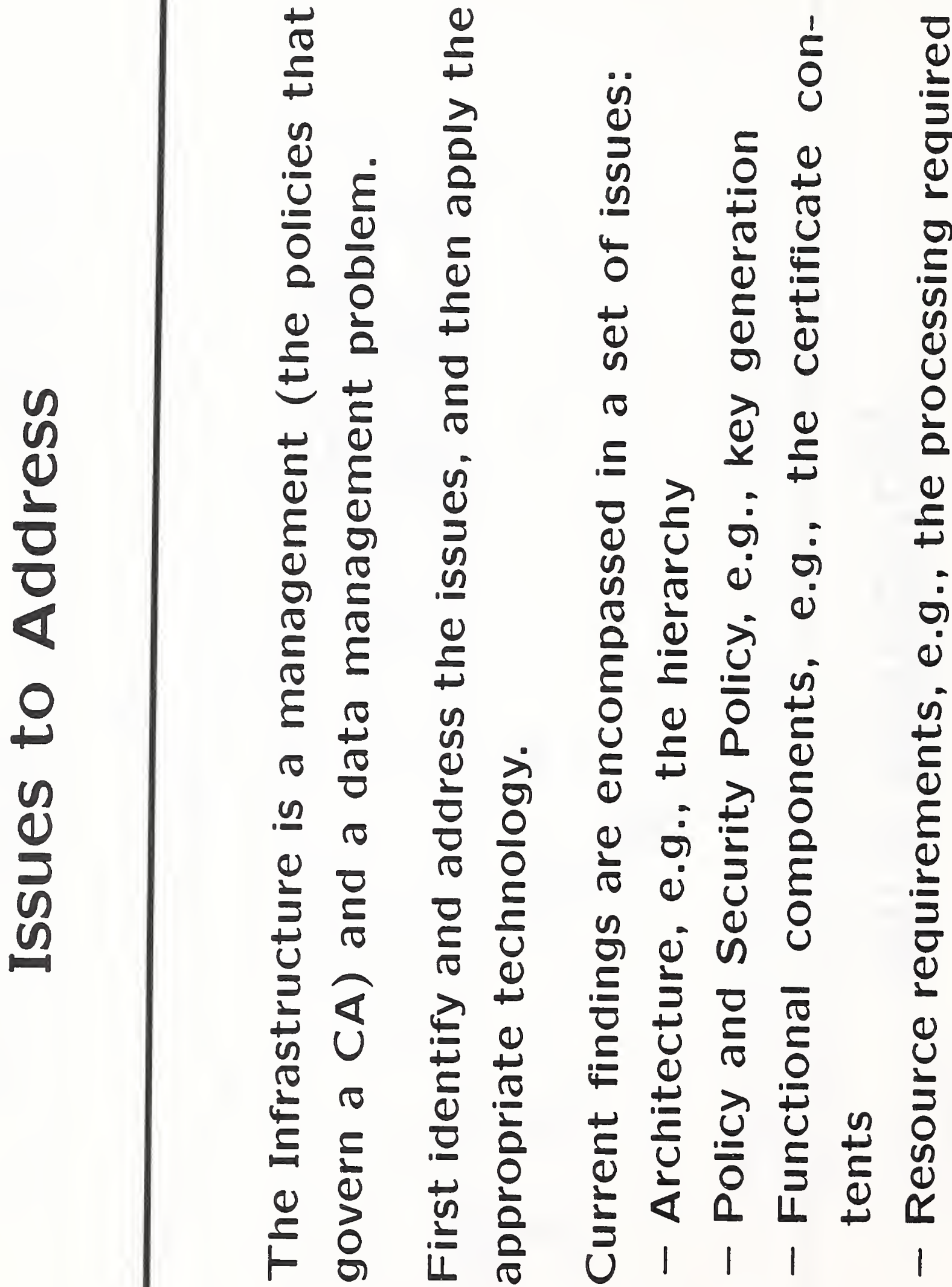


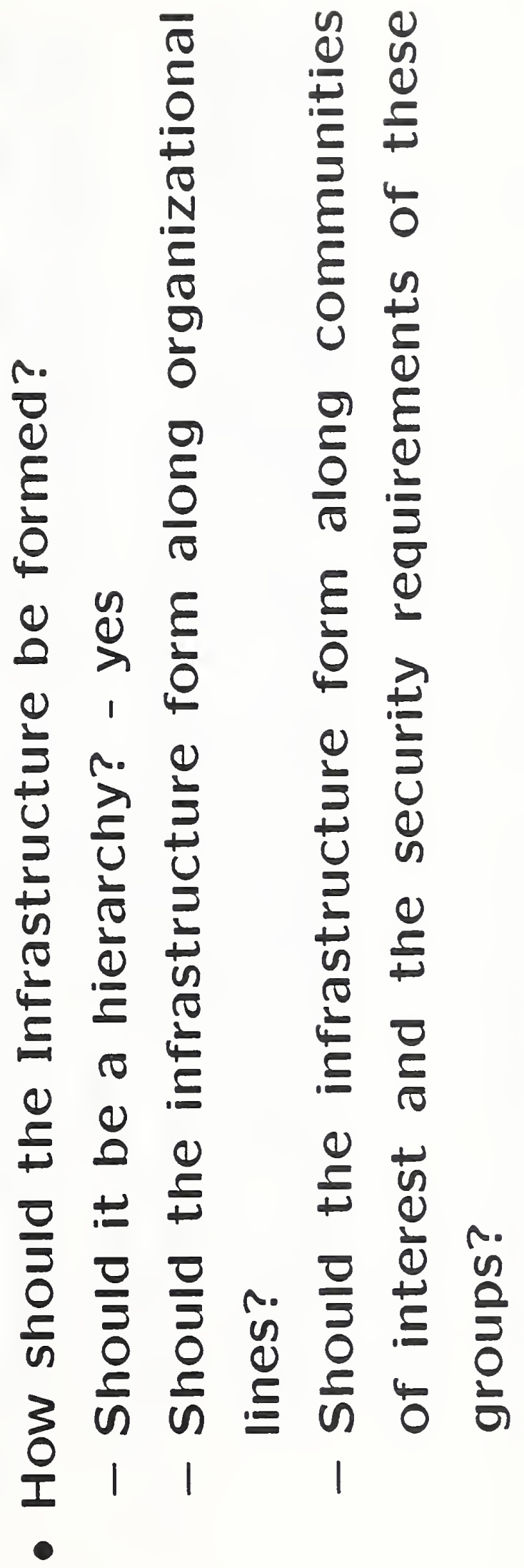




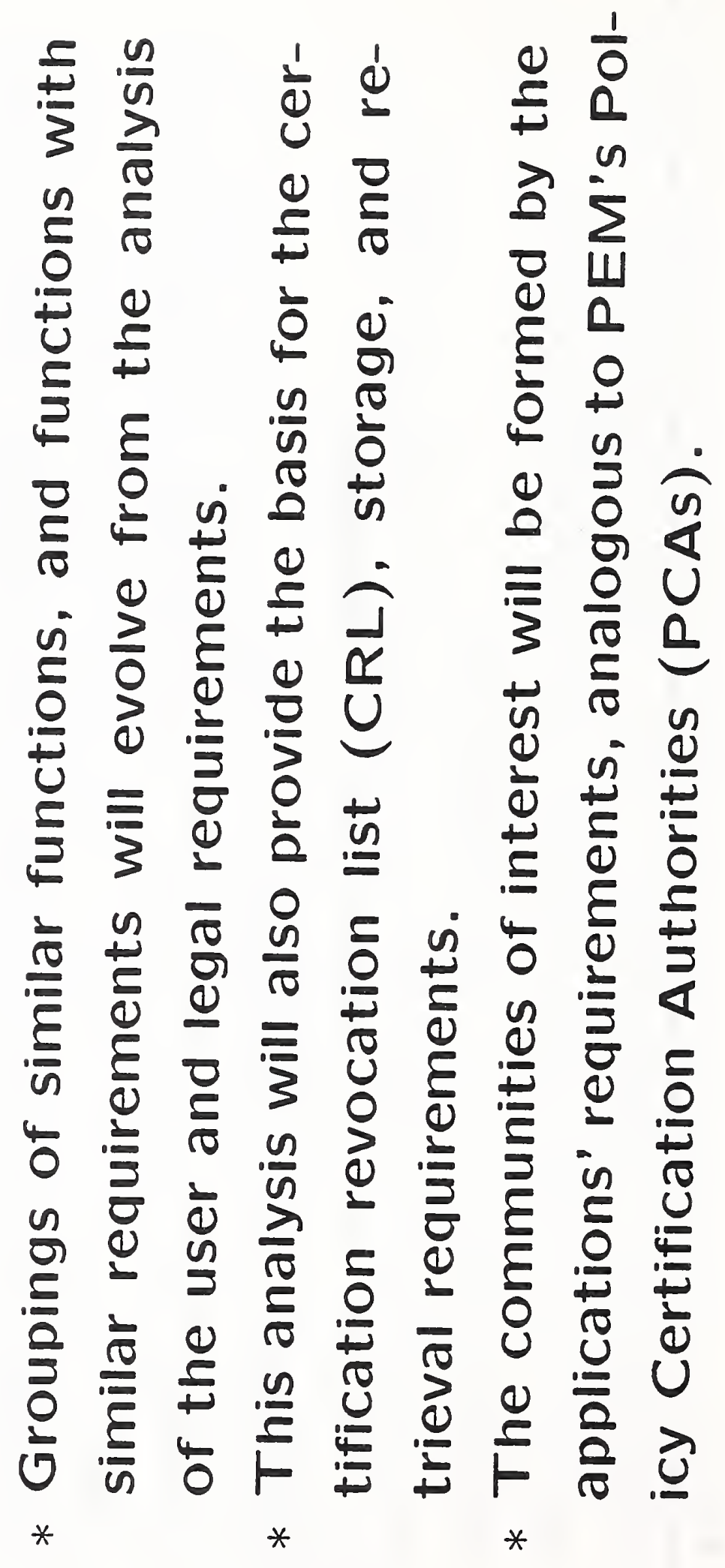




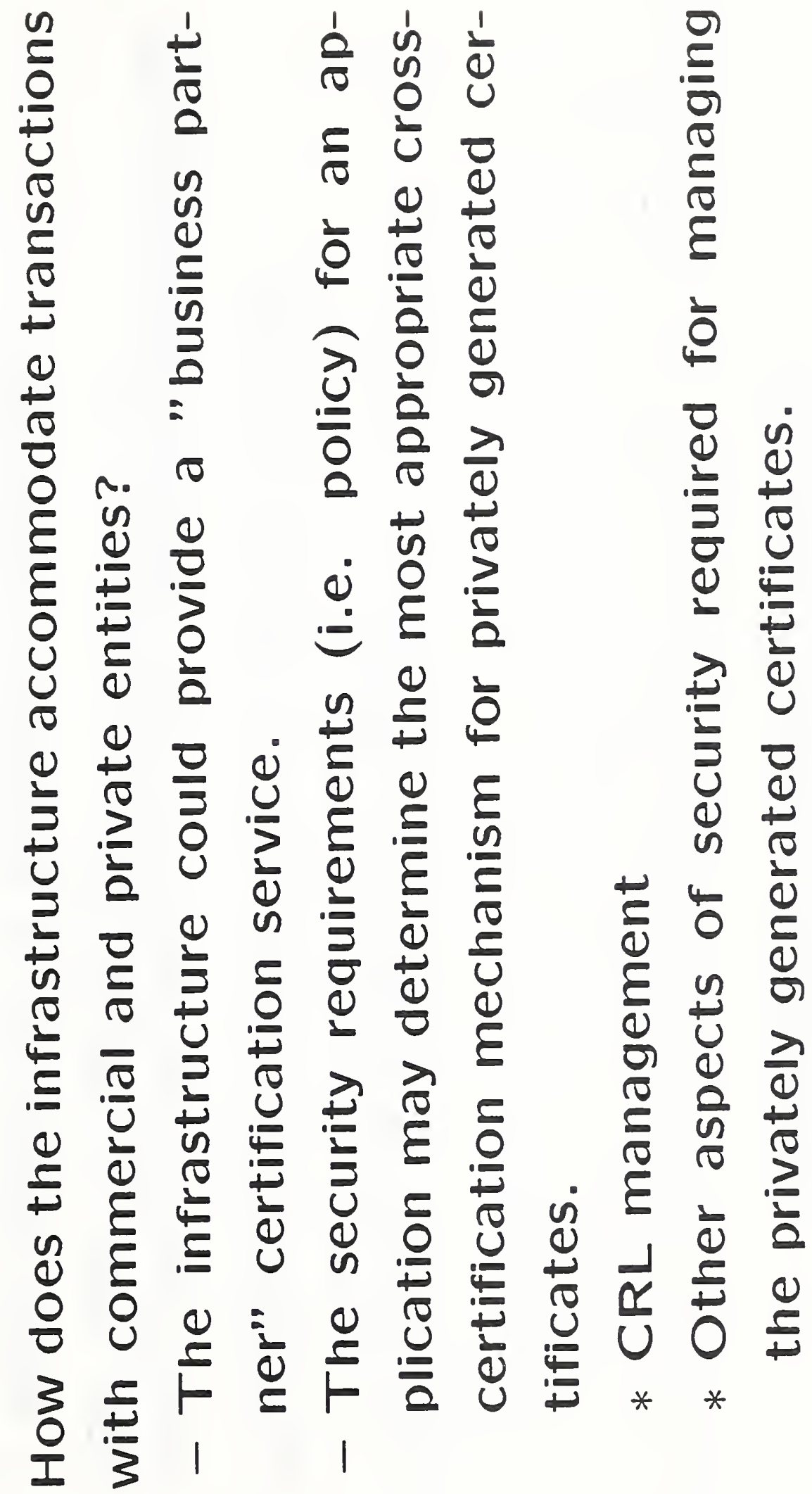



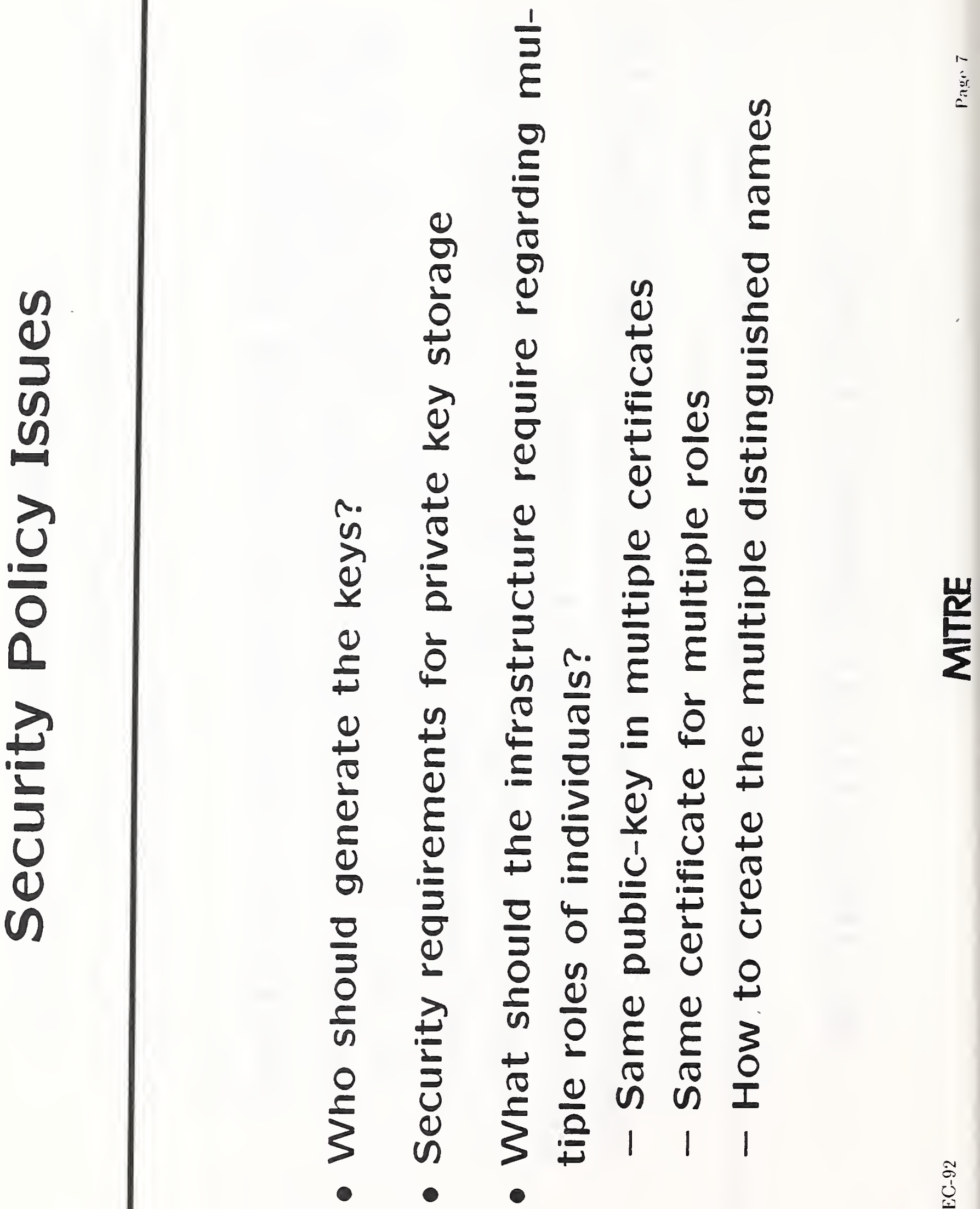

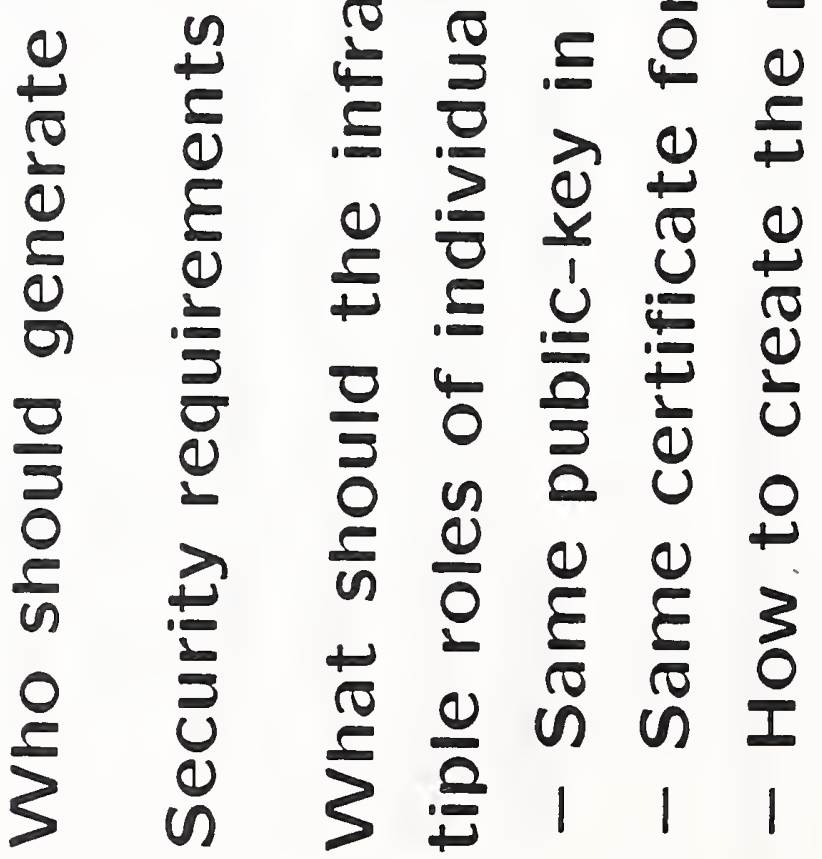



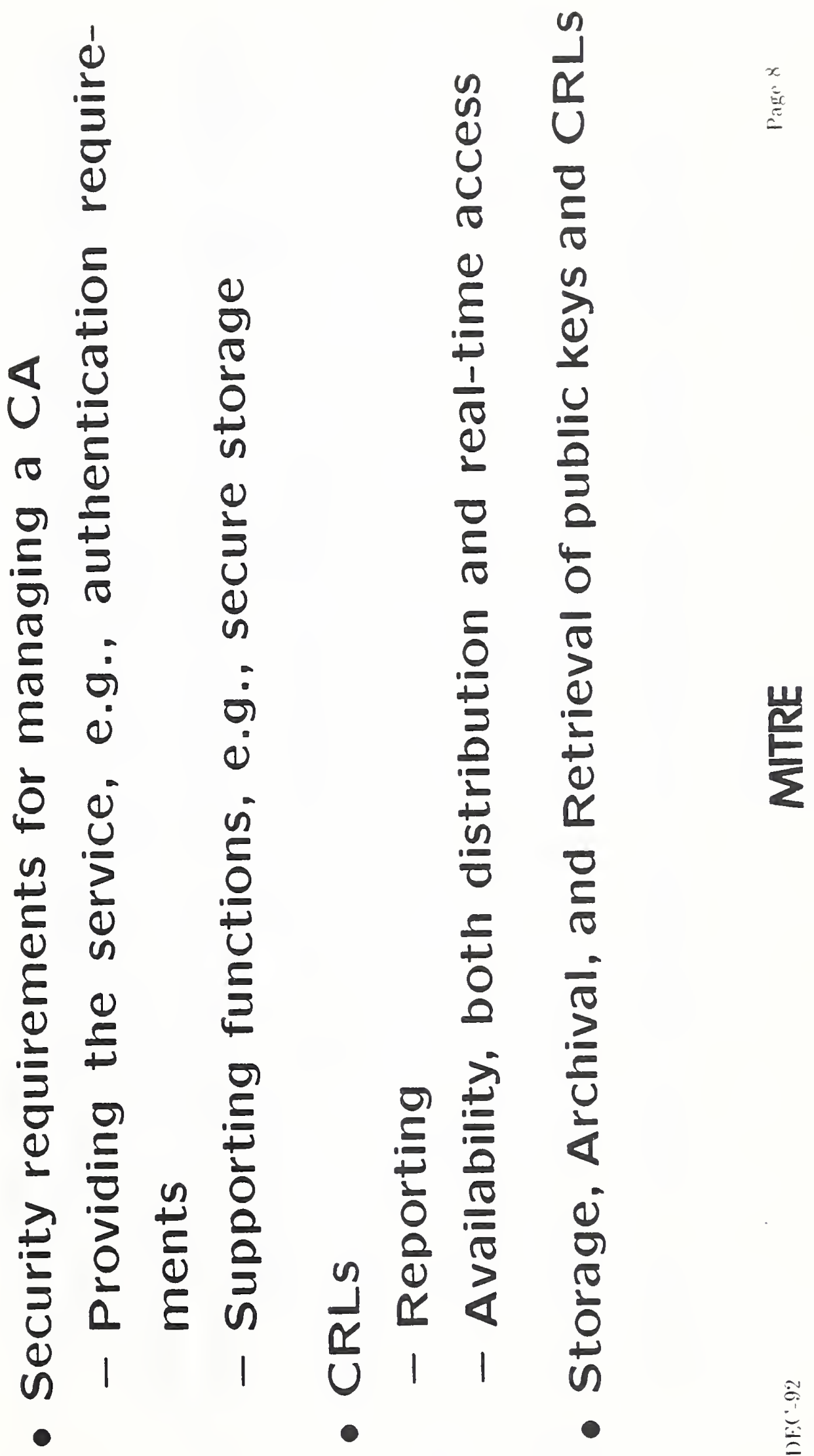


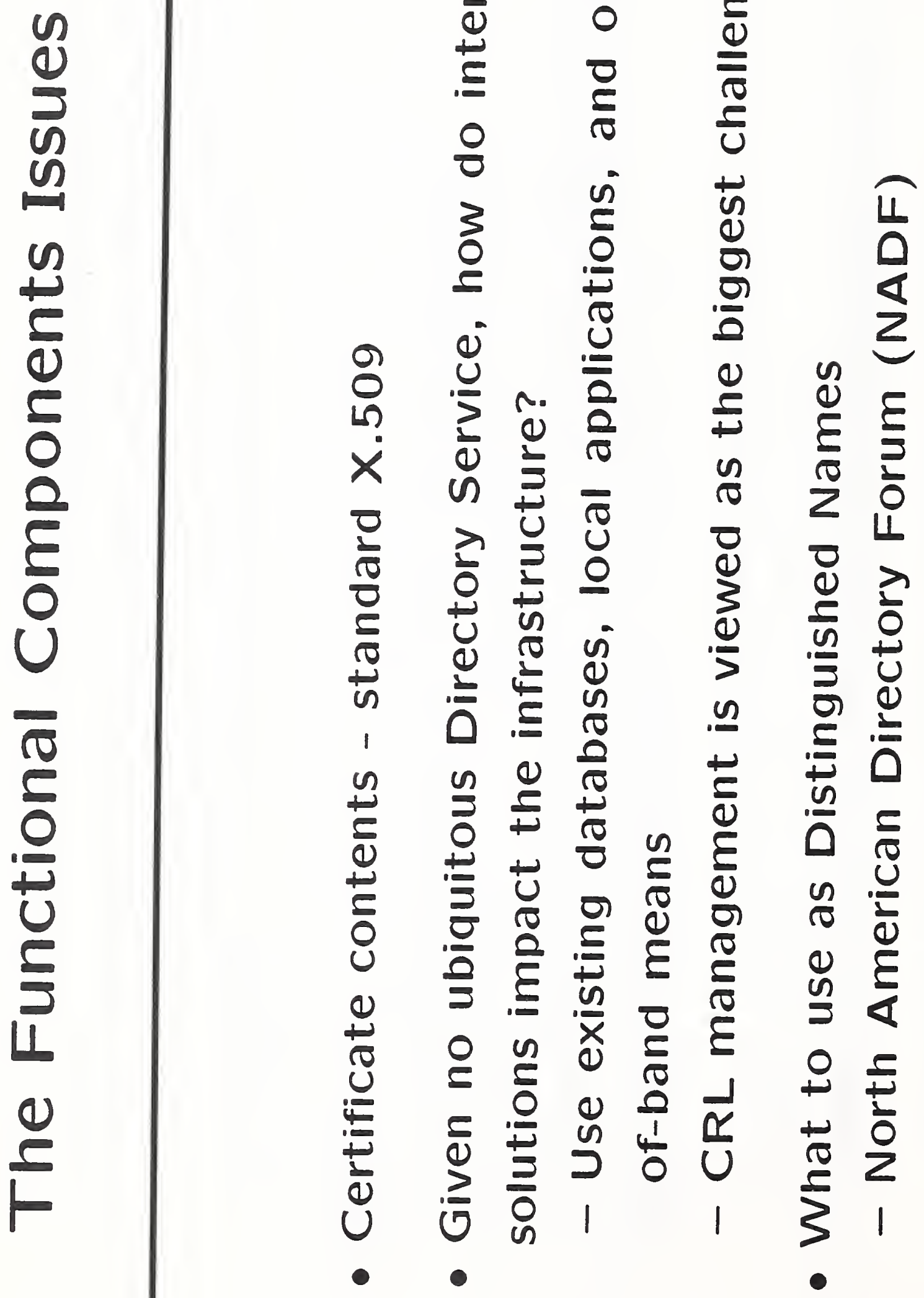




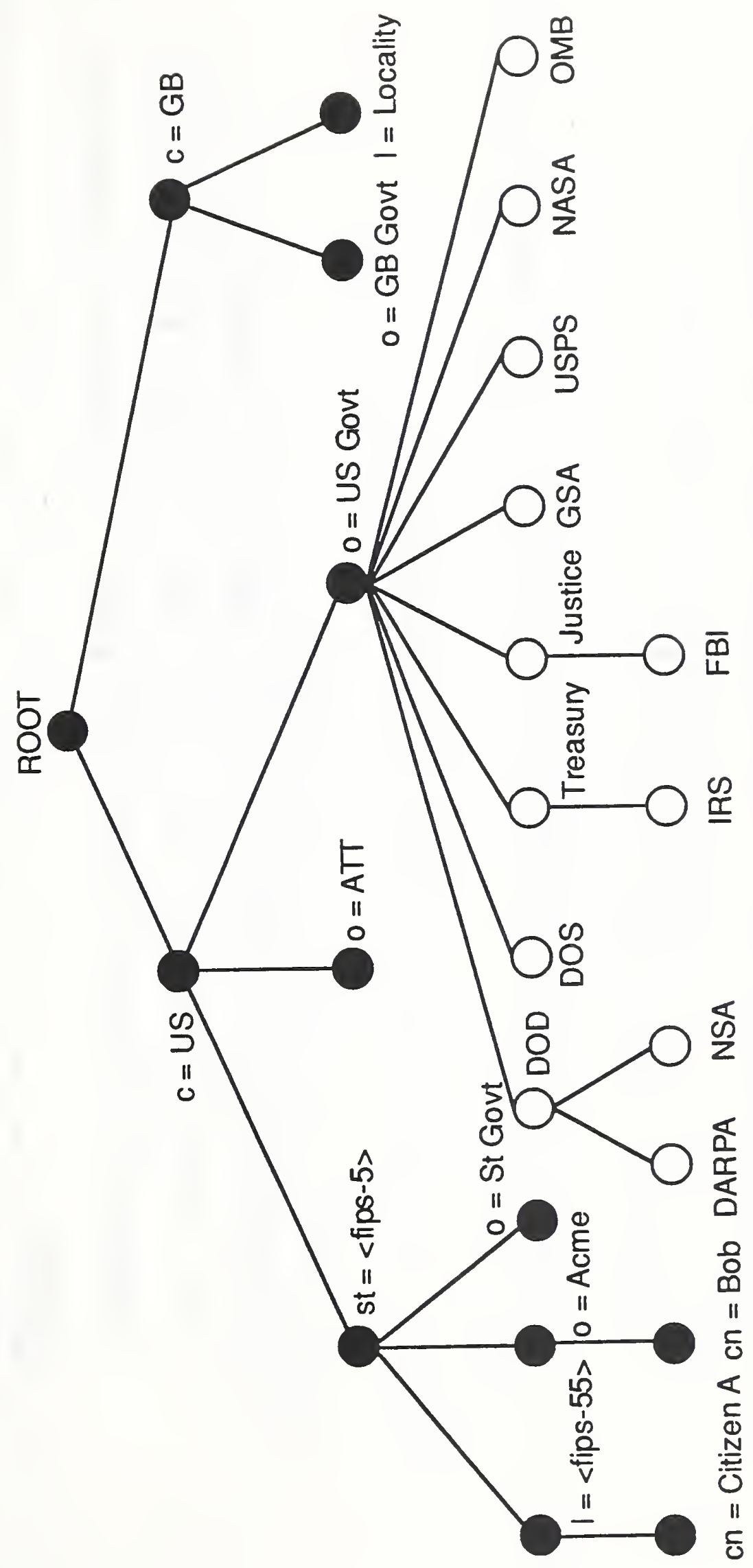

崖 

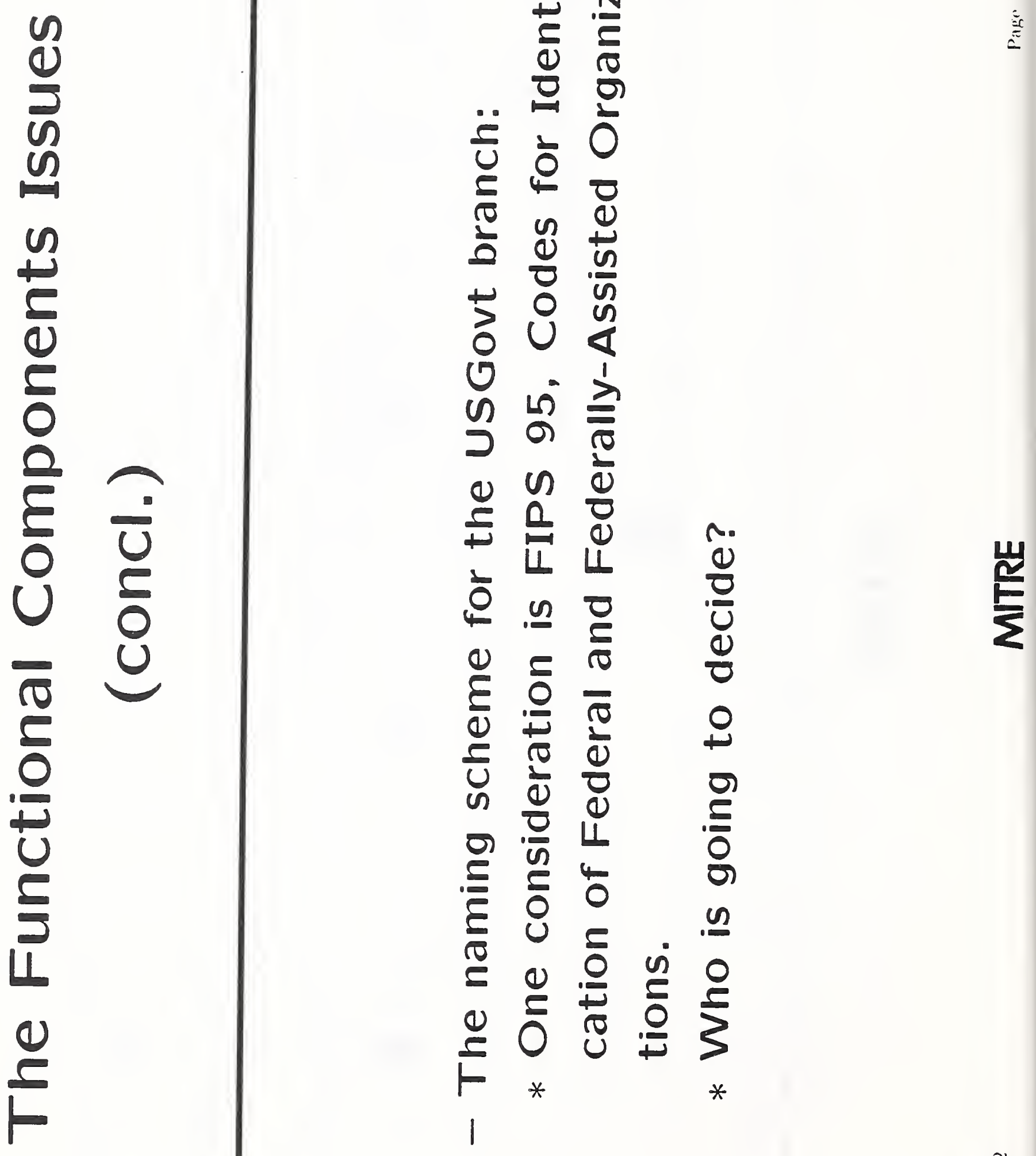

$\frac{\mathfrak{c}}{0}$ 


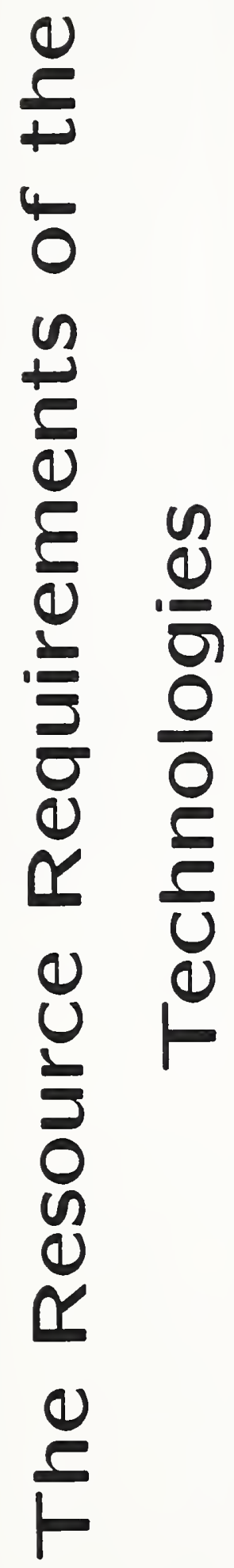

$\frac{E}{3}$

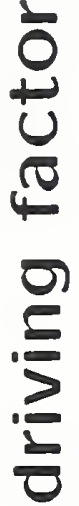

른

N.

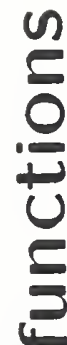

U

3

है

$\therefore \frac{0}{0} \stackrel{0}{0}$

$\begin{array}{lll}0 & 0 & 0\end{array}$

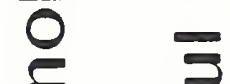

$\stackrel{1}{2}$

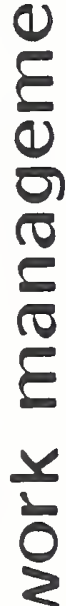

$\underline{\underline{E}}$

0 ह

$0 \stackrel{0}{0}$

E

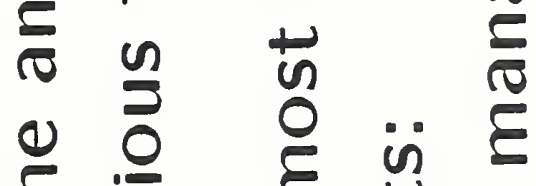

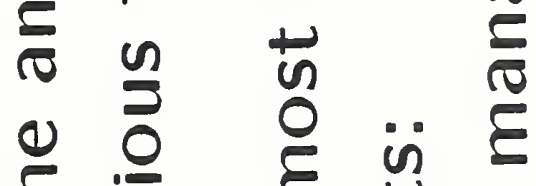

(1)

E

$+0$

o) $\omega^{\prime} x$

है

$+$

8

(1) 0

E $\pi$ ह

+ E O

U

(1) 는

ज

0

$\because U$

$+01$

잉

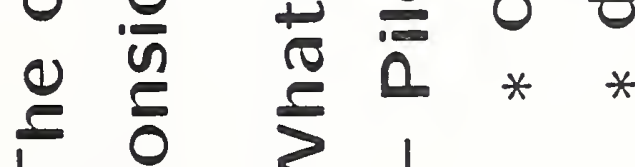

0

E 031 

APPENDIX C

ELECTRONIC SIGNATURE

THE KEY TO MOBILITY

Commission of the European Communities

Results of the Call for Ideas

October 1992 


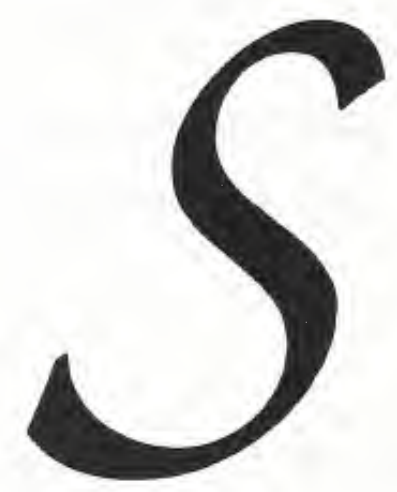

\title{
Electronic Signature The Key to Mobility
}

\author{
Results \\ of the \\ Call for Ideas
}

October 1992

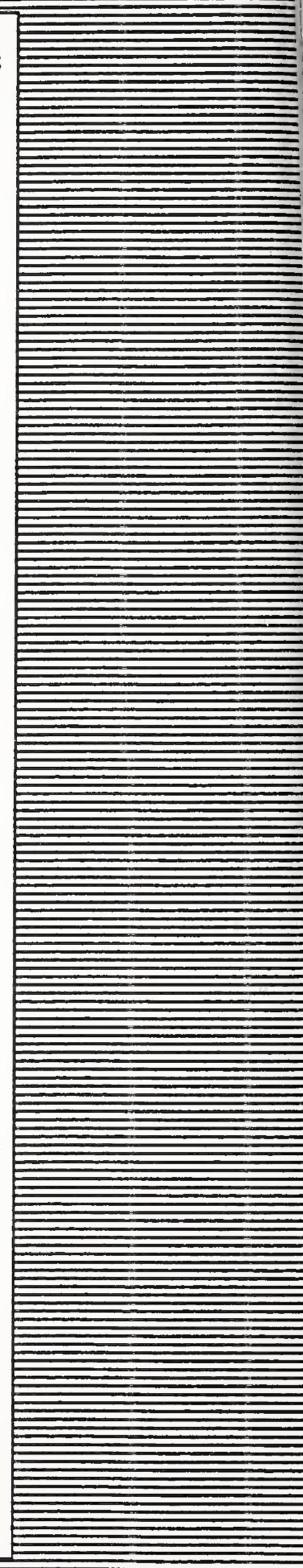




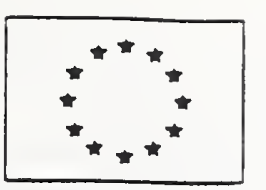

Directorale-General XII

Information Technologies and Industries, and Telecommunications

Dinestorale $B$ - Acions RDT: Telecommenicasions

\section{Electronic Signature}

The Key to Mobility

Results of the Call for Ideas

\section{TABLE OF CONTENTS}

1. Introduction

2. Summary of Contributions

21 Overview of Responses

2.2 General Comments

3. Overview of Issues

3.1 Specific Issues and Ideas

Annex A List of Contributors

Annex B Summary of Interest

B.1 Main Areas of Interest

B.2 Sector Respoluses

Annex C Some Contributions of Interest

The views put forward in this report are those extracted from the contributions received under the "Call for Ideas". This report should not be viewed as presenting the formal view of the Commission of the European Communities. 


\section{INTRODUCTION}

The Council of Ministers adopted on March 311992 an action in the field of Security for Information Systems. This action is now implemented in close collaboration with the administrations of the Member States via the Senior Officials Group on Information Systems Security, SOG-IS.

As part of its work, SOG-IS agreed on a consultation of interested sector actors on the concept of Electronic Signature - The Key to Mobility.

As a first step, it was decided that the current views on the use and functions of such a capability should be identified through a 'Call for Ideas'. To facilitate this process, an initial Reflection Note was distributed in May 1992, as a first indication of the scope under consideration.

A large number of contributions were received in response to this 'Call for Ideas'. This present document provides an indication of the important comments and ideas with respect to the Reflection Note and some of the issues requiring further consideration. Also included in the Annex of this present draft are a selection of those contributions that provided the most interesting feedback.

This document and the contributions identified in the Annex will be used as the basis of the workshop that is being scheduled. This workshop will assist in the consolidation of the contributions received and a clarification of the scope and action with regard to an Electronic Signature capability.

The emphasis in this document is on the ideas received. Tnis document, therefore, does not present results from other Community activities, of which there are several, related to the concept of an Electronic Signature; for example results from the TEDIS programme (see TEDIS Programme 1988-89 Activity Report COM(90) 361 Final, the Reports of the TEDIS Workshops June 1989, and the Report "Service Infrastructure for EDI Security", etc.) or other actions related to data protection, legislation and regulatory issues .

The views put forward in this report are those extracted from the contributions received under the "Call for Ideas". This report should not be viewed as presenting the formal view of the Commission of the European Communities. 


\section{SUMMARY OF CONTRIBUTIONS}

\subsection{Overview of Responses}

The Reflection Note on Electronic Signatures (ESs) resulted in an overwhelming response from a wide cross-section of interested parties. The written responses provided a wealth of ideas, some old ideas presented in a different form and some completely new ideas. In addition, these contributions raised a number of issues.

There was a general feeling that an ES capability has a significant part to play in public, private and commercial life. It was also felt that the ES concept is one of the early steps towards the long term use of information security technology satisfying a broad base of application needs.

Despite the lack of an exact definition for an ES, there was no shortage of responses with feasible interpretations of the ES concept. There were a number of contributions that defined an ES as a concept capable of offering 'personal identification', 'originator authentication' and 'equipment / resource identification'.

Other contributions were less broad in their approach focusing on a more restrictive set of functionality. Some contributions quite simply equated the ES concept with digital signatures, smart cards and existing products and technology. Whatever the finally agreed definition is, the wealth of ideas as a result of the call reflects considerable interest and concern in this area.

As one might expected user requirements, legal and regulatory issues, technology and operational aspects featured high in many of the contributions. What follows is a summary of the major issues that appear in the contributions. This list of issues is not exhaustive and the planned ES workshop will no doubt identify possibly more issues.

\section{General Comments}

\section{Requirements, Economics, Markets, Legal \& Regulatory Aspects}

o A high level model is required to match user requirements and application needs against the technological possibilities for an ES capability

- Early action is required to distil an agreed long-term vision of the expected role of ESs within society

o It is important to have as wide a view as possible with regard to the possible application of an ES capability, current attempts at providing an ES capability often satisfy narrow operational requirements, in particular the significance of mobility is less pronounced

- The significance of mobility for economic success and positioning is increasing: there is a need for a socio-economic reference model for the use of ESs

- Need to develop specific users scenarios illustrating the role of an ES in real areas of application

- Greater awareness and application of an ES capability is needed before establishments will be ready to accept them

- Legal acceptance and admissibility of the ES methodology is a major prerequisite and in some areas of ES application of paramount importance 
- Work on legal and regulatory aspects should be given a high priority complementing all other areas of activity exploiting existing work on digital signature

- Different ES applications may have different legal and regulatory demands

- Legislation associated with electronic documents (e.g. in Sweden) uses the concept of signature to prevent document forgery

\section{Functional Capabilities, System Concept \& Technology}

- Agreement is required on the following - What range of functions should the ES have? What are the minimum desirable security requirements for each type of function? Which functions are technically feasible?

- The ES capability should be part of the comprehensive open systems architecture currently being developed, taking into account existing standards and technology were they exist?

- ES and distributed system security go hand in hand, and so the ES concept should be an integral part of future distributed system strategy and policy

o It is important to consider what connects, and not what divides (which often is the case when commercial interests are involved)

- Standardisation is a major technical problem with regard to signature technology e.g. establishing an open systems approach to ES facilities

- The ES technology should be developed to an acknowledged level with regard to functionality and assurance, in particular the concept should be developed consistent with the ITSEC approach

\section{Operational \& Management Aspects}

o Potentially ES technical issues are of less complexity compared to those concerned with the administration and management of an ES capability

o A user-organisation design concept needs to be developed

o Information flows, data linking and their system re-evaluation e.g. in the area of medical informatics information labelling

- Lost cost solutions are required for the management of ESs with supporting operational infrastructure

- There is a need for one access device to access many services and so it is necessary to manage different services within different application segments

o The method of management should have high integrity

\section{Verification of ES Concept}

- First prototypes should be well focused on areas of immediate significance to ES to validate early user acceptance and to show the benefits and opportunities provided by $E S$ in a realistic environment

- Such verification of the ES concept is required at an early stage of the ES activity before large scale implementation and introduction can take place 


\section{OVERVIEW OF ISSUES}

\subsection{Specific Issues and Ideas}

The following issues and ideas have been extracted from the contributions received. This is not a definitive list of the issues and ideas on those presented. However, they do represent a large sample of the major issues identified by the contributors.

\section{Use and Application of the ES Capability}

- The following is a list of suggested uses of the ES capability compiled from the contributions received (NB because of the wide range of terms used to mean different things or to illustrate different concepts, the list below does not differentiate between the terms used):

- 'personal identification', 'originator authentication' and 'equipment / resource identification'.

- applications requiring the use of non-repudiation services

- electronic passports / ID cards

- product stamping to ensure its integrity and authenticity (e.g. software stamping, together with its development / updating / maintenance history)

- electronic document security / copy management and protection

- use in personal communications

- electronic mail folder

- electronic purse / wallet

- road transport payments (parking, fuel stations, tolls, information services, road haulage payments)

- access to databases and more general to telematic services

- applications requiring use of remote control capabilities (e.g. in safety critical and hazirdous environments)

- physical access

- The following is a list of suggested areas of application compiled from the contributions received:

- telecommunication \& broadcast systems (e.g. GSM, satellite services, television services)

- personal mobile appliances (e.g. PDAs, personal communicators, personal information, personal payments etc)

- aerospace systems

- medical systems (e.g. patients records, medical databases, primary care systems, distributed decision and executive support systems, telemedicine services (home care \& mobile), communications, drug administration, general administration, access to restricted areas) 
- transport systems (e.g. airport environment - aircraft maintenance, customs \& VAT, duty free, access to restricted areas, ticketing and reservations, baggage control etc)

- industry in general (e.g. for production control, mobile data gathering (PDAs), sales)

- social services \& local government systems (e.g health, welfare, taxation, passports, Customs \& Excise etc)

- police systems (e.g. communications, access to restricted areas, electronic police records)

- banking \& payment systems, retail systems

- EDI-based trading systems \& other VAN systems

- teleshopping / telebanking

- The broad scope of ES suggests that it might not be feasible to produce a unique universal ES solution (but it is essential to deline a broader approach which defines a conceptual framework (i) allowing for a variety of ES solutions on a per application domain(s) basis, (ii) for ensuring upward compatibility between ES solutions of varying complexity and (iii) open to simple solutions that are technically and economically feasible)

- A need to consider the requirements of personal data protection and the prevention of data linking

- There is a need for users to be on an equal footing with application / service providers - current systems do not offer the same level of protection to users as to the providers of services and products

- The legal and logical aspects of security must be looked at together from a business point of view (commercial interests), a personal point of view (data privacy interests) and a public point of view (society and the quality and safety of life)

\section{Functions of the ES Capability}

- The following is a list of suggested functions of the ES capability compiled from the contributions received (NB because of the wide range of terms used to mean different things or to illustrate different concepts, the list below does not differentiate between the terms used):

- user / data origin identification and authentication

- copy management

- user access control

- data / file / document access control

- the integrity / authentication of data / documents / messages / resources etc

- confidentiality

- authorisation, audit and accountability 
- electronic personal organisers, notebooks, pen computers and Personal Assistants (PAs) / Personal Data Assistants (PDAs)

- The ES capability as a new technology versus the use of current smart card technology

o Notarisation techniques need to be considered

- Tamper proofing techniques are important

o Biometric techniques should be considered (voice, finger print etc)

- Commensurate with the scope of the ES capability the memory capacity could be significantly large (secret / private information, control information, work space, program memory etc) - this may be a practical limitation to its final definition

- The ES capability must be user / owner / closed group activated only

- The ES capability should have a keyboard and display as suggested in the Reflection Note

\section{Operational and Management Aspects}

o An easy to use, cost-effective solution is needed for ES

- Multi-system portability and interworking is essential in multi-application and service environments

o ES product related security evaluation is important

o The security management of the ES functionality should be as simple as possible without compromising the security of the ES overall

- Control of the use and issue of ESs are an important concerns needing practical solutions (economic, legal and personal issues). What are the requirements on trusted mechanisms and processes for the deployment and maintenance of ES capabilities? There are important issues concerned with the personalisation of ES related products

o What international aspects need to be considered e.g. public-key certificates in the case of digital signature techniques, directory services for certificates?

o The establishment and operation of some of the technical / legal aspects for handling repudiation / non-repudiation claims etc

- ES solutions must aim to exploit future technology

o Is there a need for ES related product identifiers as in the case with GSM? 


\section{ANNEX A LIST OF CONTRIBUTORS}

Thanks are due to the following individuals and organisations for their contributions in response to the Call for Ideas.

ABI, UK

Alcatcl Telecom, Nonway

Alcatel TITN Answare, France

Allianz, Germany

Anitra Medienprojekte GMBH

Ascom Tech AG, Swizerland

Association Belge des Banques, Belgium

Bakkenist, The Netherlands

Baltimore Technologies, Ireland

Bancamatic, Italy

Bancsto, Spain

British Bankers' Association, UK

British Computer Society, UK

British Telecommunications PIC UK

Bull, France

Bull CP8, France

Bundesverband deutscher Banken, Germany

CAP debis GEl, Germany

CAP SESA Finance, France

CEC DG XIII/D-5, Belgium

CEPIS, UK

Comatlas, France

Compurcr Audit Specialist Group - BCS, UK

Computcr \& Systems Tclccommuniations Lid., UK

Data Sccurity Consultant, UK

Der Landcsbcauftragrc für den Datenschulz N-W, Germany

DCE Ncdcrland B.V., The Netherlands

Digital, France

EDP Audit Pool, The Netherlands

EDS, Belgium

EDS Scicon, UK

ENST Bretagnc, Francc

Fcrn Universitat, Germany

Fraunhofcr-IAO, Gcrmany

Gemplus Card International, France

Gencsis, Austria

Gencva Management Group, Switzerland

Gcscllschaft für Mathcmatik und Datenverarb., Germany

Gescllschaft fur Mathematik und Datenverarb, Germany

Gicseckc \& Devrient GmbH, Germany

Hewlat-Packard Labs, UK

IBM Europcan Networking Center, Germany

IBM Scmea S.p.A., Itały

Information Sccurity Corporation, USA

Information \& Systcms Management Ltd, UK

Inforama, France

Innenministerium Baden-Württemberg, Germany

Intercai Advanced Telematic Skills, The Netherlands

via Internct

via Internct

via Internct

ITS, Sweden

Johan Wolfgang Goethe - Universität Frankfurt, Germany
P W Lever

K Prestiun

B Passagez

B Senff-Schöne

W Boc

A Beuchat

$J$ Van den Nieuwenhof

$P$ van der Meijs

Dr M Purser

A Biasiotti

3 D Lifante

A A Ketrley

Dr F E Taylor

$D$ Willets

D Pinkas

J Patarin

N Schmizz

F-P Heider

$P$ de Kervasdoue

P Husson

P Walmisley

A Dubreuil

Dr J A Mitchell

Dr S Castell

D Watts Davies

Dr P S Pütter

$\mathrm{H}$ Wiercnga

$Y$ Le Roux

$H$ de Zwan RA

$\mathrm{H}$ Ardies

TC R Nicholson

$P$ Rolin

Prof.Dr-Ing F Kaderali

H Mcitner

O Trcbuca

Ms I Schaumüller

$\mathrm{R} I$ Polis

M Agi

Prof Dr E Raubold

Prof Dr E Klein

Dr V Varadharajan

Dr $\mathrm{H}$ Fanderl

F Zanon

T J Venn

E T Peers

R Guillaumor

Dr Frömel

$R$ van Eijk

Dr J Linn (USA)

Mr Kent (USA)

B Kaliski (USA)

$P$ Hoving

Prof C P Schnor 
K\&M Technologies

The Kingswell Parnership, UK

KPMG, The Nesherlands

KPMG Consultants Lud, London, UK

Kypiokom \& P3K, Germany

Logica Defence \& Civil Government Lrd, UK

Logica Finance Lid, UK

The Management Consulting Group, UK

Marinade Lid, UK

Math RiZK, University of Louvain, Belgium

Matra Marconi Space, France

MHP B.V. Associates, The Netherlands

Ministry of Dcfence, UK

Ministry of Finance SAMS, Sweden

The Mitre Corporation, USA

National Physical Laboratory, UK

Nationale Raad voor de Volksgezondheid, The Netherlands

Northcrn Tclccom, UK

O.C.T

Ott Technology Sofrwarc Sprl, Belgium

PBS, Denmark

Philips MBLE Belgium

Philips/TRT, France

Protcrarms, France

PTT Rescarch, The Nctherlands

Royal Holloway \& Bedlord New College, London

RWTUV, Germany

SAP AG, Gcrmamy

Saritcl s.p.a. Sarin Tclcmatica. Itaty

Sccurity Engincering. Switzcrland

Sccurity \& Standards Consultancy Ltd.UK

SEMA Group Consulting Lid, UK

SEPT (France Télćcom-La Poste), Francc

Sicmens AG, Germany

Sicmens Nixdorf, Germany

Stockholm University, Swcden

Swcdish Committee on Computer Related Crime, Sweden

Swedish National Police Board, Sweden

TcleTrust Deutschland c.V

Thomson-CSF/RGS, France

Triple P. Management B.V., The Netherlands

TSC, Spain

UCL, UK

University College Dublin, Ircland

University Computcr Laboratury

Universitär Hildeshcim. Gcrmany

Univcrsity of Patras, Greecc

Univcrsitat Karlsruhc, Germany

UTI Maco Bclgium

XP Conscil, France

Zergo Consultants Lid. UK
HJ Kugler

W List

H Roos

Dr B Collins

C Ruland, I Fernandez

I Wilde

$G$ Smith

$\mathrm{R}$ Horrocks

$\mathrm{J}$ King

J.J Quisquater

B Hur

Ir A A van Kranenburg

$D$ Hughes

P Svenonius

$\checkmark$ Edelheit (USA)

F Wiliams

L Ottes

$J$ E Etringer

M Casteller Mart

K-W Ott

P Terp / P Fjelbye

Dr M de Soere

F Perit

A Brignone

$M$ van Zoelen

Prof. F Piper

Dr R Baumgart

KTschira

M Saponaro

Dr R A Rucppe!

J Ross

R P J Winsborrow

E Delacour

Y Léauté

D Kuse

Prof Dr S Muftic

P Furberg

J F Wester

H Reimer

I Lebidois

I Raak

LTudanca

P Kirstein

A Patel

Anderson / Kelman / Lomas

A Prizmann

Prof A A Sissouras

Dr M Waidner

M Mergeay

P-L Rcfalo

Dr J Leach 
ANNEX B, SUMMARY OF INTEREST

\section{B.1 Main Areas of Interest}

\begin{tabular}{|c|c|c|c|c|c|c|c|}
\hline$\vdots$ & $\begin{array}{c}\text { Number of } \\
\text { papers }\end{array}$ & Requirements & $\begin{array}{l}\text { Political \& } \\
\text { Legal Issues }\end{array}$ & $\begin{array}{l}\text { System } \\
\text { Concept }\end{array}$ & Technology & $\begin{array}{l}\text { Operation de } \\
\text { Management }\end{array}$ & Others \\
\hline Austria & 1 & & & - & & & \\
\hline Belgium & 7 & 3 & & 4 & 4 & 3 & 3 \\
\hline Denmark & 1 & 1 & & 1 & 2 & 1 & \\
\hline France & 15 & 5 & 1 & 10 & 9 & 3 & 1 \\
\hline Germany & 21 & 8 & 5 & 16 & 13 & 7 & 4 \\
\hline Greece & 1 & 1 & & 1 & 1 & & \\
\hline Ireland & 2 & & & 2 & 2 & 2 & \\
\hline Italy & 3 & 1 & 1 & 3 & 1 & 1 & \\
\hline Netherlands & 9 & 8 & 3 & 10 & 7 & 5 & 2 \\
\hline Norway & 1 & & & 1 & 1 & & \\
\hline Spain & 2 & & & & & 2 & 1 \\
\hline Sweden & 5 & 1 & 2 & 4 & 2 & 1 & 3 \\
\hline Switzerland & 3 & 2 & 1 & 2 & 2 & 1 & 1 \\
\hline UK & 25 & 14 & 6 & 15 & 18 & 14 & 8 \\
\hline USA & 5 & & & 5 & 6 & 6 & 6 \\
\hline Totals & 101 & 11 & 19 & 74 & 68 & 49 & 29 \\
\hline
\end{tabular}

B.2

Sector Responses

\begin{tabular}{|l|c|}
\hline & $\begin{array}{c}\text { No of } \\
\text { contributions }\end{array}$ \\
\hline Academic institutions & 20 \\
\hline Financial institutions & 2 \\
\hline Government Depts. & 10 \\
\hline Management Consultants & 23 \\
\hline IT Manufacturer & 25 \\
\hline System Houses & 16 \\
\hline $\begin{array}{l}\text { Telecommunications Operators } \\
\text { \& Equipment suppliers }\end{array}$ & 5 \\
\hline
\end{tabular}


The following contributions are a selection of those received from the individuals and organisations listed in Annex A.

Bakkenist, The Netherlands

British Telecommunications plc, UK

CAP debis GEI, Germany

EDS Scicon, UK

Fraunhofer-LAO, Germany

Geneva Management Group, Switzerland

IBM European Networking Center, Germany

KPMG Consultants Ltd, London, UK

Logica Defence \& Civil Government Ltd, UK

The Kingswell Partnership,UK

Marinade Lid, UK

Nationale Raad voor de Volksgezondheid, The Netherlands

Northern Telecom. UK

Ott Technology Software Sprl, Belgium

Philips/TRT, France

Royal Holloway \& Bedford New College, London

SEMA Group Consulting Ltd, UK

Siemens Nixdorf, Germany

Swedish Committee on Computer Related Crime, Sweden

Thomson-CSF/RGS, France

UTI Maco Belgium

Zergo Consultants Ltd. UK
$P$ van der Meijs

$D$ Willetts

F-P Heider

T C R Nicholson

$\mathrm{H}$ Meitner

R I Polis

Dr H Fanderl

Dr B Collins

$J$ Wilde

W List

$\mathrm{J}$ King

L Ottes

$\mathrm{J} E$ Ettinger

K-W Ott

F Petit

Prof. F Piper

R P J Winsborrow

D Kruse

P Furberg

J Lebidois

M Mergeay

Dr J Leach 


\title{
APPENDIX D
}

NATIONAL AERONAUTICS AND SPACE ADMINISTRATION

DIGITAL SIGNATURE AND SECURITY SERVICES (DS $\left.{ }^{3}\right)$ SYSTEM

\author{
Lawrence P. Shomo \\ NASA
}

D-1 

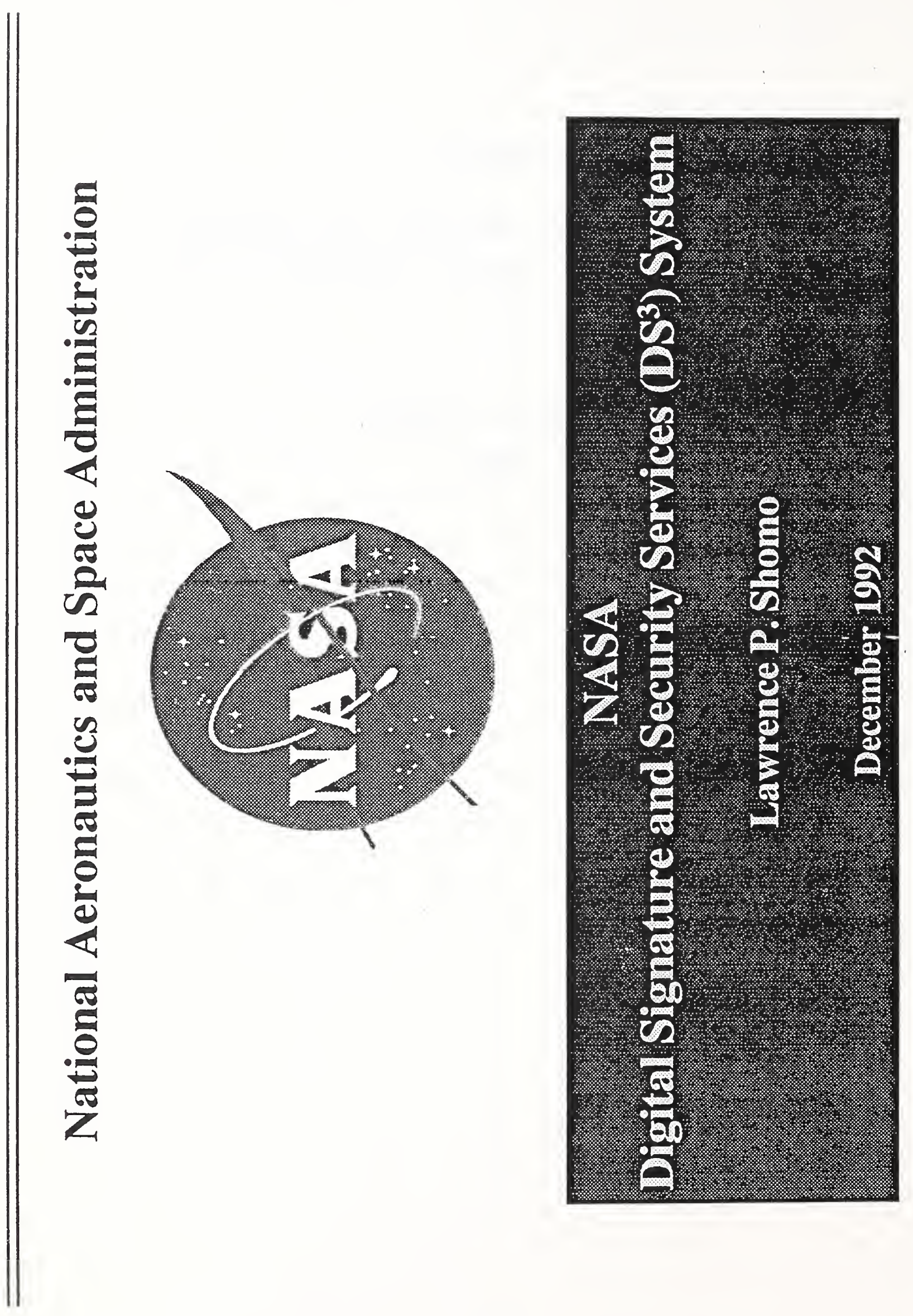

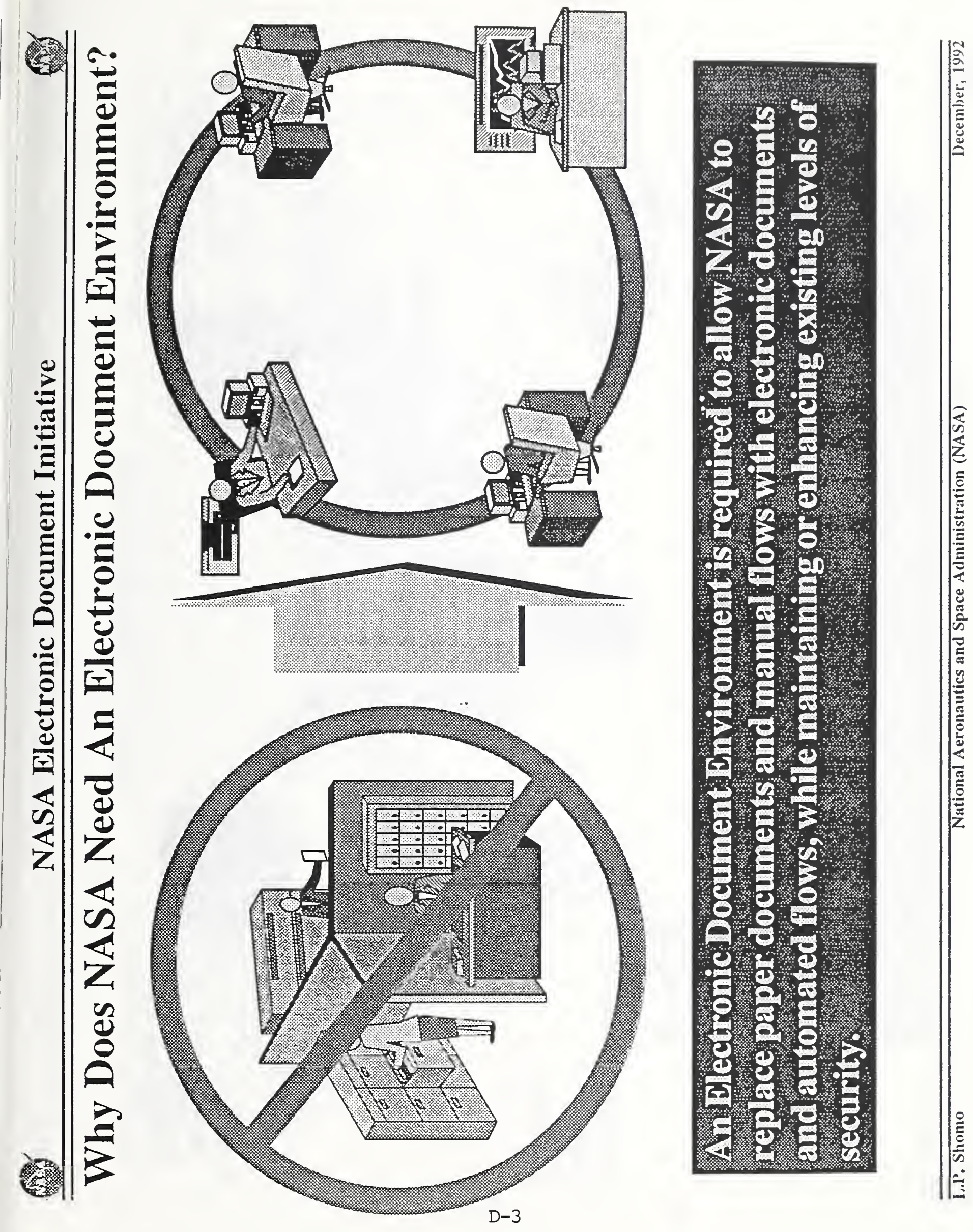


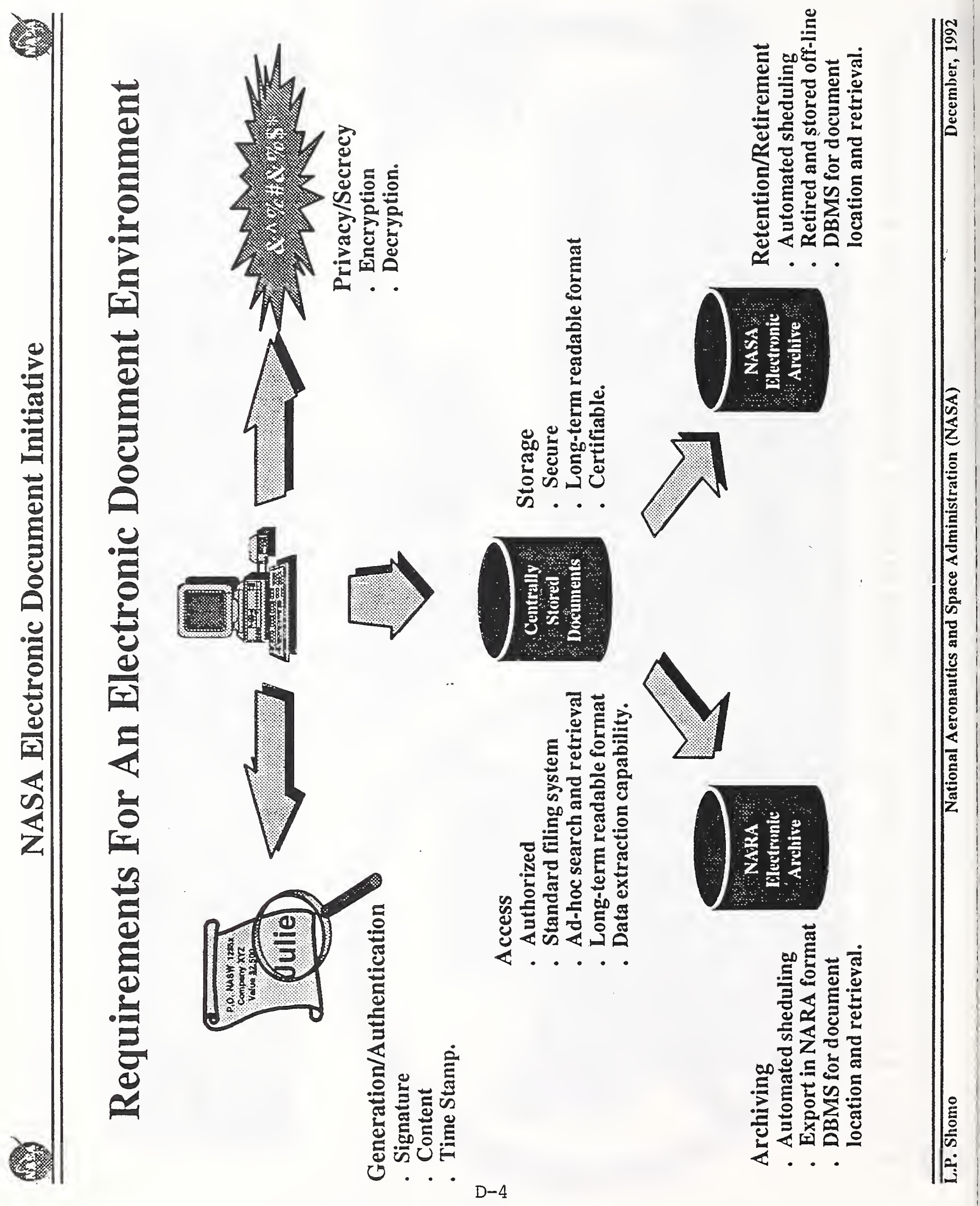




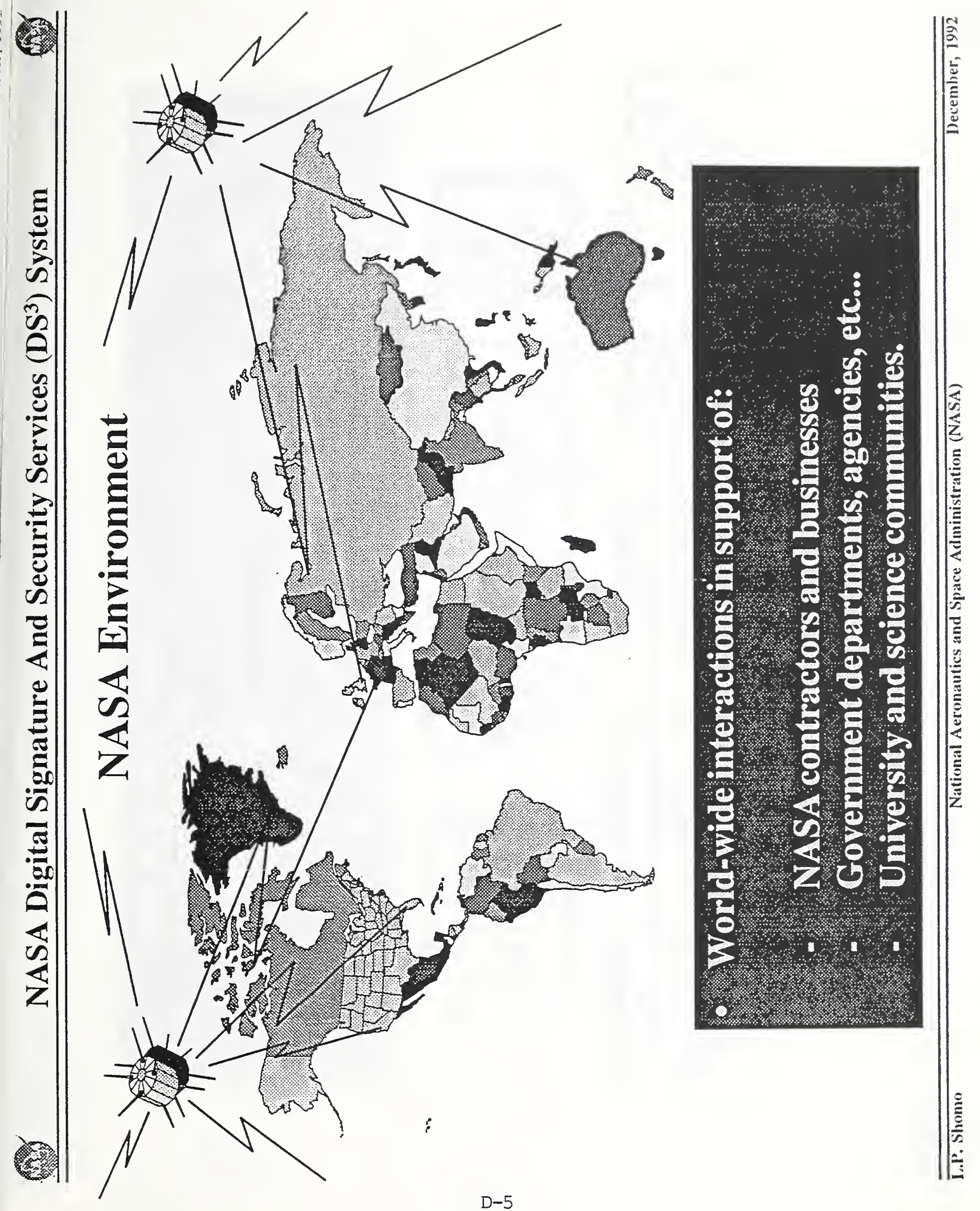



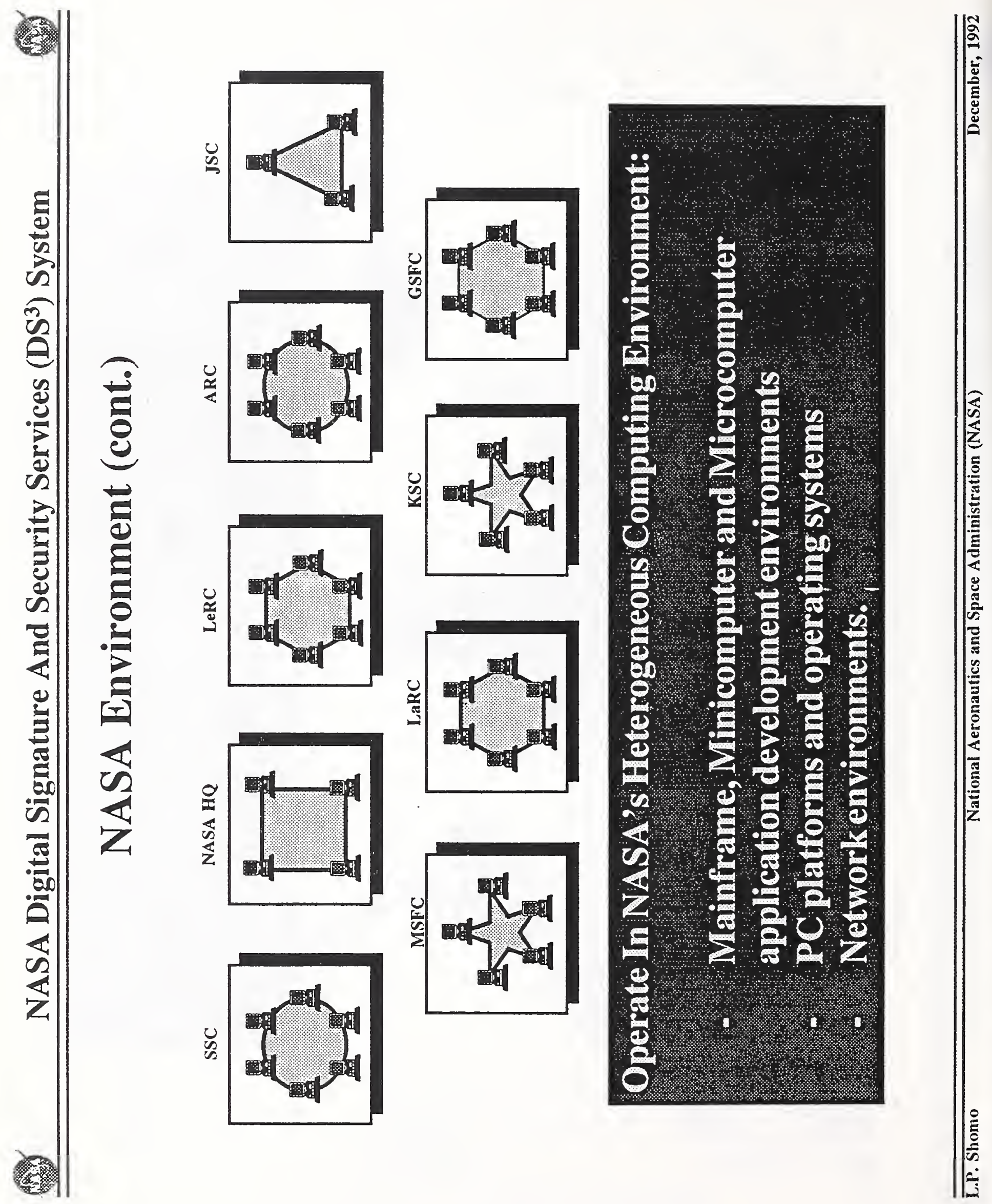

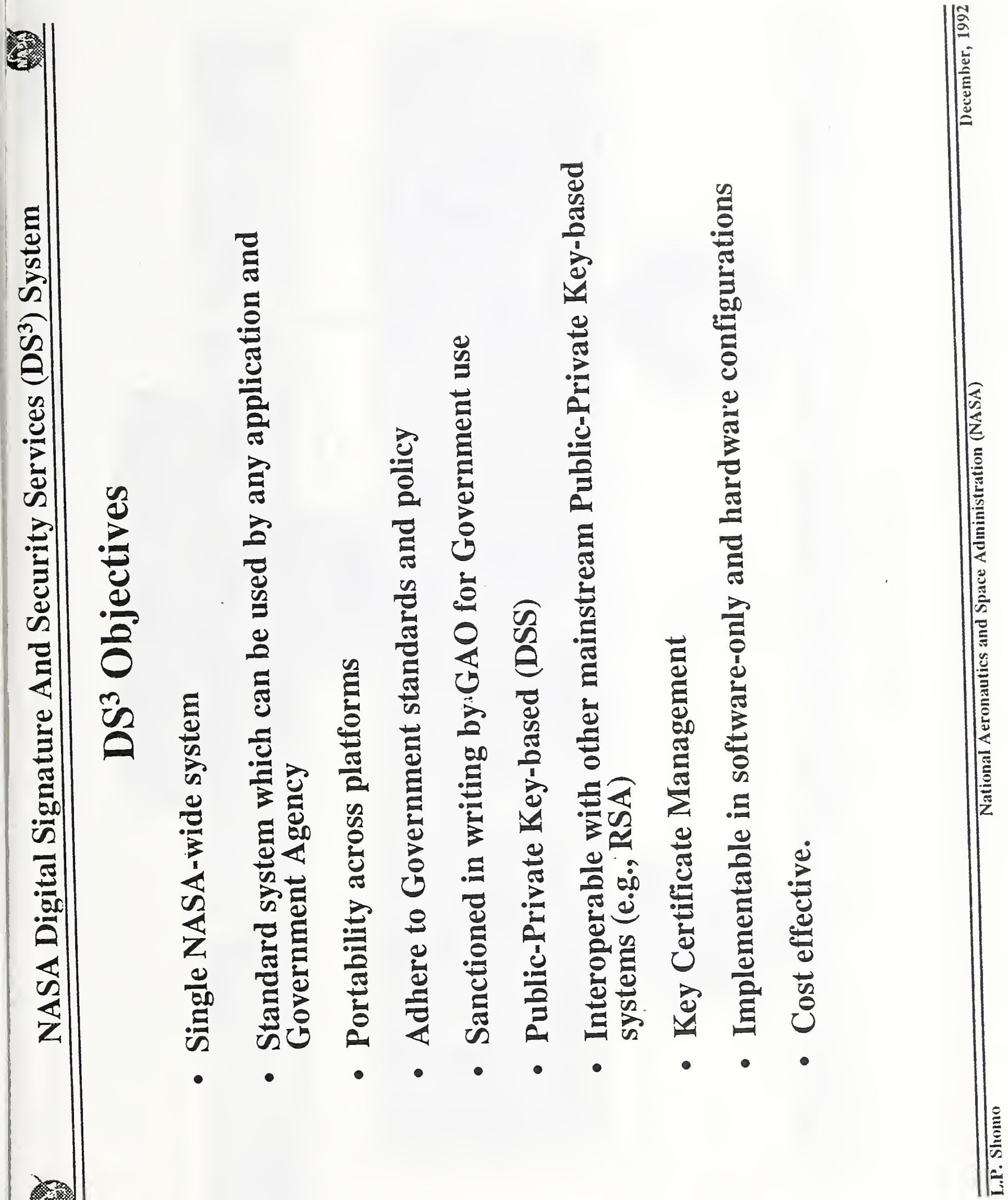


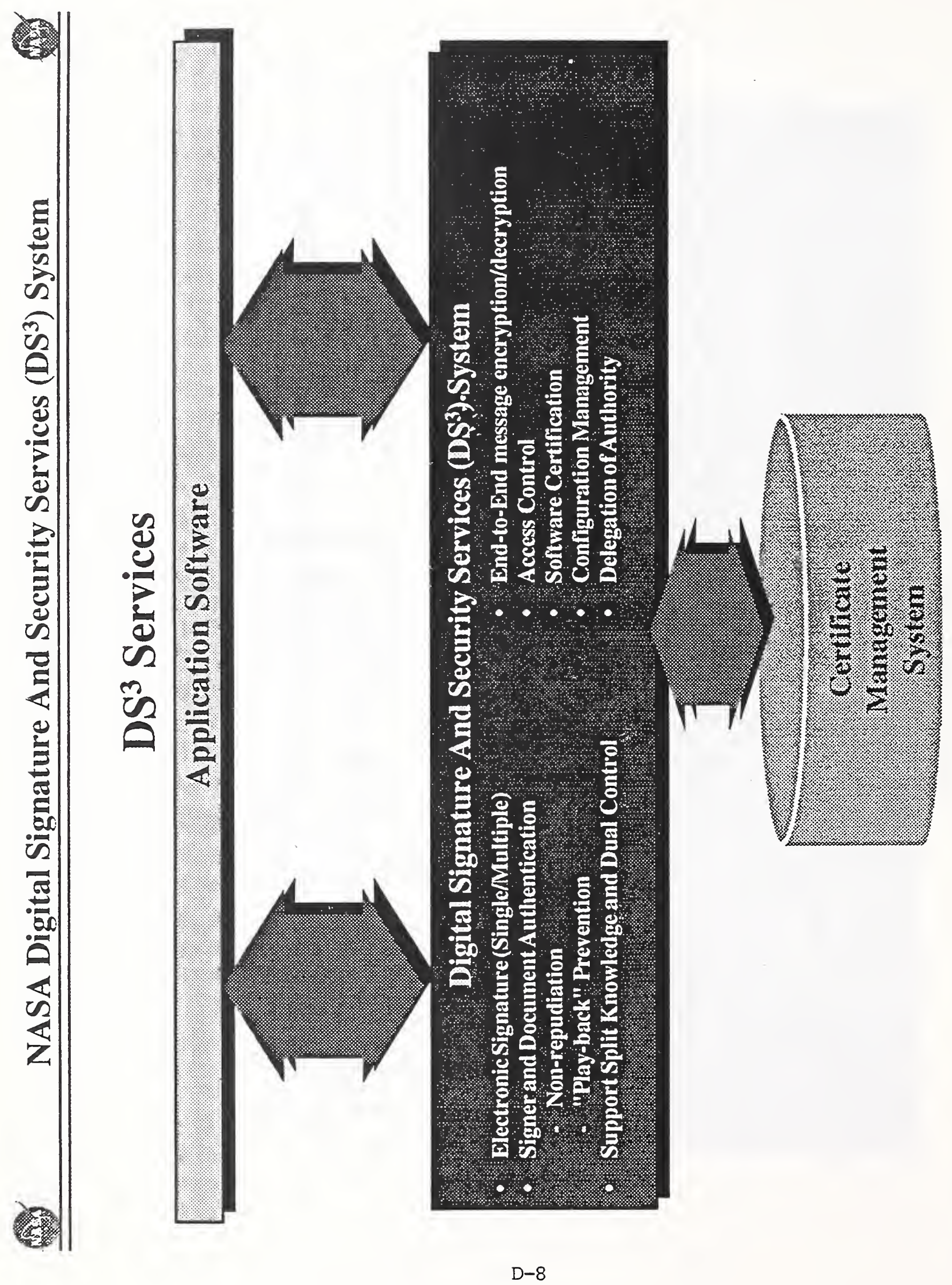

$\mid \begin{array}{ll}\alpha \\ \alpha \\ \alpha\end{array}$

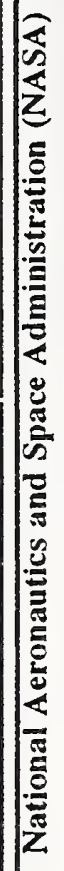

ت 

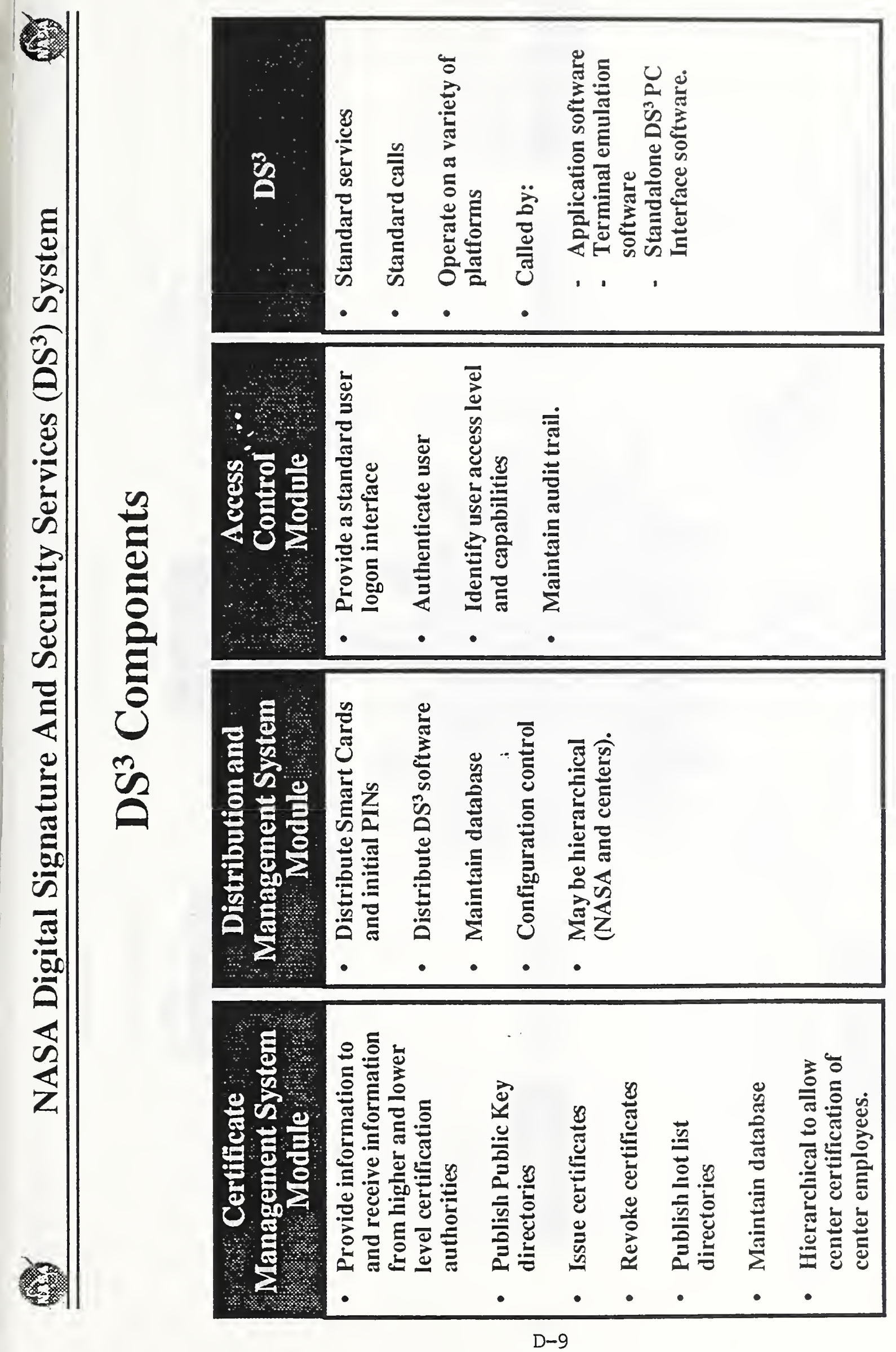


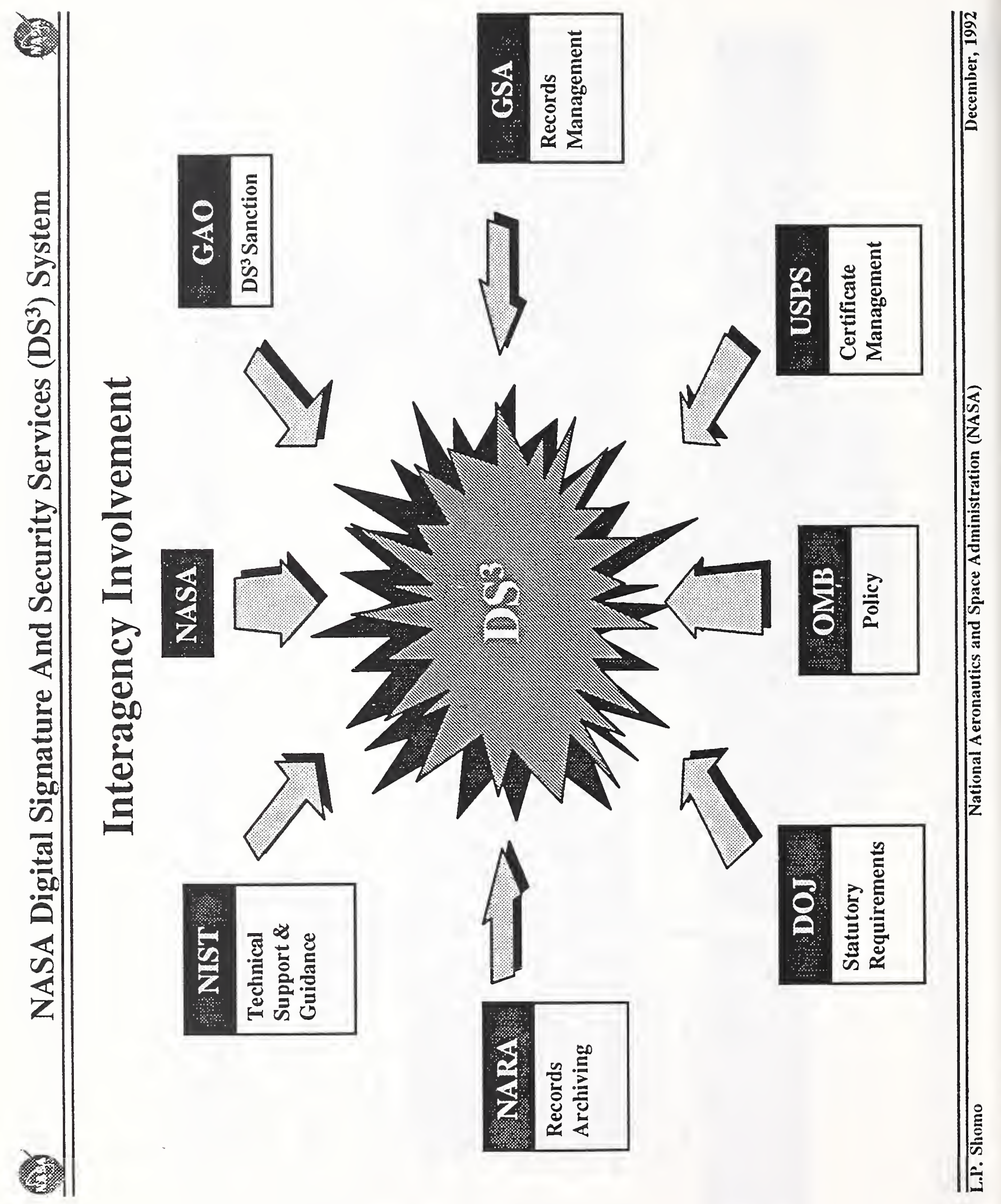




\section{APPENDIX E}

WHAT'S IN A NAM PUBLIC-KEY CERTIFICATE?

Stephen Kent

BBN Communications 


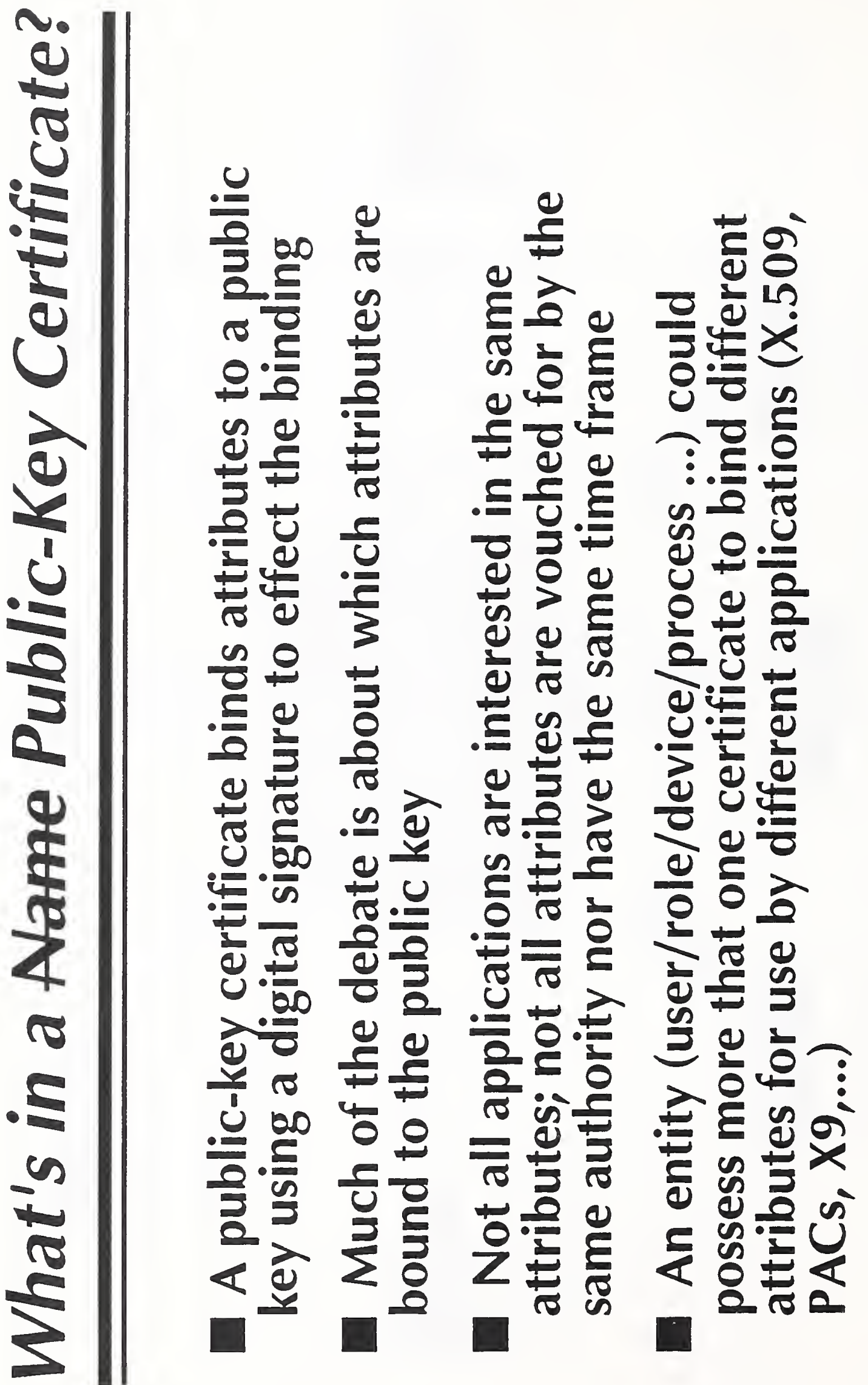




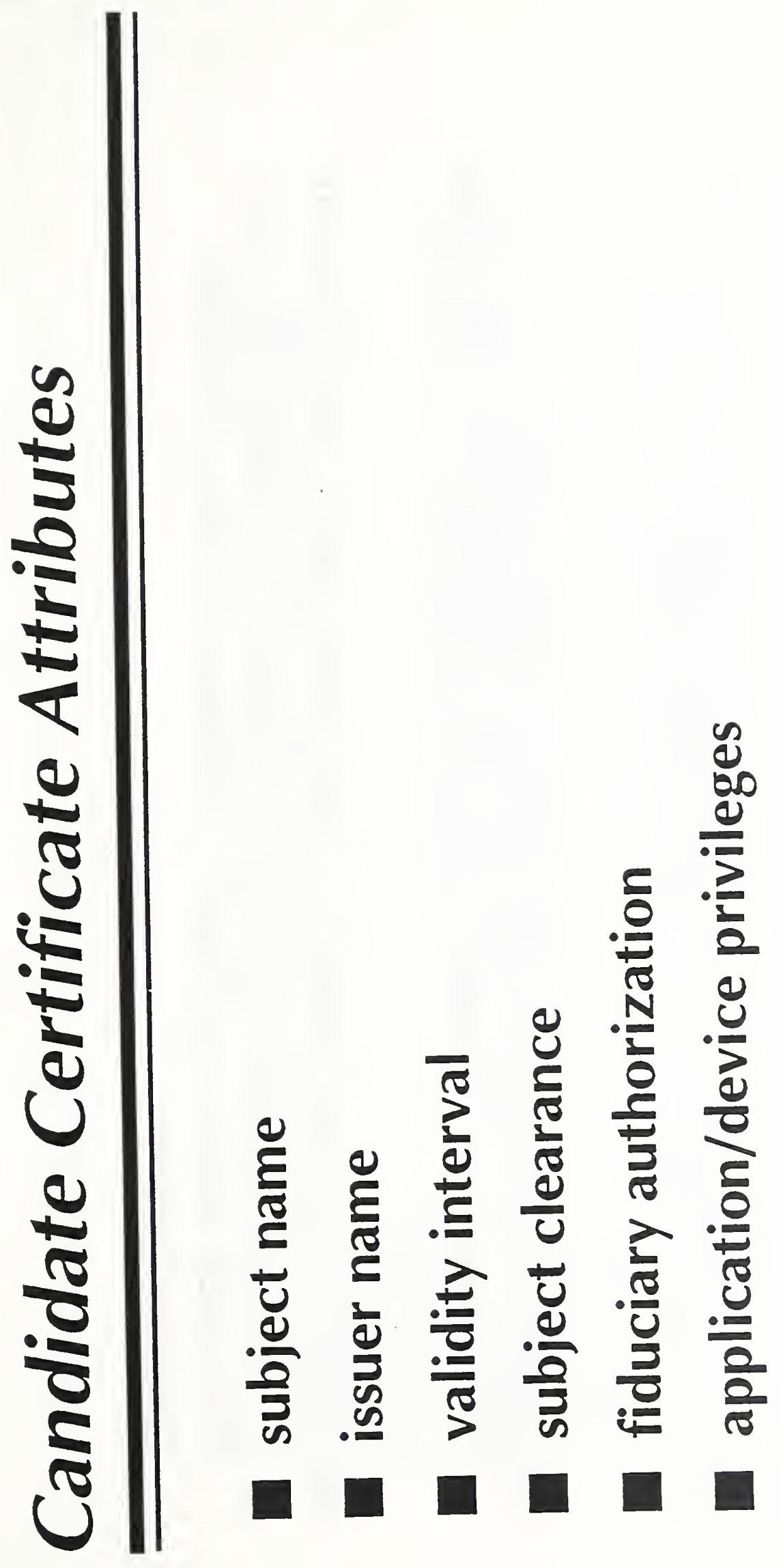




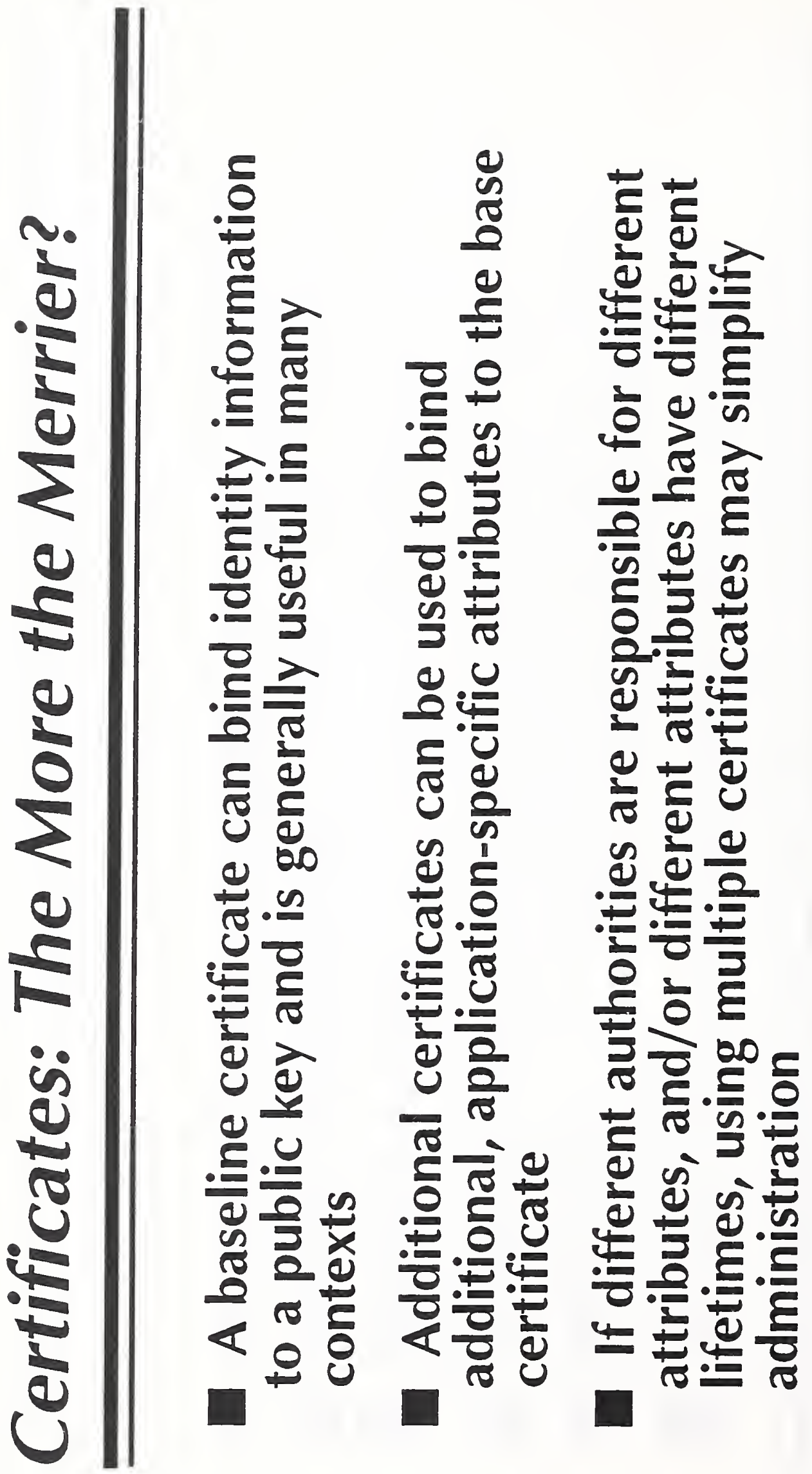




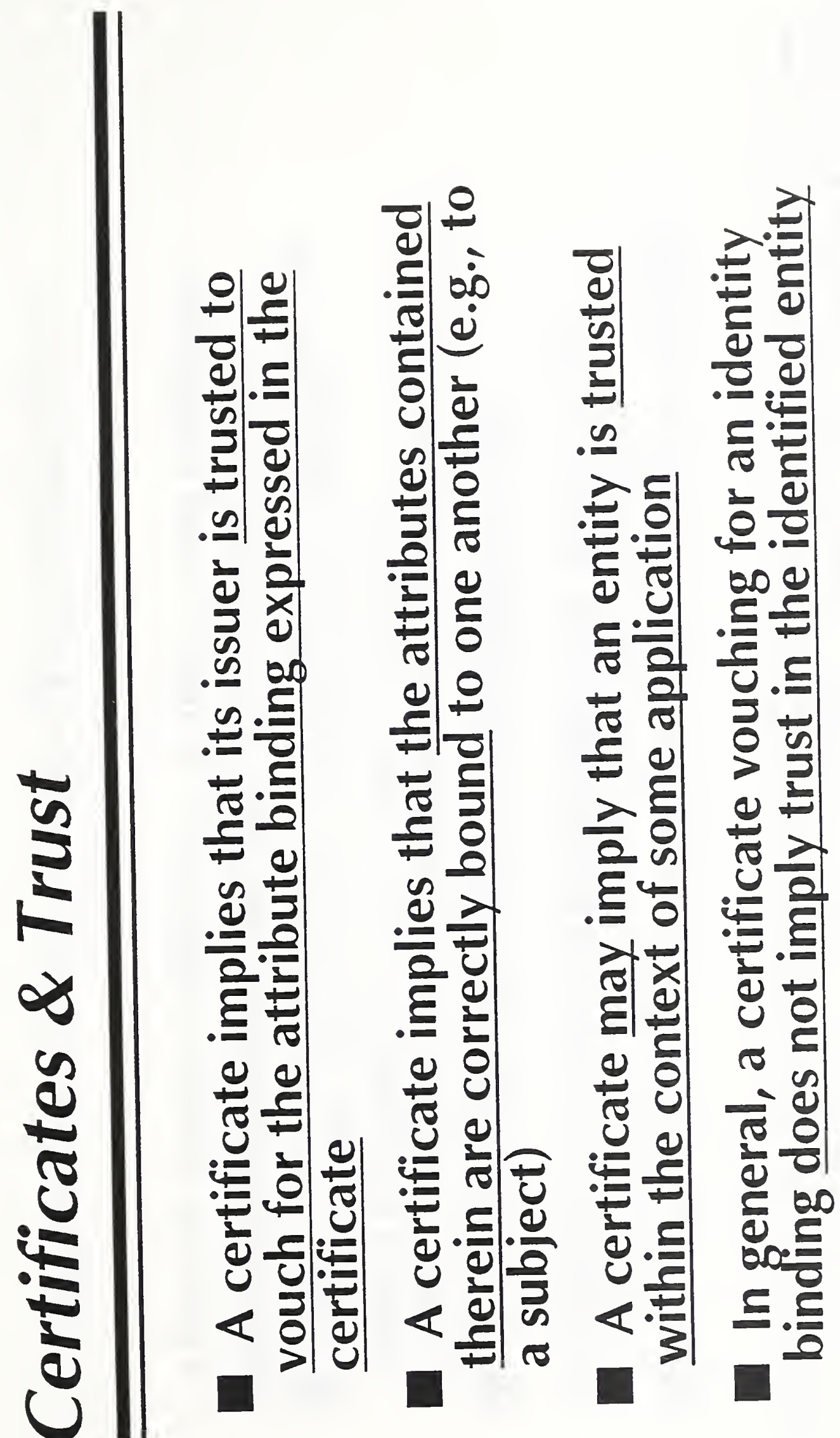




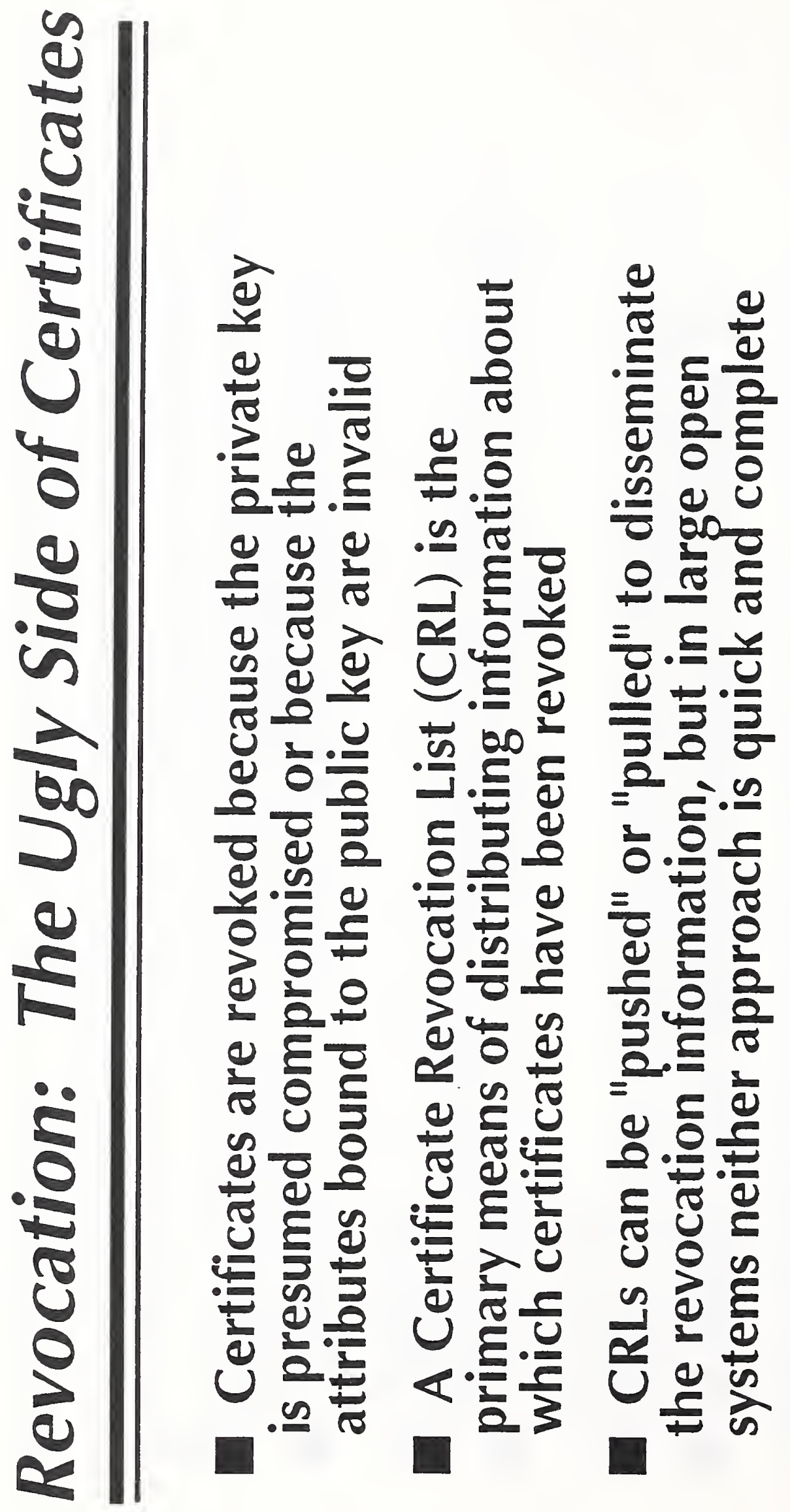




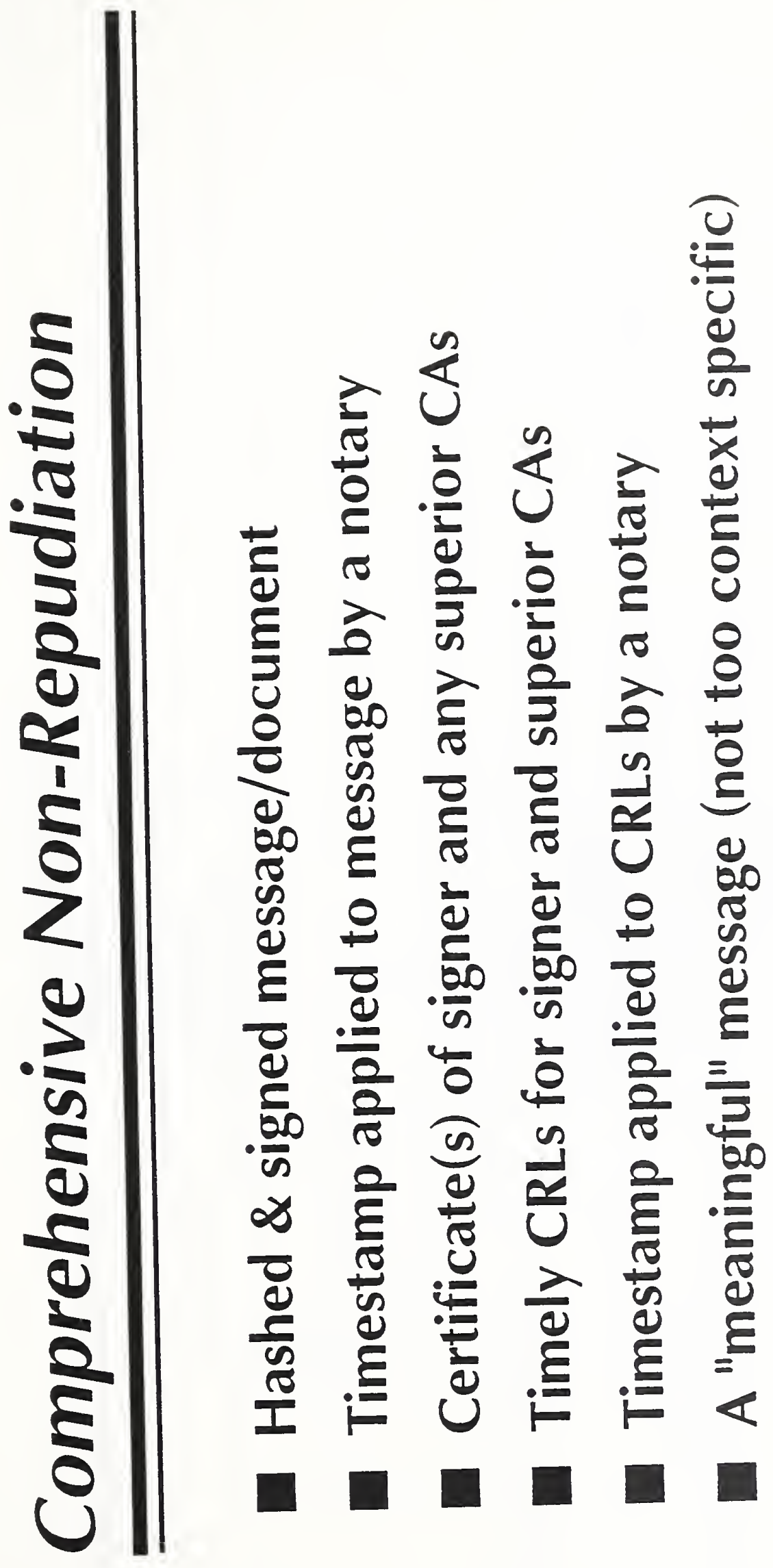




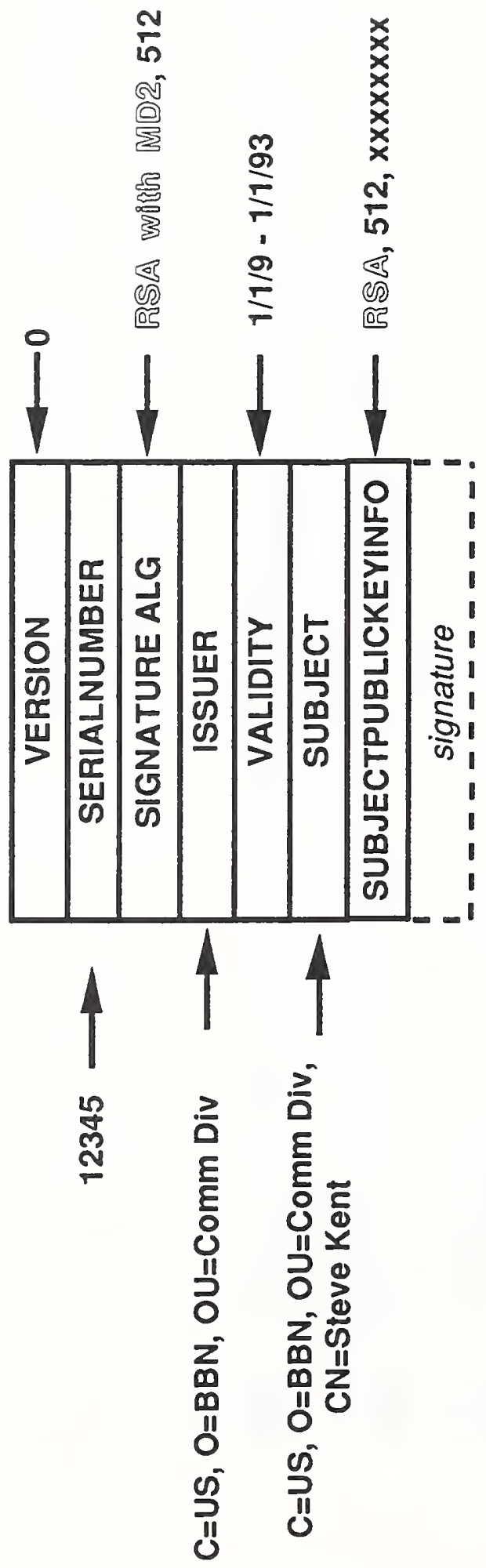

E-8 


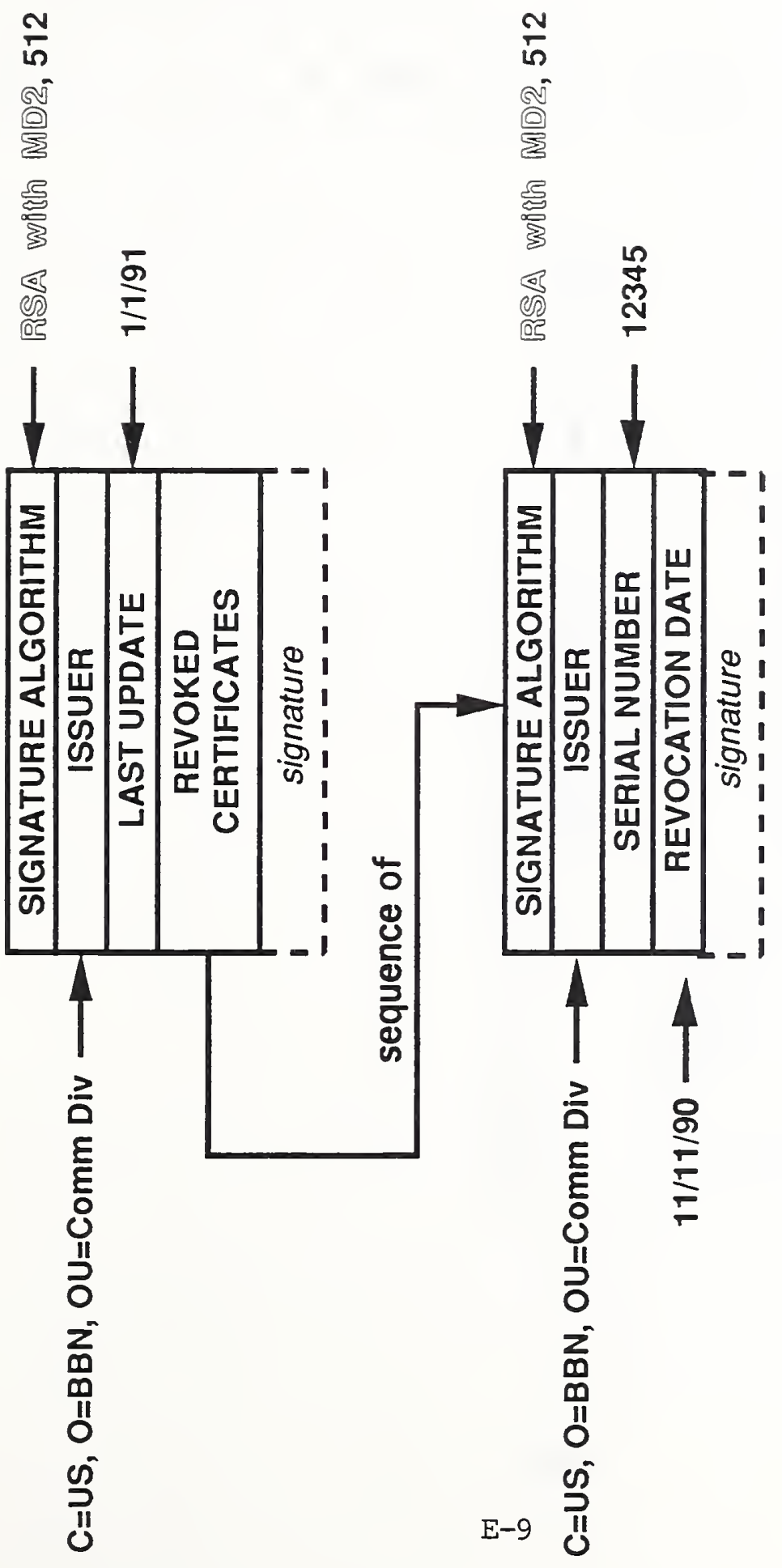




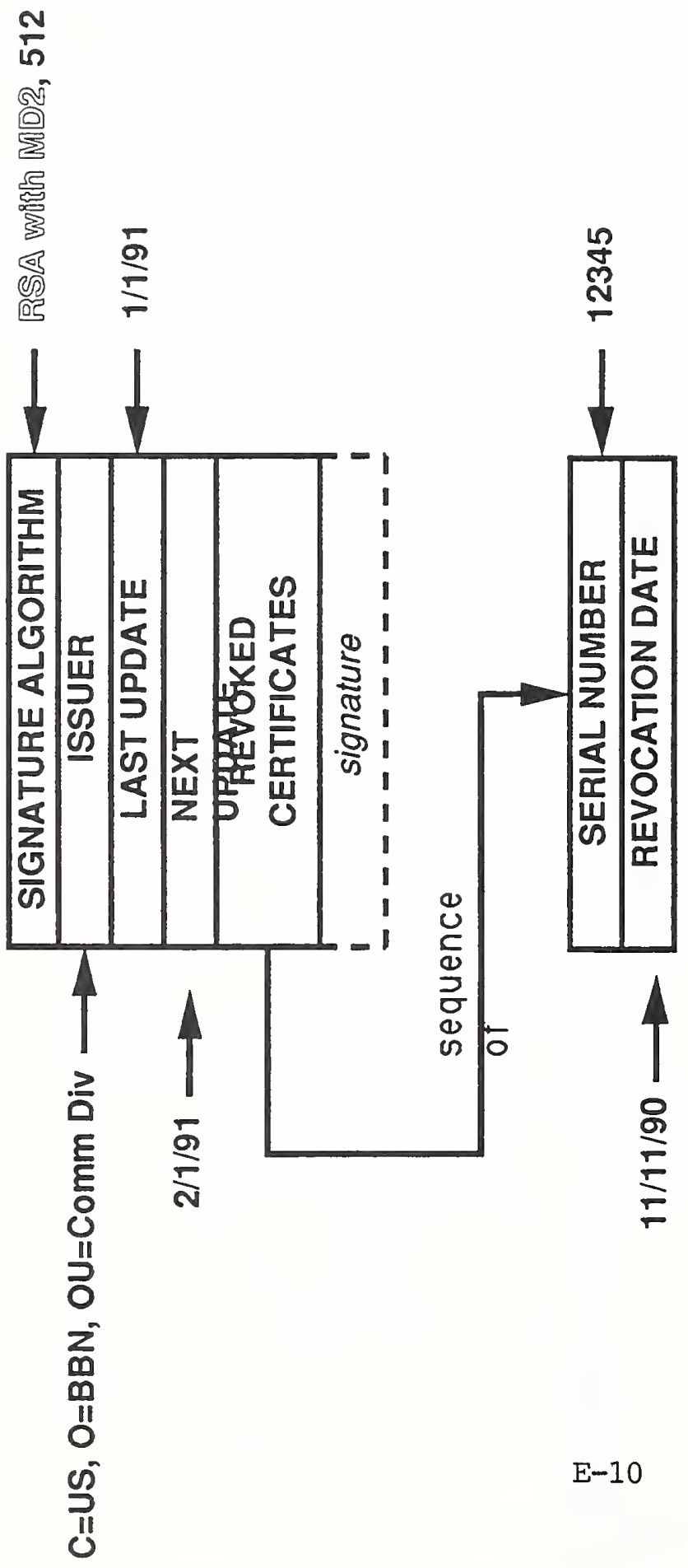


APPENDIX F

SECURITY CERTIFICATES

BSI, United Kingdom

F-1 


\title{
TITLE: Security Certificates SOURCE: BSI, UK
}

\author{
DATE: 2nd March 1992
}

IST/21 has identified a need for a single definition of the common features of a security certificate, and a method to customise this definition to specific applications. This definition would be referenced by all SC21 standards that require security certificates.

IST $/ 21$ considers that such a standard should be developed by SC27, as part of the work item on defining Security Information Objects. SC27 should attempt to extract the common features of all security cerrificaies into oue syniactic struciure, and provide a meass to cuslcraise ii io specific applications.

Several existing SC21 standards define their own form of security certificate. These definitions are summarised below, to give examples of the types of information carried in certificates. The definition to be developed need not use a ASN.1 representation compatible with these current definitions, but should be capable of providing equivalent functionality.

We note that implementations of the Directory Authentication Framework (ISO 9594-8 1988) are coming into widespread use. All future versions of the Directory specification will permit use of security certificates in the format described in the 1988 version. In the event that the security certificate format developed by SC27 does not encompass this format as a special case, then both should be registered as separate security information objects.

\section{Relation to the Security Framework}

The Security Frameworks Overview (WD, to become ISO 10181-1) describes the common features of security certificates as follows:

\subsection{Introduction}

A security certificate contains security control information. (SCI) relating to one or more security services. It is used to convey $\mathrm{SCI}$ from an authority to entities which require this information to perform a seenrity function.

In general a security certificate may contain the following SCI:

- access control information

- authentication information

- integrity control information

- confidentiality control information

- non-repudiation information

- audit information

- key management information 
as described in the the other frameworks, plus protection information as described in clause [1.3]. All the SCI carried within a security certificate is protected to provide integrity and data origin authentication. The SCI may also be confidentiality protected.

\subsection{Chaining of Security Certificates}

Where an entity may not have the SCI needed to verify a security certificate, then it may use a security certificate from another authority to provide this SCI. This process can be repeated to provide a chain of security certificates. These carry SCI which provides a secure path from a known authority (ie, one for which SCI bas already been established) to the entity requiring certified SCI.

\subsection{Security Certificate Protection Information}

The general form of a security certificate is in three fields containing:

1. SCI which is confidentiality and integrity protected

2. SCI which is integrity protected

3. information which provides the security itself

where security protection includes:

Data origin + integrity protection (eg. digital signature)

Replay protection (eg. unique token id., timestamp)

Audit information (eg. timestamp)

\subsection{Protection Features of a Security Certificate}

The information which protects the security certificate itself will include items that support integrity and data origin authentication (such as a checkvalue or digital signature).

It may also include:

1. items required for confidentiality

2. attribute that describe the characteristics of the entities that can submit the security certificate.

3. attributes that describe the characteristics of the entities which can receive the security certificate.

4. a validity time period or an expiration time derived from the creation time which prevents the indefinite re-use of the security certificate.

5. the security policy under which the security certificate must be used.

6. cryptographic parameters to protect the security certificate from unauthorised use.

$i$. the identity of the authority and the identity of the agent that issued the security certificate (so as to establisb the security certificate's origin).

8. information used for replay detection (eg. creation time) 


\subsection{Detection and Recovery Features of Security Certificates}

This section describes the security features that can be used upon detection of a security relevant event involving a security certificate as well as the features that can be used when security recovery takes place.

The detection features of a security certificate may include:

- a security certificate reference number which is unique to this security certificate witb respect to all security certificates of the same authority and agent.

- an identity field which allows audit of the entity to which the security certificate was originally issued.

Recovery features of the security certificate include:

- A reference which can be used to revoke a specifir security certificate.

- A reference which can be used to revoke a group of security certificates.

\section{Additional Requirements for Security Certificates}

The security certificate format used by the Directory (ISO 9594-8) is perceived to have the following deficiencies:

- In the event that Distinguished.iames are re-used over time, the certificate should also contain a unique numeric identifier to indicate which holder of the name was intended to be the certificate subject. (This will be added in ISO 9594-8 (1992)).

- In the event that different keys are used for integrity and confidentiality, the certificate should included multiple keys, and indicate which security services each key may be used for.

- It is not currently possible to distinguish user certificates from $\mathrm{CA}$ certificates. Thus, there is a risk of unauthorised users posing as certification authorities.

- When the certificate is a CA certificate, there should be a means for the issuer to indicate which part of the name-space has been delegated to the subject.

- The algorithm identifier used to identify the signature algorithm should also identify the encoding rules which were used to translate the presentation data value to be signed into a sequence of octets for input to the signature algoritim.

- When a certificate is stored, the concrete syntax used to encode the certificate should be held with it.

The revocation list format used by the Directory is perceived to have the following deficiencies:

- The SIGNED SEQUENCE OF SEQUENCE should be replaced by SEQUENCE OF SIGNED SEQUENCE. This would allow individual revoked certificates to be signed. This is particularly useful when non-repudiation of the revocation is required. (See directory defect report 9594/033).

- If there is a difference between the date at which a user requested the CA to revoke their certificate and the date at which the CA carried out the revocation, the revoked certificate should contain both dates. (See SC21 N1734, summary of voting on extensions to 95948, AFNOR comments). 
- There is no indication of when the next revocation list will be issued. Without this information, it is difficult to tell whether the revocation list is the most recent. (For example, an attacker knowing a compromised key and revoked key might try to make the key valid again by replacing the current revocation list with an old one).

- The Certificatelisi structure is liable to become very large. It would be useful to have a more compact format.

\section{Example SIO Definitions}

The following sections describe the security certificates defined in ISO 9594-8 and CD 10164-9. These are provided as informative examples only: the format to be developed by SC2 7 need not be identical. 


\section{Certificate}

\subsection{Purpose}

A Certificate information object is created by an issuing authority to bind security control information to an entity (the certificate subject).

\subsection{Security Services Used}

A data integrity service is used to prevent unauthorised modification of the certificate contents. A non-repudiation service is used so that if the authority issues certificates containing incorrect information, it is possible to demonstrate this to an adjudicator.

\subsection{Fields}

- version

- serialNumber

- issuer

- validity

- subject

- securityControlInformation

In v1988 certificates, the security control information is restricted to the subject's public key. In v1992 certificates, the SCI is subject's public key and optionally a unique identifier which is the subject's identity for the purposes of access control. Other forms of certificate. may define additional security control information.

- signature

A digital signature is used to provide data integrity and non-repudiation.

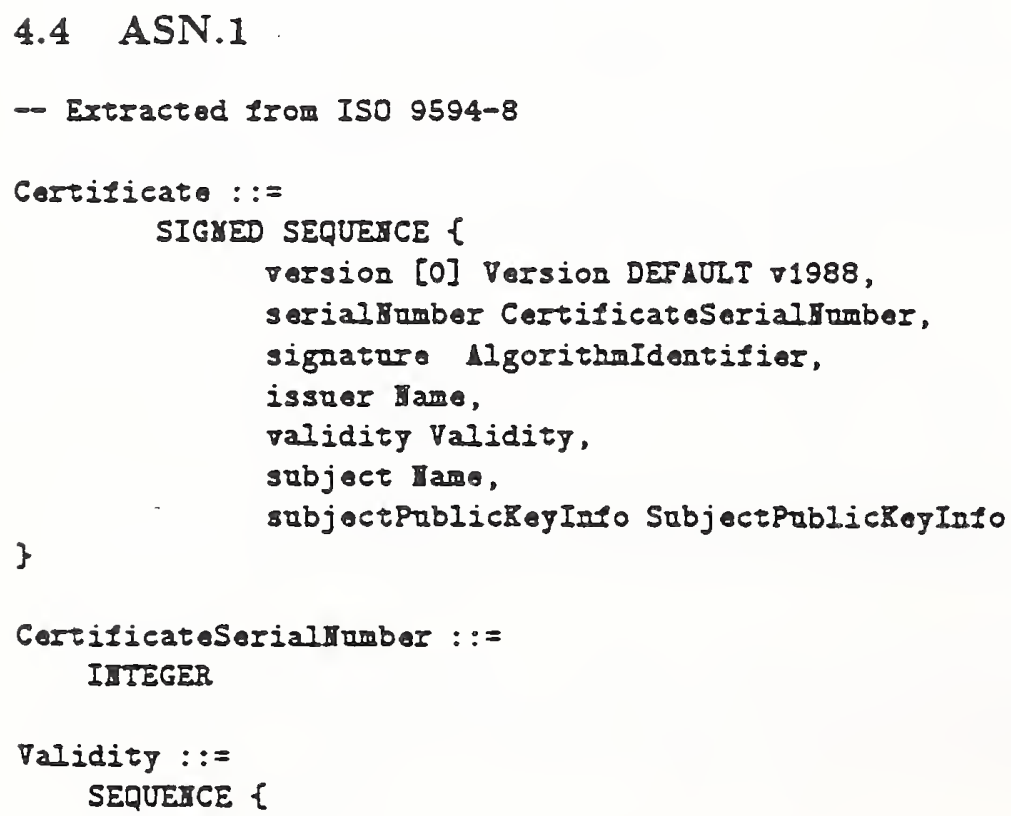




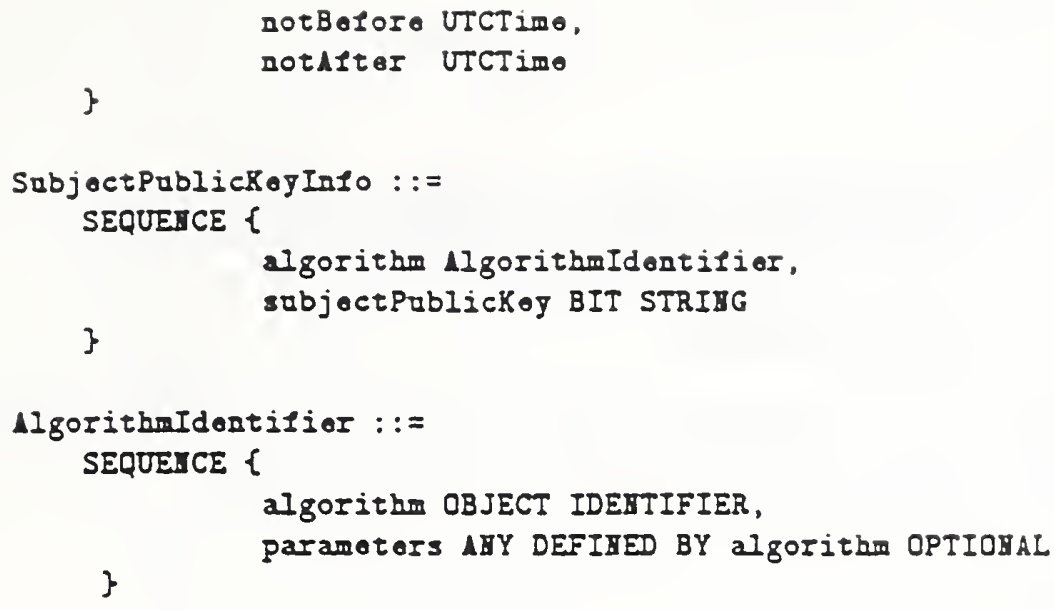




\section{Revoked Certificate}

\subsection{Purpose}

A RevokedCertificate information object is created by an issuing authority to indicate that a certificate which it had previously created should no longer be accepted.

\subsection{Security Services Used}

A RevokedCertificate is protected by a data integrity service (to prevent unauthorised entities issuing revocations) and a non-repudiation service (so that the certificate subject can complain to an arbitrator if it considers that its certificate was revoled unfairly).

\subsection{Fields}

- issuer

The name of the certificate issuer.

- certificateSerialNumber

The serial number of the certificate to be revoked.

- revocationDate

The date at which the revocation takes effect.

- signature

A digital signature is used to provide both data integrity and non-repudiation.

\subsection{ASN.1}

-- Extracted 1rom ISO 9594-8.

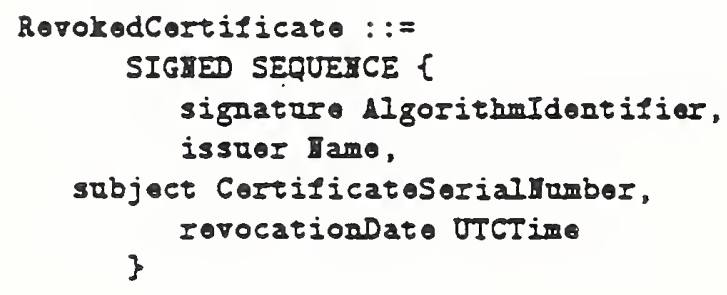




\section{RevocationList}

\subsection{Purpose}

A RevocationList is created by an authority (A) to enumerate all "active" revoked certificates issued by a set of authorities, which may or may not include A. A revoked certificate is active if it has been issued and the expiry date of the certificate it revoles has not been reached. A Revocation List provides assurance that there are no other active Revoked Certificates issued by the named authorities.

\subsection{Fields}

- issuer

The issuer of the revocation list (ie. authority A)

- lastUpdate

The time at which the list of revoked certificates was known to be complete. (ie. the time at which the revocation list was constructed).

- revokedCertificates

Details of the certificates which have been revoled.

\subsection{ASN.1}

-- Ereracted from ISO 9594-8, aith the correction in defoct report 9594/033

-- applied.

Certilicatelist : : =

SIGRED SEQUERCE \{

signatare AlgoriłhaIdentifier,

issuer Iame,

lastUpdate UTCTime

rerokedCertificates SEQUESCE OF

ReroledCertificate OPIIOYAL

\} 


\section{Access Control Certificate}

\subsection{Purpose}

An AccessControlCertificate provides assurance of the association of specific $\mathrm{ACI}$ values with an entity (in CMIP, this will be either a CMIP initiator or a managed object).

\subsection{Security Services Used}

An aecess control certificate is protected by an integrity service and a non-repudiation service.

\subsection{Fields}

- proxy

- security DomainAuthority Name

- security DomainAuthoritySignature

- security DomainName

- timeOfCreation

- validFrom

- validUntil

- validationIdentifier

- validationKey

- accessControllnformation

- cryptographicAlgorithm

- cryptographicChecksum

\subsection{ASN.1}

- Ertracted Irom CD 10164-9

AccesscontrolCertificate ::= SEQUERCE $i$ proxy [O] IKPLICIT $\triangle$ ccessControlCertificate OPIIOHAL, secariegDomaianthorityllame [1] IMPLICIT SecurityDomainathority Hame OPTIOHAI, securitgDomaiaAuthoritgSignature [2] SecaritgDomaialuthoritgSignatare OPTIOHAL, securityDomainitame [3] IXPLICIT SecuritjDomaindame OPIIOHAL, timeofCreation [4] IMPLICIT GeneralTime OPIIOHAL, validFrom [5] IYPLICIT GeneralTime OPIIOHAL, validUntil [6] IXPLICII GeneralIime OPTIOAAI, validationIdentifier [7] IKPLICIT ValidationIdentifier OPIIOBAL, validationkey [8] IMPLICIT Validationkey OPIIOMAI, accesscontrolinformation [9] SEQUERCE \{ capability [1] IRPLICIT SET OF Capability OPIIORA, identity [2] IKPLICII Initiator Iame OPIIOHA, 
label [3] IMPLICIT SET OF SecarityLabel OPTIOIAL \} erfptographiedlgorithm [10] IMPLICII CryptographicAIgorithm OPIIOHAL, \} eryptographicchecksum [11] CryptographicChecksum OPTIOAAL

Generaltime : := GeneralisedTime

Cryptographicdlgorithm : := OBJECT IDEITIFIER

CryptographicChocksum : : IHIEGER

SecurityDomaiaAuthority Iame : : DistinguishodBame

SecuritydomaindutboritySighatrre : := DCTET STRIBG

ValidationIdontifior ::= IJTEGER

Validationkey : : = IBTEGER 



\author{
APPENDIX G \\ X9.F.1 STANDARDS ACTIVITIES: \\ AN INTRODUCTION
}

Blake Greenlee

M. Blake Greenlee Associates, Ltd. 


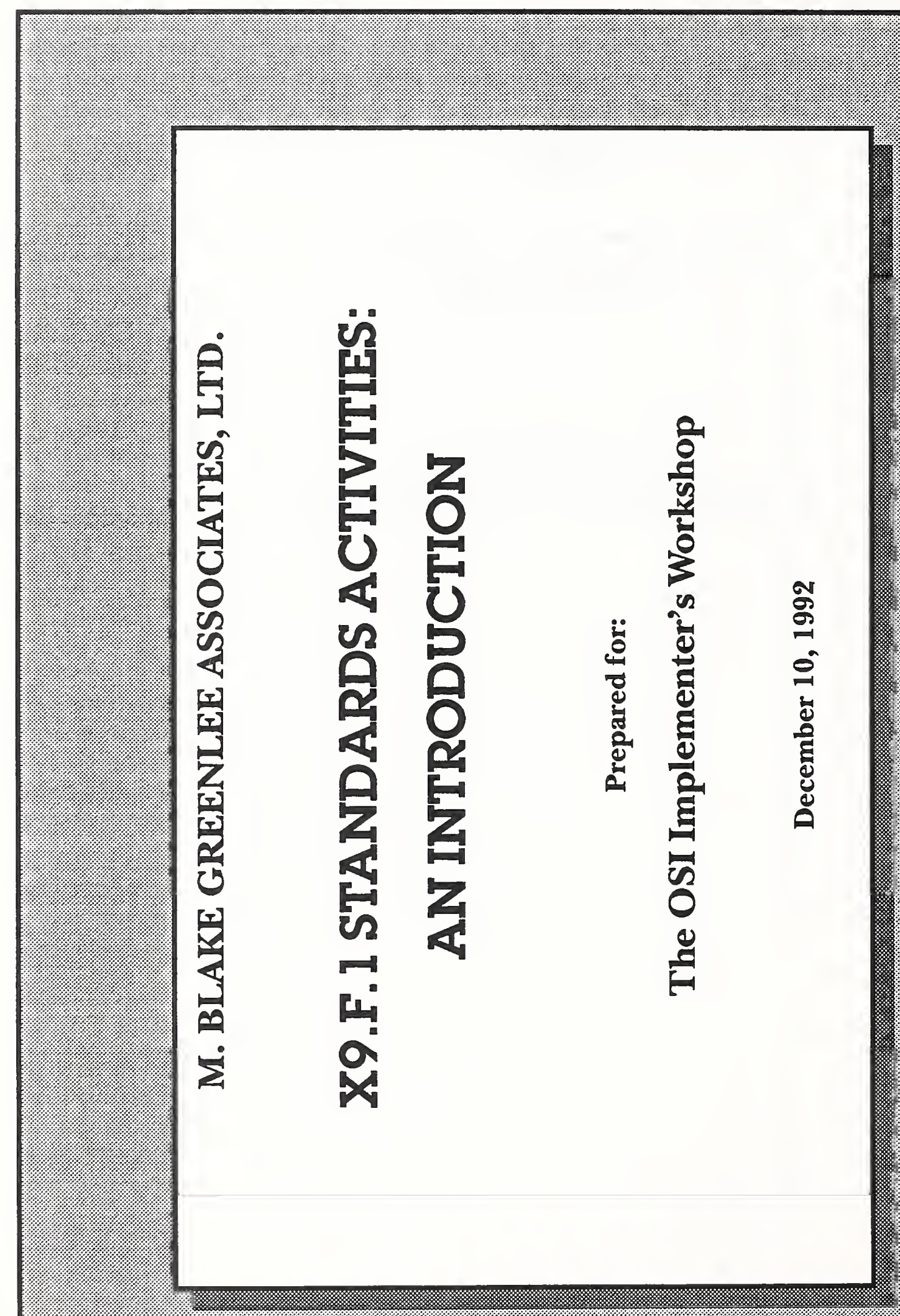

G-2 
ญู

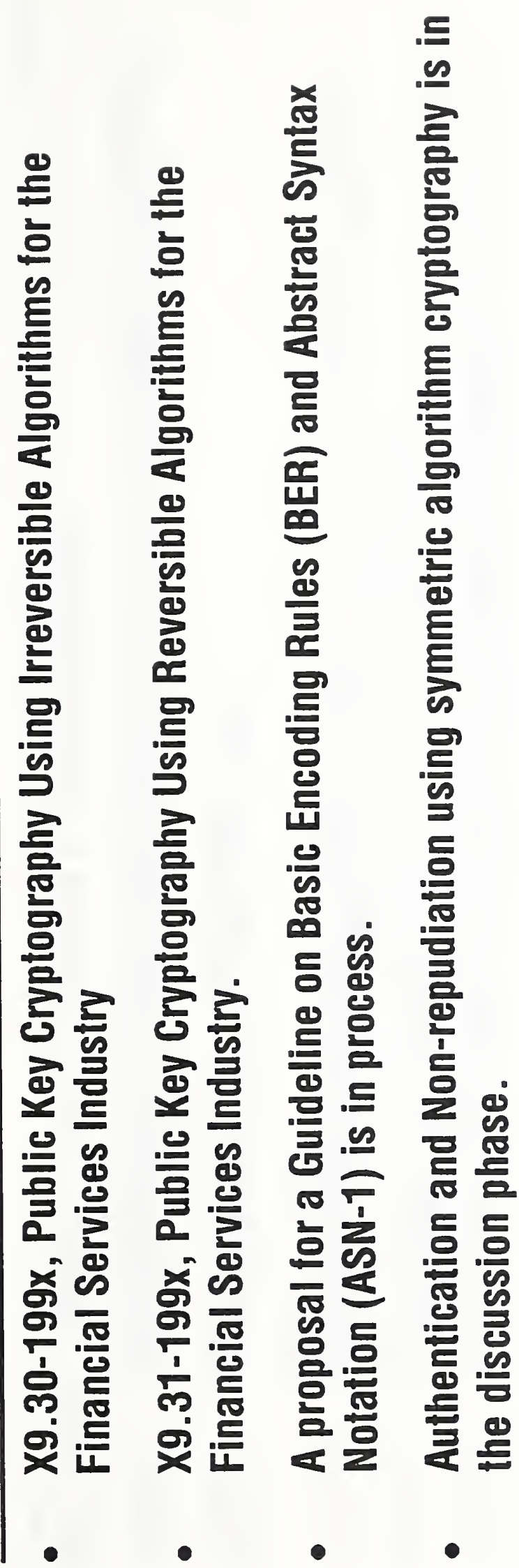

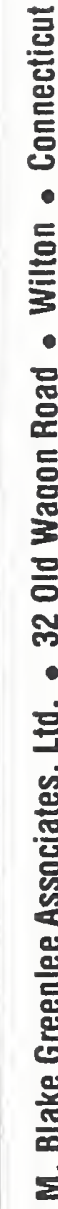




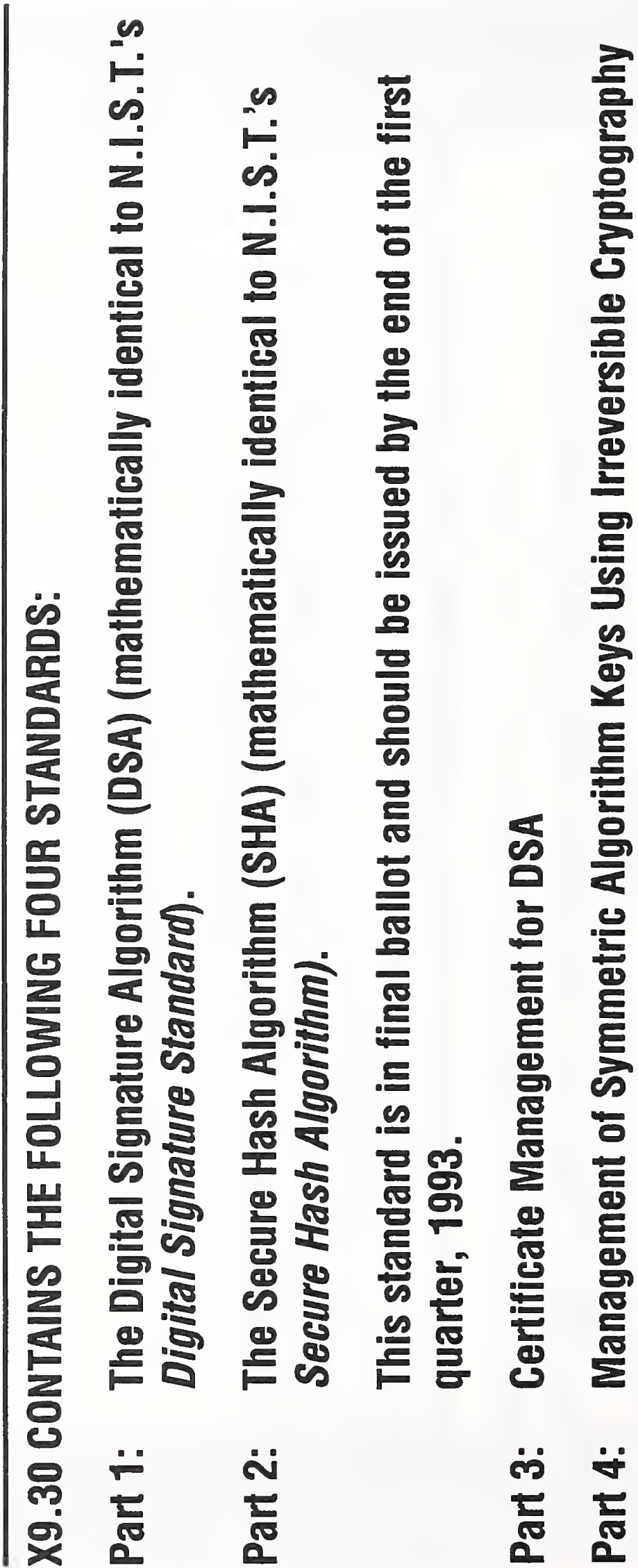


02

10

ค 1

A 1

A 1 स

요

O.

क 는

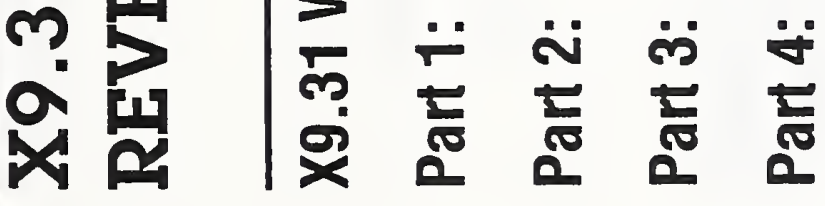


รี

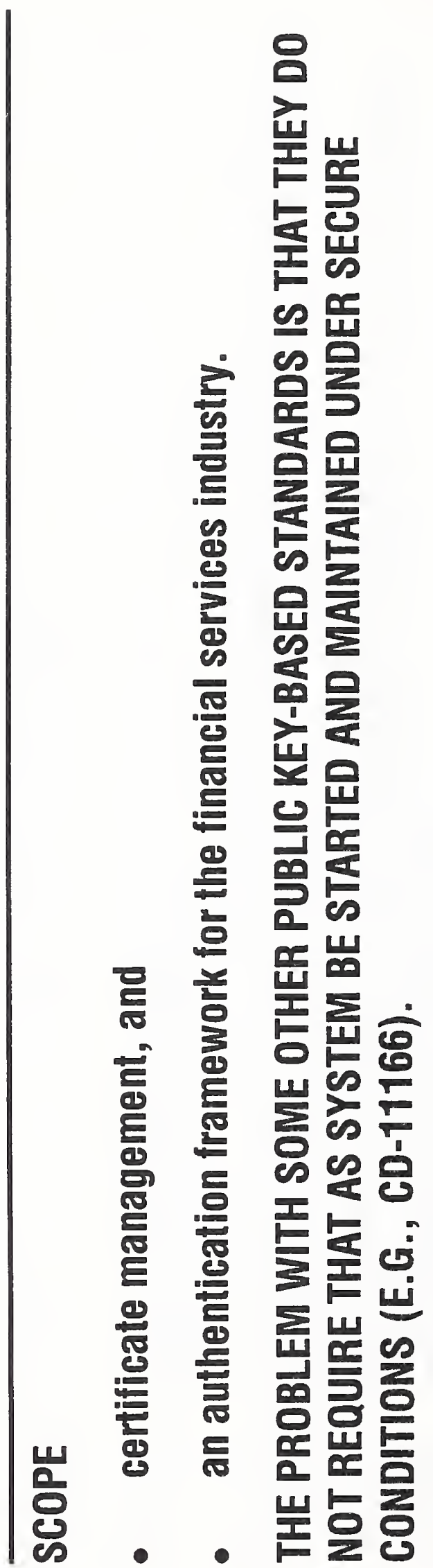

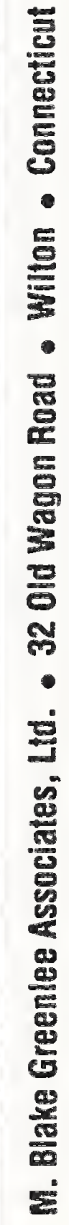

Q1

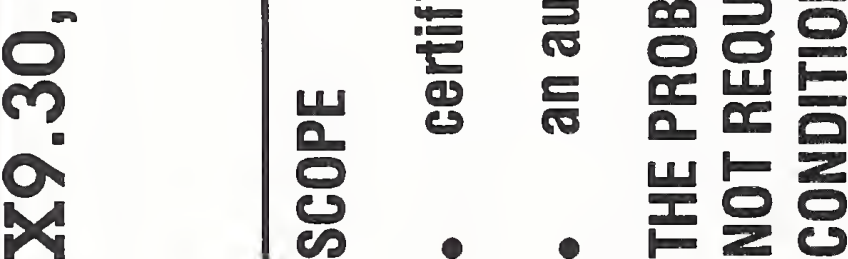




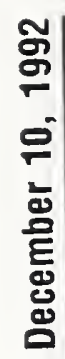

를

일

능 몽

뜰 른

을

d)

을 흔

는

'흐리 영

휴 है

를 츨 훙

을 을

그 은

$\sigma$ 믈 을

를 능

진

드를

잉을

U 1 은

응

$\geqslant$ व

뚜

틀

ค 등

1

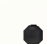

풀

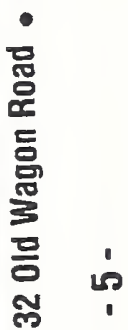

$\bullet$

i

i 


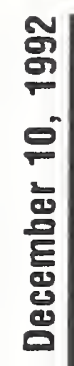

든

ณ

4

닌

0

2

0

A.

2

ह1)

$\rightarrow$

다

0

थ

도

ค

1

22

4

0

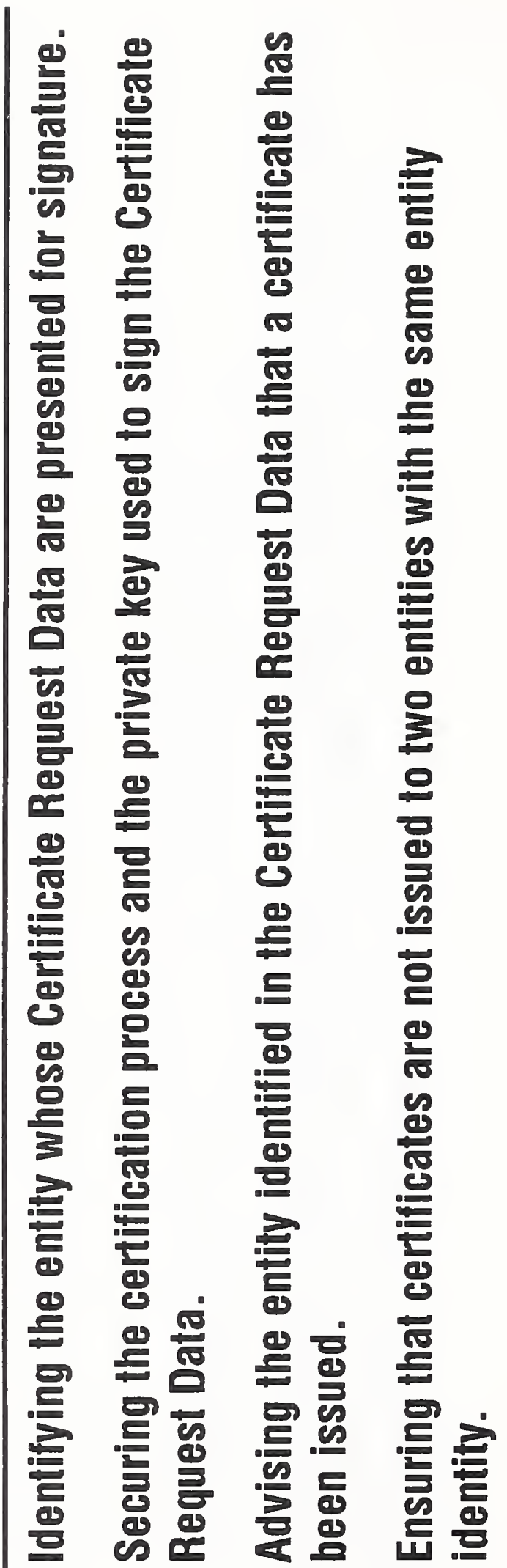

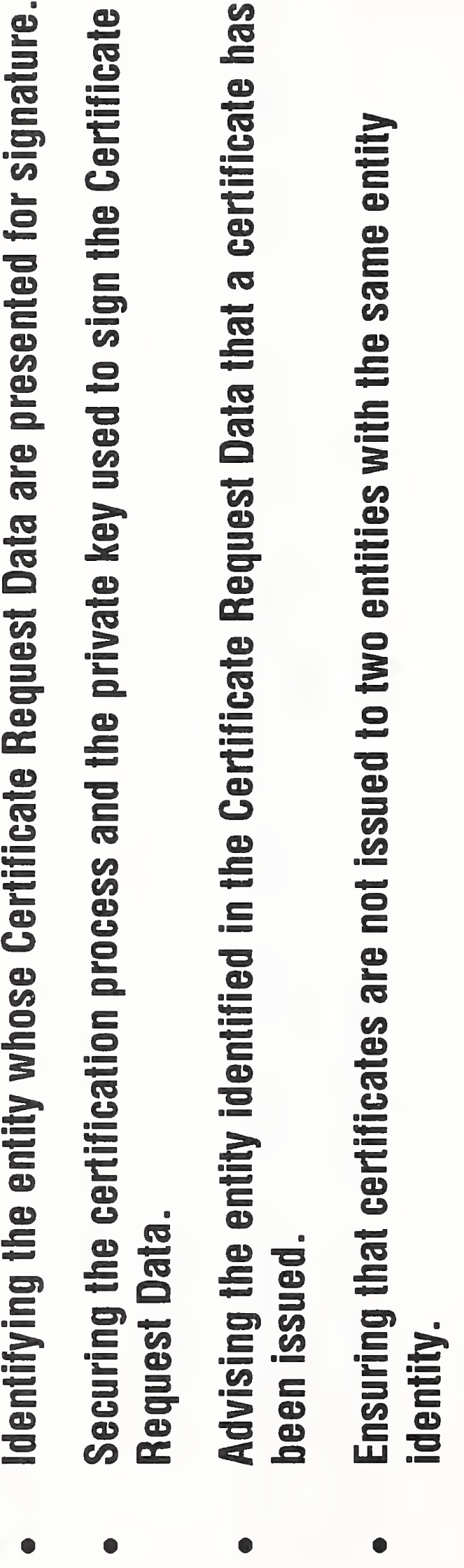

G-8

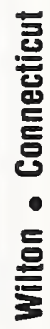

.

풍

틈

疍

등

ฆิ

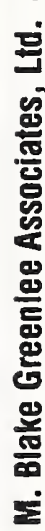


รั

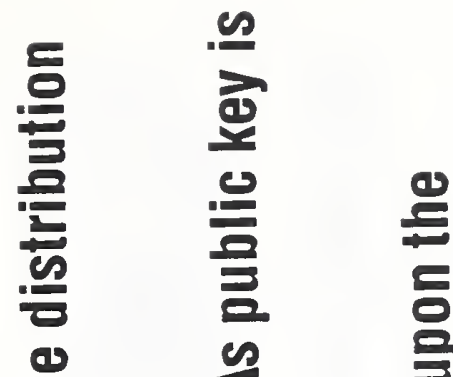

14

2

$\therefore$ 를 할

$\underline{\underline{E}}$

बे b

두

을 을

를 을

ल 를

a 0

이 0

르

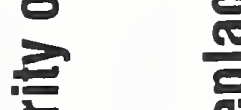

2

를

이 은

d 6 닌

른 를 홍

등

क

으

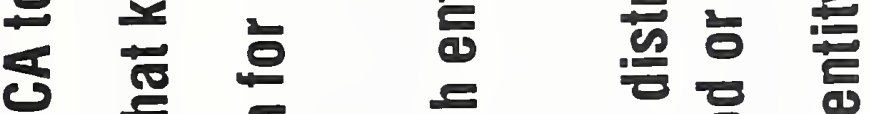

들

a

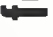

도

(1)

을 웅

힌 을을 을

(1)

0 을

룽응

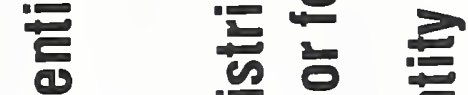

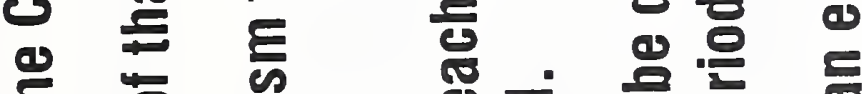

응 000

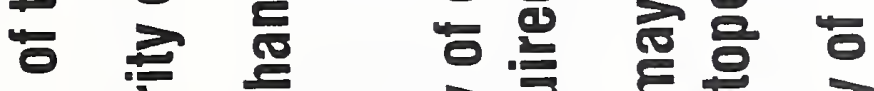

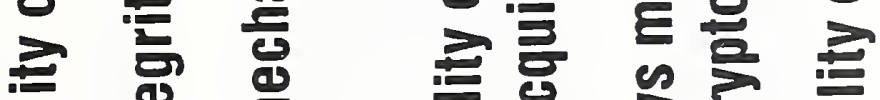

이 일

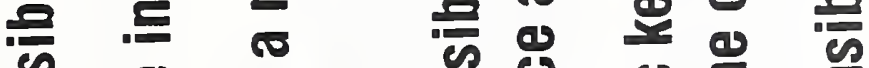

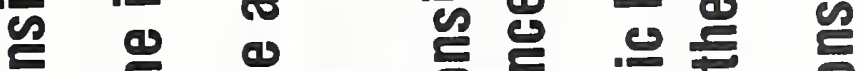

을 응

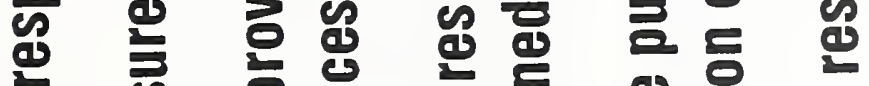

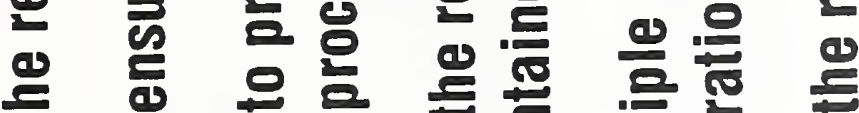

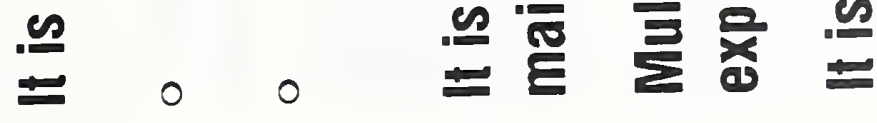




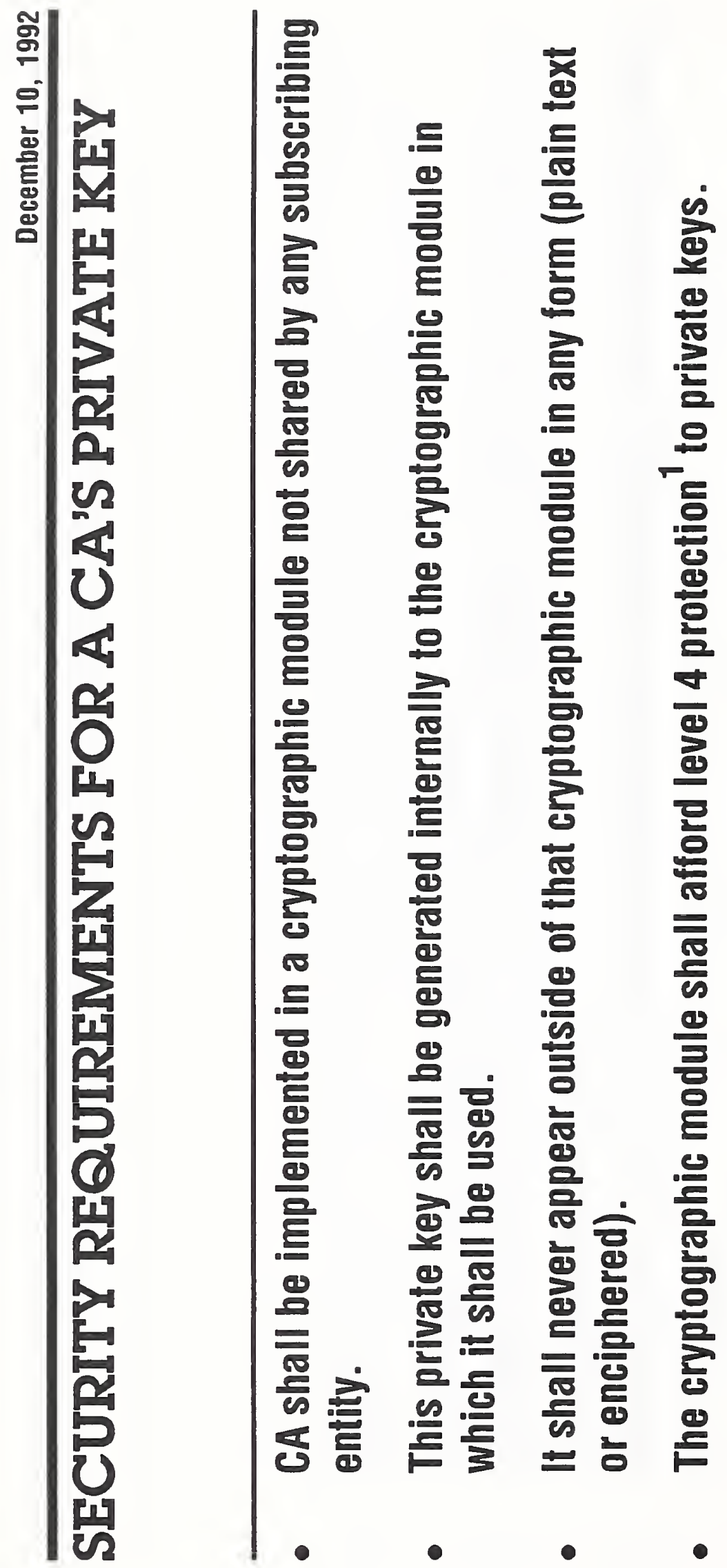

|्रा 


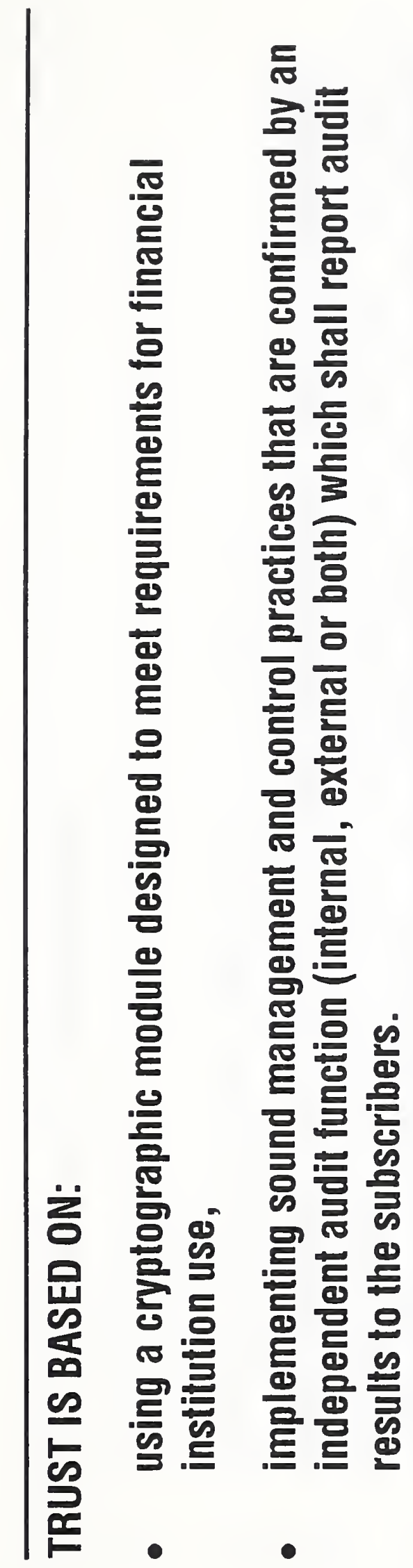




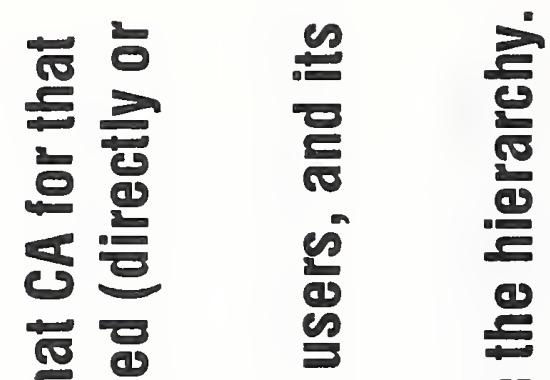

$\Rightarrow$ 을 틀

E 닌

क

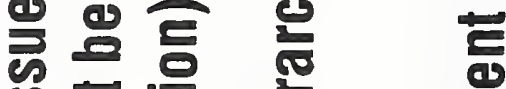

क

ल

ब 0 क

은 는

$-20$

45 E

$\therefore$ ब

(6) 50

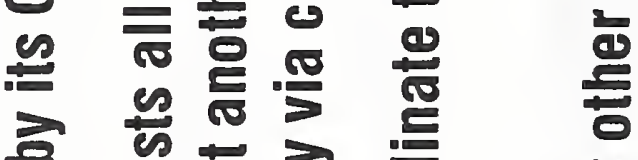

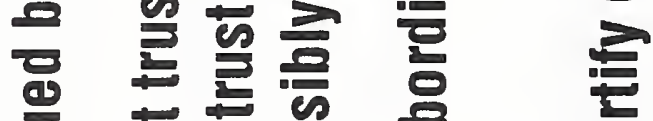

해유

¿2

잉 0

6

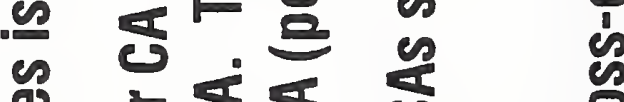

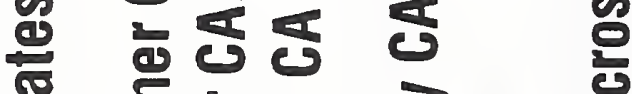

는

후요

ब ब ल ब

힐 을

울 0 을

을 2 을 흔

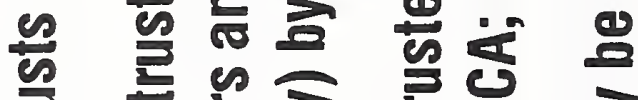

당

릴 인

닝

\%

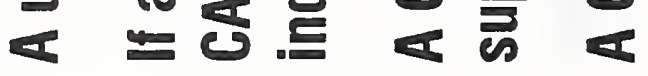

돈도

a

ตอ

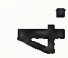




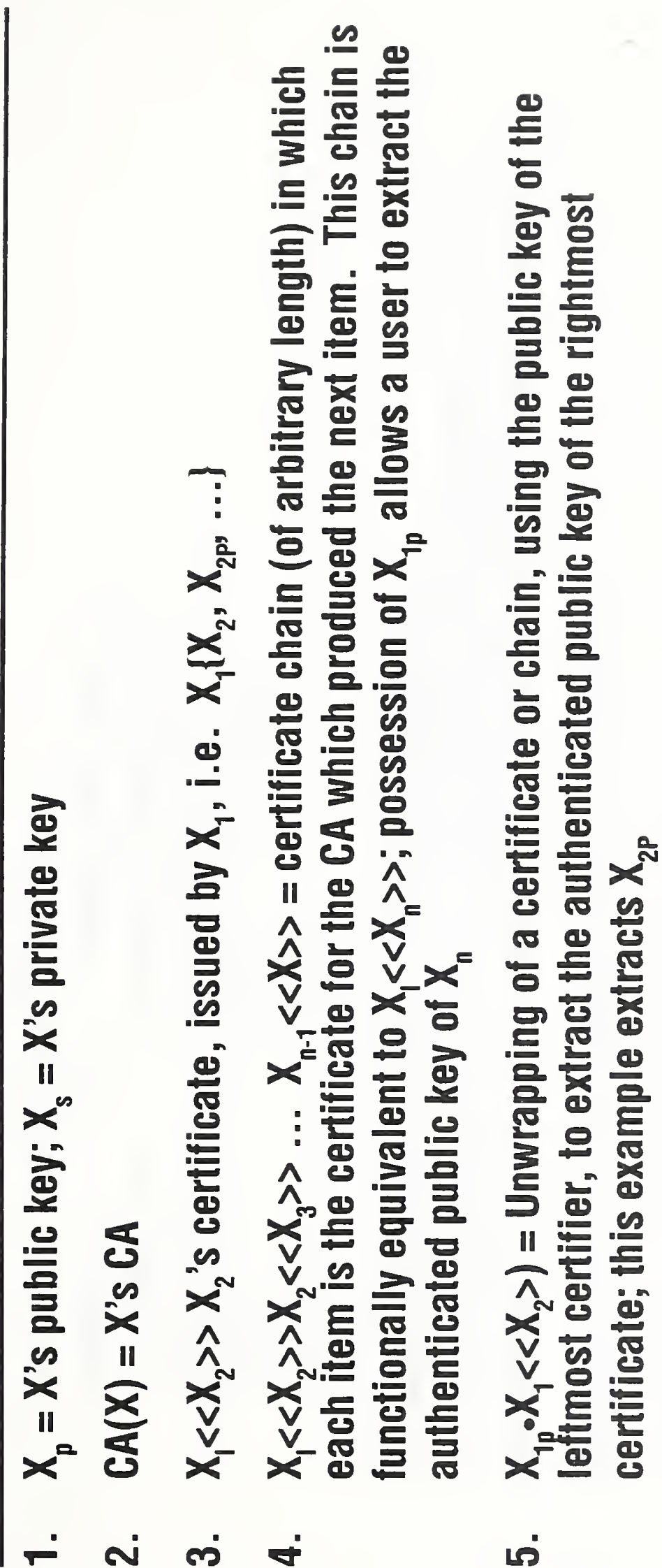

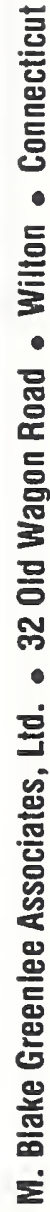

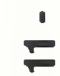

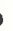

단

تص

$+1$

15

Q

2

12

5

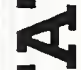

5

0

$\boldsymbol{N} \boldsymbol{N} \boldsymbol{\nabla}$

ص 

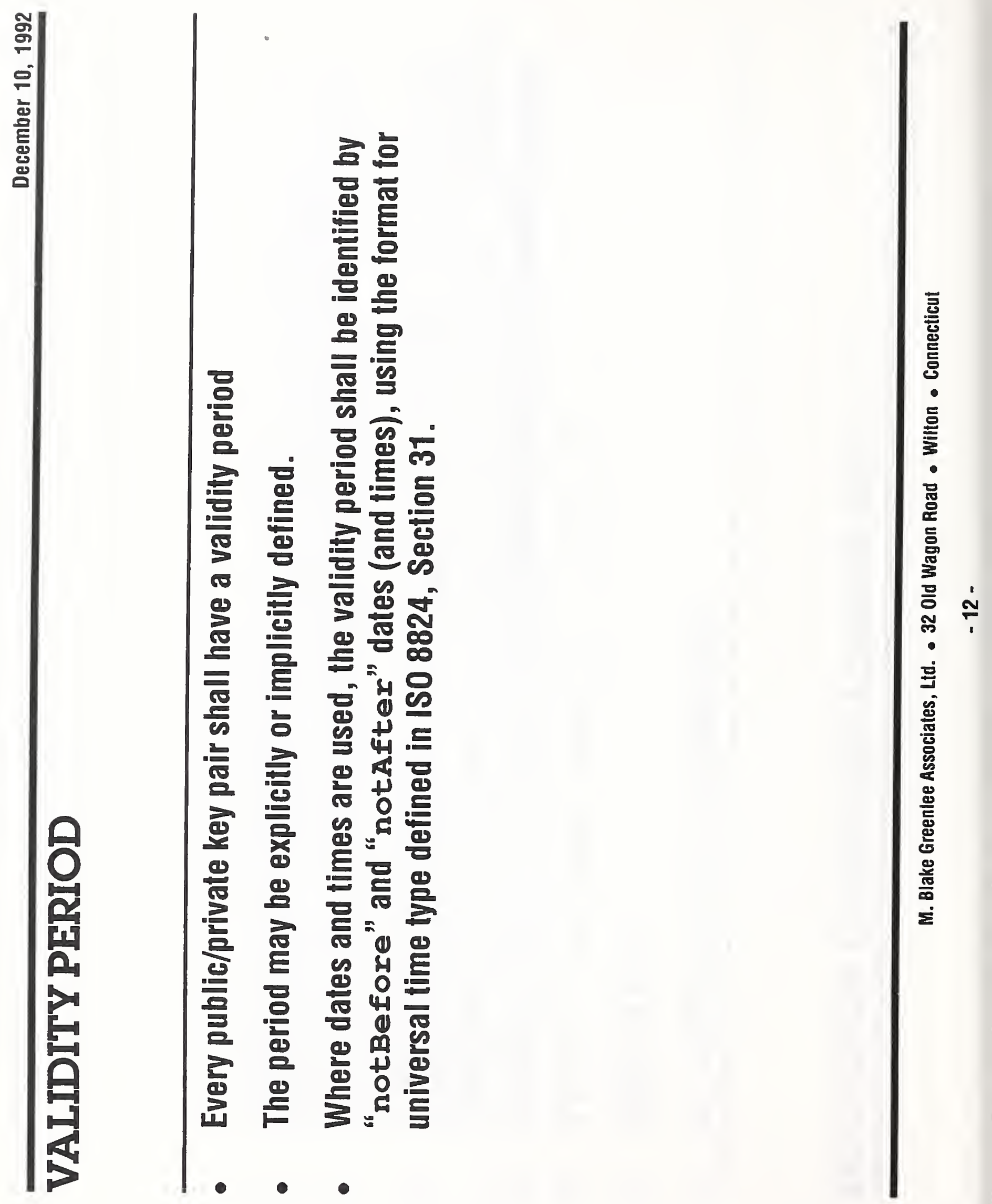


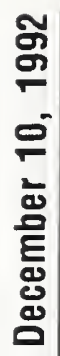

है

도.

E

4

2

ㄴ.

5

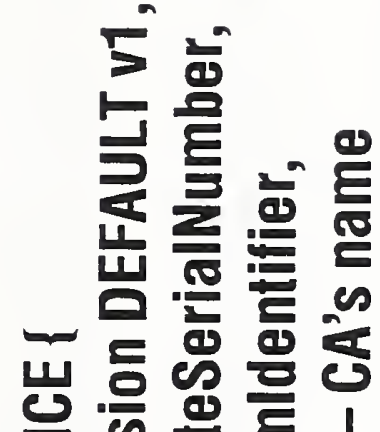

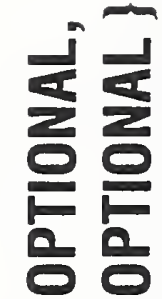

을 흘 을

क 트 ।

을 으

드르

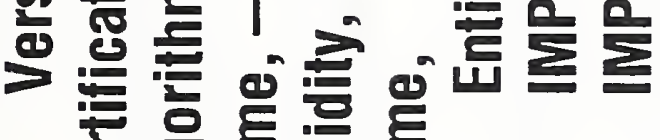

너

불을은

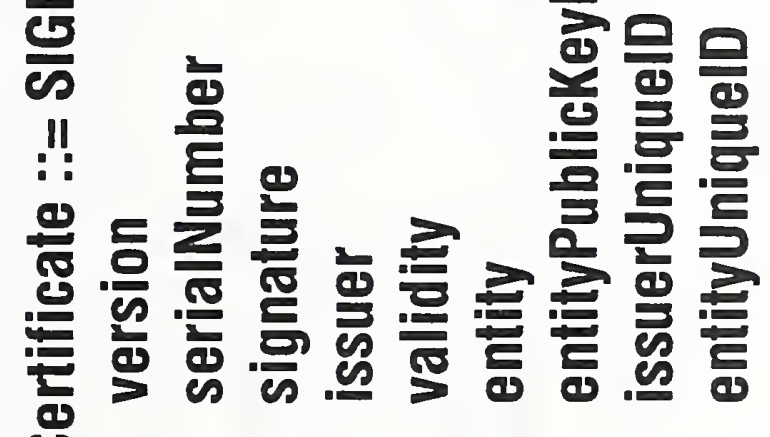


ฮै

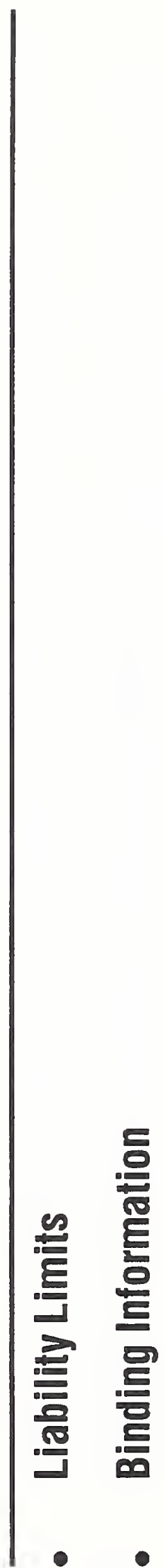

武

풍

드

0

든

5

คอ

D

든

5

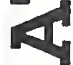

0

1

ข?

5

단

$\Longrightarrow$

ก

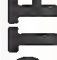

Q

2

5

을 

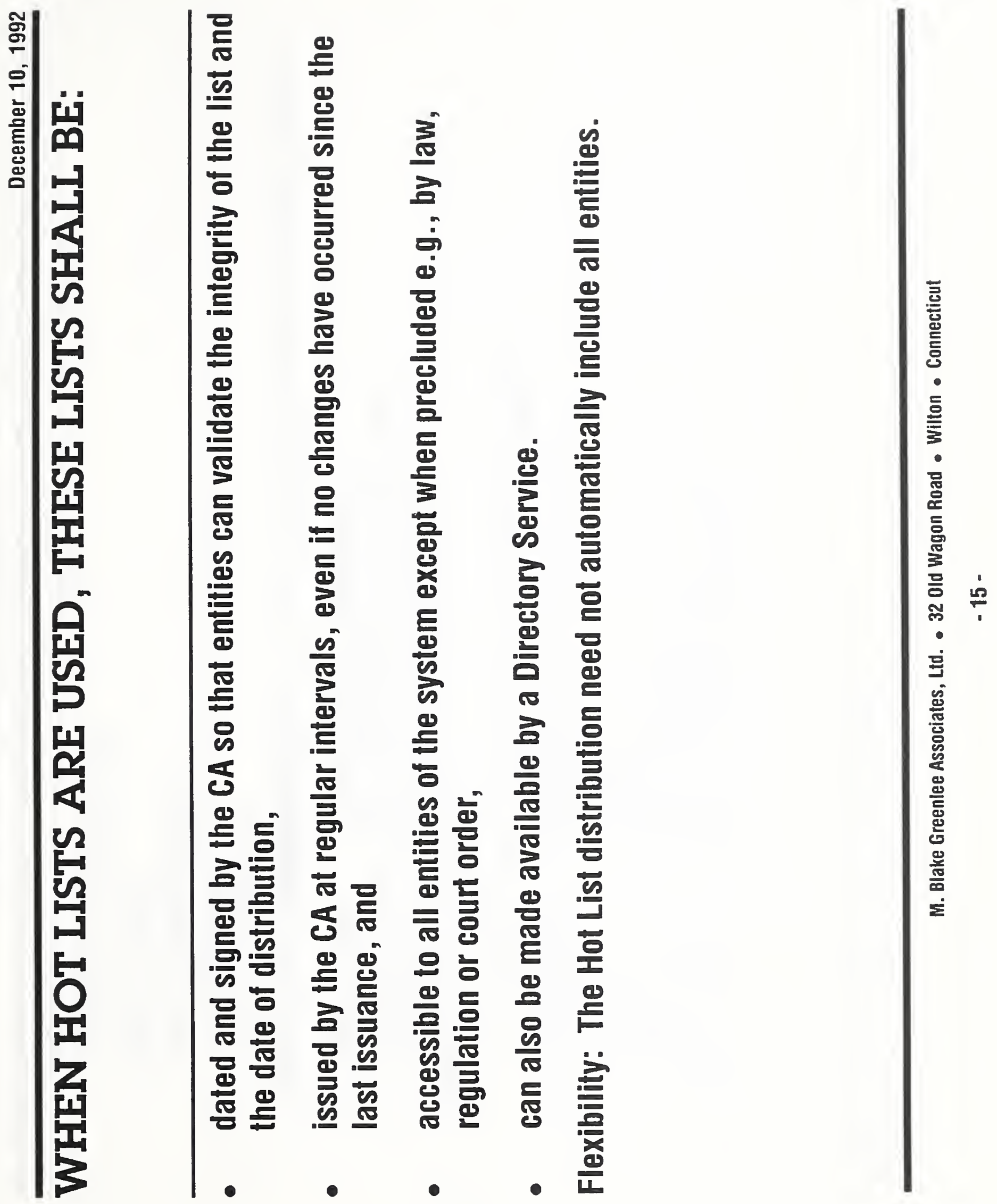


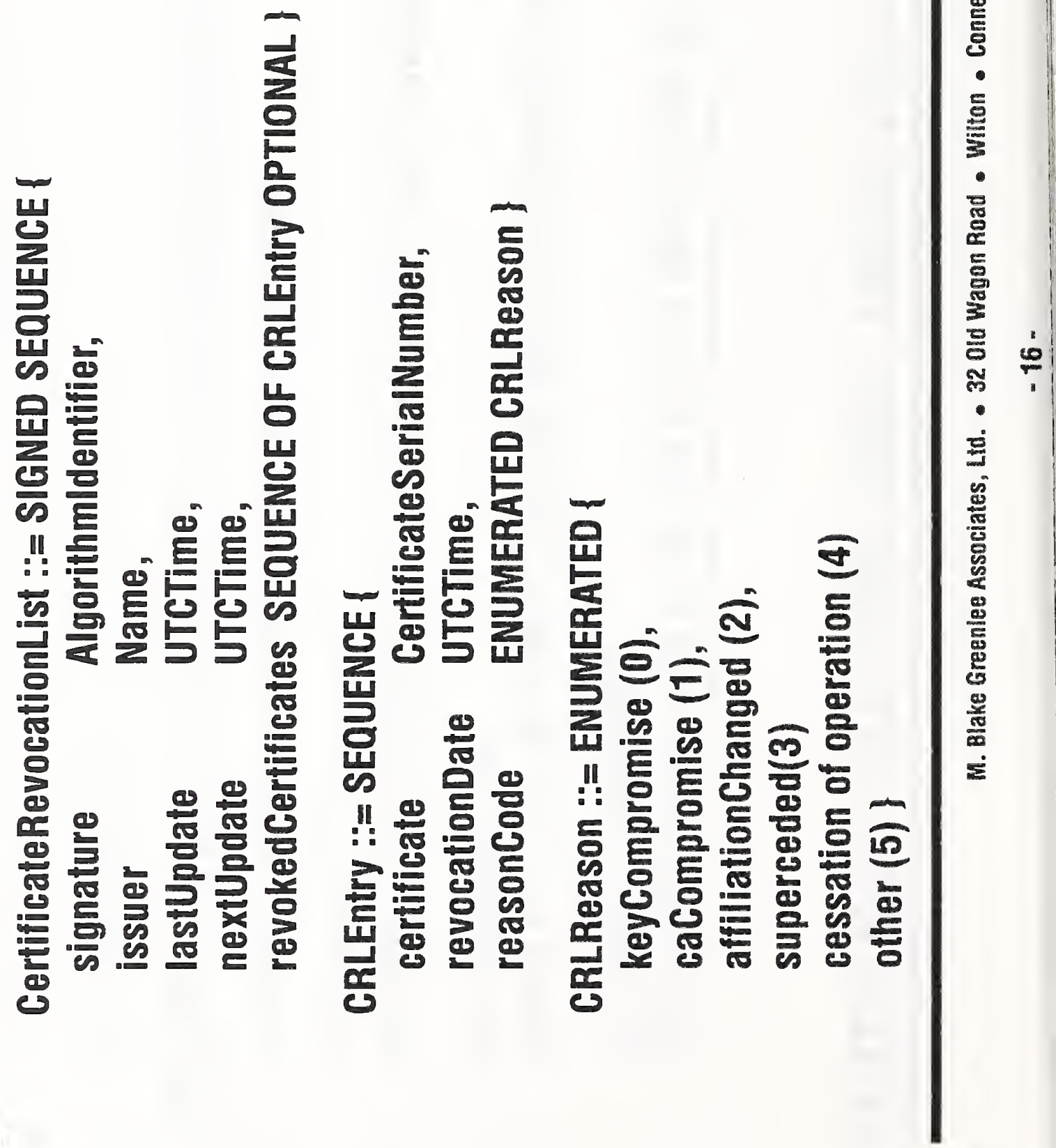




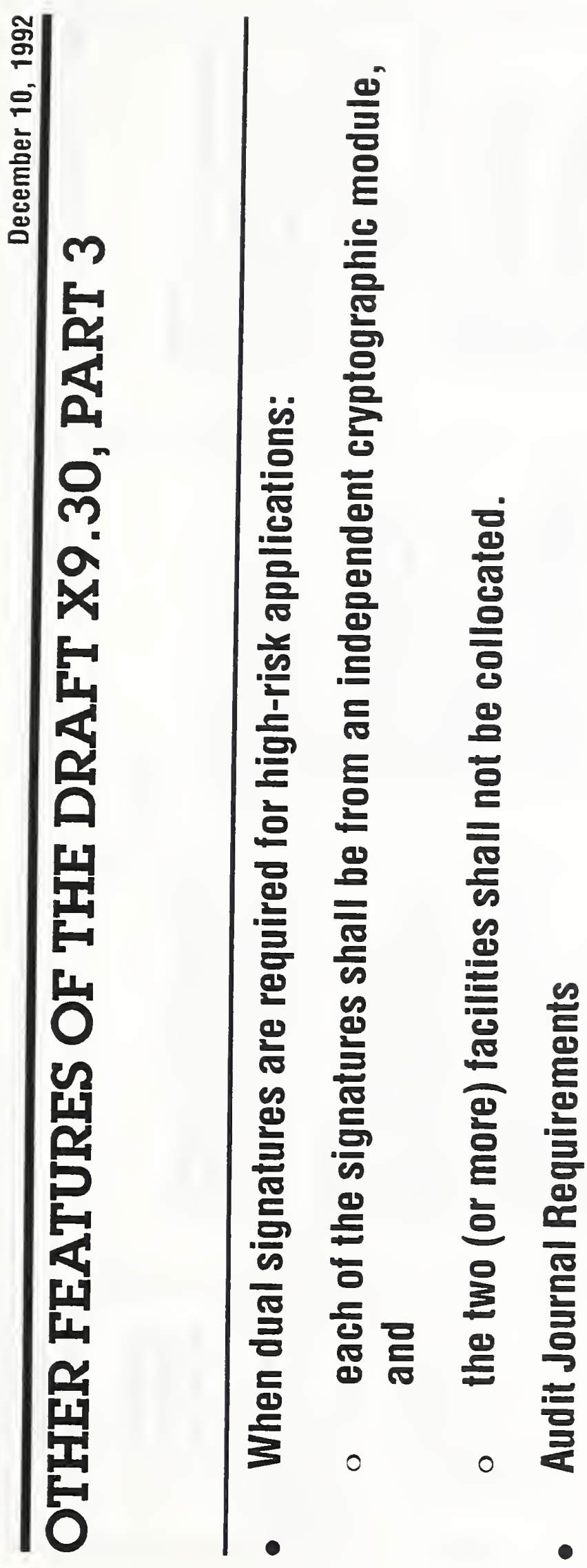

클

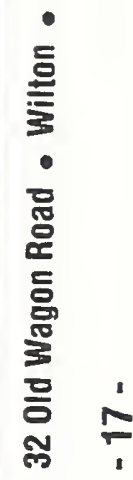

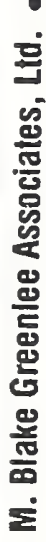


ฐั

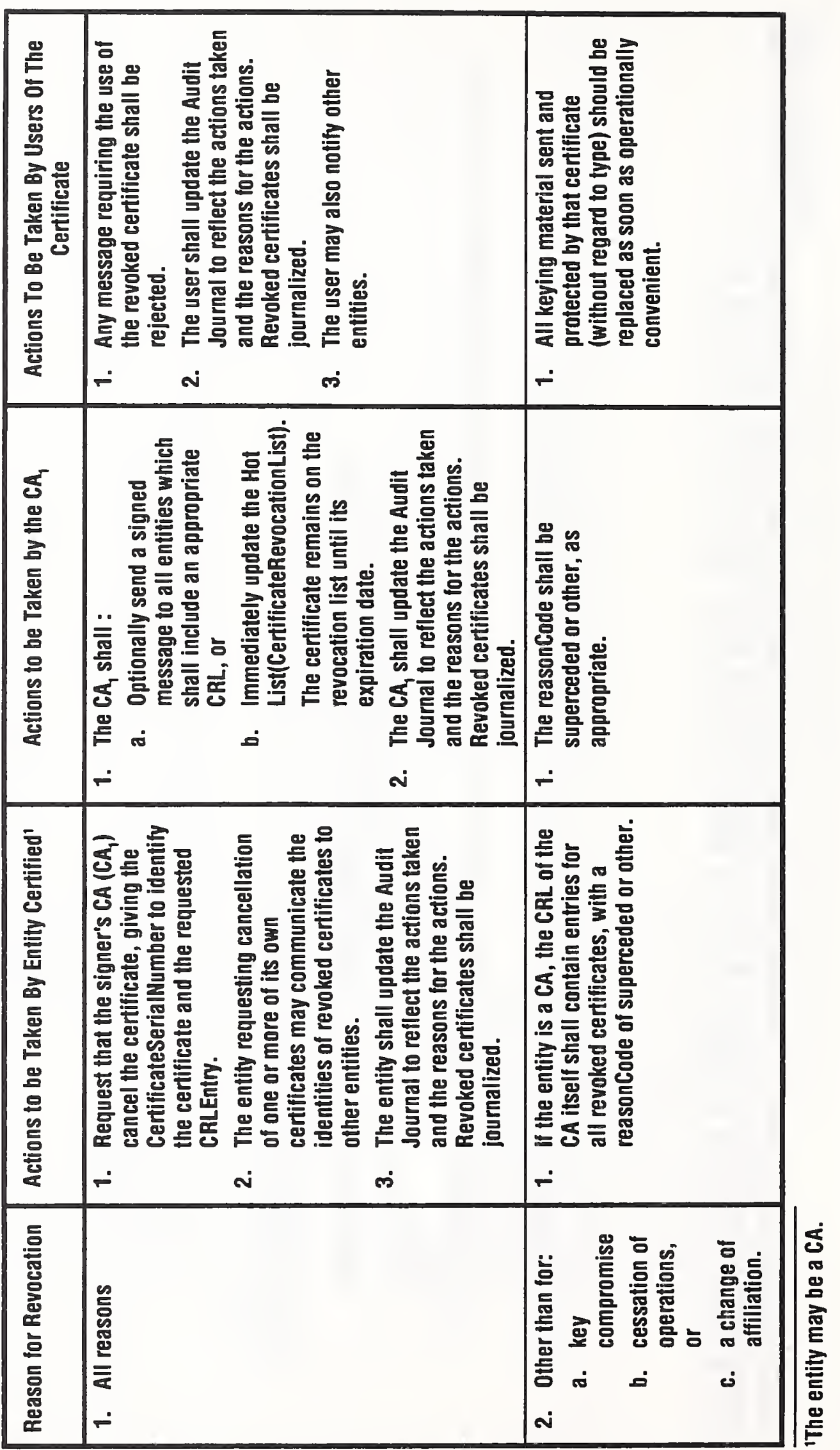




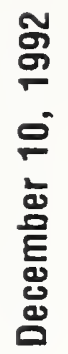

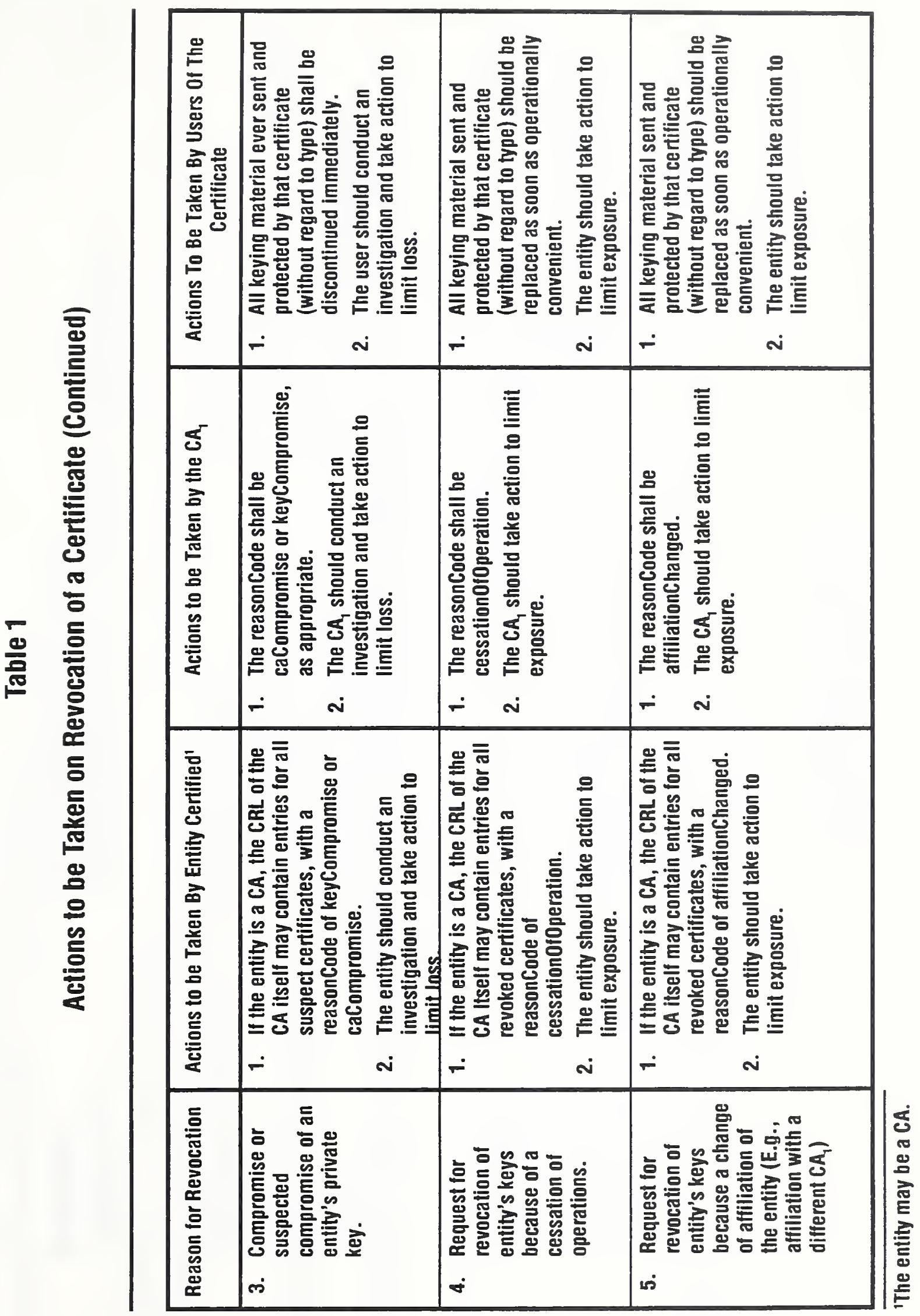




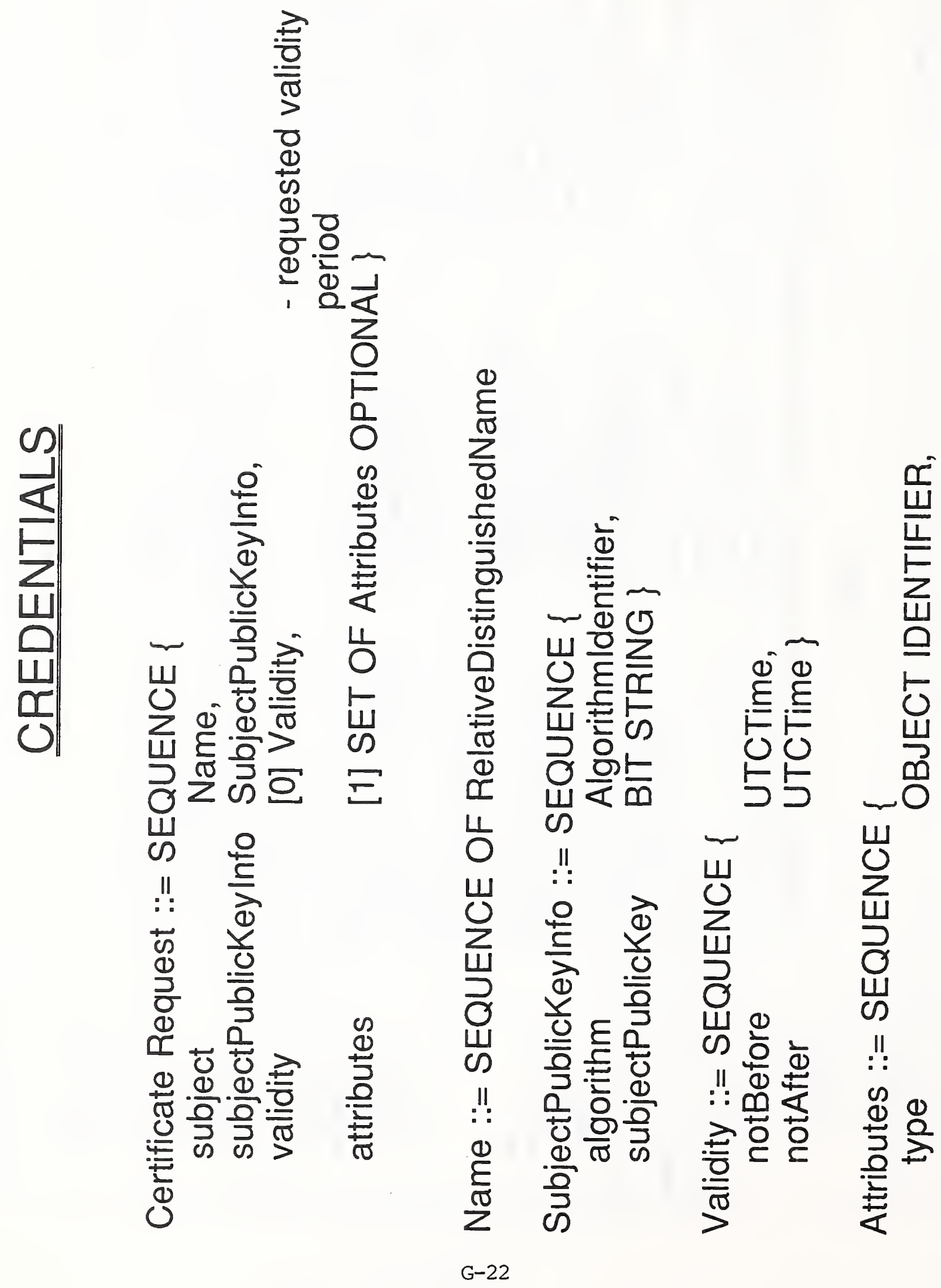




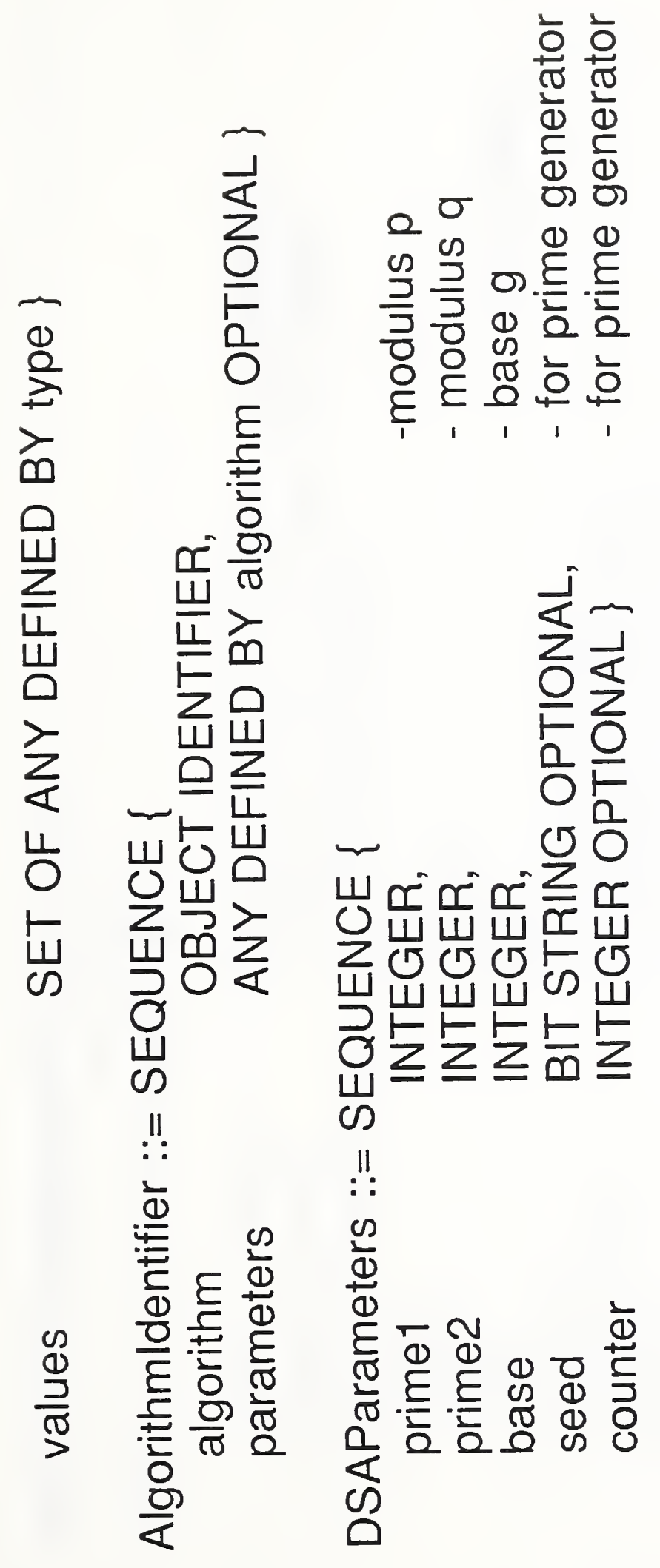



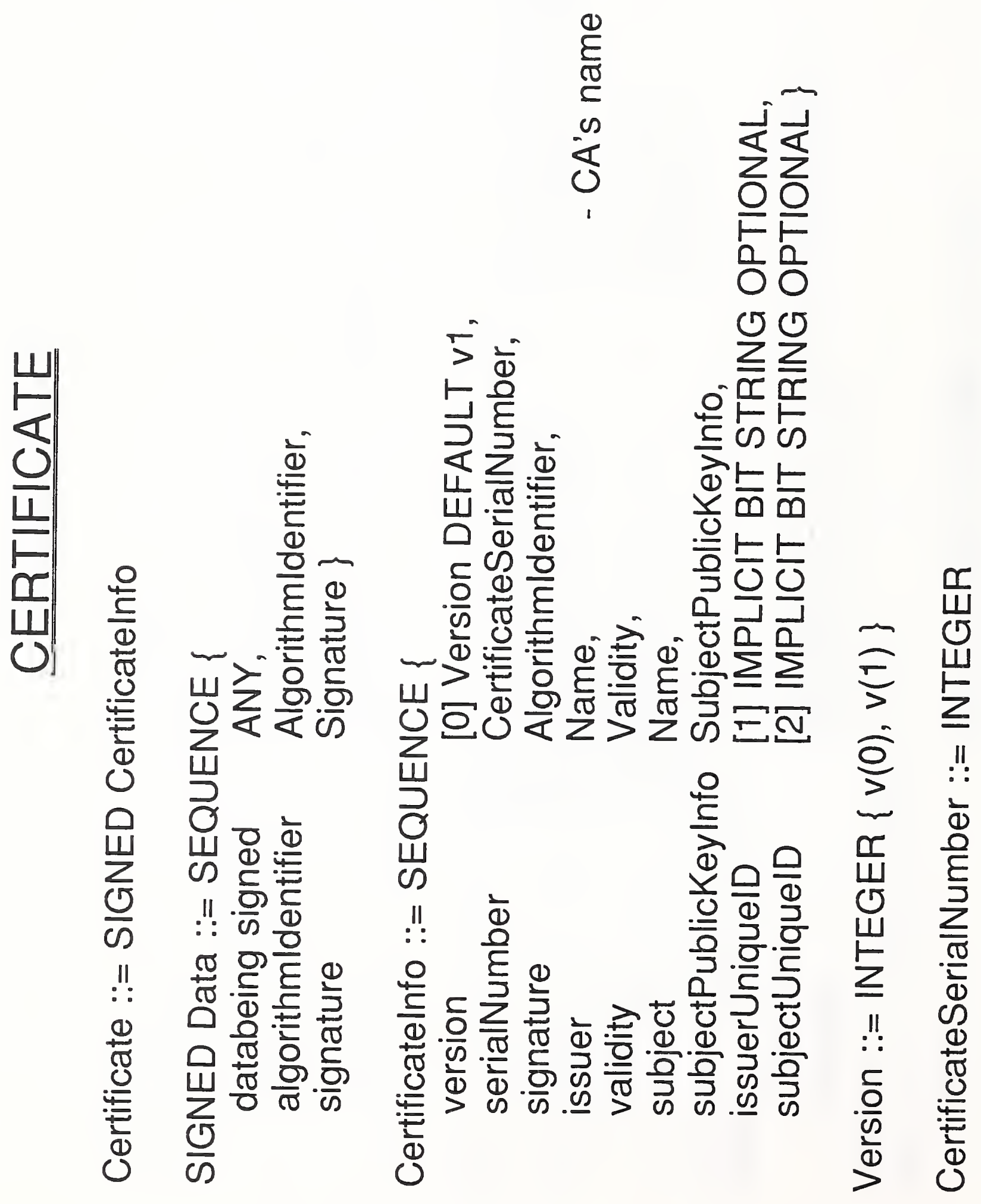


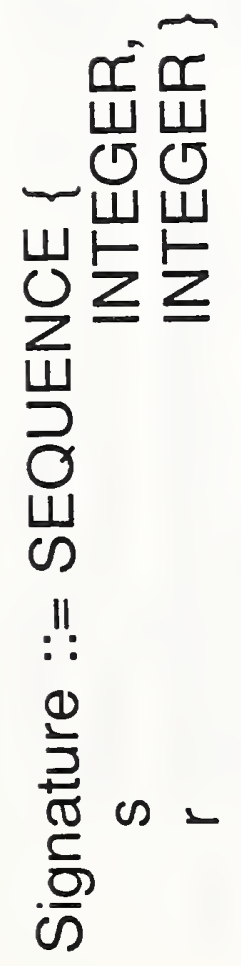

G-25 

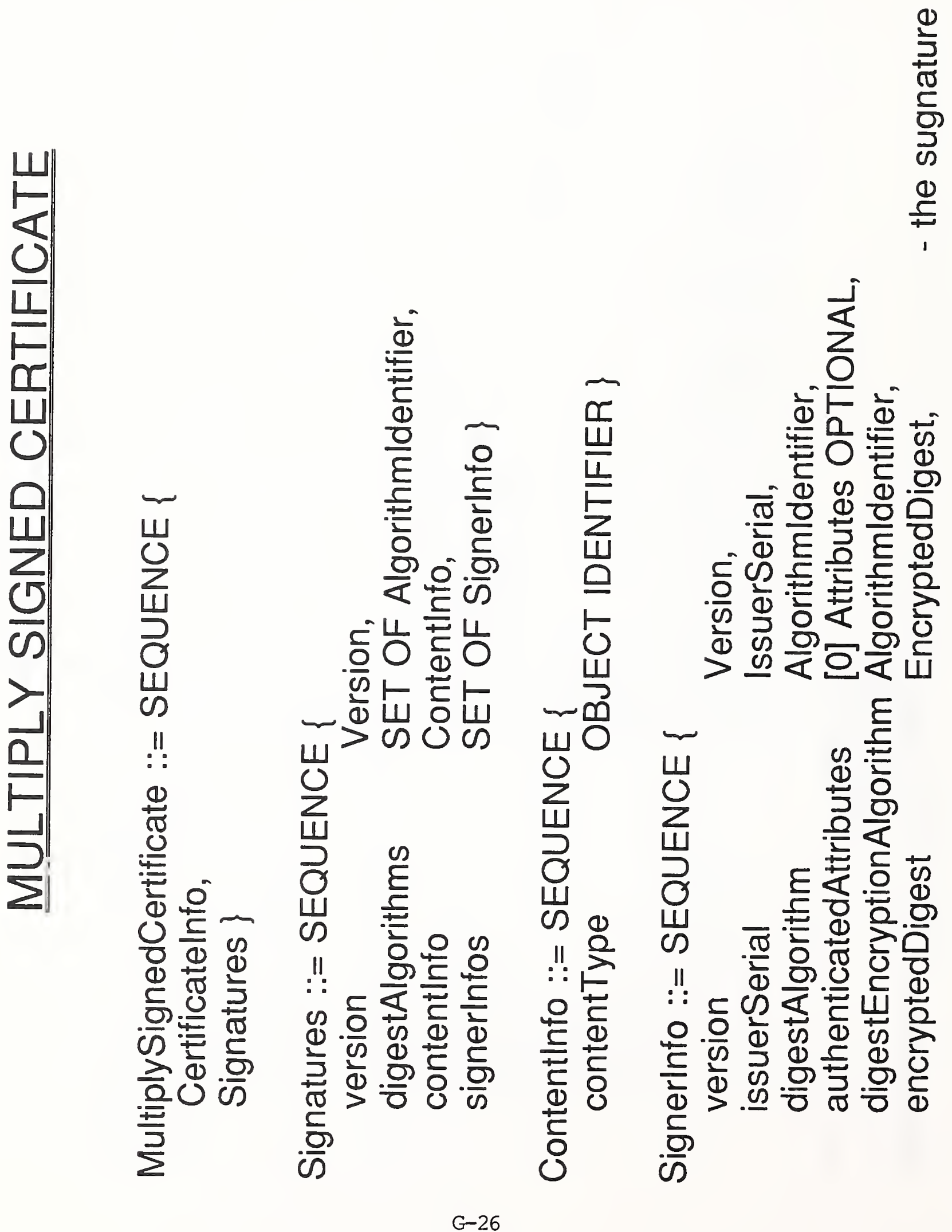


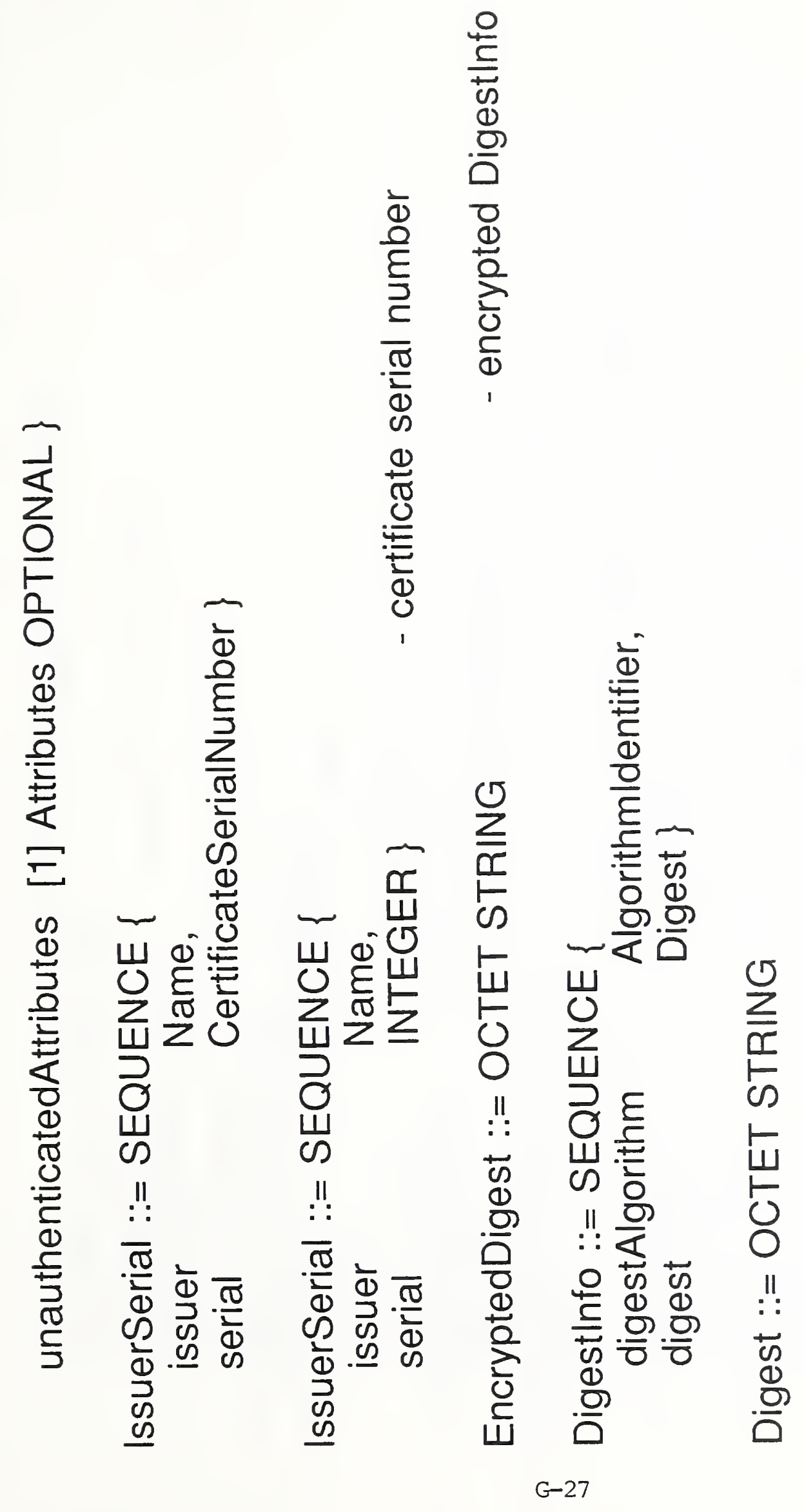




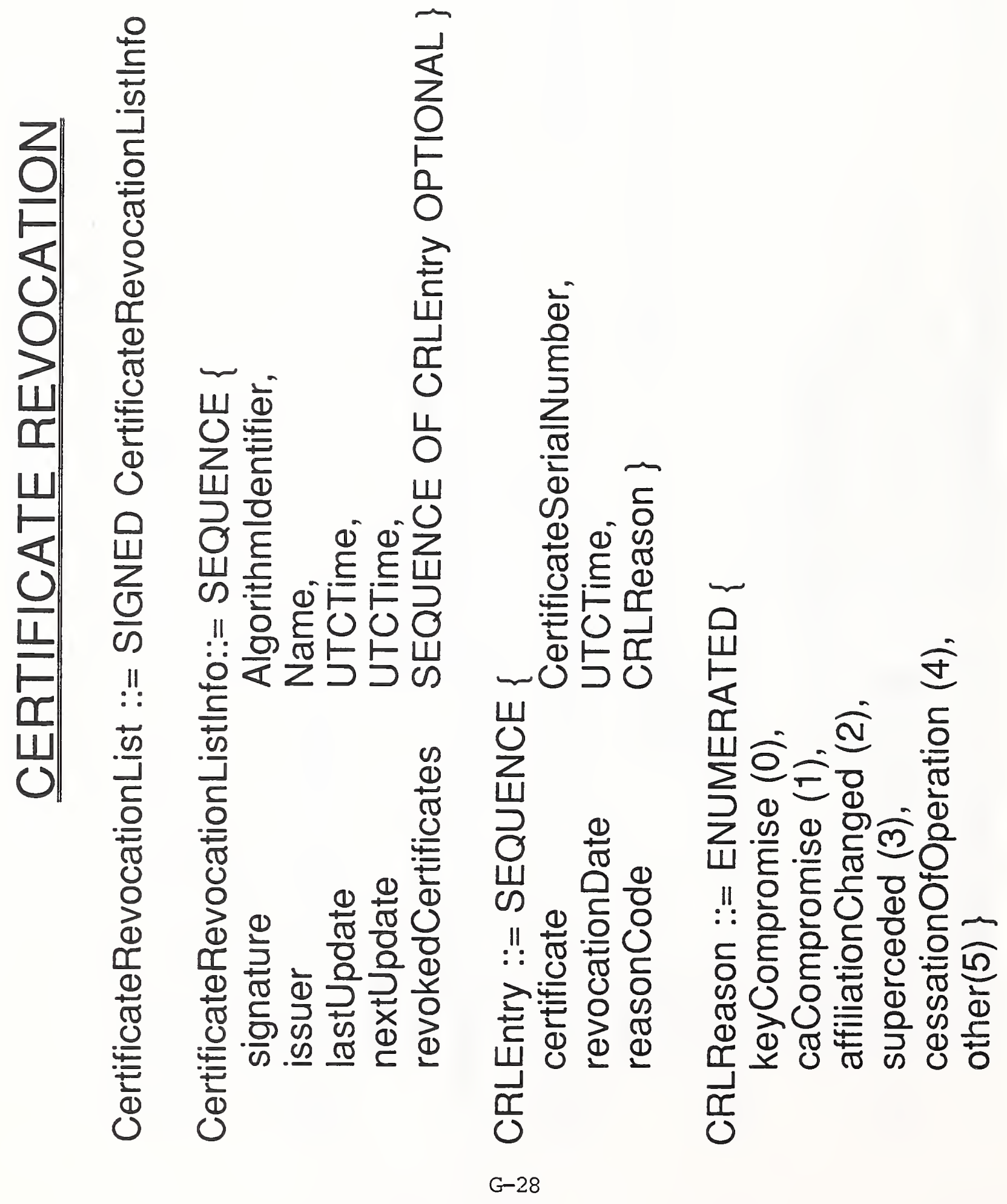


山!
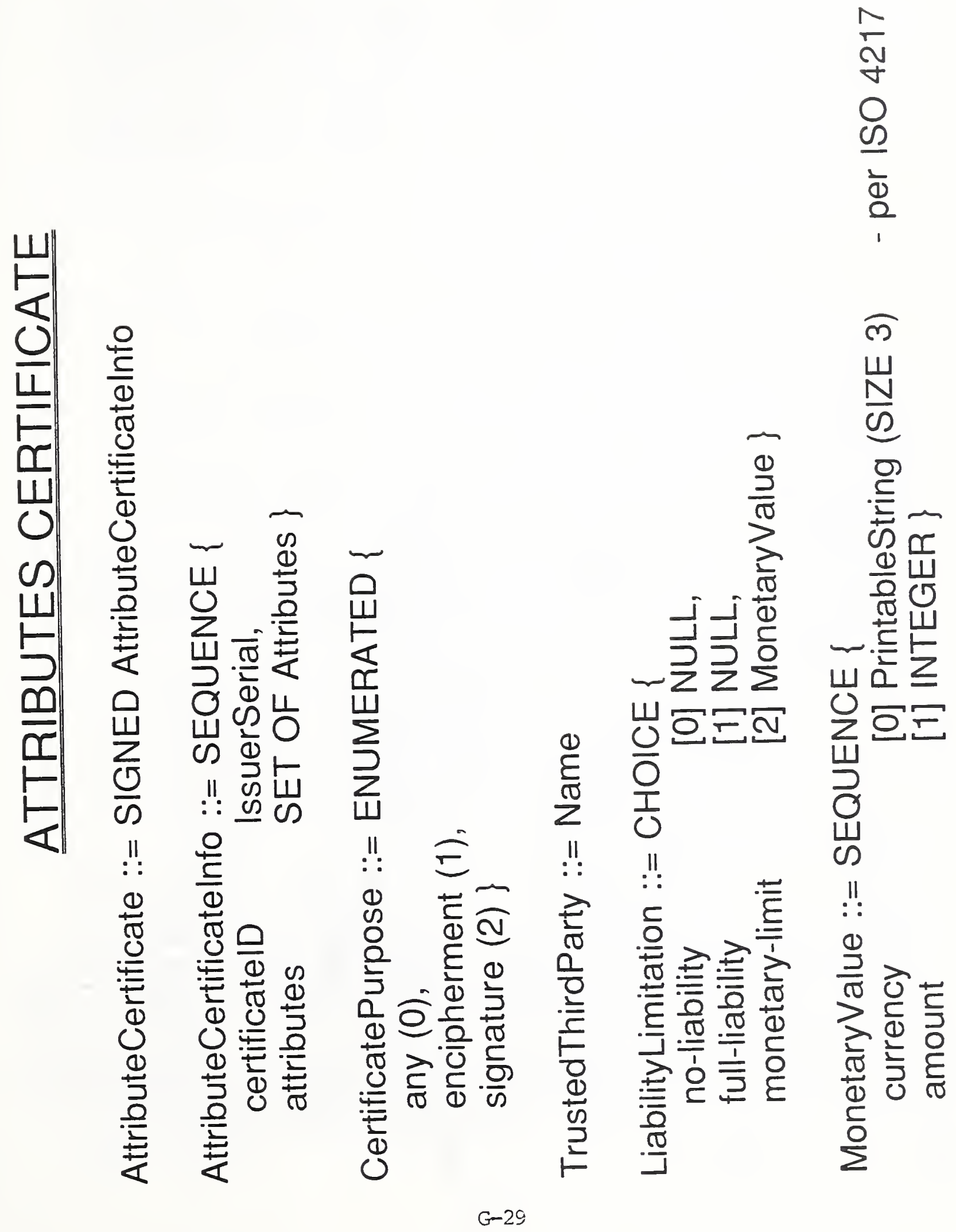


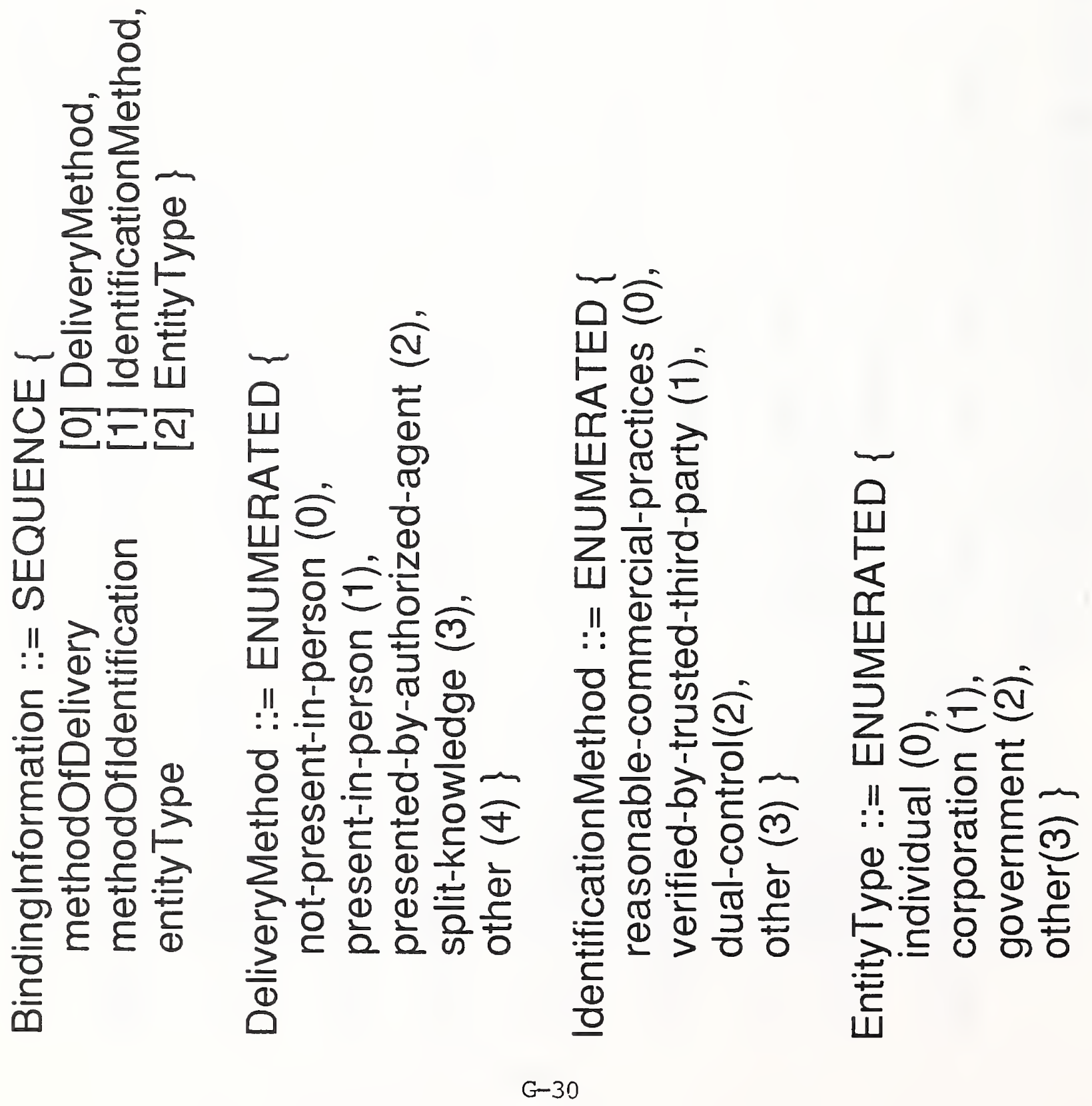




\section{Certificate Format Discussion \\ Discussion Points}

1. X.509, PEM, and X9F all use the X.509 certificate as a base. X9F uses the 1992 version, while PEM uses the 1988 version. The 1992 version contains unique ID (UID) fields for issuer and subject, which are used to prevent name reuse (for the subject), and to indicate which certificate is needed to validate a signature (for the issuer). (In this second case, the UID serves as an identifier for the public key, in addition to distinguishing between multiple uses of a name; this may have some impact on the internal structure of the UID.)
a) Is the X.509 certificate suitable for our purposes?
b) Which version is preferable (1988 or 1992)?
c) If 1992 certificates are used, what are the exact semantics of the UID?
d) How will common DSA parameters (prime and generator) be managed? They could be conveyed in each certificate, per the ASN.1 presented previously, but this seems like a waste of storage/bandwidth. Alternatively, DSA parameters could be tied to a CA (and its subordinates), and retrieved from the CA's certificate (or distributed along with the trusted public key of a $\mathrm{CA}$ ). Or the parameters could be tied to the (X.500) naming hierarchy in a similar manner.

2. $\mathrm{X} 9 \mathrm{~F}$ additionally defines an attribute certificate to contain other (optional) useful information, in the form of X.500-style attributes (type plus one or more values). The following attributes were felt to be useful for the financial community:

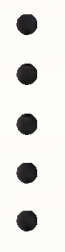

liability limitation,

binding information (method of identification, method of delivery),

certificate purpose (encipherment and/or signature),

names of any trusted third parties used to convey credential information, and

Common DSA parameters (for some "subtree" of the name space).

a) Is a similar "extension" mechanism required in this case? If so, what attributes would be useful?

b) Is the attribute certificate issued by the same CA which issues the public key certificate, or might separation of duties dictate that a different entity is responsible for issuing an attribute certificate (e.g. one with monetary transaction limits)?

3. $\mathrm{X9F}$ allows for the use of multiple signatures on certificates used with high value transactions. The multiple signature structure allows for joint signatures, as well as nested (counter)signatures, and is based on RSADSI's "PKCS \#7: Cryptographic Message Syntax." 
a) Is such a mechanism useful in this case?

b) Can this mechanism usefully be applied to individual messages/transactions, as well as to certificates?

c) Given a signature on a certificate or message, (how) does one indicate which other signatures are required?

4. Certificates as defined in X.509 are useful in providing the following security services: integrity, authentication, and non repudiation (of origin). It may be useful to examine other security services to determine whether they might make use of this infrastructure, particularly if the extension mechanism of point 2 is used.

- Peer Entity Authentication: The use of signatures for this purpose (generally using a challenge/response mechanism) is well documented in the literature and in existing standards (e.g., X.400 and X.500).

- Confidentiality: Symmetric key management can be performed using, e.g., RSA public keys to encrypt DES keys a la PEM, ISO CD 11166-1, etc. Certificates would be used in this case to hold the (trusted) public keys.

- Access Control and Authorization: The use of certificates to contain access control information is also well documented. (Note that we are referring to longlived access control information, with a lifetime similar to that of the public key certificate. Other mechanisms, such as ECMA PACs, are defined for use on a short term, e.g. per connection, basis.) Two examples are:

- In the DoD environment, SDNS Access Control (SDN.802).

- In the commercial environment, Electronic Document Authorization (Proceedings of the 1990 NCSC).

- Non Repudiation: Additional non repudiation mechanisms beyond the use of (originator) signatures are discussed in the ISO Non Repudiation Framework (Working Draft). These include Time Stamping Services and Third Party Notaries.

a) What other security services should the infrastructure support?

5. The CRL format of X.509 was extended in PEM to include a "next update" time. This prevents attacks based on preventing delivery of CRLs to an entity. X9F further extended the CRL to include a revocation reason fo: each entry, since different actions are required of the entity and $\mathrm{CA}$ in different cases.

a) What CRL format is suitable for these applications? 


\title{
APPENDIX H
}

ASN. 1 STRUCTURES FOR CERTIFICATE MANAGEMENT

\author{
Rich Ankney
}

Fischer International 


\title{
ASN.1 Structures for Certificate Management
}

\author{
Rich Ankney \\ Fischer International \\ (703) 818-0713 \\ ankney@emc2-tao.fisc.com
}

This paper describes the various ASN.1 structures used in the $\mathrm{X} 9 \mathrm{~F} 1$ certificate management standards.

\section{Signatures}

A signature is generally represented as the output of the SIGNED macro, i.e. a BIT STRING. The macro is defined as:

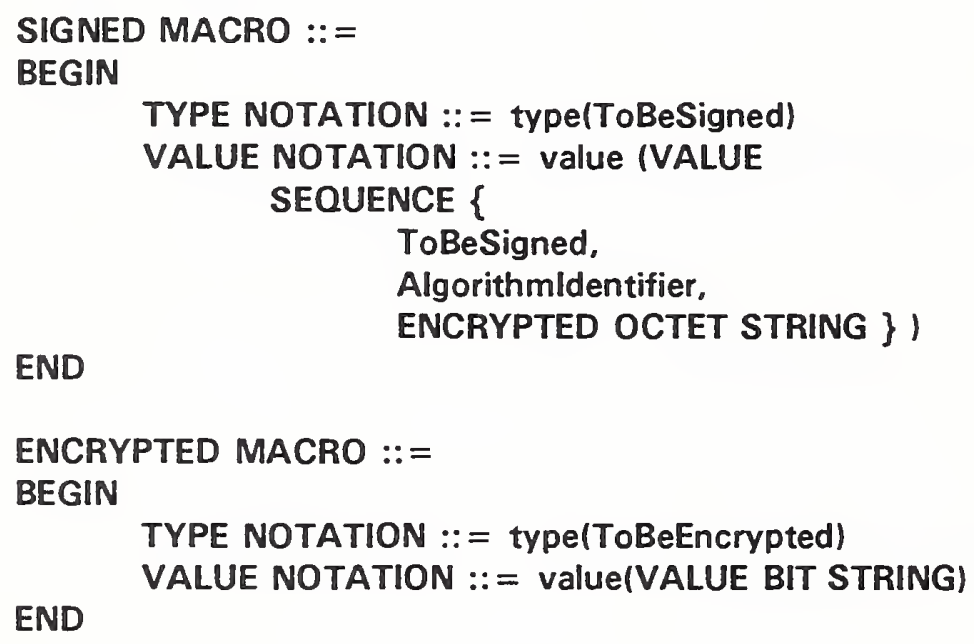

So a SIGNED DataToBeSigned (with DataToBeSigned being an arbitrary type) expands to:

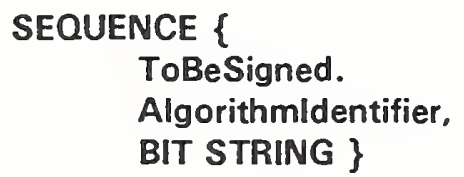

While an RSA signature, being a single integer, is mapped into a BIT STRING in the obvious way (MSB to LSB), the DSA signature consists of two integers, $r$ and $\mathbf{s}$. These need to be encoded into a BIT STRING for use as an ASN.1 signature. The signature should be interpreted as being (the BER encoding of the type:

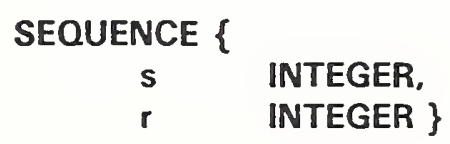


That is, the encoding of the sequence is wrapped inside a BIT STRING.

\section{Public Keys}

Public keys are generally conveyed within a BIT STRING, as defined in the following section. Within the bit string, there is typically some additional structure. This will be represented as the BER encoding of the appropriate structure as defined in this section. A public key is always conveyed as a BER encoding, but the bit string in which it appears is encoded using the mechanism appropriate to the network.

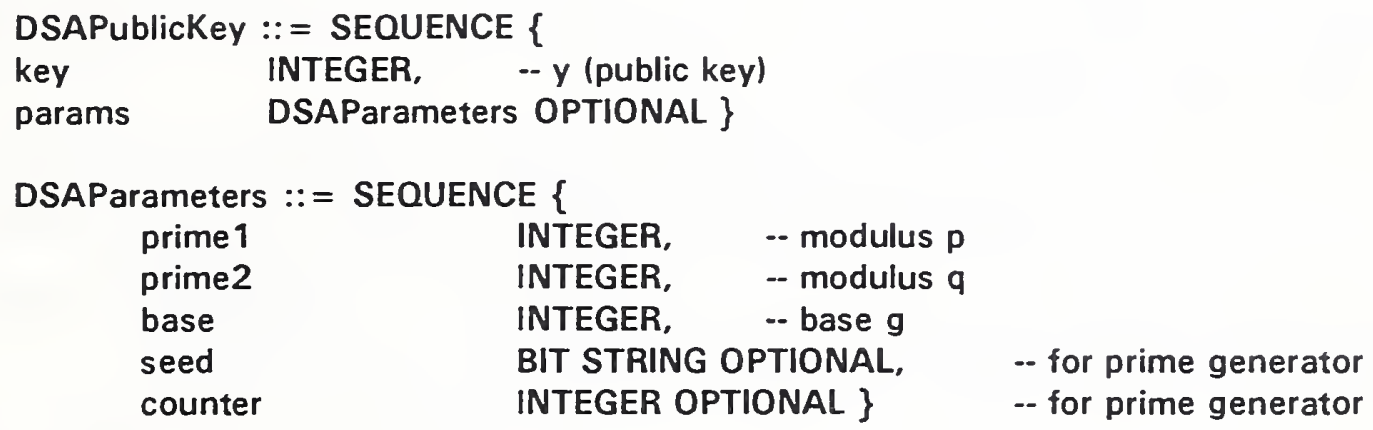

For an RSA public key, this bit string is the ASN.1 encoding of the following structure, as defined in X.509:

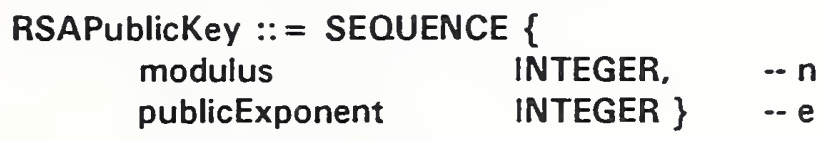

\section{Certification Requests}

The CertRequestData include that information which the subject wishes to have certified.

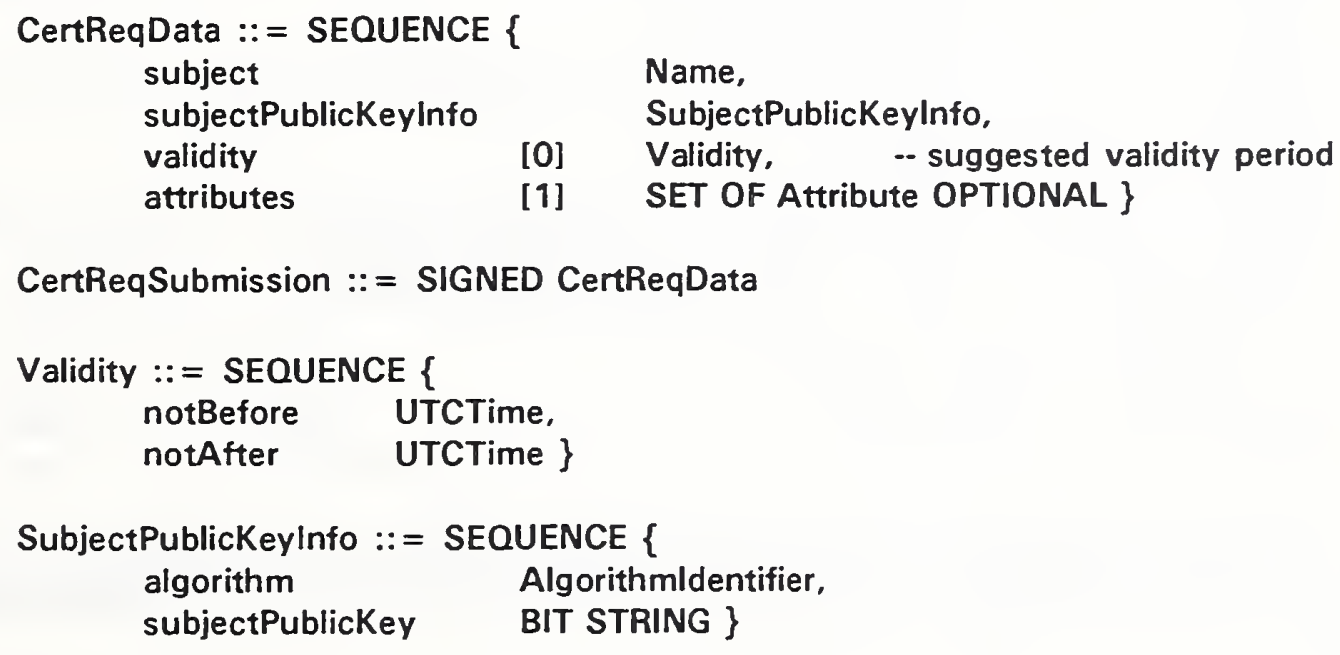




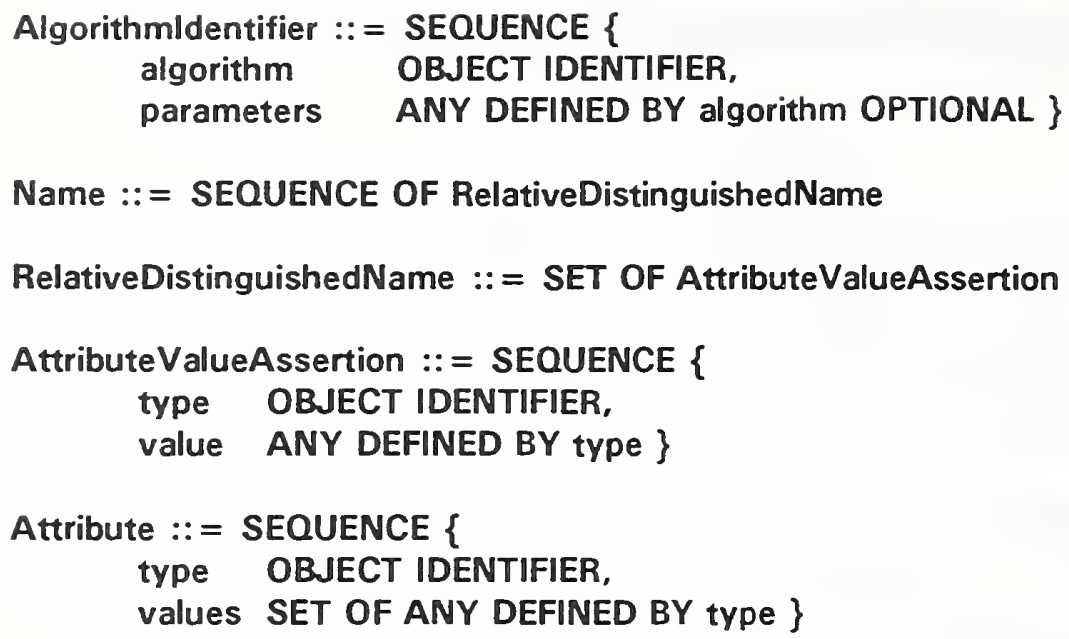

The validity field may be overridden by the CA in the certificate created from the credentials.

The subjectPublicKey field contains a bit string which is the public key of the subject. (This bit string may contain a BER encoding as discussed above.)

The Name follows the definition of X.500, but the structure rules (allowable name forms) need not follow the schema described in X.521.

The attributes component is a (possibly empty) set of other information whose association with the entity must also be certified by the CA.

\section{Public Key Certificates}

An X.509 (public key) certificate has the following contents:

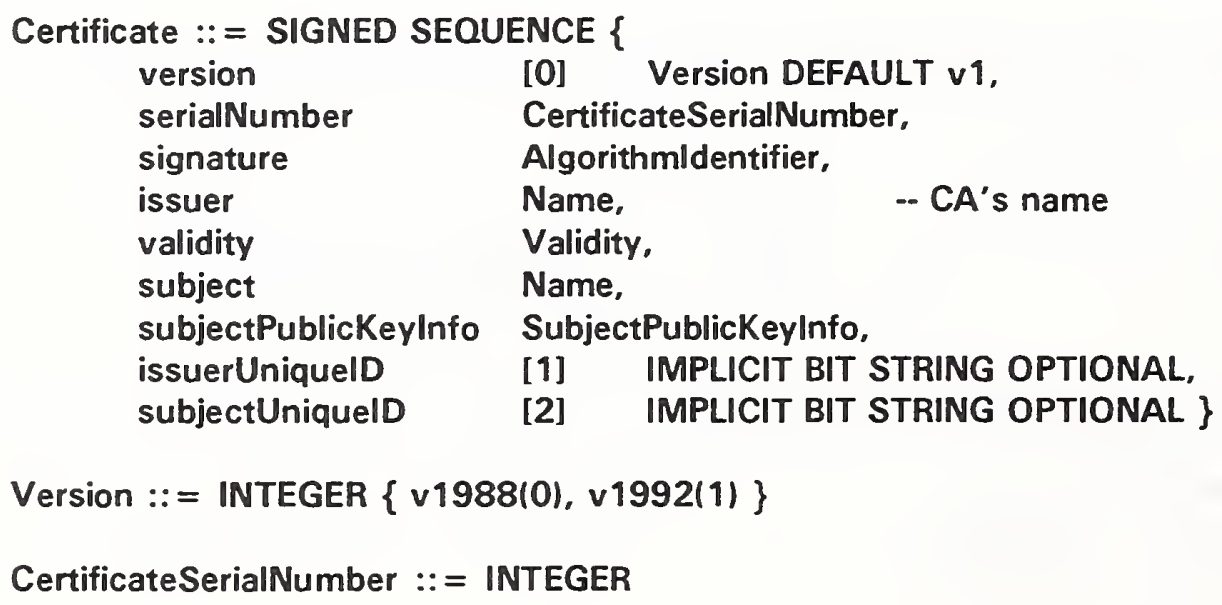

The version is used to differentiate between versions of the certificate. The validity field indicates the period when the certificate is valid. (This may be different from that requested by 
the subject in the Credentials.) Note the CA's (issuer's) certificate indicates the validity of the CA's public key. The signature and issuer fields are added by the CA. The certificateSerialNumber field uniquely identifies this certificate among all those issued by the CA. (Thus the combination of issuer name and serial number will, ideally, uniquely identify a certificate, assuming proper procedural controls on serial number assignment by the CA.) The subjectUniqueID field is provided by the $\mathrm{CA}$ and may be used to distinguish between reused instances of a name. The issuerUniqueID field performs a similar function for the CA name.

\section{Certificate Revocation Lists}

The following "hot list" format is based on that of Internet RFC 1114, with the addition of a reason code.

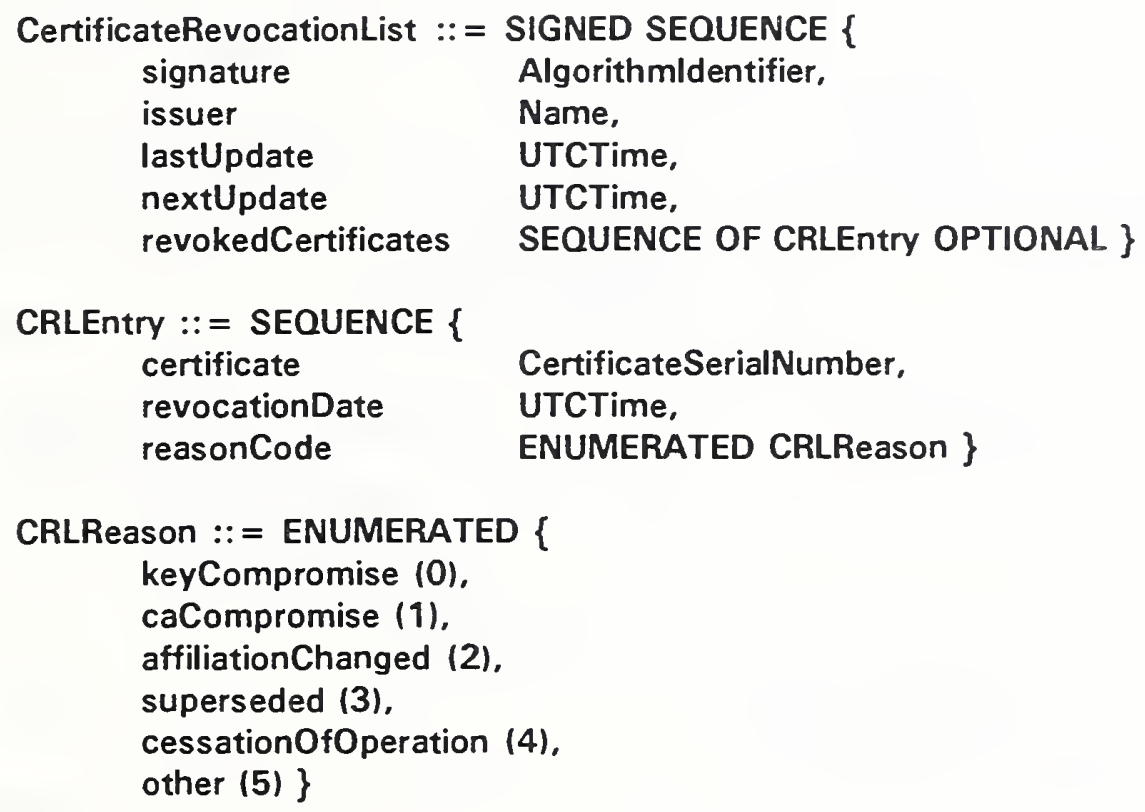

\section{Attributes}

The (optional) attributes associated with the subject / certificate are carried in a separate structure which is also signed by the CA. This structure is the attributes certificate.

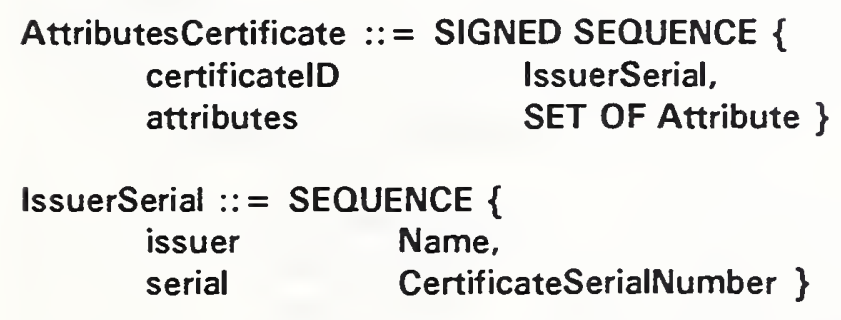

The issuer and serial number are those of the base X.509 certificate, and would be used to . retrieve the attributes certificate in the event the subjectUniquem field is not used for that 
purpose.

Following are some useful attributes for attribute certificates. (We only define the syntax for the attribute values; object identifiers are defined elsewhere.)

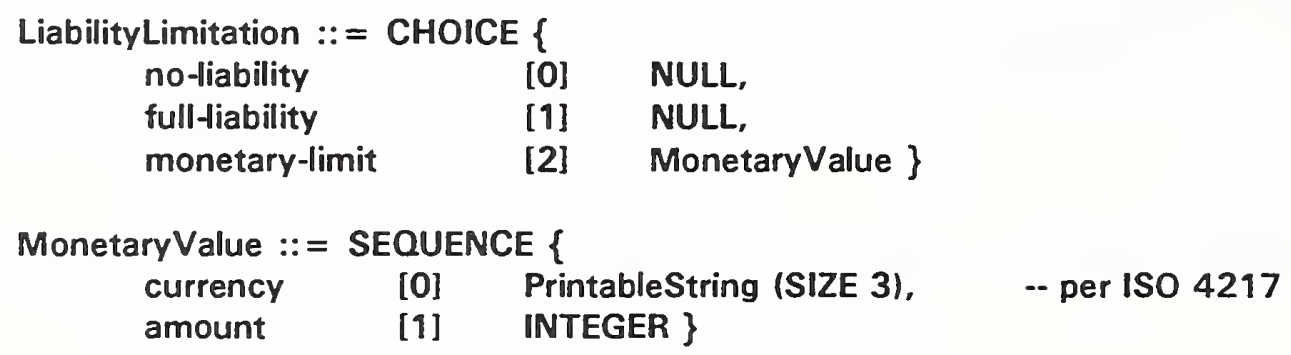

This attribute defines the limits of a CA's liability in the event of key compromise, etc. One might find this attribute in a CA's certificate.

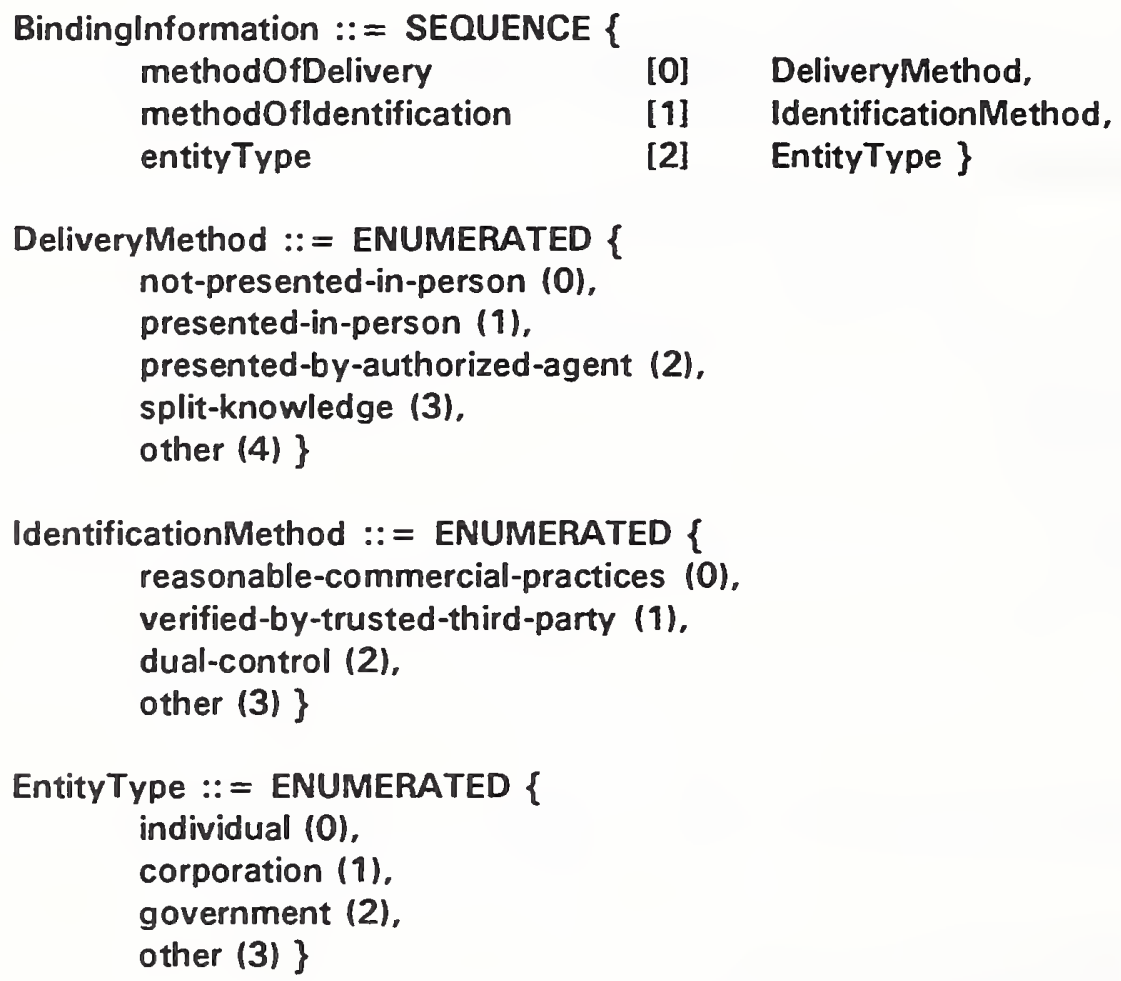

This attribute indicates the criteria used to bind the public key (and optionally attributes) to the identity of the entity being certified.

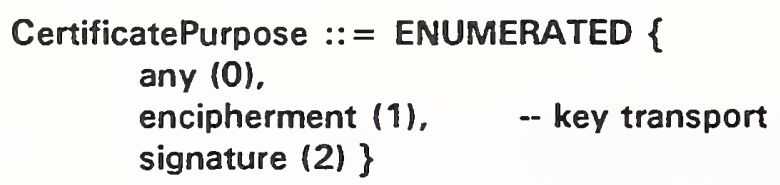


This attribute indicates what functions the public key contained in the certificate may be used for.

$$
\text { TrustedThirdParty ::= Name }
$$

This attribute conveys the names of one or more third parties which were involved in the identification process. This would allow a complete trail to be constructed from top-level CA through all involved parties to the certificate subject.

Additionally, if a set of DSA parameters $(p, q$, and $g$ ) are associated with a given CA's users rather being common to the whole network or unique to a single user, this information could be carried as an attribute in the CA's certificate.

\section{Multiple Signatures}

For high-risk applications it may be desirable to require multiple signatures on the certificate by the $\mathrm{CA}$, with the signatures being performed in independent cryptographic facilities (with different private keys).

We define a MULTIPLY-SIGNED macro:

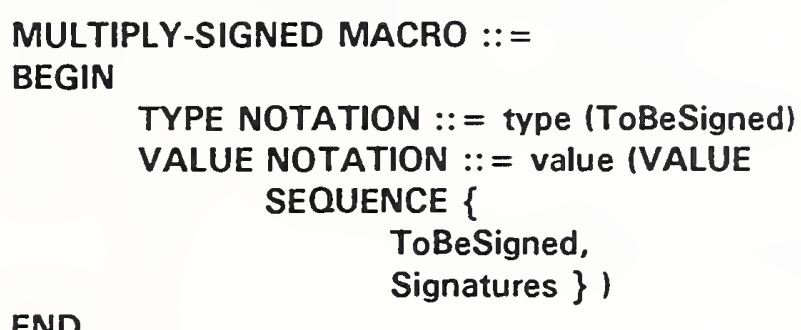

A multiply signed certificate is then:

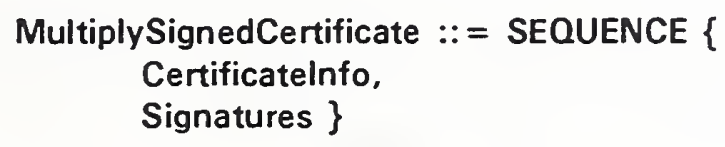

The Signatures type is a subtype of SignedData, defined in "PKCS \#7: Cryptographic Message Syntax", constrained to carry only signature information. SignedData is defined as follows:

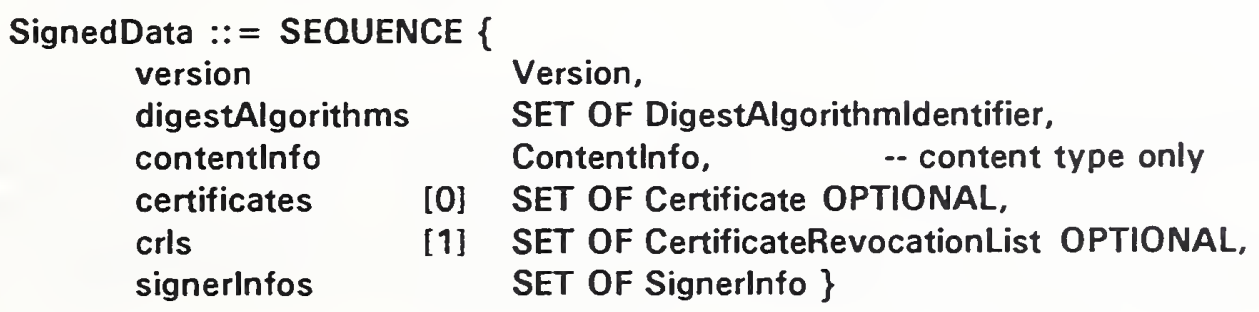




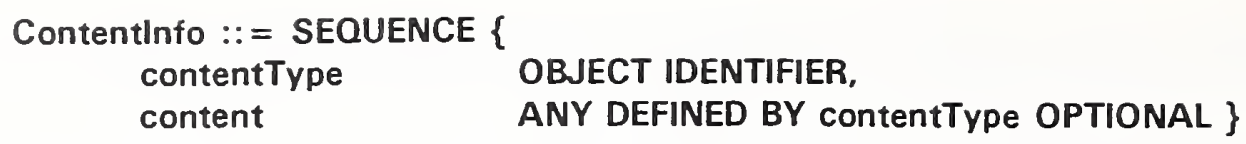

We require that the content field of the ContentInfo be absent, and in addition that the certificates and crls fields be absent. The content types indicate what type of information is being signed. The object IDs are defined elsewhere, but might include data (messages), publickey-certificate, attribute-certificate, etc. Using the subtype notation of IS 8825:

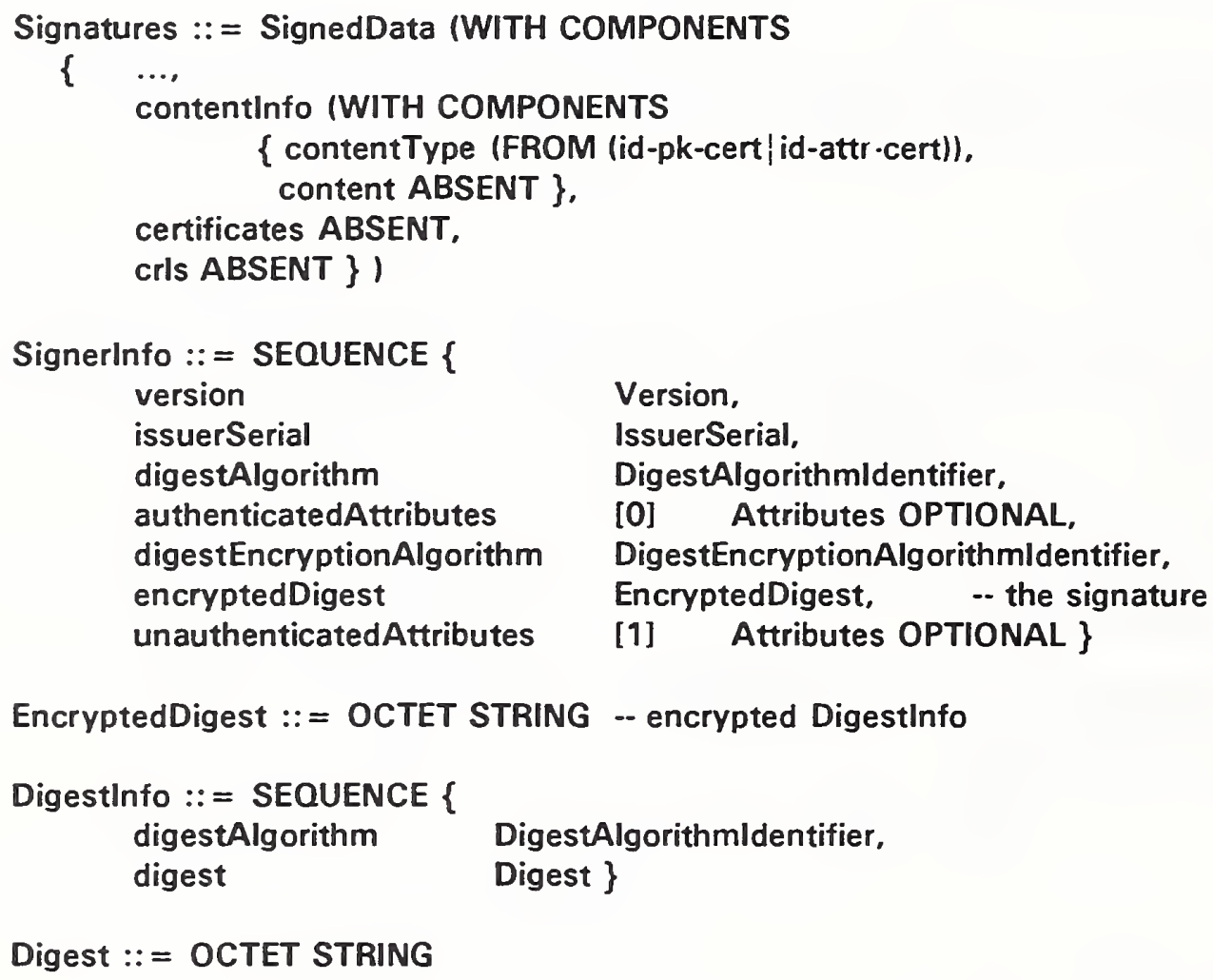

A SignerInfo contains the signed digest of the associated cuntent, and identifies the algorithms used to compute and sign the digest. It may also contain other information in the authenticated attributes; this information, if present, is included in the signature computation. Attributes consist of a type and one or more values, as defined in and other standards.

The authenticated attributes contained in the SignerInfo might include timestamps, comments and annotations, etc. If present, they must include the content type of the contentInfo being signed, and the message digest of that content.

A useful unauthenticated attribute is the countersignature, whose format is simply a SignerInfo. Its signature is computed on the encrypted digest (i.e. signature field) of the enclosing SignerInfo (and any authenticated attributes which might be present in the countersignature). Since the countersignature is of type SignerInfo, it may itself contain countersignatures; this allows construction of arbitrarily long chains of countersignatures. 


\title{
APPENDIX I
}

\section{U.S. POSTAL SERVICE SECURITY OFFERINGS}

\author{
Chuck Chamberlain
}

\author{
U.S. Postal Service
}




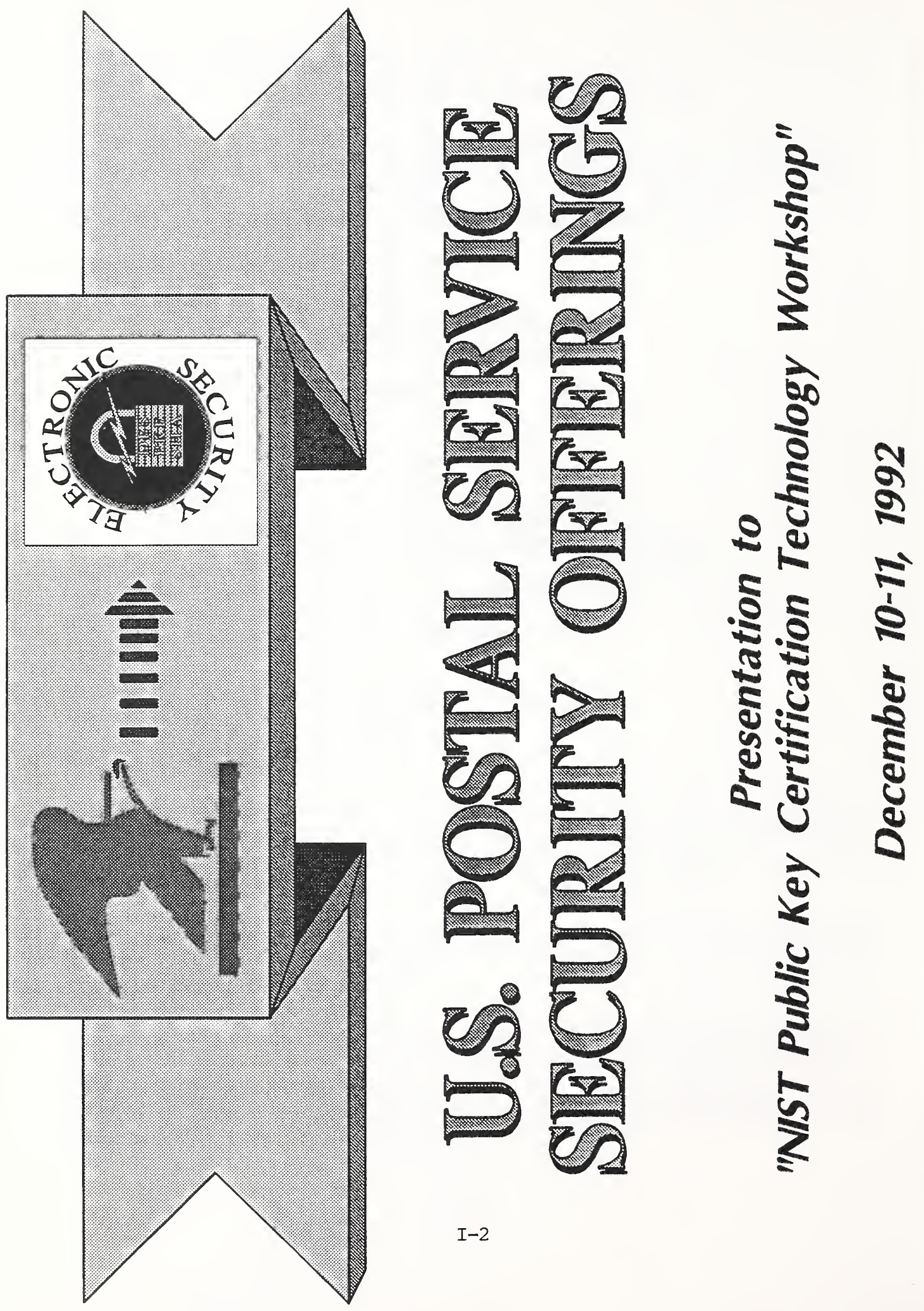




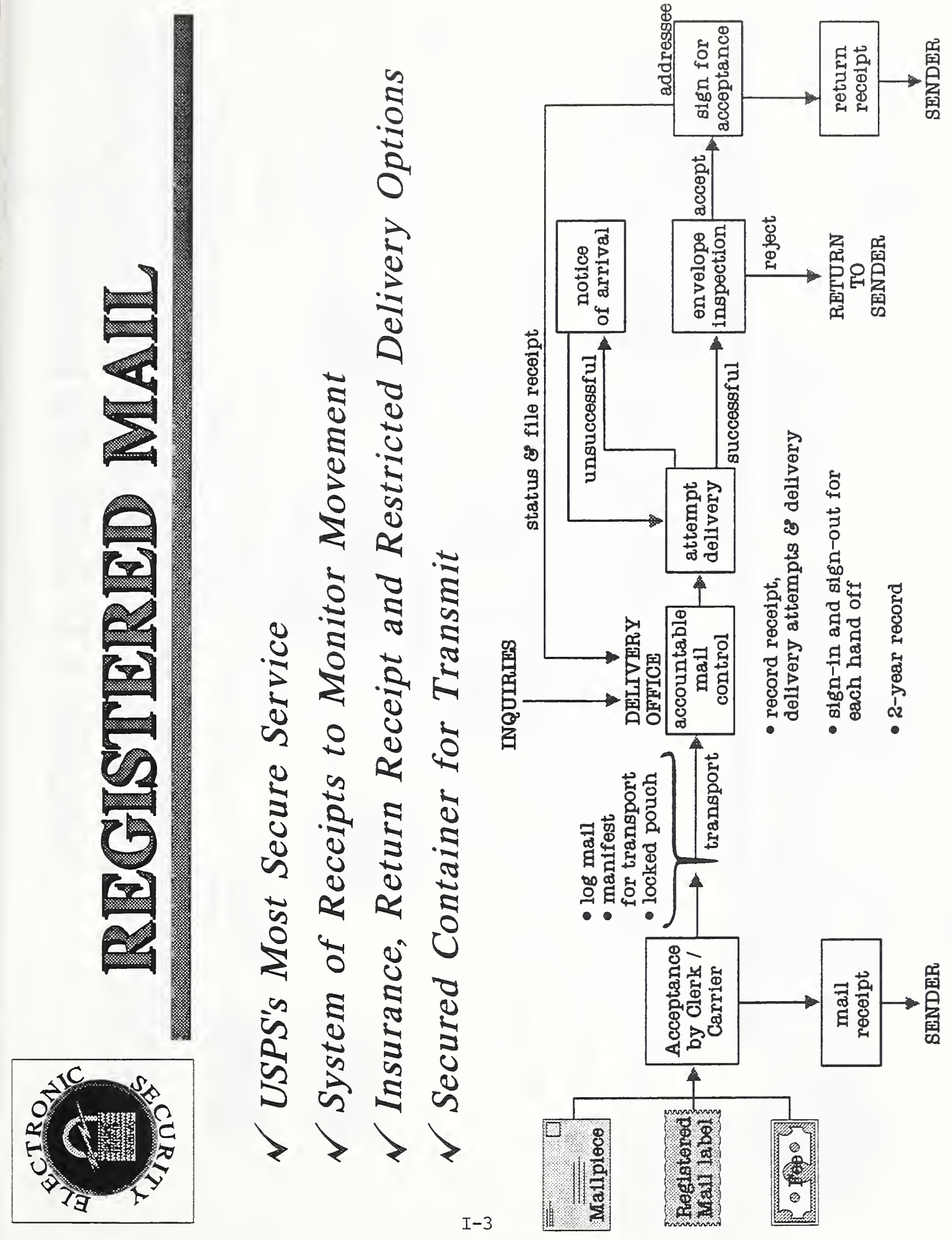




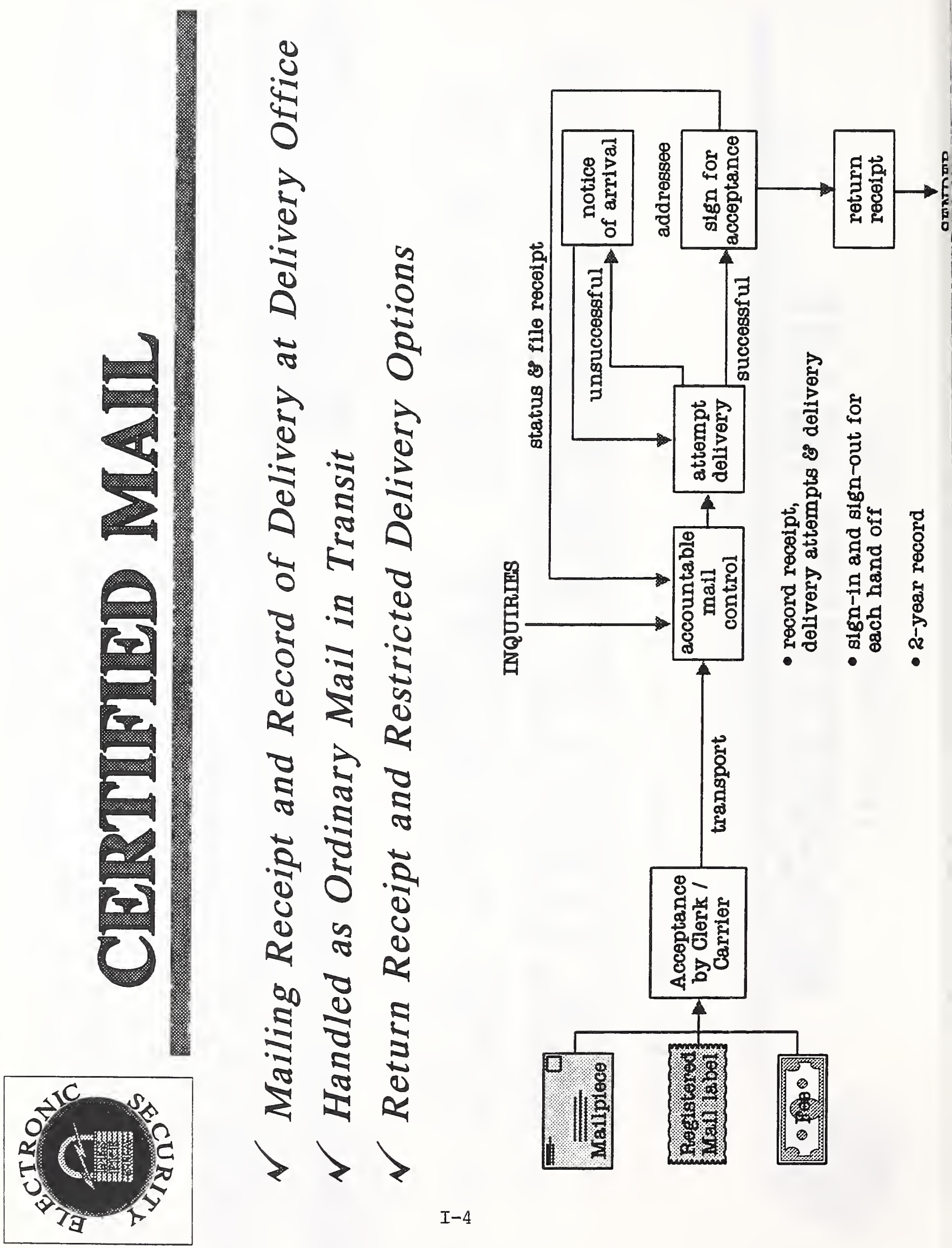



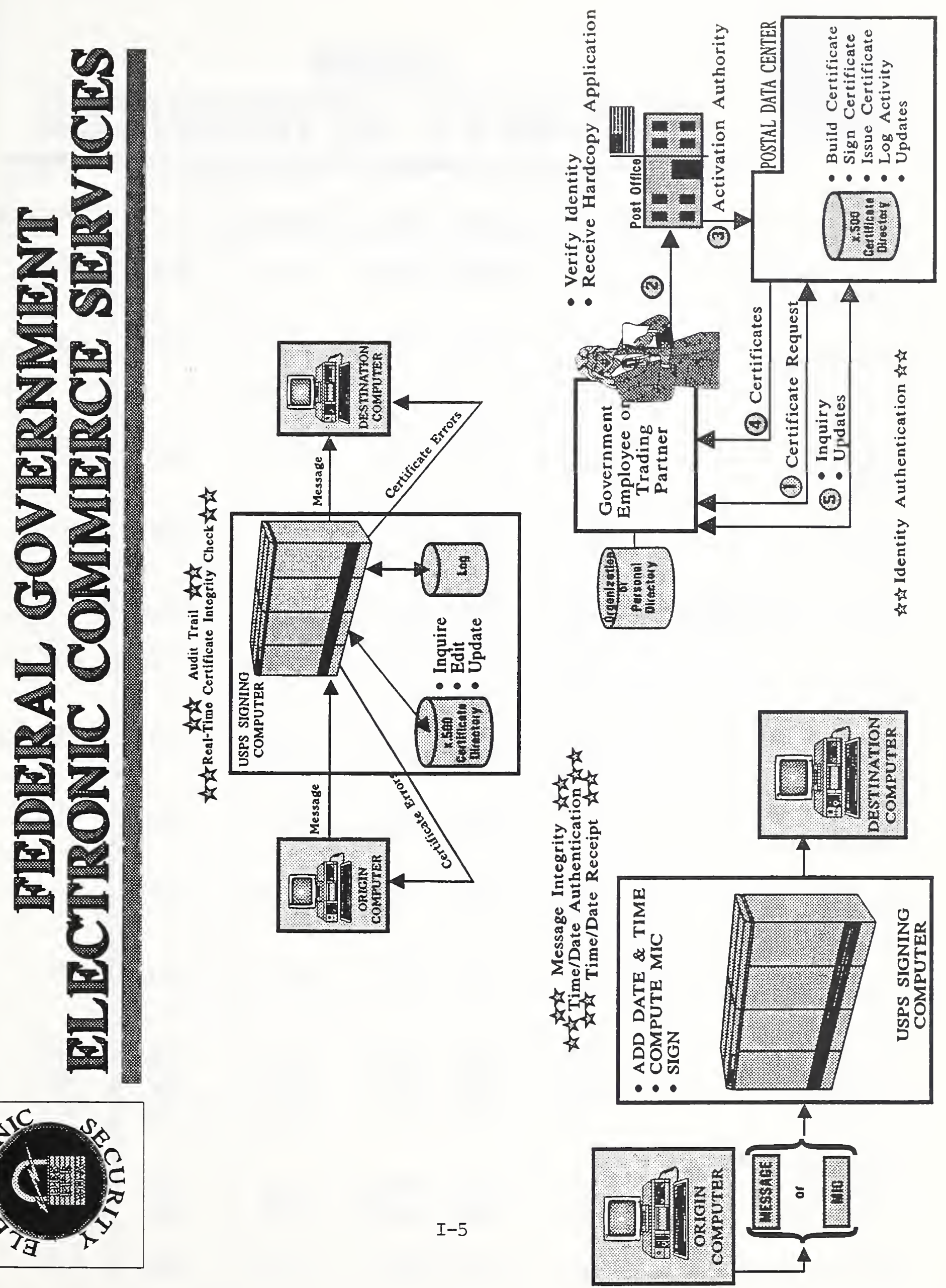

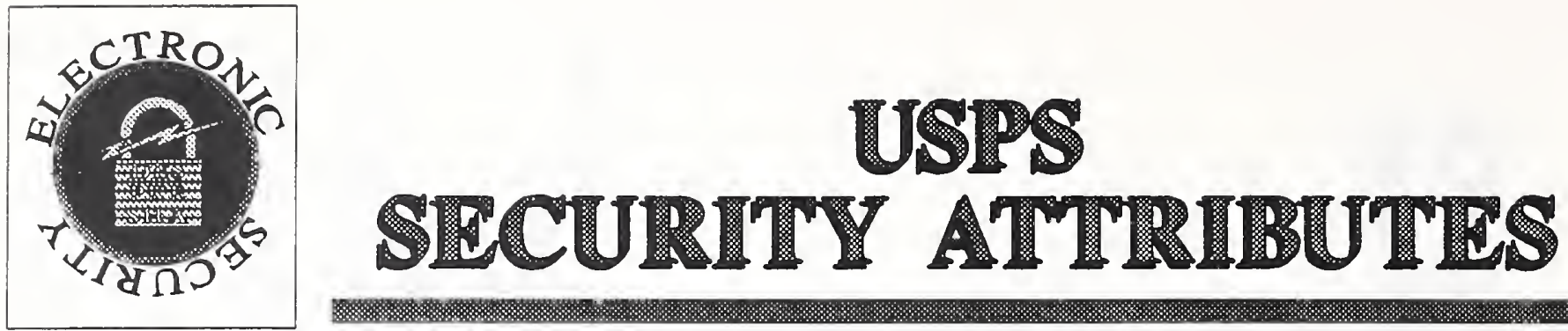

Reg 1C. Regis. Cert. Express Priority Electronic

Control Totals

\& Manifesting

Criminal

Investigations

\& Prosecutions

Delivery

Audit Trail

Delivery

Notification

Employee Screening

Facility

Security

ID Check

for Pick-Up

Machine

Security

Mailbox

Protection

Message Encryption

Sealed

- Envelopes

- Containers

- Transp.

Time/Date of USPS

- Receipt

- Delivery

NO

YES YES YES

NO

NO

YES

YES

YES

YES

YES

$T B D$

NO

YES YES Y YES

NO

YES YES YES

YES

YES

YES

YES

YES

YES

YES

YES

$N / A$

YES YES

YES

NO

YES 
APPENDIX J

AMERICAN NATIONAL STANDARD X9.30-199X WORKING DRAFT

1992 American Bankers Association 
Title: X9-Financial Services

Accredited by the

Dermis Browstaol

American National Standards Institute

WORKING DRAFT

\section{AMERICAN NATIONAL STANDARD \\ $\mathrm{X} 9.30-199 \mathrm{X}$}

PUBLIC KEY CRYPTOGRAPHY USING IRREVERSIBLE ALGORITHMS FOR THE FINANCIAL SERVICES INDUSTRY:

\section{PART 3: CERTIFICATE MANAGEMENT FOR DSA ${ }^{\odot}$}

Price per copy:

Notice -- Warning to readers of this document

This document is in the working document stage. It has not yet been processed through the consensus procedures of $X 9$ and ANSI.

Many changes which may greatly affect the contents can occur before this document becomes an American National Standard. The developmental committee may not be held responsible for the contents of this document as it currently exists.

Implementation or design based on this working paper is at the risk of the user. No advertisement implying compliance with this "Standard" should appear as it is erroneous and misleading to so state.

Copies of the draft proposed American National Standard will also be available from the $X 9$ Secretariat when the document is finally announced for two months public comment. Notice will be issued in the trade press.

Copies of this document are available from the X9 Secretariat at the price listed above. Please send a self- addressed mailing label with your order.

Secretariat: American Bankers Associatio Standards Departmer 1120 Connecticut Ave., N.K Washington, DC 2003

(C) 1992 American Bankers Association All rights reserved 


\section{Contents}

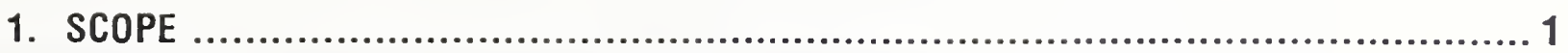

2. DEFINITIONS AND COMMON ABBREVIATIONS .......................................... 1

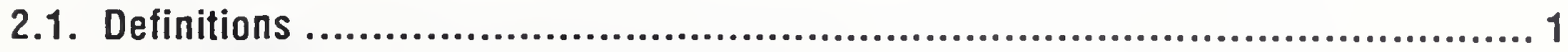

2.2. Common Abbreviations and Acronyms ............................................ 6

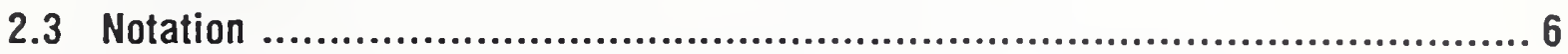

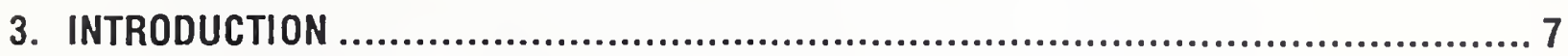

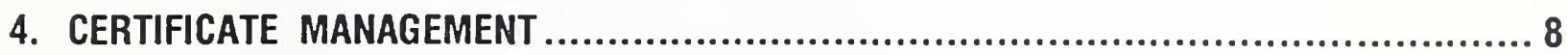

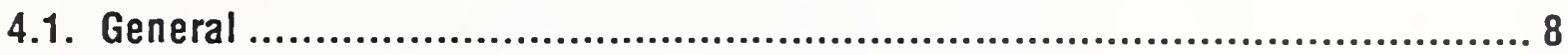

4.2. The Certification Authority (CA) .................................................... 11

4.2.1. Certification Authority Responsibilities ....................................... 11

4.2.2. Distribution of a CA's Public Key ............................................. 11

4.2.3. Security Requirements for a CA's Private Key .............................. 14

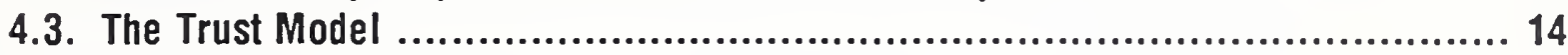

4.5. Certificate Generation ............................................................. 16

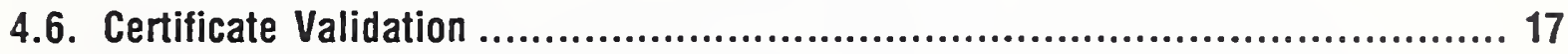

4.7. Certificate Revocation List (CRL) ............................................. 17

4.7.1. General Requirements ...................................................... 17

4.7.2. Revocation of certificates for reasons other than for key compromise, cessation of operations, or a change of affiliation............................ 19

4.7.3. Compromise or suspected compromise of an entity's private key............ 20

4.7.4. Request for Revocation of Entity's Keys Because of a Cessation of Operations. 21

4.7.5. Request for Revocation of Entity's Keys Because a Change of Affiliation of the Entity (E.g., affiliation with a different CA1). ................................. 23

4.7.6. Revocation of Certificates for Public Keys Which Are Used to Protect Symmetric Algorithm Key Exchanges ......................................... 24

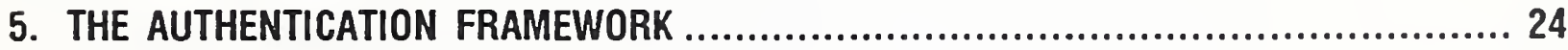

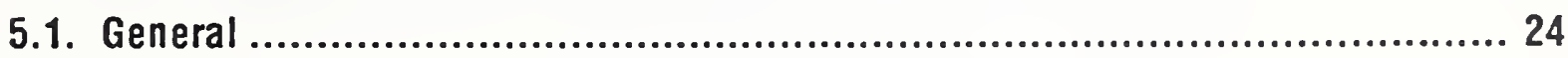

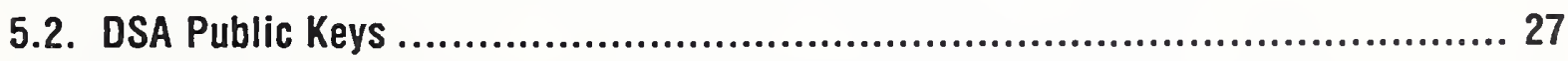

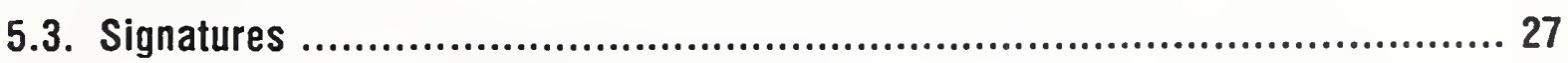

5.4. Certification Request Data (CertReqData) ........................................ 28

5.5. Public Key Certificates ............................................................... 30

5.6. Attributes and Attribute Certificates ............................................... 32

5.6.1. Attributes .................................................................. 32

5.6.2. The Attributes Certificate ..................................................... 34

5.7. Certificate Revocation Lists ....................................................... 35

5.8. Multiple Signatures ................................................................. 36 
5.9. Authentication Without a Common CA ........................................... 40

6. AUDIT JOURNAL REQUIREMENTS ................................................. 47

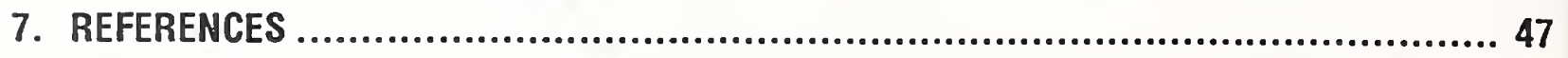

APPENDIX A SUGGESTED REQUIREMENTS FOR THE ACCEPTANCE OF CERTIFICATION

REQUEST DATA .......................................................................... 49

A.1 Acceptance of the Certification Request Data of an Individual ...................... 49

A.1.1 Low Risk Applications ....................................................... 49

A.1.2 High Risk Applications ...................................................... 49

A.2 Acceptance of the Certification Request Data of a Legal Entity ...................... 49

A.2.1 A financial institution in a peer-to-peer relationship ......................... 49

A.2.2 A business customer of a financial institution ............................... 50

A.3 Customer Key Integrity ............................................................ 50

A.3.1 Customer's Undertakings Regarding Key Integrity ......................... 50

A.3.2 Certifying Authority's Integrity Cross-checks .................................. 51

APPENDIX B EXAMPLES OF CROSS CERTIFICATION AND COMMON ANCESTOR ............. 52

B.1 Introduction .................................................................... 52

B.2 Example l: Cross Certification ..................................................... 52

B.3 Example 2: Least Common Ancestor .............................................. 52

APPENDIX C OBJECT IDENTIFIERS AND ATTRIBUTES ..................................... 54

C.1 Object Identifiers ................................................................ 54

C.2 Attributes ......................................................................... 55

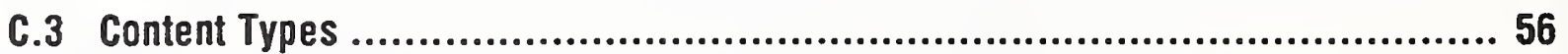

APPENDIX D RECOMMENDED CERTIFICATION AUTHORITY AUDIT JOURNAL CONTENTS

AND USE ............................................................................ 57

D.1. Audit Journal Contents and Protection ............................................... 57

D.1.1 Information to be included in all journal entries ............................ 57

D.1.2 Events to be Journalized ....................................................... 57

D.1.3 Actions to be Journalized ...................................................... 58

D.1.4 Security-sensitive events to be Journalized ....................................58 58

D.1.5 Information, messages and data to be Journalized ........................... 59

D.2. Audit Journal backup ................................................................ 59

D.3. Audit Journal use ..................................................................... 59

APPENDIX E MULTIPLE SIGNATURES ON MESSAGES .................................... 60 


\section{$\mathrm{X} 9.30$}

\section{PART 3: CERTIFICATE MANAGEMENT}

\section{SCOPE}

This Standard defines certificate management and an authentication framework for the financial services industry.

The binding association between the identity of the owner of a public key and that key shall be documented in order to prove the ownership of a public key. This binding is called a "Certificate". Certificates are generated by a trusted third entity known as a Certification Authority (CA).

The structure encompassing CAs and the entities that they certify is called an "Authentication Framework." To ensure interoperability and security, rules, procedures and the functions of the entities and CAs shall be agreed upon and managed.

This Standard specifies the contents of certificates, the credentials required to obtain a certificate, and procedures for certificate generation, validation, and revocation, for Digital Signature Algorithm (DSA) public key certificates. A related standard, X9.31-3, addresses the management of RSA certificates. DSA shall always be used to certify a DSA (or other irreversible algorithm) public key.

It also recommends some useful attributes, encoding schemes, and operational procedures (e.g., distribution mechanisms, and acceptance criteria for submitted credentials).

\section{DEFINITIONS AND COMMON ABBREVIATIONS}

\subsection{Definitions}

Accountability

Asymmetric Key System

Attribute

Attributes Certificate
The property that ensures that the actions of an entity may be traced uniquely to the entity.

A cryptographic algorithm that uses two related keys, a public key and a private key. The two keys have the property that, given the public key, it is computationally infeasible to derive the private key.

Information, excluding the public key, which is provided by the entity or the CA and certified by the CA in an AttributeCertificates. Examples include the CA's liability limitations and binding information.

A set of attributes along with a certificate identifier that is bound to an entity's certificate by the CA. 
Audit Journal

Audit Trail

Data Origin

Authentication

Authorization

Certificate

Certification

Authority (CA)

Certification Path
A chronological record of system activities which is sufficient to enable the reconstruction, review, and examination of the sequence of environments and activities surrounding or leading to each event in the path of a transaction from its inception to output of final results.

See Audit Journal.

Corroboration that the identity of the originator of a data unit is as claimed. Data integrity is implied.

As used in this Standard, authentication shall be by means of a digital signature and certificates or the process of ANSI X9.9-1986 ${ }^{1}$.

The granting of rights.

A certificate contains the public key of a legal entity together with other information. The CA's digital signature renders the certificate unforgeable.

A Center trusted by one or more users to create and assign certificates.

An ordered sequence of certificates of entities which, together with the public key of the initial entity in the path, can be processed to obtain the public key of the final entity in the path.

Certification Request Data The "Certification Request Data" (CertReqData) of an entity includes the entity's public key, entity identity and other information included in the certificate or otherwise used in the certificate management process.

Certificate Revocation List A list of revoked certificates.

Compromise

A violation of the security of a system such that an unauthorized disclosure of sensitive information may have occurred.

Confidentiality

The property that information is not made available or disclosed to unauthorized individuals, entities, or processes.

Cross Certification
Cross certification is used by one CA to certify any CA other than a CA immediately adjacent (superior or subordinate) to it in a hierarchy.

${ }^{1}$ ANSI X9.9-1986, Financial Institution Message Authentication (wholesale) (revised). 
Cryptographic Module

Cryptography

Cryptoperiod

Cryptographic Key (Key)

Cryptographic Keying Material

Data Integrity

Digital Signature

Dual Control
In the X.509 trust model, a CA always certifies its superior and subordinates, and cross certifies other CAs.

The set of hardware, firmware or software or some combination thereof, that implements cryptographic logic, cryptographic processes, or both.

The discipline which embodies principles, means and methods for the transformation of data in order to hide its information content, prevent its undetected modification and/or prevent its unauthorized use.

The time span during which a specific key is authorized for use or in which the keys for a given system may remain in effect.

A parameter that determines the operation of a cryptographic function such as:

1. the transformation from plain text to cipher text and vice versa,

2. synchronized generation of keying material,

3. digital signature computation or validation.

See Keying Material.

Property that data has not been altered or destroyed.

A cryptographic transformation of data which, when appended to a data unit, provides the services of:

1. origin authentication,

2. data integrity, and

3. signer non-repudiation

A process of utilizing two or more separate entities (usually persons), who are operating in concert, to protect sensitive functions or information. Both entities are equally responsible for the physical protection of materials involved in vulnerable transactions. No single person shall be able to access or to utilize the materials (e.g., cryptographic key).

For manual key and certificate generation, conveyance, loading, storage and retrieval, dual. . control requires split knowledge of key among the entities. (Also see Split Knowledge) 
Entity

Financial Message

Forgery

Hash

Hot List

Interoperability

Key

Keying Material

Key Management

Key Pair
A legal entity or an individual. Note that a Certification Authority is an entity.

A communication containing information which has financial implications.

The fabrication of information by one individual, entity or process and/or the claim that such information was received in a communication from another individual, entity, or process.

A (mathematical) function which maps values from a large (possibly very large) domain into a smaller range. A 'good' hash is such that the results of applying the function to a (large) set of values in the domain will be evenly (and randomly) distributed over the range.

A (cryptographic) hash function is a mathematical function which maps values from a large domain into a smaller domain, and has appropriated cryptographic properties (See X9.30-199x: Part 2, Secure Hash Function, Section 3). It may be used to compress a potentially long message in a representative message image ("hash value" or "message digest") sufficiently compact to be input into a digital signature algorithm (e.g., DSA, as defined in X9.30-199x: Part 1, The Digital Signature Algorithm).

See Certificate Revocation List

The ability to exchange keying material, both manually and in an automated environment, with any other entity implementing this standard, providing that both implementations use compatible options of this standard and compatible communications facilities.

See Cryptographic Key.

The data (e.g., keys, certificates and IVs) necessary to establish and maintain cryptographic keying relationships.

The generation, storage, secure distribution and application of keying material in accordance with a security policy.

When used in public key cryptography, a public key and its corresponding private key. 
Keying Relationship

Legal Entity

Message

Module

Non Repudiation

Optional

Originator

Private key

Public Key

Recipient

Repudiation

Security Life

Split Knowledge
The state existing between a communicating pair or between members of a group (logical entity) during which time they share keying material.

A group or area that has legal recognition, e.g., a corporation, labor union, state or nation.

A communication containing one or more transactions or related information.

See Gryptographic Module.

The prevention of the denial by an entity of having participated in a communication, creation, or authorization of some data.

Not required by this standard or not required to meet an optional provision of this standard.

The person, institution or other entity that is responsible for and authorized to originate a message.

In an asymmetric (public) key cryptosystem, that key of a user's key pair which is known only by that user.

In an asymmetric key system, that key of a user's key pair which is publicly known.

The person, institution or other entity that is responsible for and authorized to receive a message.

The denial by a user of having participated in part or all of a communication. See non-repudiation which has the opposite meaning.

The time span over which cryptographically protected data have value.

A condition under which two or more entities separately have key components which, individually, convey no knowledge of the resultant cryptographic key. The resultant key exists only within secure equipment as the automatically generated, exclusiveor'ed result of the full length key components which each individual entered separately and confidentially. 


\section{CERTIFICATE MANAGEMENT}

\subsection{General}

This section defines a CA's controls and other management requirements for a CA and its subscribers. The CA has a public/private key pair and uses the Digital Signature Algorithm (DSA) and the Secure Hash Algorithm (SHA) to produce certificates.

The binding of an entity's public key and identity is verified by using the public key of one or more CAs. The certificate(s) and its validation shall be maintained by the verifier in an audit journal. A CA may issue certificates to entities or other CA's.

Entities or CAs can use these certificates to authenticate themselves to other entities and to CAs. Hence, authentication may involve a chain of certificates. The validator's CA's public key corresponding to the private key used by the validator's $C A$ to sign the end certificate shall be obtained and authenticated by some means other than by the use of certificates. See Section 4.2 and Appendix A, Suggested Requirements for the Acceptance of Certificate Request Data.

Once a certificate has been generated, the integrity of its contents is protected. This Standard does not require that certificates be given confidentiality protection. A valid copy of the CA's public key is required by the verifier in order to validate a certificate. Given the assumption that the $\mathrm{CA}$ is a trusted third entity, this permits the verification of the binding between an entity's public key, its identity and other needed information.

Examples of CA relationships are illustrated in Figures 1 and 2.

Each group (such as a retail credit authorization network, a clearing house, a financial institution or a subgroup thereof) may have its own CA. To make intergroup authentication services possible, CAs shall either have a common CA to authenticate them, or the CAs shall cross certify each other. If a common CA is used, this common CA shall be a mutual point of trust for the entities.

An entity may have one or more valid certificates for backup or transition.

The information which an entity presents to a $\mathrm{CA}$ in order to obtain a certificate is:

- $\quad$ Certification Request Data.

Certification Request Data includes the entity's public key, identity and other information used in the certificate management process. 


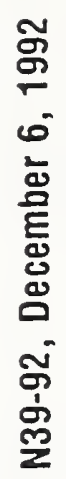

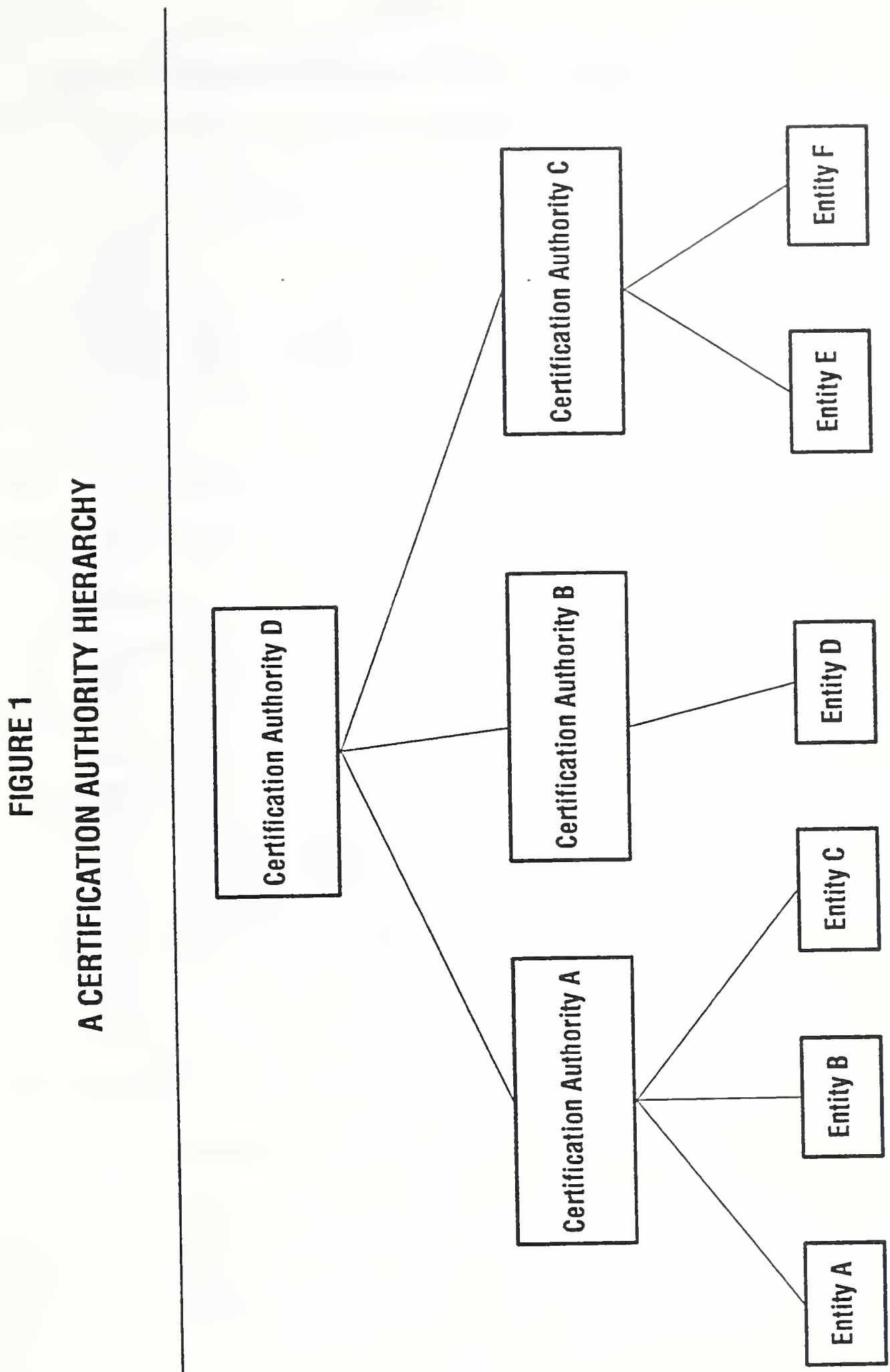




\section{FIGURE 2}

\section{A NON-HIERARCHICAL CERTIFICATION AUTHORITY CHAIN}

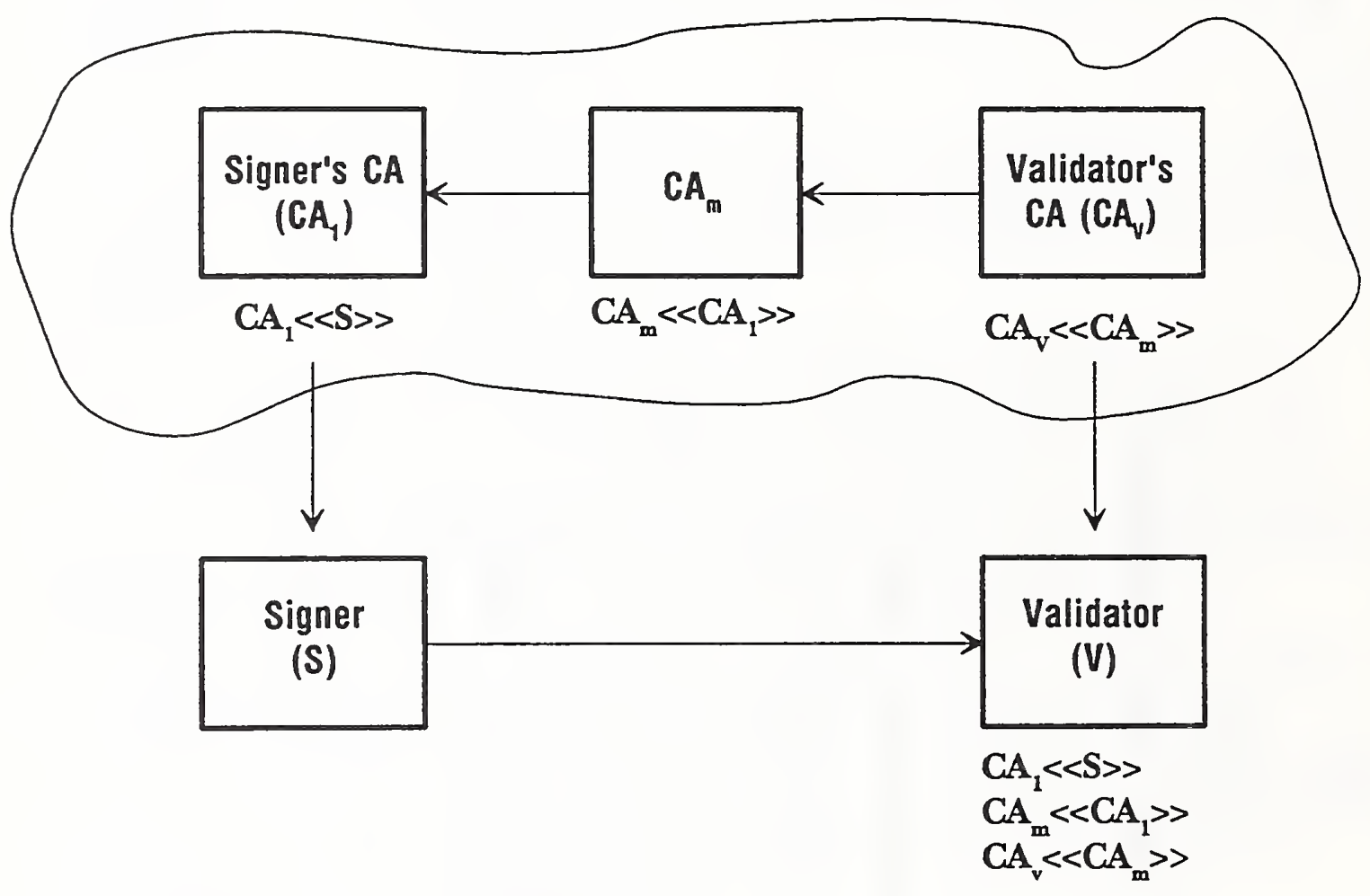

- V starts with an authenticated copy of the public key of $\mathrm{CA}_{\mathrm{v}}$

- $\quad \mathrm{V}$ checks the signature of $\left.\mathrm{CA}_{v}<<\mathrm{CA}_{\mathrm{m}}>\mathrm{CA}_{\mathrm{m}}<<\mathrm{CA}_{1}>\mathrm{CA_{1 }}<<\mathrm{S}\right\rangle>$ 
- additional data required for identification

See Appendix A.

The CA issues a certificate containing an entity's public key and any other information added by the CA (See Section 5.5.5). The binding of the entity's public key to its identity is accomplished by having the CA generate the certificate, thereby attesting to the relationship of the information therein and ensuring its integrity.

Each entity shall generate its own public/private key pair(s) and shall be responsible for the quality of that key pair and for ensuring the privacy and integrity of the private key. The CA shall be responsible for the certification process.

\subsection{The Certification Authority (CA)}

\subsubsection{Certification Authority Responsibilities}

The Certification Authority shall be solely responsible for:

1. Verifying the identity of the entity requesting a certificate.

2. Securing the certification process and the private key used to generate the certificate.

3. Advising the entity identified in the certificate that a certificate has been issued. The means used to convey this advice shall be independent of the method used to convey the certificate to the entity.

4. Ensuring that certificates are not issued to two different entities with the same entity name.

Appendix A contains suggested requirements for the acceptance of Certificate Request Data. See Section 6 for audit journal requirements.

\subsubsection{Distribution of a CA's Public Key}

\section{a. General}

The integrity of a CA's public key is essential. When a hierarchy or chain of CAs is employed, the integrity of the hierarchy or chain depends on the integrity of the public key and confidentiality of the private key of every CA in the certification path. It is the responsibility of the CA to:

1. distribute its public key, validity period and the unique identity corresponding to $\mathrm{Xp}$, and

2. ensure the integrity of that key during distribution, or 
3. to provide a mechanism for detecting its modification during the distribution process.

As in the case of the delivery of Certificate Request Data, a digital signature may be used to detect errors in the distribution process.

It is the responsibility of each entity to ensure that:

1. it possesses and uses the correct $\mathrm{CA}$ public key, and

2. that the integrity of the CAs public key is maintained once acquired.

Multiple public keys, each corresponding to a CA's public/private key pair, may be distributed to provide for replacement of a public key upon the expiration of the cryptoperiod of a given public/private key pair and for backup and recovery purposes.

CA public keys stored in such local caches should be protected against accidental or deliberate modification by either a digital signature or a Message Authentication Code ${ }^{3}$.

\section{b. Certified Delivery of a CA's Public Key}

A CA's public key may be distributed using one or more of the following certified methods:

1. Direct electronic transmission from the root $\mathrm{CA}$, or retrieval from a remote cache or directory service

a) If an entity has an authenticated copy of a currently valid public key of the $C A$, say $\mathrm{CA}_{\mathrm{n}} \mathrm{p}$ :

(1) a new public key, $\mathrm{CA}_{\mathrm{mP}}$, may be sent by the $\mathrm{CA}$ to the entity by electronic transmission,

(2) the message transmitting $\mathrm{CA}_{\mathrm{mP}}$ shall be signed by the $\mathrm{CA}$ using $\mathrm{CA}_{\mathrm{n}} \mathrm{s}$, and

(3) on receipt, the entity shall authenticate the received public key, $\mathrm{CA}_{\mathrm{mP}}$ using $\mathrm{CA}_{\mathrm{n}} \mathrm{P}$

An authenticated public key is a public key which was obtained from a certificate validated as described in Section 4.6, or a public key distributed as described in this Section 4.2.2.

${ }^{3}$ ANSI X9.9, OpCit. 
b) If an entity does not have an authenticated copy of a currently valid public key of the $\mathrm{CA}$, that entity may obtain a copy when applying for a certificate. The $\mathrm{CA}$ 's public key $\left(\mathrm{CA}_{\mathrm{nP}}\right)$ should be transmitted using a machine readable media. The delivery of the media (when used) shall be authenticated.

c) If the CA's key is contained in a certificate in a path, the initial certificate in a path shall be validated via a public key which is not contained in a certificate. The validator shall ascertain that the public key is currently valid.

2. From a remote cache or directory service

If an entity has an authenticated copy of a currently valid public key of the $C A$, say $\mathrm{CA}_{n} \mathrm{P}$ :

a) the entity may request a new public key, $\mathrm{CA}_{\mathrm{mP}}$ from a remote cache or directory service,

b) the message transmitting $\mathrm{CA}_{\mathrm{mP}}$ shall be signed by the $\mathrm{CA}$ using $\mathrm{CA}_{n} \mathrm{~S}$, and

c) on receipt, the entity shall authenticate the received public key, $\mathrm{CA}_{\mathrm{mP}} \mathrm{u}$ using $\mathrm{CA} \mathrm{nP}$, or

\section{c. Trusted Delivery of a CA's Public Key}

The CA's public key may be embedding in a cryptographic module (module) in equipment prior to shipment.

1) If an entity has an authenticated copy of a currently valid public key of the $C A$, say $\mathrm{CA}_{\mathrm{n}} \mathrm{p}$ :

a) A new public key, $\mathrm{CA}_{\mathrm{mP}}$ shall be signed by the $\mathrm{CA}$ using $\mathrm{CA}_{\mathrm{n}}$ s. The $\mathrm{CA}_{\mathrm{mP}}$ and the signature shall be loaded in the module in a secure environment and under appropriate controls and procedures before the module or the equipment containing the module is distributed, and

b) on receipt, the entity shall authenticate the received public key, $\mathrm{CA}_{\mathrm{mP}}$ using $\mathrm{CA} \mathrm{nP}$, or

2) If an entity does not have an authenticated copy of a currently valid public key of the CA, the distribution of the equipment or other medium shall be authenticated. 


\section{d. Extraction of a CA's Public Key From a Certification Path}

A CA's key may be contained in a certification path, in which case it may be validated using the public key from the previous certificate in the path. The initial certificate in a path is validated by a public key which is not contained in a certificate, and may be distributed by one of the methods described above. The validator shall ascertain that this public key is currently valid.

Figure 3 Summarizes the above methods of distributing a CA's public key.

\subsubsection{Security Requirements for a CA's Private Key}

Since the certificate generated by a CA shall be used to provide proof of the identity and integrity of the entity's public key, the CA shall be implemented in a cryptographic module not controlled or accessed by any subscribing entity. Since the cryptographic module employs the private key of the CA which issues the certificate, this key shall be given a high level of protection since its possession would enable an intruder to masquerade as the $\mathrm{CA}$ and generate forged certificates. This private key shall be generated internally to the cryptographic module in which it shall be used. It shall never appear outside of that cryptographic module in any form (plain text or enciphered). The cryptographic module shall afford level 4 protection ${ }^{4}$ to private keys.

\subsection{The Trust Model}

The Certification Authority is "trusted" by its subscribers. Such trust is based on the use of:

- cryptographic module designed to meet the requirements for financial institution use,

- sound management and control practices that are confirmed by an independent audit function (internal, external or both) which shall report audit results to the subscribers.

A C25 level of functionality is recommended.

1. A subscriber trusts all certificates issued by its CA;

2. If a subscriber's CA issues a certificate whose subject is another $\mathrm{CA}$, then the subscriber trusts all certificates issued by that other $\mathrm{CA}$,

3. A CA is trusted:

a)

to certify its subscribers

${ }^{4}$ As defined in draft Federal Information Processing Standard 140-1.

${ }^{5}$ As defined in CSCSTD-001-83, Department of Defense Trusted Computer System Evaluation Criteria, August 15, 1983. 


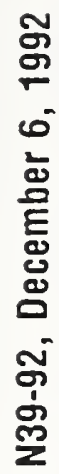
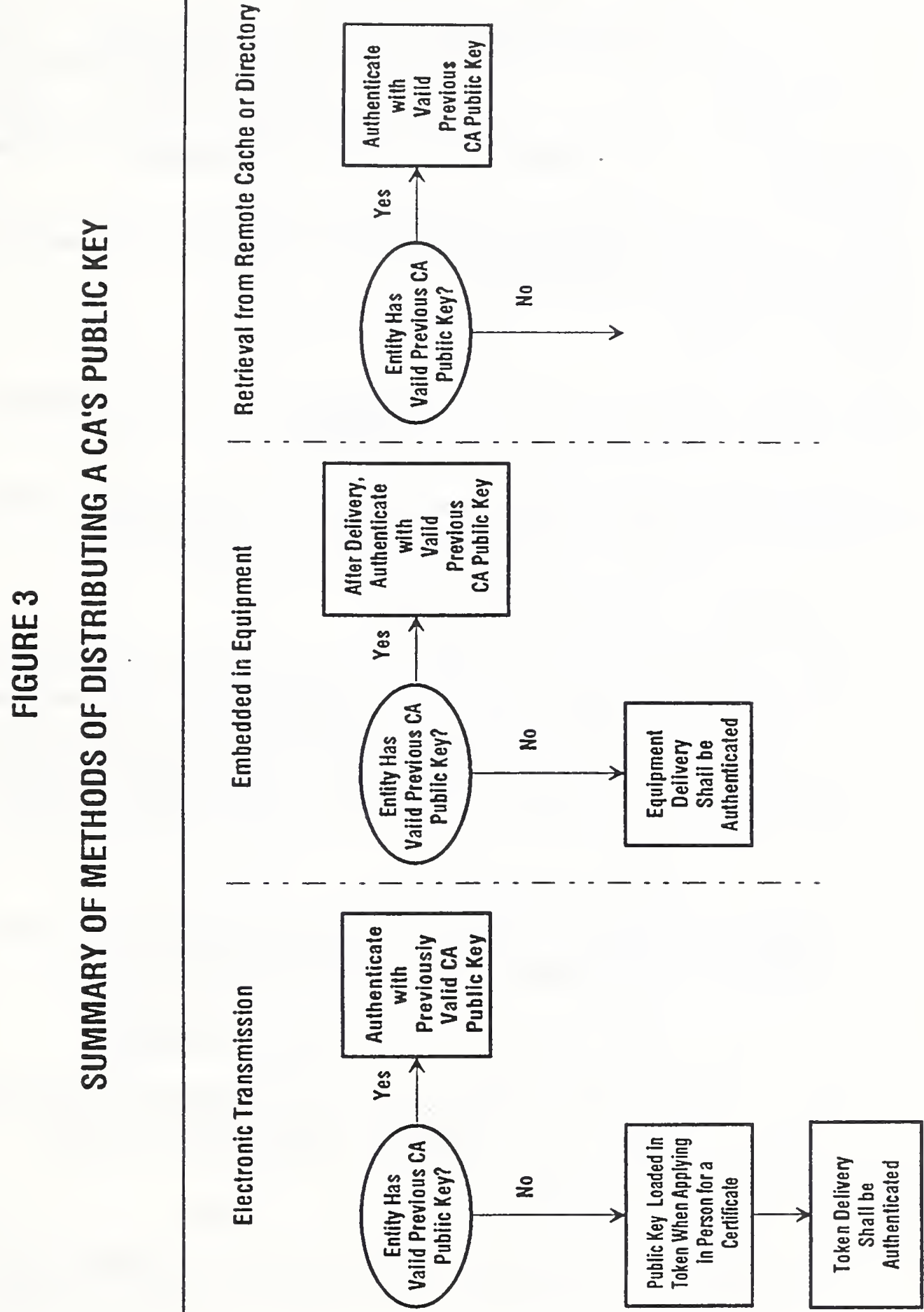

13 
b) in the case where the CA is in a hierarchy, to certify CAs, if any, immediately adjacent to it (either superior or subordinate) in the hierarchy,

c) optionally, to cross-certify other CAs

4. A CA may be trusted to cross-certify other CAs not adjacent to it in the hierarchy.

Requirements for cross certification may be more stringent than for normal certification.

Examples illustrating this model are contained in Section 5.10. Other trust models are discussed in Appendix B.

\subsection{Certificate Generation}

The certificate generation process shall take place prior to the signing and sending of financial transactions or other messages.

Generation of a certificate is a five-step process. The following is an overview of the process with references to pertinent sections in this Standard.

1. Preparing Certificate Request Data

The Certificate Request Data shall be prepared by the entity requesting a certificate. The entity shall use a digital signature to allow the detection of errors in the certificate application process. The private key used for signing the Certificate Request Data shall be that corresponding to the public key in the Certificate Request Data. See Section 5.4, below.

2. Accepting Certificate Request Data

Suggested requirements for accepting Certificate Request Data are contained in Appendix A. See also Section 5.4, below.

3. Checking Certificate Request Data for errors and changes

The CA shall use the public key contained in Certificate Request Data to verify the signature on the Certificate Request Data submission.

4. Generating the certificate.

The certificate contains the Certificate Request Data, information provided by the Certification Authority, and the signature. See Section 5.5.

In high risk financial applications, two signatures from independent ${ }^{\circ}$ cryptographic facilities may be used to ameliorate the risk in the event that the private key of a CA is compromised. See Section 5.9.

$$
\mathrm{J}-18-16-
$$


5. Creating the Audit Journal entry.

Actions of the $\mathrm{CA}$ in the certificate generation process shall be journalized See Section 6, below.

Figure 4 summarizes the certificate generation process.

\subsection{Certificate Validation}

To validate a certificate, the receiving entity:

1. obtains the certificate of the sending entity and any CA certificates in the certification path from the sender to the recipient from:

- the sending entity,

- a Directory Service or

- a local cache.

2. checks the validity of the certificates (see Section 5.10), This implies loose synchronization and secure maintenance of the clocks of the sender, recipient and all CAs in the path.

3. checks the Certificate Revocation List, and

4. verifies the CA's signature on all certificates in the certification path (see Section 2.3).

\subsection{Certificate Revocation List (CRL)}

\subsubsection{General Requirements}

A certificate has a lifetime which is indicated by a validity period stated in the certificate or is otherwise defined by the CA's management (such as the expiration date of an IC $\left.\operatorname{card}^{6}\right)$. Certificates may only be revoked prior to their scheduled expiration by the CA that issues the certificate. This may occur for a number of reasons, including:

- compromise or suspected compromise of an entity's ${ }^{7}$ private key,

- cessation of operations,

- change of affiliation of an entity (E.g., affiliation with a different $C_{1}$ ), or

${ }^{6}$ An Integrated Circuit Card (IC card) is often referred to as a "Smart Card."

The entity may be a CA. 


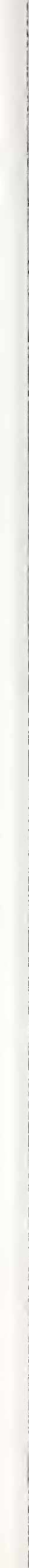




\begin{abstract}
APPENDIX $\mathrm{K}$
CONTRIBUTION TO THE

WORKSHOP ON ELECTRONIC SIGNATURES
\end{abstract}

George Papapavlou

Brussels, 1 December 1992 
The main purpose of this brief contribution is to argue in favour of the inclusion of criminal law considerations in the future work both on information security, in general, and electronic signatures, in particuiar. In the 10 minutes I have at my disposal this has to be done in a telegraphic way. Essentially I will give very brief answers to the following questions:

1) What is computer related crime?

2) What is the relevance with electronic signatures?

3) What is the relevance with information security?

4) What has been done sofar in the Member States and in the Community?

5) What an be done in the furure?

1) What is computer related crime?

There is no single definition of this concept. I may use the OECD definition "computer abuse is considered as any illegal, unethical or unauthorized behaviour relarisg to the automatic processing and the transmission of datan or a senior expert's definicion "any illegal action in which a computer is a tool or object of the crime". What is more inportant is to understand that the computer today offers some highly sopinisticated opportunities for law-breaking.

A recent Council of Europe report distinguishes twelve different conputer related illegal acts: computer related fraud; computer forgery; damage to computer data or programs; computer sabotage; unauthorized access; unauthorized interception; unauthorized reproduction of a protected computer program; mauthorized reproduction of a topography; alteration of computer data or computer programs; computer espionage; unauhorized use of a computer; unauthorized use of a protected computer program.

As there is a known difficulty with reporting such illegal acts to the police and going to courh estimates of losses suffered differ widely. There is no doubt, however, thar we are talking of a problem with serious economic, social and strategic dimensions. 
Two of the illegal acts I mentioned, computer related fraud and computer forgery have a clear relationship. Any manipulation of an electronic signature oi any form would fall under the one and/or the other of these acts. Compurer related fraud is defined by the COE 1990 report as "the input, alteration, erasure or suppression of computer data or computer programs, or other interference with the course of data processing, that influences the result of data processing, thereby causing economic or possessory loss of property of another person with the intent of procuring an unlawinl economic gain for himself or for another person". Compurer forgery is derined as "the imput, alteration erasure or suppression of computer data or computer programs, or other interference with the course of data processing, in a manner or under such conditions, as prescribed by national law, that it would constinte the offence of forgery if it had been committed with respect to a traditional object of such an offence".

3) What is the relevance with information security?

I think this is very dear. It is like the relationship berween criminal law propisions on theft and a lock or alarm system to prevent thef. Techoical security measures are necessary but not sufficient Legal measures, in the form of criminal law, are also required to act both in a preventive and in a repressive way. It is clear that technical or orgarizational and other practical measures have to be taken to prevent the illegal acts I listed before. It has to be made clear, however, that these are illegal acts punishable by law. I don't think I need to argue this point any further.

4) What has been done sofar internationally, in the Member States and in the Community?

Efforts aiming at better protection of computer related economic values started not with criminal but civil law provisions in the context of topography and computer programs. Criminal law provisions were first introduced in the seond half of the 1980s.

I will of course, refer to some importane developments only: Internationally there have been 5 Ho important initiatives, both of a non-legally binaing narre. In September 1989 the Council of Europe Comminee of Miristers adopied Recommendation $N^{\circ} R(89) 9$ by which it asked Member states to take into account when reviewing their legisiation or initiating new legislation, the report on computerrelated crime (that I referred to already) and to report to the S.G. of the C.OE during 1993 on any relevart developments in their legislation, judicial practice and experiences of international legal co-operation. The report concerned not only inciudes detailed description and analysis of the various illegal acts that should be included in narional subsiantive penal laws but also has an analysis of the very important issue of procedural law and international cooperation which are necessary if substantive law provisions are to become effective.

In September 1992 the OECD - at the level of experts - finalized Guidelines for the Security of Information Systems and a relevant draft recommendation of its Council of Mrnisters. The guidelines include reference to the adoption of appropriate policies, laws, decrees, rules and international agreements, including provision for penal, administrative or other sanctions for misuse of information systems; jurisdictional competence of courts including rules on extraterritorial jurisdiction, and administrative competence of other bodies; murual assistance, exrradition and other internarional cooperation in penal matters; and means of obtaining evidence in information systems and the admissibility of such evidence in penal and non-penal legal and administrative proceedings.

$$
\mathrm{K}-3
$$


Af the level of national legisiation most Community Member States have adapted their penal laws in some way in order to deal with computer-related criminal acts (examples: the Danish 1985 "penal code amendment act", the German 1986 "second law for the prevention of economic crimes"; the French 1988 "loi sur la fraude informatique" and the UK 1990 "Compurer Misuse Act)".

Due to obvious competence questions no specific penal Iaw measures have sofar been taken by the Community. In the context of the rarious legal issues identified in relation with the MMPACT programe on the information services market computer related crime has been srudied in 1987 and discussed in 1988 with our group of legal experts called the LAB but no decisions on further acrion were taken because of the competence questions I mentioned but also because of other urgent priorities.

Moreover, in March 1990 the Commission organized a 2-day conference in Luxembourg, jointly with the Council of Europe, part of which was dedicated to the issue of cumputer related crime.

5) What can be done in the future?

Since 1987 when we first studied this problear, a number of things have happened which in my view, justify its reexamination.

a) The two international initiatives, COE report and OECD Guidelines, that I have referred to already. In addition, since September, the COE has reopened this dossier by starting discussions on the issue of penal procedure and intemational cooperation;

b) the gradually increasing awareness of this problem by Community Member States most of which - if not all - have introduced relevant provisions in their penal laws;

c) two Councli direcrives - insider trading and money laundering - which include linited - penal provisions;

d) initiatives taken to combat fraud against the Community (DG XX);

e) the Maastricht Treaty in its article $\mathrm{K} 1$ provides for a number of issues on which legal cooperation among Member States will have to be increased. These inciude the combat of intermational - scale frand, judicial cooperation in civil and peral matters and police cooperation for combatting (among other things) serious forms of international crime;

D) Last but not least, the Information Security action plan (INFOSEC), adopted by Council last March, makes references to action also in the legal field.

All these developments indicate that there is now much more room for Community involvement in the field of computer related crime Of course, the Community has no competence to propose specific penal sancrions. Moreover the debate following the Maastricht Treaty Danish and French experiences has led to more emphasis being given to the so-called subsidiarity principle. Be that as it may, I think a number of Commanity-level actions could still be considered.

I will give some ideas starting with the minimalist and ending with the maximalist approach.

First computer telated crime in its different aspects (substantive law, procedural law, training and awareness, etc.) should be inciuded in the legal issues to be examined in the context of the information security action plan. One or more meetings with $\mathrm{K}-4$ 
Member States Ministry of Justice officials could be organized to have an exchange of views and precise information on the current situation in each Member State.

Second, once the Maastricht Treaty is ratiffed, and the modalities of closer judicial and police cooperation are established, it should be emphasized to the appropriate Commission services and to the Member States that such cooperation should also cover computer related crime, by nature often of an international nature and requiring particulariy quick and effective cooperation procedures. It might be useful to establish a link with the relevant work currently undertaken in the Councli of Europe. We will follow developments there but it might also be useful if SOGIS members take direct contact with their officials attending the COE meetings.

Third, information awareness and training initiatives may be undertaken, in parallei with similar initiatives concerning security. DG XIII has made a short study and conld propose a number of such iniriatives.

Fourth, it is certain that the Community does not have a competence to propose specific penal sanciions. What it could do, if it was considered necessary, is list a number of actions related to data processing that would not be allowed, and ask Member States to provide for effective sanctions. In addjion establish a mechanism for effective isvestigation and copperation among Mernber States. This has been done in the contexr of the money laundering and insider trading directives. I am nor proposing this at this tage. When we first studied the problem there did seem to be serions gaps in the laws of certain Member States. This seems to be less the case now with the recent adaptations of penal laws. First we need precise up to date information in order to see if there is still a need for encouraging penal sanctions. Effective procedural and mutul cooperation measures, however, certainiy need to be seriousiy considered. 



\begin{abstract}
APPENDIX L
VIEWGRAPHS PRESENTED AT

NIST SYMPOSIUM ON APPLICATIONS

OF THE DIGITAL SIGNATURE STANDARD
\end{abstract}

Stephen Kent

BBN Communications 
The following set of viewgraphs were prepared by Dr. Stephen Kent, BBN, and presented at a NIST Symposium of Applications of the Digital Signature standard. This Symposium was held in February, 1993. Since the viewgraphs reflect some of the discussion of the workshop and the results of the workshop, they are included in the report of the workshop. However, they were prepared subsequent to the workshop and hence are not officially a part of the proceedings summary.

Dennis Branstad, Editor 


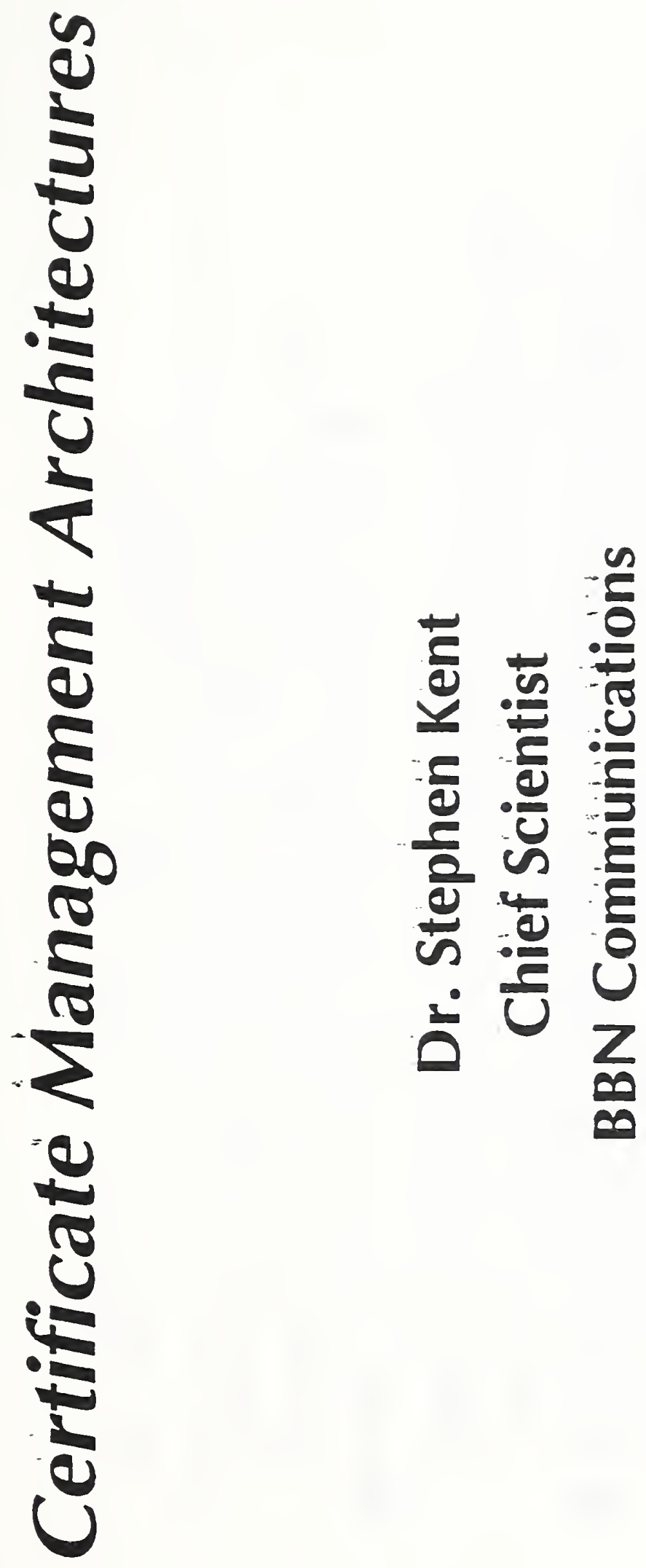




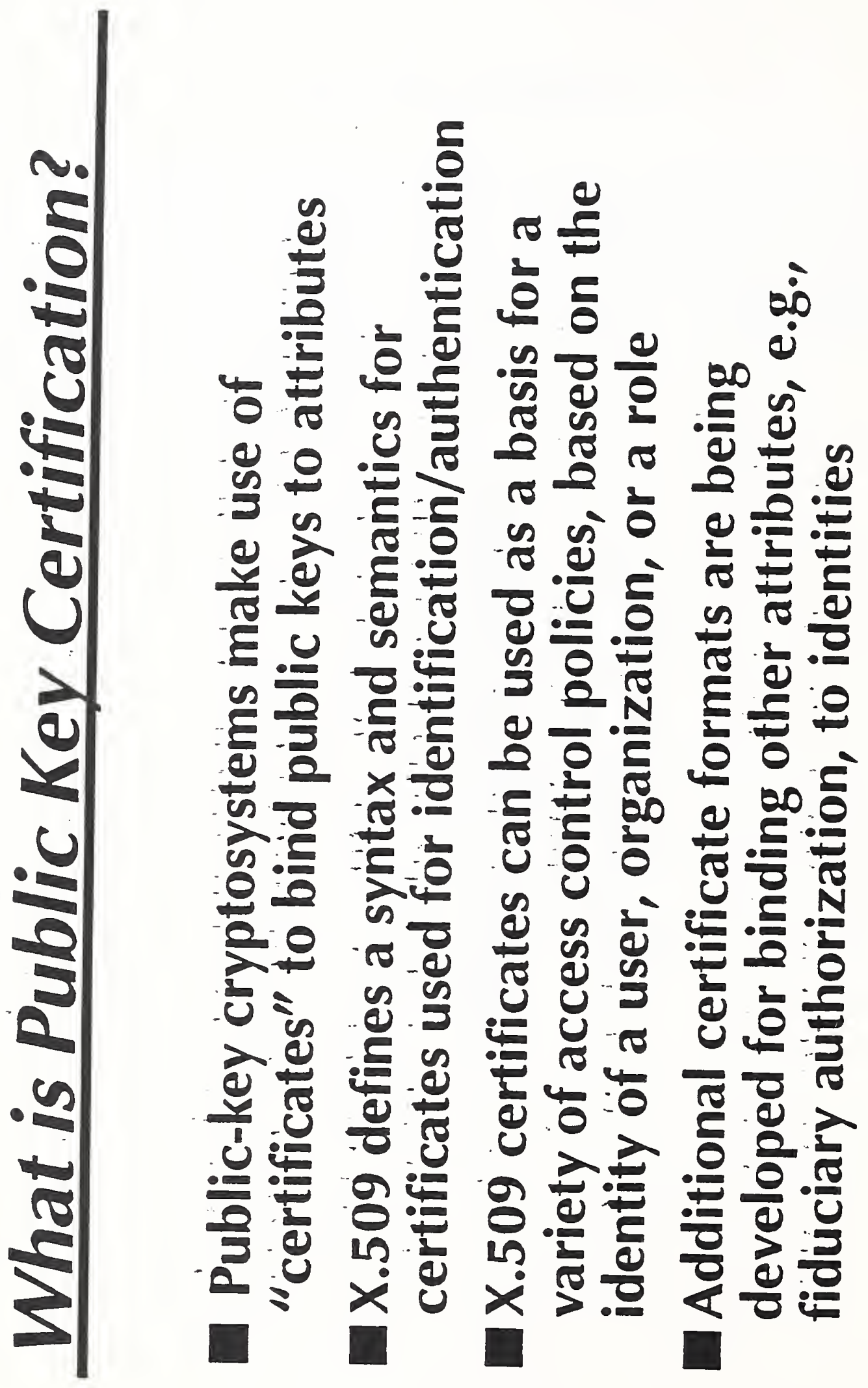




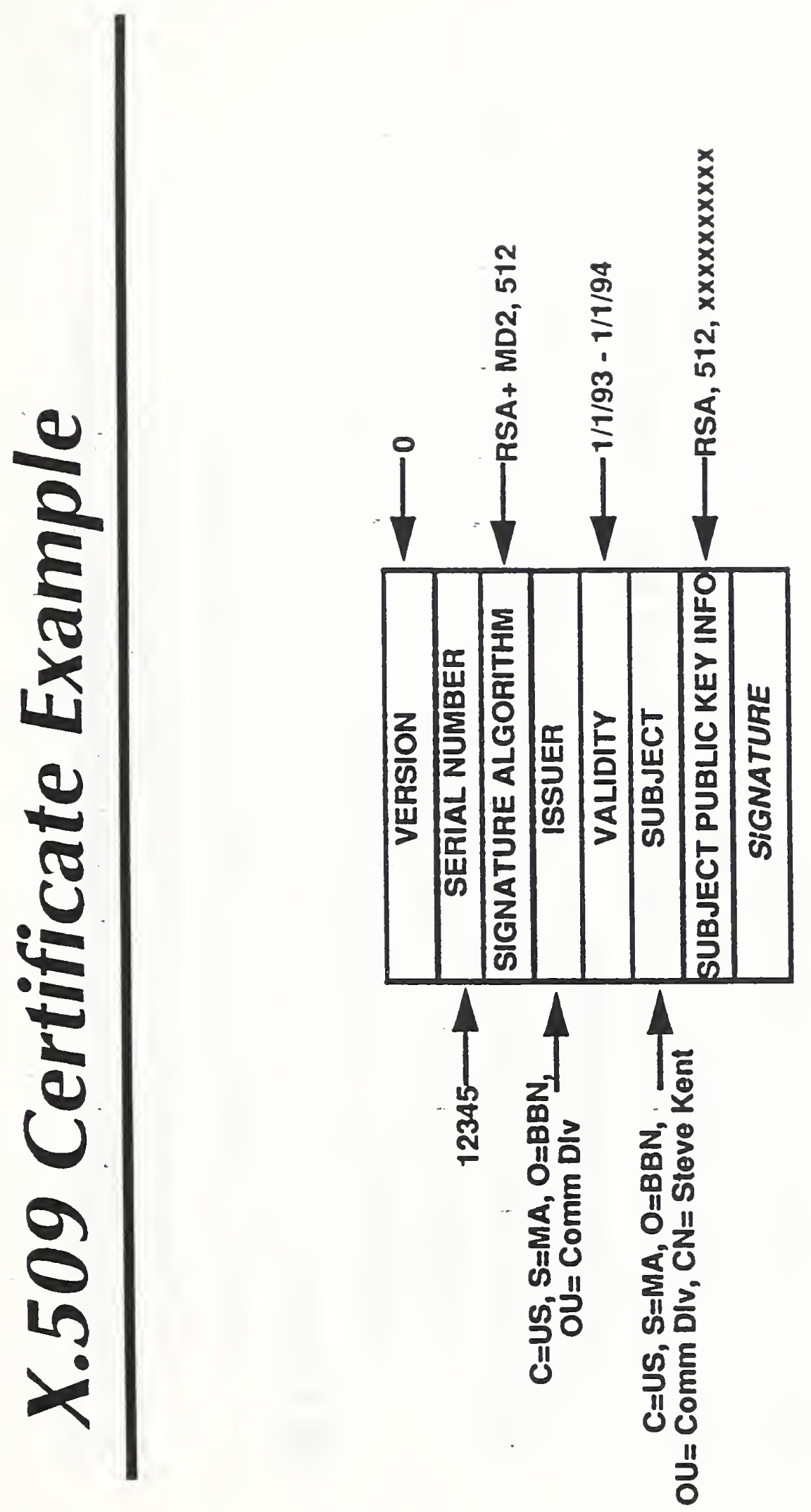




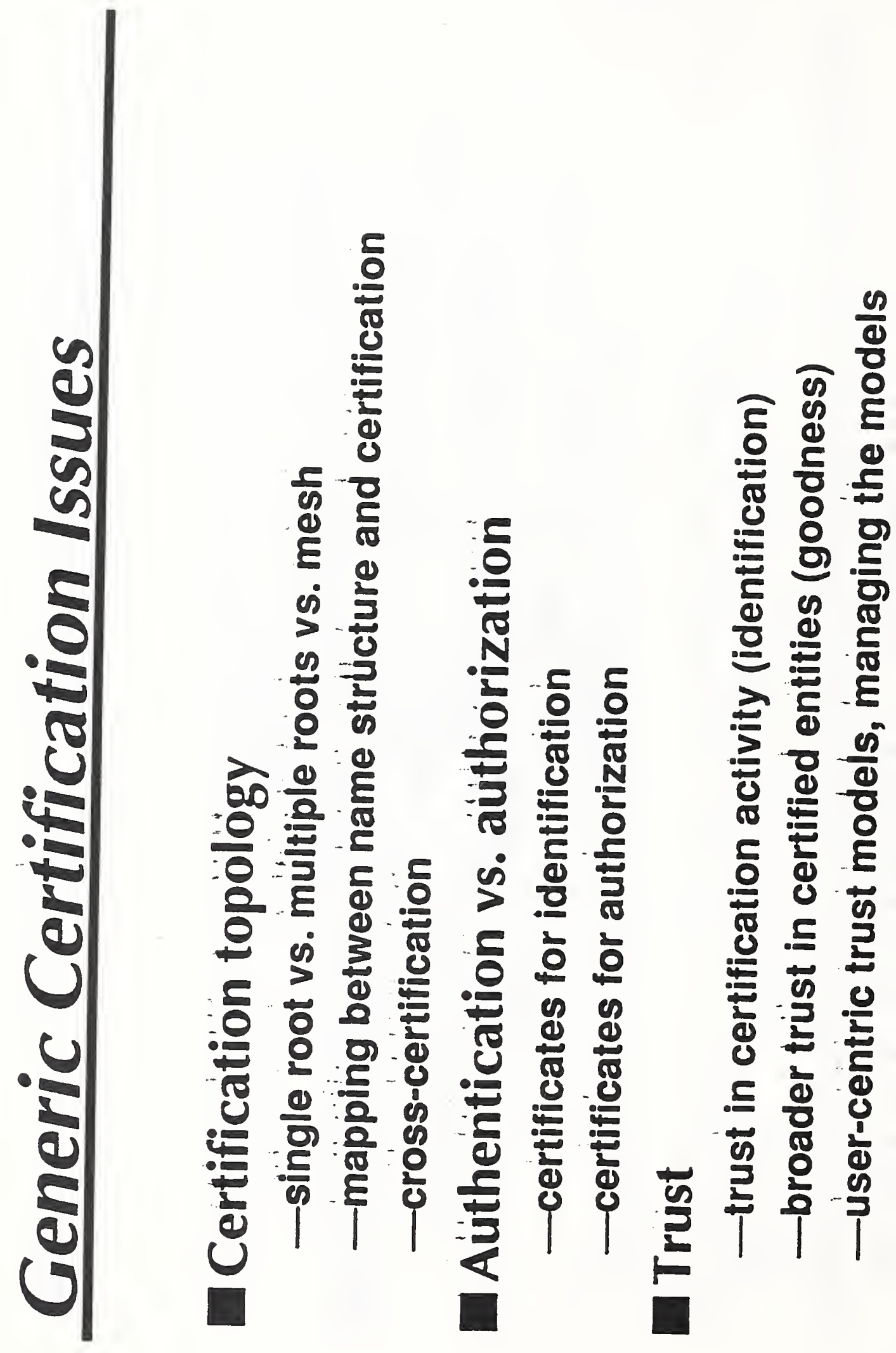




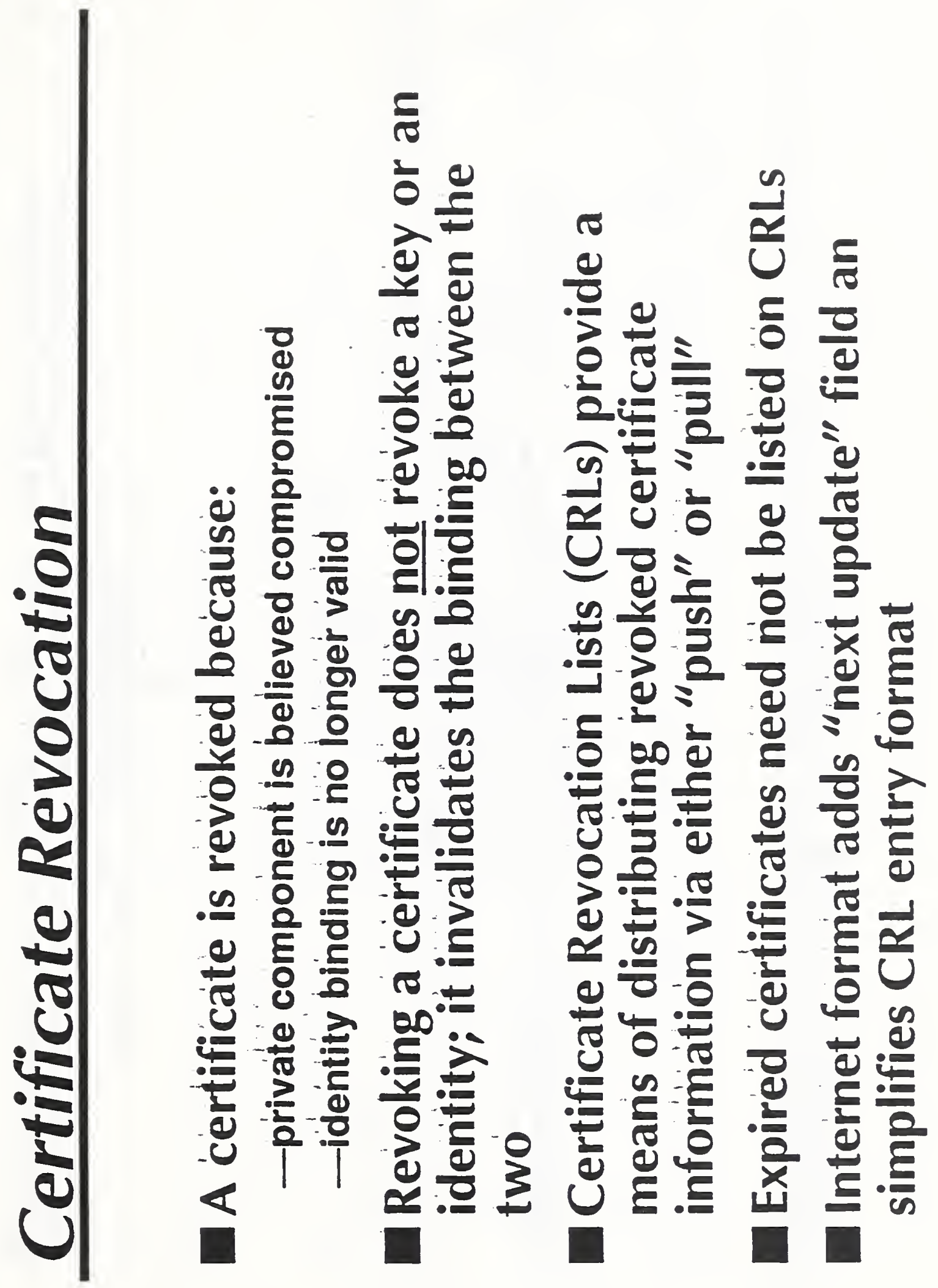



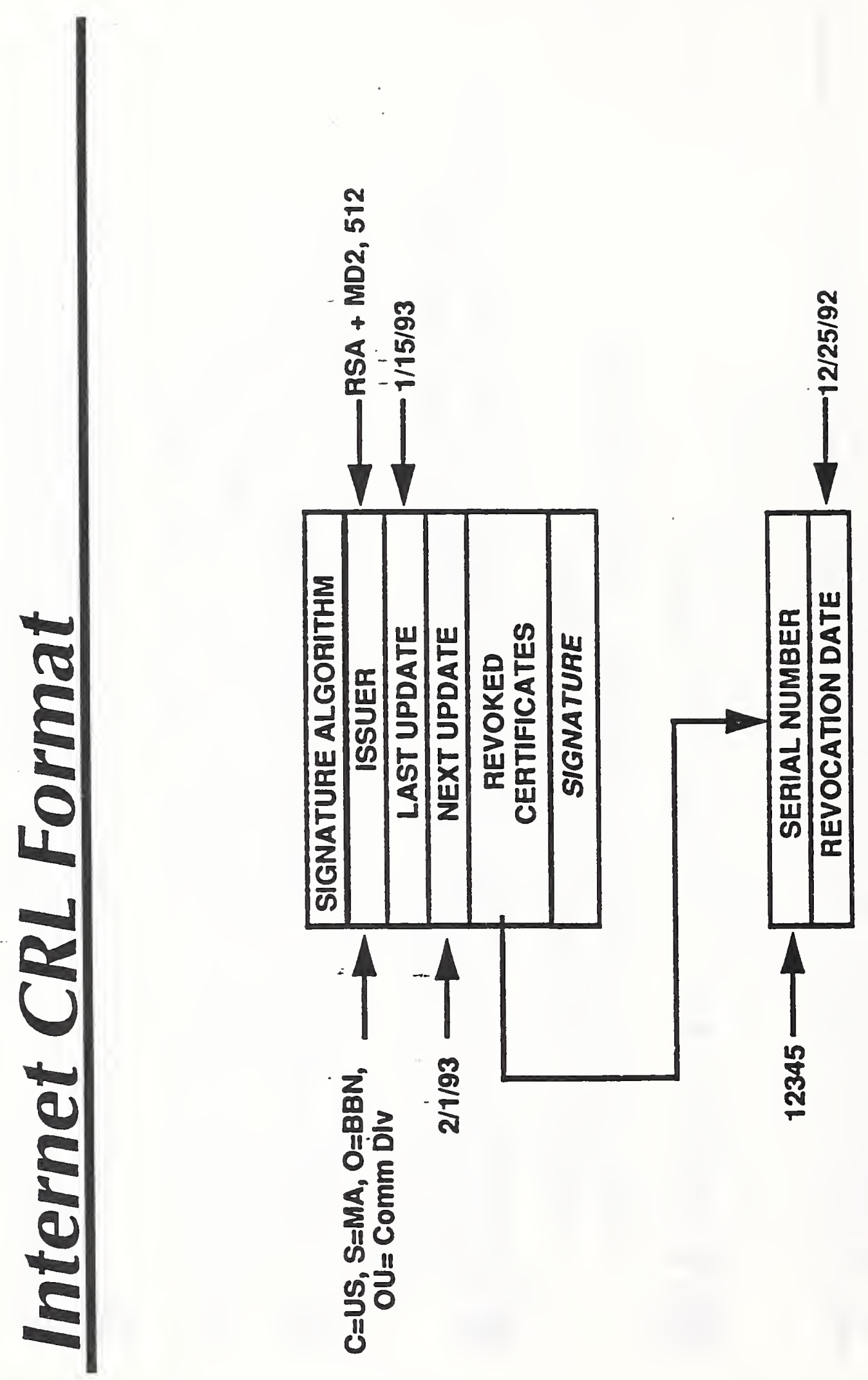


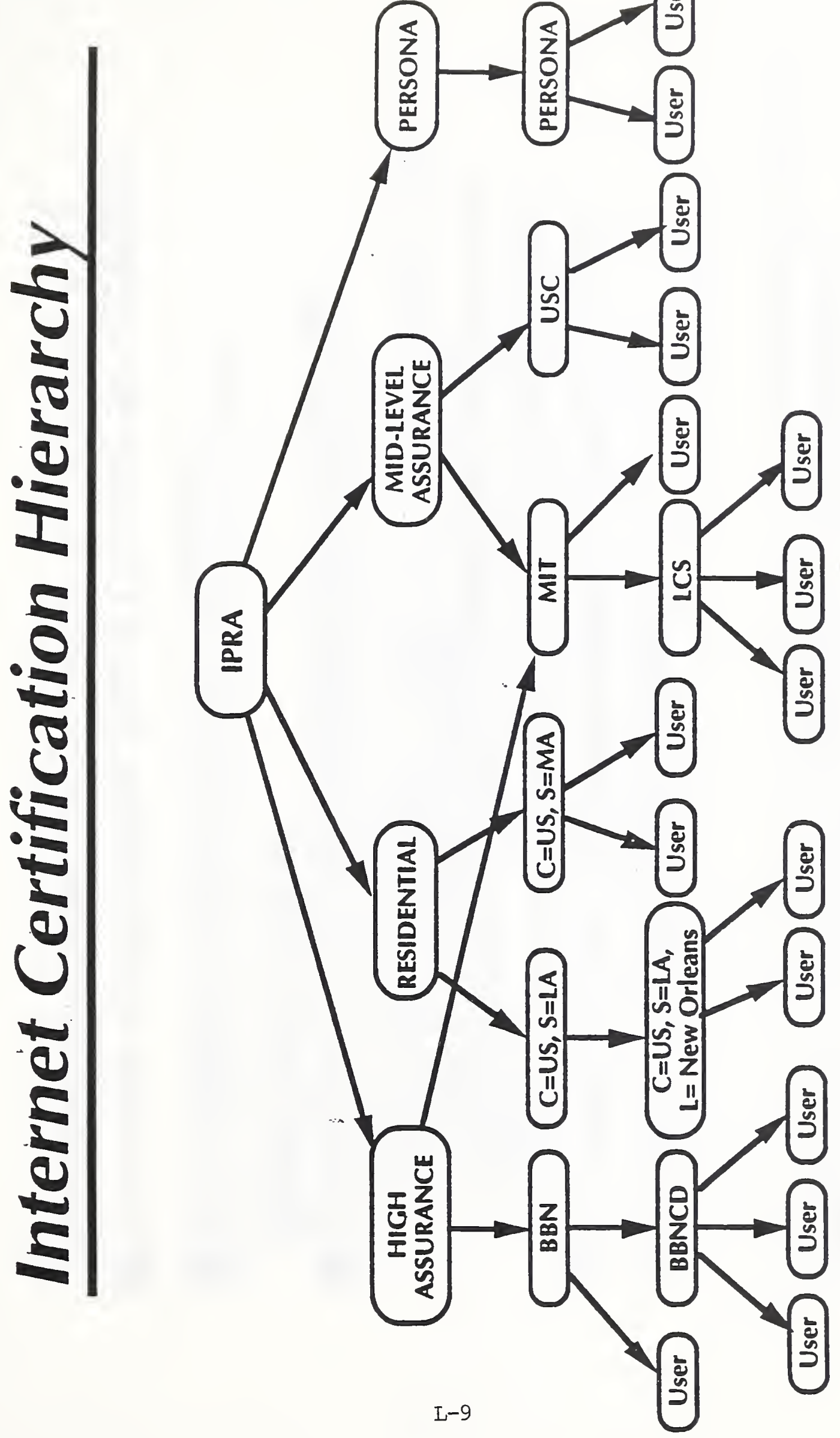




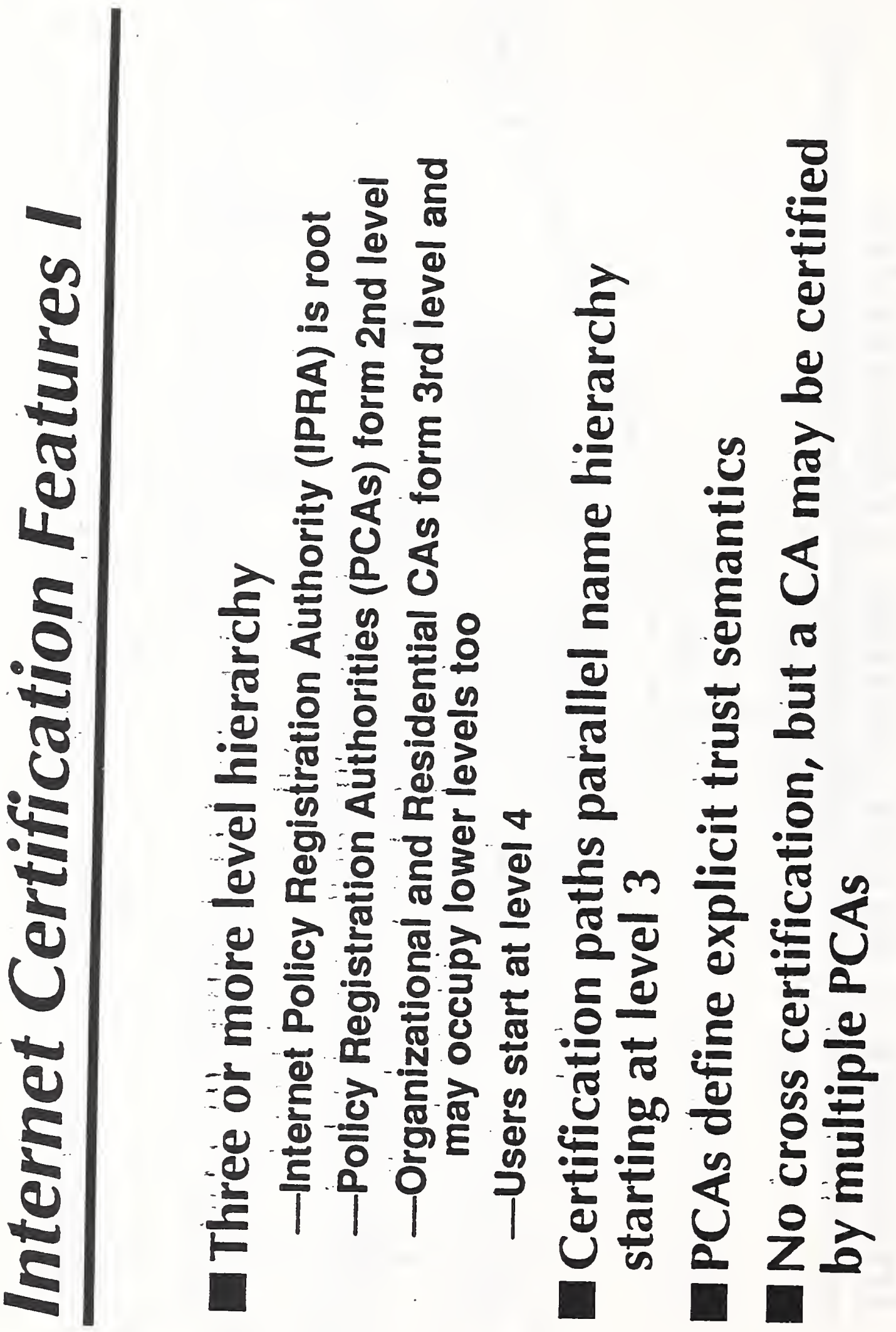




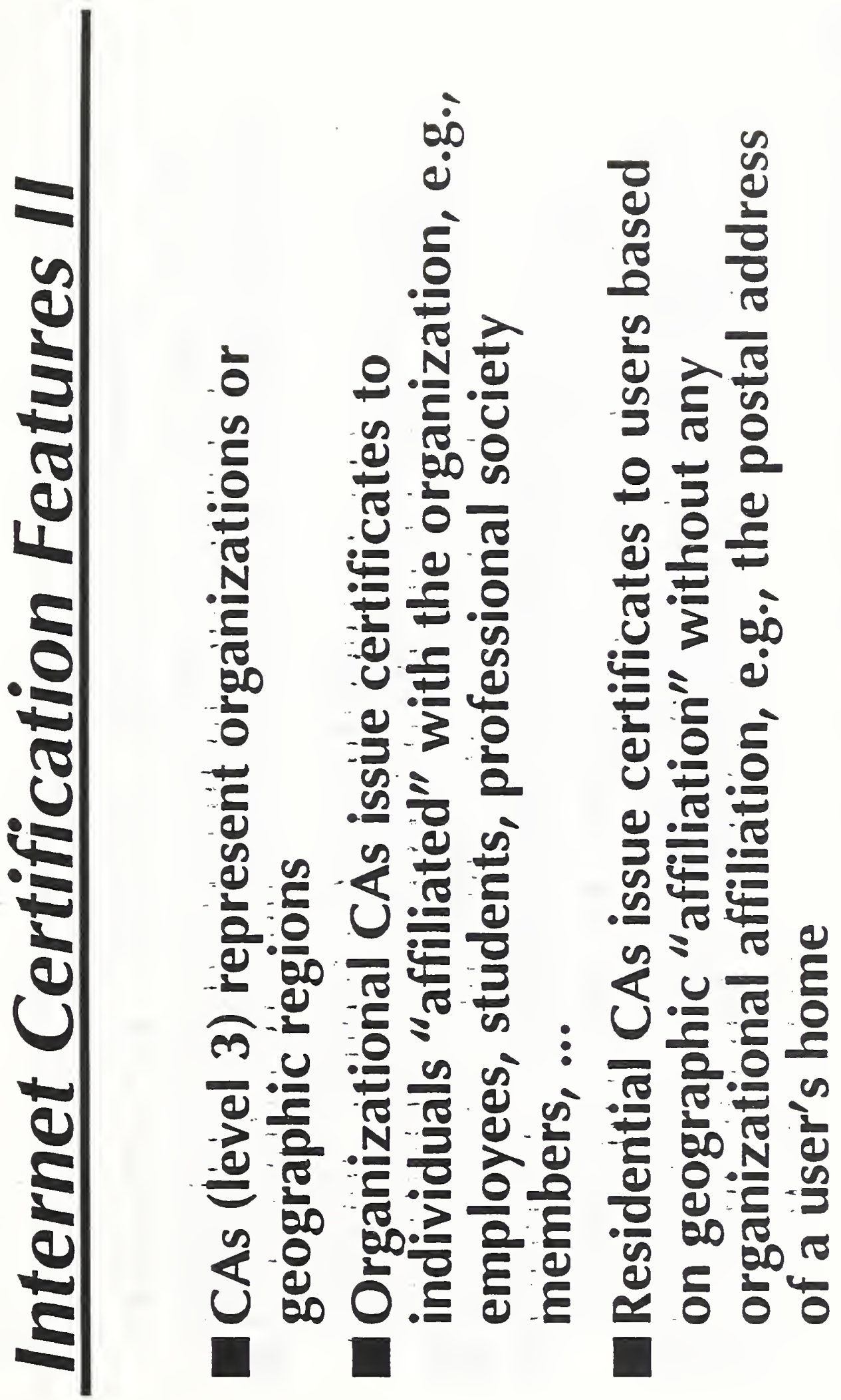




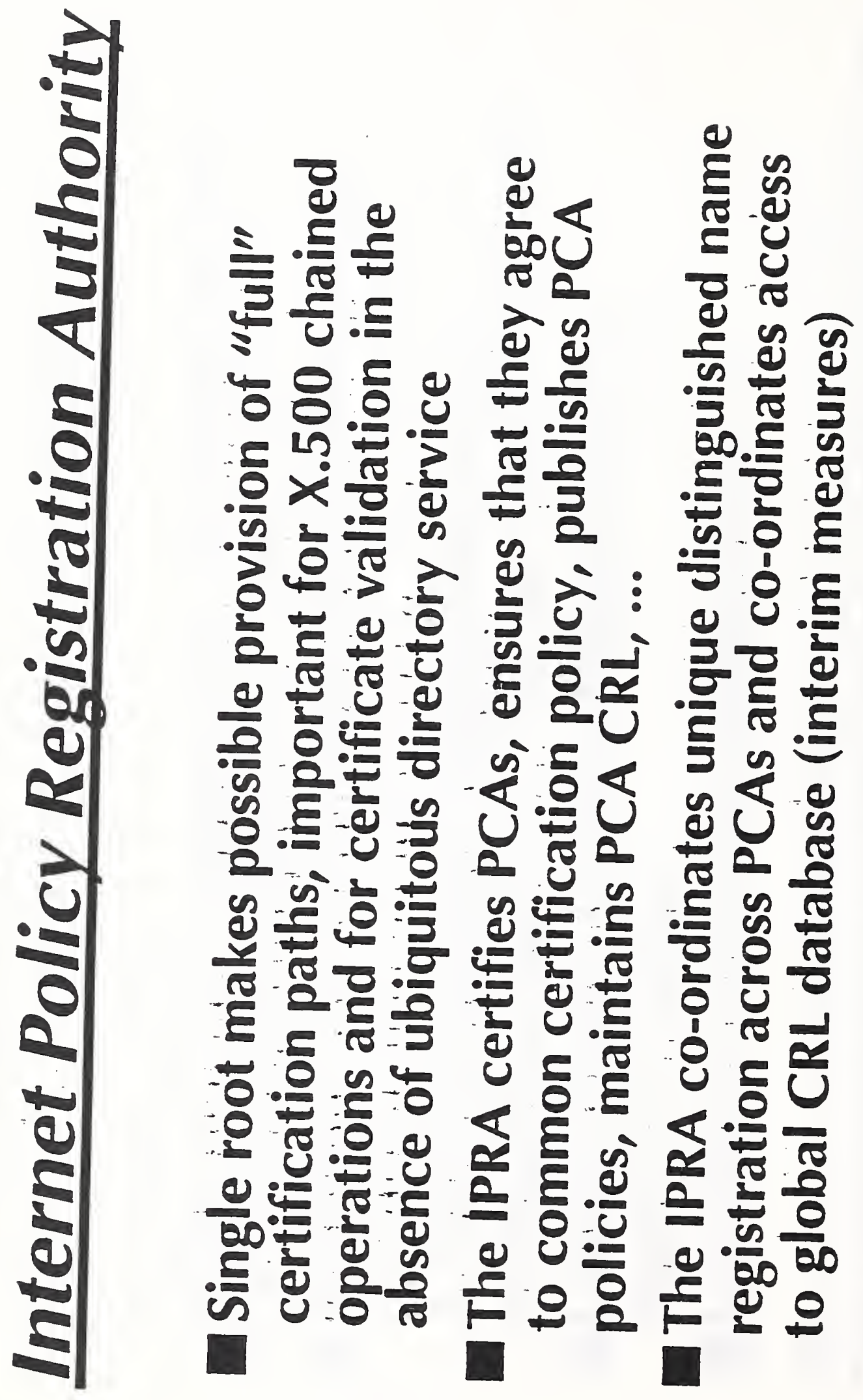




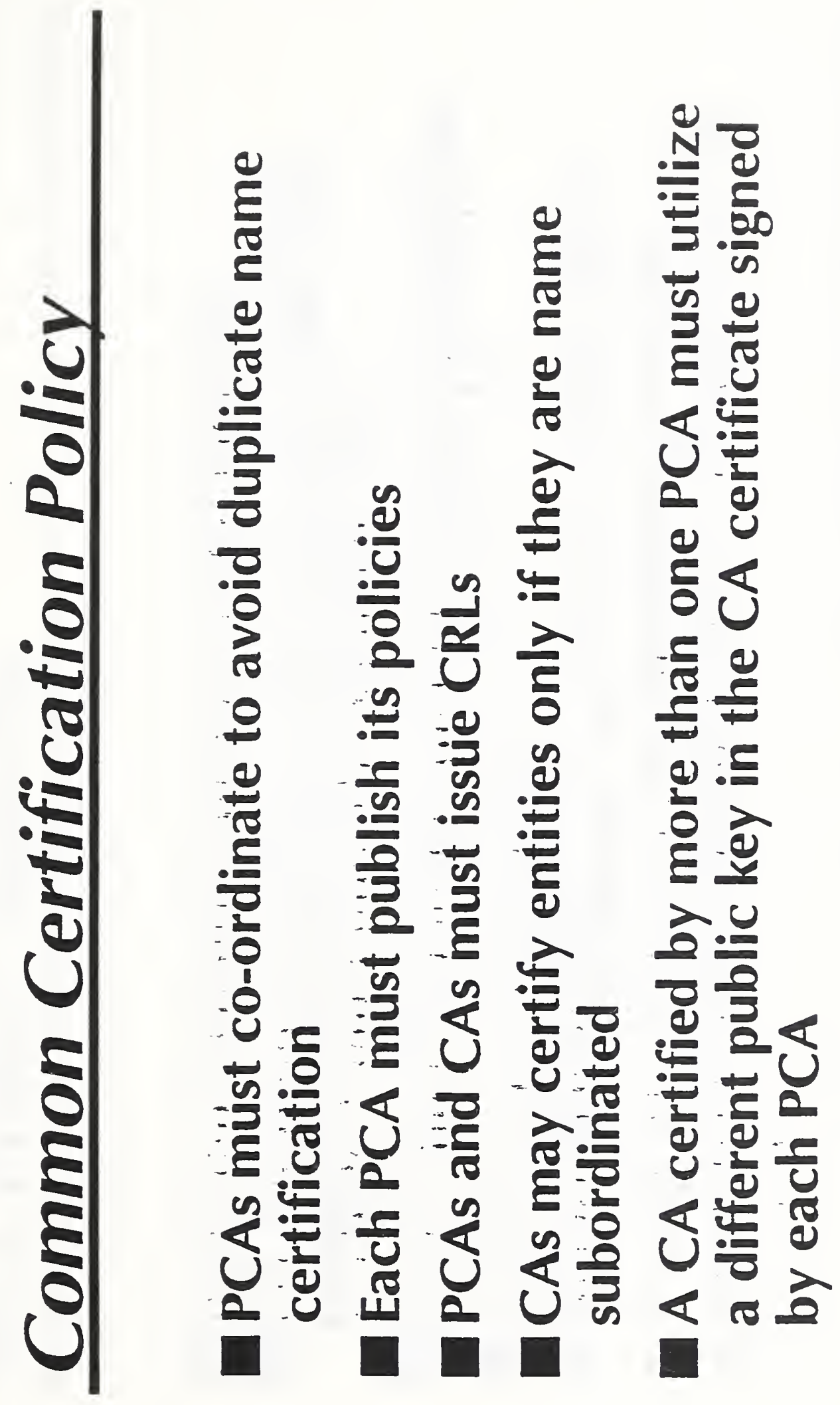




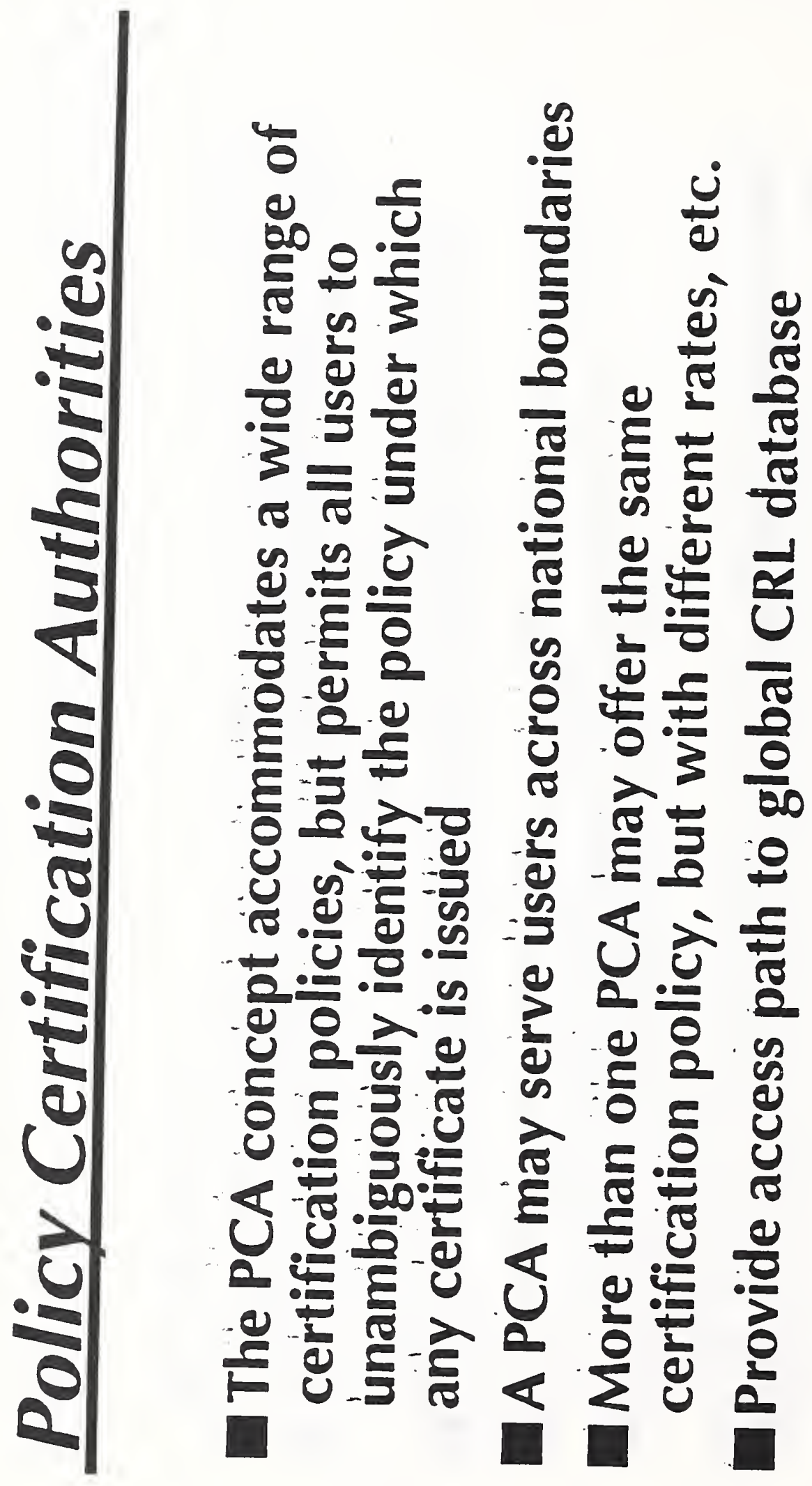




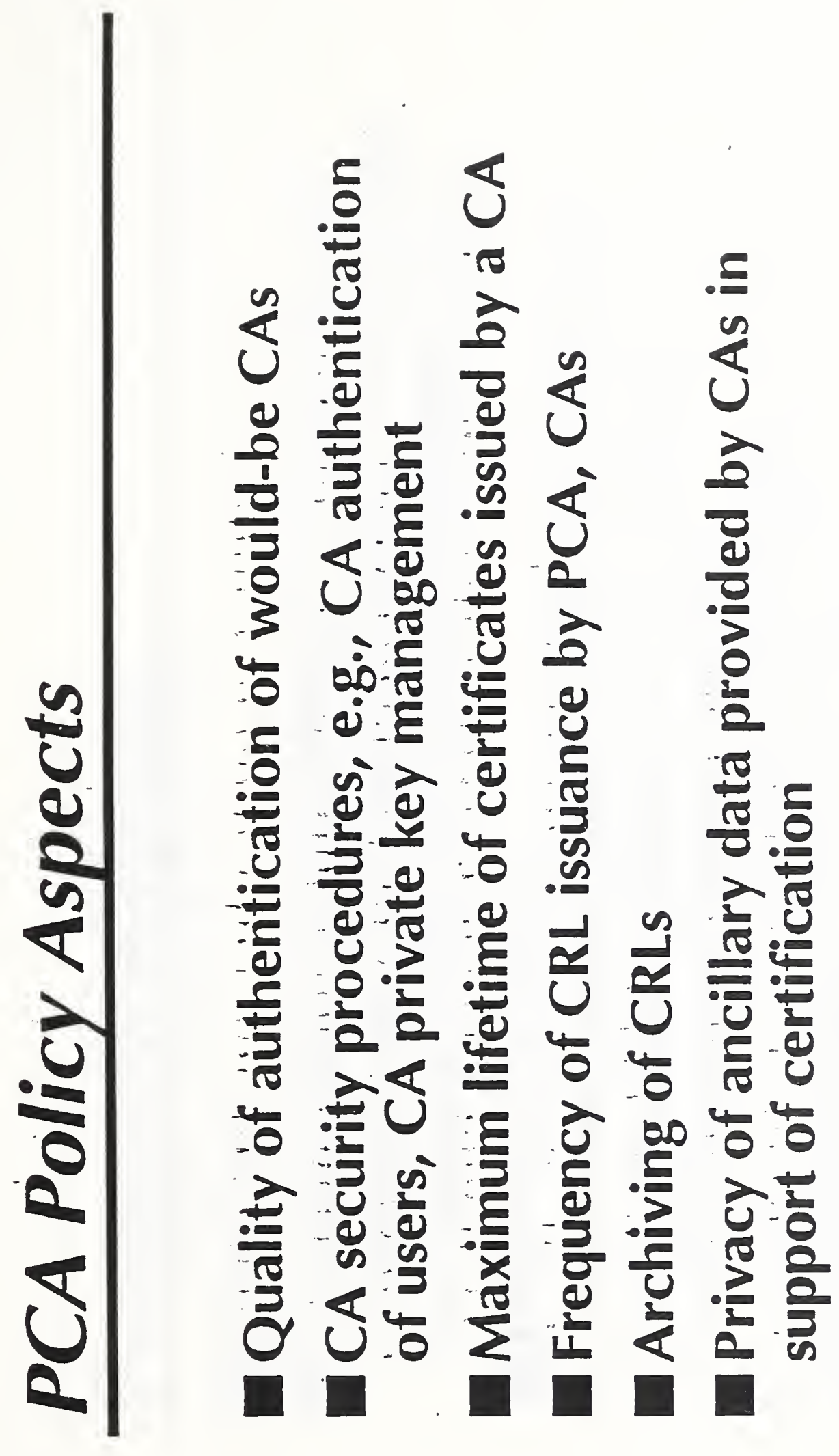




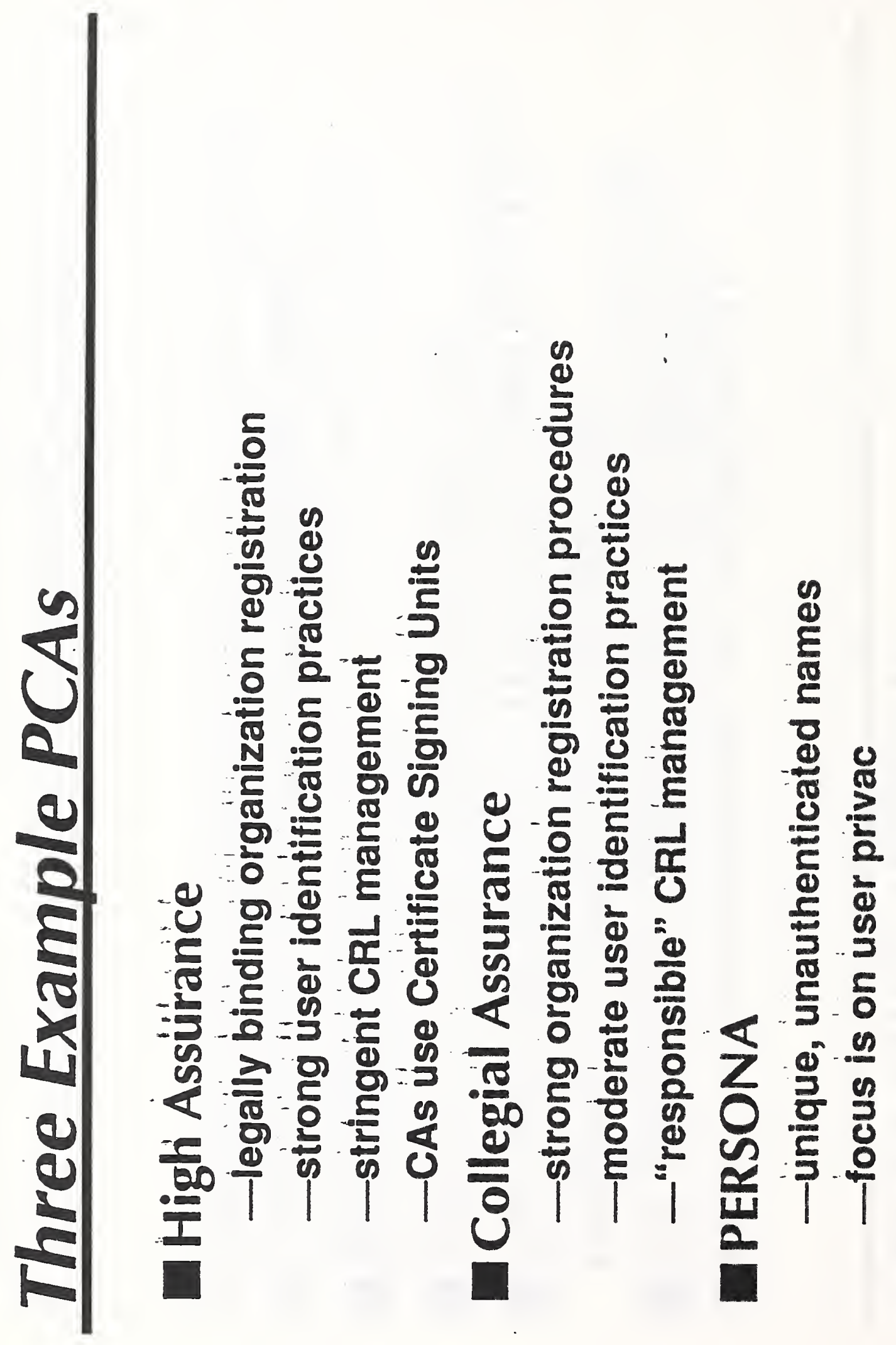




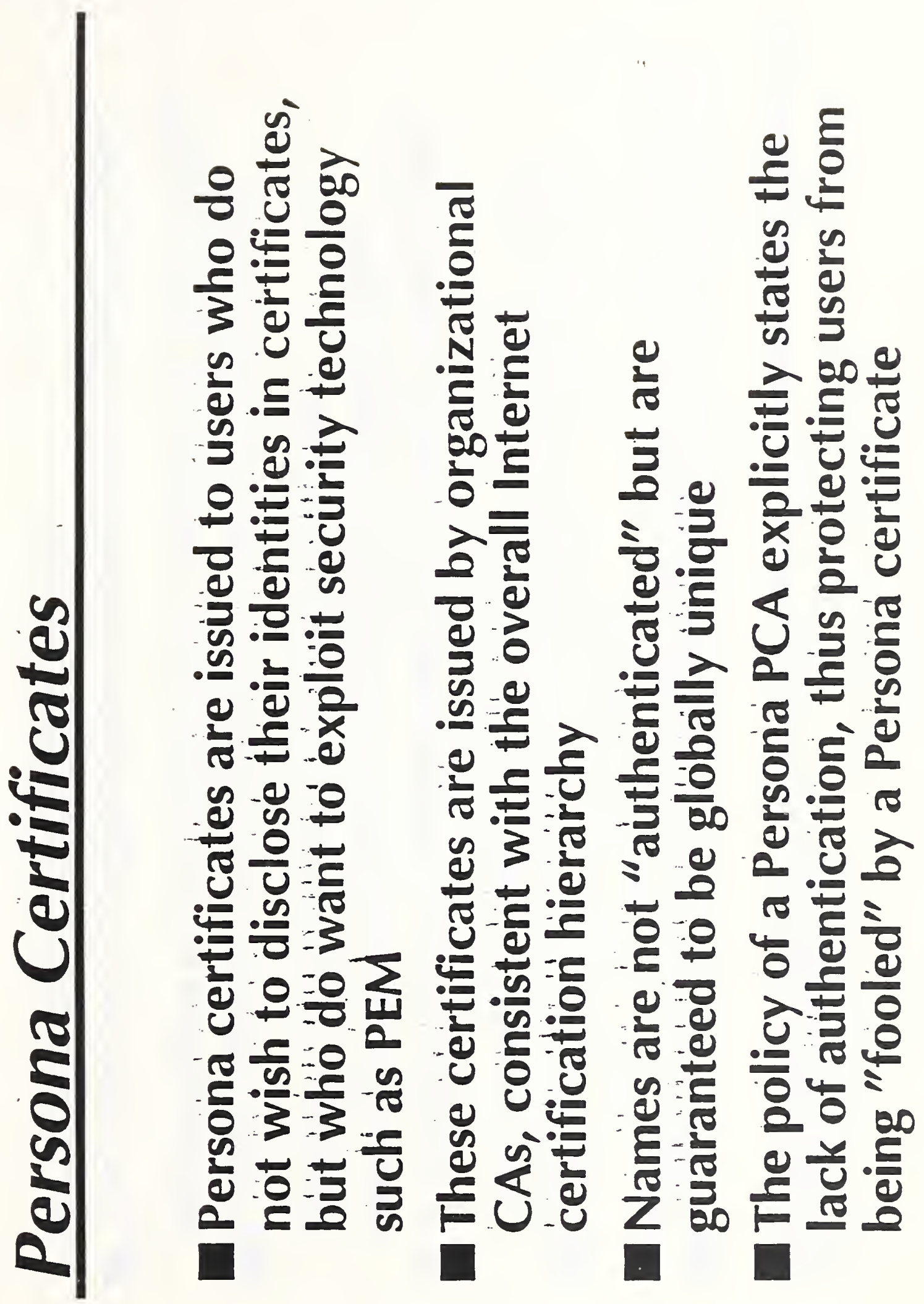




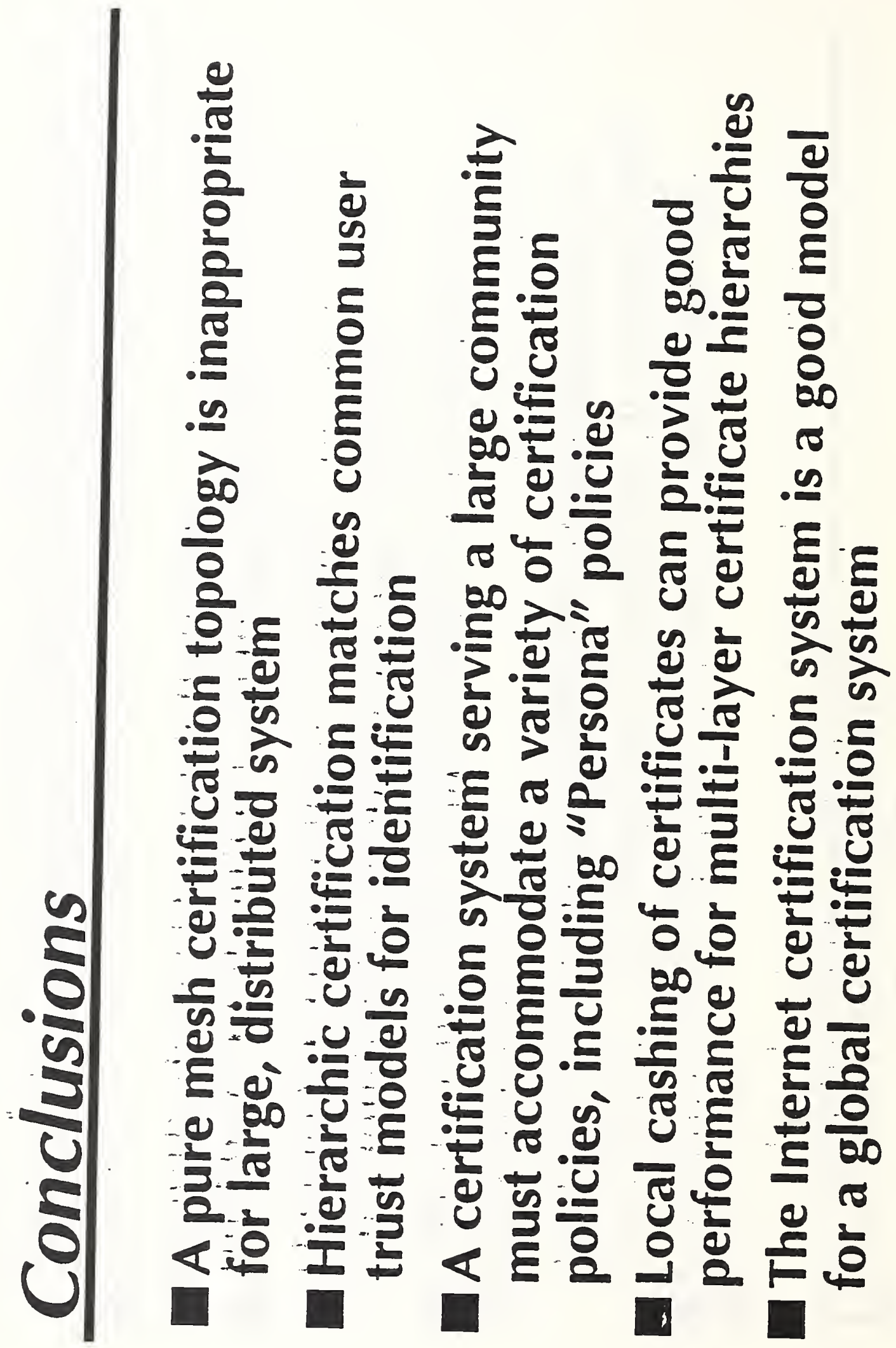



